\title{
WestVirginiaUniversity
}

THE RESEARCH REPOSITORY @ WVU

Graduate Theses, Dissertations, and Problem Reports

1999

\section{Inter-laboratory variability of the Marshall test method for asphalt concrete}

\author{
Michael S. Hughes \\ West Virginia University
}

Follow this and additional works at: https://researchrepository.wvu.edu/etd

\section{Recommended Citation}

Hughes, Michael S., "Inter-laboratory variability of the Marshall test method for asphalt concrete" (1999). Graduate Theses, Dissertations, and Problem Reports. 947.

https://researchrepository.wvu.edu/etd/947

This Thesis is protected by copyright and/or related rights. It has been brought to you by the The Research Repository @ WVU with permission from the rights-holder(s). You are free to use this Thesis in any way that is permitted by the copyright and related rights legislation that applies to your use. For other uses you must obtain permission from the rights-holder(s) directly, unless additional rights are indicated by a Creative Commons license in the record and/ or on the work itself. This Thesis has been accepted for inclusion in WVU Graduate Theses, Dissertations, and Problem Reports collection by an authorized administrator of The Research Repository @ WVU. For more information, please contact researchrepository@mail.wvu.edu. 


\title{
INTER LABORATORY VARIABILITY OF THE MARSHALL TEST METHOD FOR ASPHALT CONCRETE
}

\author{
Michael S. Hughes
}

Thesis submitted to the College of Engineering and Mineral Resources at West Virginia University in partial fulfillment of the requirements for the degree of

Masters of Science

In

Civil and Environmental Engineering

John P. Zaniewski, Ph.D., Chair

W.J. Head, Ph.D.,

Gerry Hobbs, Ph.D.

Department of Civil and Environmental Engineering

\author{
Morgantown, West Virginia \\ March 1999
}

Keywords: Marshall Mix Design, Asphalt Concrete, Inter Laboratory Variability, Statistical Analysis 


\section{A b s tract \\ Inter Laboratory Variability of the Marshall Test \\ Method for Asphalt Concrete \\ Master's Theses \\ Michael S. H u ghes}

Statistical quality control measures, such as used by the West Virginia D ivision of Highways (WVDOH), require quantification of the variability of the test methods to set meaningful material acceptance parameters. The Division currently uses the Marshall method for asphalt concrete mix design and quality control. Although the Marshall method will be replaced as the Division transitions to the Superpave method, in the interim, the Division will continue to use the Marshall method. The objective of this project was to determine multi-laboratory precision statements for the Marshall method that the WVDOH can use in developing statistically based quality acceptance specifications.

The Marshall method has been in use for more than 50 years. However, an examination of the literature did not reveal a data source that could be used for developing the precision statements. Thus, an experiment was designed to generate the data needed for the development of precision statements for the Marshall method. D ata from the literature were compared to the results of the experiment performed during this research. The literature data demonstrated that the data collected during this research are in reasonable agreement with the experience of other asphalt technologists.

An inter-laboratory study was performed in accordance with ASTM standards to evaluate the multilaboratory variability of test methods. All WVDOH laboratories, two contractor laboratories and the Asphalt Technology Laboratory at West Virginia University (WVU) participated in the study. The experiment included three WVDOH asphalt concrete types. All samples were mixed at the WVU laboratory and shipped to the laboratories for compaction and testing using the Marshall method. From the results of these tests, within-laboratory and between laboratory precision statements were developed for 102mm and 152mm Marshall test specimens.

A side issue evaluated during this project was mixing of large quantities of material needed for the 152mm Marshall samples and for Superpave. Traditional laboratory mixers lack the capacity to conveniently prepare these larger mix quantities. A five gallon bucket style mixer was evaluated, and operating procedures were established. This mixer was an efficient tool for preparing large size samples for laboratory testing. 


\section{A ck nowl edgments}

The author would like to express his gratitude to Dr. John Zaniewski, the author's advisor. Without the guidance, support and personal commitment, the author would never have had the opportunity to pursue his Master of Science degree and participate in this research.

Special thanks are also extended to Dr. W. J. Head and Dr. Gerry Hobbs, the author's other committee members for their assistance and support on the study and in classes.

The author also extends his thanks to Mr. Larry Barker, project monitor from the West Virginia Division of Highways for all of his assistance throughout this project.

Special thanks is given to the author's wife, Misty, mother, Mary, and brother, Kevin. Their

love and support throughout this project and the author's entire academic career have been a source of strength and motivation.

Final thanks are given to the author's father, Tom who has supported the author through every step of his becoming an engineer. The author's father has been an excellent role model in work and in life. The author hopes to someday be as great an engineer and man as he. 


\section{Table of Contents}

Chapter

1 Introduction

Page

1.1 Introduction

1.2 Problem Statement

1.3 Objectives

1.4 Thesis Summary

$2 \quad$ Literature Review

2.1 Introduction

2.2 Single Laboratory Variability

2.3 Inter-Laboratory Variability

2.4 Calibration of Marshall Hammer

2.5 Summary

3 Bucket Mixer Testing

3.1 Introduction

3.2 Mixer D escription

3.3 Mixer Evaluation

3.4 Mixer Capacity

3.5 Temperature Tests

3.6 Conclusion

4 Mix D esign Procedure and Sample Preparation

4.1 Introduction

4.2 Aggregate Preparation

22

4.3 Specimen Fabrication

4.4 Specimen Testing

4.5 Mix Design Results

4.6 Sample Fabrication

37

4.7 Specimen Distribution

5 Data Analysis and Results

5.1 Introduction

5.2 Test for Outliers 
Chapter $\quad$ Page

5.3 Preliminary Data Analysis $\quad 40$

5.4 Precision Parameters for All Data 56

5.5 D ata Analysis and Precision Parameters without D istrict 3

5.6 Analysis of O ther Studies $\quad 60$

5.7 Evaluation of Q uestionnaire Information 64

5.8 Precision Statements 66

5.9 Summary of Analysis 68

6 Conclusions and Recommendations 70

6.1 Conclusions $\quad 70$

6.2 Recommendations 71

References $\quad 72$

Appendix

A Procedure for D eveloping Precision Statements 73

B D ata from Previous Studies $\quad 80$

C Bucket Mixer Instructions $\quad 85$

D Mix D esign Charts $\quad 87$

E Laboratory Data $\quad 97$

F Laboratory Instructions, Q uestionnaire and D ata Sheets 105

G Variability Analysis Tables 112

Vita 125

$\begin{array}{ll}\text { Signature Sheet } & 126\end{array}$ 


\section{List of Figures}

Figure $\quad$ Page

3.1 Diagram of Bucket Mixer 13

3.2 Isometric D rawing of Paddle 14

$\begin{array}{ll}\text { 3.3 First Bucket Mixer Configuration } & 15\end{array}$

3.4 Aggregates Lodged Against Paddle in the Second Configuration 16

3.5 Segregation of Aggregates with Mixer Tilted Away from Lock Stops 17

4.1 Three Methods for D etermining D ense Gradation Line 24

4.2 Gradation of First Wearing 1 Sample 26

$\begin{array}{lll}4.3 & \text { Gradation for First Base 2 Sample } & 27\end{array}$

$\begin{array}{lll}4.4 & \text { Base } 1 \text { Gradation } & 27\end{array}$

4.5 Temperature-Viscosity Curve for Asphalt Cement Used in the 29 Research

4.6 Second G radation Attempt for Wearing 1

4.7 Third G radation Attempt for Wearing 1 (G reer G radation) 34

4.8 Forth G radation Attempt for Wearing 1

4.9 Gradation for Second Base 2 Mixture (G reer G radation) 36

5.1 Base 1 Rice Specific G ravity Variance versus Laboratory 45

5.2 Base 2 Rice Specific G ravity Variance versus Laboratory 45

5.3 Wearing 1 Rice Specific G ravity Variance versus Laboratory 45

5.4 Base 1 Marshall Stability Variance versus Laboratory 46

5.5 Base 2 Marshall Stability Variance versus Laboratory 46

5.6 Wearing 1 Marshall Stability Variance versus Laboratory 46

5.7 Base 1 Marshall Flow Variance versus Laboratory 47

5.8 Base 2 Marshall Flow Variance versus Laboratory 47

5.9 Wearing 1 Marshall Flow Variance versus Laboratory 47

5.10 Base 1 Bulk Specific G ravity Variance versus Laboratory 48

5.11 Base 2 Bulk Specific G ravity Variance versus Laboratory 48

5.12 Wearing 1 Bulk Specific Gravity Variance versus Laboratory 48

5.13 Wearing 1 Percent Air Voids Variance versus Laboratory 49 
5.14 Base 1 Percent Air Voids Variance versus Laboratory 49

5.15 Base 2 Percent Air Voids Variance versus Laboratory 49

5.16 Chart of Interactions in Maximum Theoretical Specific G ravity 51

5.17 Chart of Interactions in Marshall Stability 52

5.18 Chart of Interactions in Marshall Flow 53

5.19 Chart of Interactions in Bulk Specific G ravity 54

5.20 Chart of Interactions in Percent Air Voids 55

5.21 Re-heat Temperature versus Base 1 Stability 65

5.22 Re-heat Temperature versus Wearing 1 Stability 65

5.23 Plot of Re-heat Temperature versus Base 2 Stability 65

D.1 Percent Air Voids Versus A sphalt Content for Base 1

D.2 Stability Versus Asphalt Content for Base 1

D.3 Flow Versus Asphalt Content for Base 1

D.4 Unit Weight Versus Asphalt Content for Base 1

D.5 Percent VMA Versus A sphalt Content for Base $1 \quad 90$

D.6 Percent VMA Versus A sphalt Content for Base 1

D.7 Percent Air Voids Versus A sphalt Content for Base 2

D.8 Stability Versus Asphalt Content for Base 2

D.9 Flow Versus Asphalt Content for Base 2

D.10 Unit Weight Versus Asphalt Content for Base 2 92

D.11 Percent VMA Versus A sphalt Content for Base 2 93

D.12 Percent VFA Versus Asphalt Content for Base 2 93

D.13 Percent Air Voids Versus A sphalt Content for Wearing 1

D.14 Stability Versus Asphalt Content for Wearing $1 \quad 94$

D.15 Flow Versus Asphalt Content for Wearing 1

D.16 Unit Weight Versus Asphalt Content for Wearing 1

D.17 Percent VMA Versus A sphalt Content for Wearing 1

D.18 Percent VFA Versus Asphalt Content for Wearing 1 


\section{List of Tables}

Table

Page

2.1 Calibrated Machine Blow Count 11

3.1 Temperature at Completion of Mixing for Different Bucket 20

Configurations in Celsius

4.1 Specific G ravity of Individual Aggregate Sizes 23

4.2. Superpave Specifications for $37.5 \mathrm{~mm}$ Nominal Aggregate Size Mix 24 (Wearing 1)

4.3 Superpave Specifications for 19 mm Nominal Aggregate Size Mix 25 (Base 2)

4.4 Superpave Specifications for 37.5 mm Nominal Aggregate Size Mix 25 (Base 1)

4.5 WVD OH Master Ranges for Base 1, Base 2, and Wearing 26

4.6 Gradations Used in Study 36

5.1 Base 1 Within-laboratory Averages and Standard D eviations 41

5.2 Base 2 Within-laboratory Averages and Standard D eviations 42

5.3 Wearing 1 Within-laboratory Averages and Standard D eviations 43

5.4 Test for High and Low Variability 44

5.5 Precision of Rice Specific Gravity (all data) 57

5.6 Precision of Stability (all data) 57

5.7 Precision of Flow (all data) 58

5.8 Precision of Bulk Specific Gravity (all data) 58

5.9 Precision of Percent Air Voids (all data) 59

5.10 Test for High and Low V ariability without D istrict $3 \quad 60$

5.11 Precision of Rice Specific G ravity without District 3 61

$5.12 \quad$ Precision of Stability without D istrict $3 \quad 61$

$5.13 \quad$ Precision of Flow without District $3 \quad 62$

5.14 Precision of Bulk Specific G ravity without District 3

5.15 Precision of Percent Air Voids without District 3

5.16 Comparison of Standard D eviations From Average Laboratory Results 64 From Different Inter-laboratory Studies 
$\underline{\text { Table }}$

A.1 Approximate Values (Upper 5 percent Level) for the Ratio of the Largest Variance to the Sum of the Variances

A.2 Approximate Values (Upper 5 percent Level) for the Ratio of the

Highest to Lowest Variance

A.3 Example Calculation of Components of Variance 78

B.1 Precision Summary of Study by ASTM 81

B.2 Georgia Laboratory Comparison Study 82

B.3 Utah-Marshall Study, Same Operator, Different Equipment at Various 83 Laboratories

B.4 Utah-Marshall Study, D ifferent O perator and Equipment at Various 83 Laboratories

B.5 Canadian Mix Exchange 84

E.1 Compacted Base 1 Samples Raw Data 98

E.2 Compacted Base 2 Samples Raw Data 99

E.3 Compacted Wearing 1 Samples Raw Data 100

E.4 Base 1 Rice Samples Raw D ata 101

E.5 Base 2 Rice Samples Raw D ata 102

E.6 Compacted Wearing 1 Rice Samples Raw Data 103

E.7 Questionnaire Results 104

G.1 Base 1, Rice, Within-Laboratory Average and Variance 113

G.2 Base 2, Rice, Within-Laboratory Average and Variance 113

G.3 Wearing 1, Rice, Within-Laboratory Average and Variance 114

G.4 Base 1, Stability, Within-Laboratory Average and Variance 114

G.5 Base 2, Stability, Within-Laboratory Average and Variance 115

G.6 Wearing 1 Stability, Within-Laboratory Average and Variance 115

G.7 Base 1, Flow, Within-Laboratory Average and Variance 116

G .8 Base 2, Flow, Within-Laboratory Average and Variance 117

G.9 Wearing 1, Flow, Within-Laboratory Average and Variance 117

G.10 Base 1, Bulk Specific Gravity, Within-Laboratory Average and 118 Variance 
Table $\quad$ Page

G.11 Base 2, Bulk Specific Gravity, Within-Laboratory Average and 118 Variance

G.12 Wearing 1, Bulk Specific Gravity, Within-Laboratory Average and 119 Variance

G.13 Base 1, Percent Air Voids, Within-Laboratory Average and Variance 119

G.14 Base 2, Percent Air Voids, Within-Laboratory Average and Variance 120

G.15 Wearing 1, Percent Air Voids, Within-Laboratory Average and 120

Variance

G.16 Outlying Percentile for Rice Specific G ravity 121

G.17 Outlying Percentile for Marshall Stability 122

G.18 Outlying Percentile for Marshall Flow 123

G.19 Outlying Percentile for Bulk Specific G ravity 124

G.20 O utlying Percentile for Percent Air Voids 124 


\section{INTRODUCTION}

\section{INTRODUCTION}

In the late 1860's the first bituminous pavements were placed in Washington D .C. These pavements were a significant improvement over the common earth road surfaces of the day. However, with continuous growth in traffic, particularly during World War II, the need to improve pavement quality became an important issue to highway agencies and the Department of D efense. As a result, mix design methods were developed for improving the quality of asphalt concrete. One of these methods, developed by Bruce Marshall, has been widely adopted by state highway agencies, including West Virginia.

The West Virginia Division of Highways, WVD OH, uses statistical quality control methods. Under these methods, the precision of all test procedures must be known in order to ensure equitable evaluation of contractors' products. Although the Marshall method has been in use for approximately 50 years, the precision of the method is not quantified in the ASTM standard test method. Hence, the WVD OH needs to quantify the precision of the Marshall method as it is implemented in the state. This need defined the primary objective of this research. In essence, this requires performing a test method precision experiment as described in ASTM Standard C 802 "Standard Practice for Conducting and Inter-laboratory Test Program to Determine the Precision of Test Methods for Construction Materials." The standard requires preparing and distributing at least 3 replicate samples of 3 material types to a minimum of 10 laboratories. Obviously, sample preparation is a significant effort during this type of experiment.

\subsection{PROBLEM STATEMENT}

Even though the Superpave procedures will eventually replace the Marshall procedure for mix design and quality control, in the interim, WVDOH will continue to use the Marshall method. For quality control, the inter-laboratory precision and variance in the Marshall method must be 
quantified for statistical based quality control methods. In a previous project, single laboratory precision of the Marshall method was evaluated (Head, 93). The current project expands on the work of Head to include inter-laboratory precision.

\subsection{BJECTIVES}

The objective of this research was to develop precision statements for Marshall parameters. The Marshall parameters evaluated during this project were stability, flow, air void, maximum theoretical specific gravity, and bulk specific gravity.

The precision statements must apply to all laboratories working for and with WVD OH, therefore, all WVD OH district laboratories and the central laboratory participated in the study. In addition, since contractors have a direct responsibility for quality control, contractors laboratories were included in the study. The precision statements must be valid for all asphalt concrete types, so three mix types were included in the research. To ensure the experiment design and analysis fulfilled these objectives, ASTM standard practices for performing precision statements were used during the research.

The Marshall method was developed to accommodate mixes with relatively small maximum size aggregates. This permitted the use of a $102 \mathrm{~mm}$ diameter mold, which can accommodate a $25 \mathrm{~mm}$ maximum aggregate size. Recently, in response to heavier traffic loads, highway agencies have introduced mixes with larger maximum aggregate sizes to improve mix durability. Consequently, there is a need to increase the Marshall sample size to accommodate the larger size aggregates. The use of larger sample molds is also accommodated in more modem mix design methods, such as the Superpave system developed during the Strategic Highway Research Program. Both the large Marshall mold and the mold used for the Superpave system require approximately 4,000 $\mathrm{g}$ of aggregate as opposed to the 1,200 $\mathrm{g}$ sample needed for the standard Marshall mold.

Increasing the sample size significantly affects laboratory sample preparation. Due to the mass of material required, it is difficult to prepare samples using traditional methods. In response to this need, industry has introduced a large capacity mixer for asphalt concrete. Since the 
objective of this project required preparation of many samples, the large capacity mixer was evaluated.

\subsection{THESIS SUMMARY}

This thesis is organized into six chapters and seven appendices. Following the introduction chapter is a summary of the literature. Given the fact that the Marshall method was developed 50 years ago and was the standard method for approximately seventy-five percent of the stated highway agencies, the lack of information on the test method precision seems unusual. The literature survey found two studies covering single-laboratory precision and two reports on inter-laboratory precision. The studies indicate the variability of the Marshall method is relatively high. Others have recognized this fact and studies of methods for reducing the variability have been conducted. One such study was reviewed to highlight the difficulty in reducing the variability of the seemingly simple Marshall mix design method.

One aspect of the standard Marshall test method is the small mold size which limits the maximum aggregate size that can be considered for mix design. To overcome this limitation, an ASTM test method for using a $152 \mathrm{~mm}$ diameter mold was developed. In addition, the Superpave method uses large sample sizes. Chapter 3 outlines a method for mixing large samples.

Chapter 4 presents the process used to select the specific aggregate gradations and asphalt contents for the mixture types used during this research. The types of mixtures were selected in concert with the project sponsor. Once the mixture types were selected, samples of aggregate were obtained from Greer Industries. A Marshall mix design was preformed to determine the optimum asphalt content. However, mixes with the Greer aggregates failed to meet all the WVD OH Marshal criteria. Therefore the mix designs used by the G reer plant for D OH projects were used for the research.

The samples were prepared in the WVU Asphalt Technology Laboratory and distributed to the 10 WVD OH district laboratories, the WVD OH central laboratory, two contractor laboratories, and the WVU Asphalt Technology Laboratory. The samples were tested using 
standard Marshall methods adopted by WVD OH. The test results were returned to the researchers and analyzed as reported in Chapter 5.

Chapter 6 presents the conclusions and recommendations for the research project. The objective of the project was achieved with the presentation of precision statements, which the WVD OH can implement. However, the research discovered two issues which should be evaluated further. First, data from one of the laboratories was discarded as being too variable. The reasons for this variability should be investigated and the equipment and testing technique should be modified as needed. Second, when the research project was designed, three material types were selected as specified by the ASTM standard for developing precision statements. However, two of the material types are compacted in $102 \mathrm{~mm}$ molds and the other in $152 \mathrm{~mm}$ molds. There were significant differences in the variability of test results obtained with standard and large molds. In essence, the precision statements developed during this research treated the standard and large molds as separate test methods. 


\section{LITERATURE REVIEW}

\subsection{INTRODUCTION}

The Marshall mix design method was developed approximately 50 years ago and was adopted as the standard mix design for the majority of state highway agencies. Standard Marshall test methods were published by both the American Society for Testing and Materials (ASTM), and by the American Association of State Highway and Transportation O fficials (AASHTO). However, these standards lack quantified precision statements.

ASTM published standands for developing precision statements which were extensively used for this project. These standards are summarized in Appendix A.

ASTM precision statements recognize the difference in precision that can be achieved within a single laboratory and between multiple laboratories. Two studies were found which examined the within, or single-laboratory variability. One examined the repeatability of the Marshall stability test using a single technician but two "identical" Marshall hammers (Kovac, 62). The other study examined the single laboratory variability for four asphalt concrete types used by WVD OH (Head, 93). Two studies were found which evaluated the inter-laboratory variability. One study was performed specifically to develop precision statements for Marshall stability tests performed on $152 \mathrm{~mm}$ samples (Kandhal, 96). The other study presents a compilation of inter-laboratory Marshall variability data that were collected, but not published, by several agencies (Siddiqui, 95).

Each of these studies demonstrated considerable variability in the Marshall test method. Therefore, although it is not directly related to the current project, information on ways to reduce variability in the Marshall method was sought. The Federal Highway Administration (FHWA) sponsored a study for calibrating the compaction effort of the Marshall hammer (Sherton, 94). 


\subsection{SINGLE LABORATORY VARIABILITY}

In 1962, Kovac expressed concern that publications in the proceedings of the Association of Asphalt Paving Technologists, AAPT, indicated the standand deviation of the Marshall Stability test was in the range of 1980 and $5930 \mathrm{~N}$ (Kovac, 62). Kovac preformed an experiment to quantify the single operator standard deviation. Factors and levels in the experiment were:

1. Compaction hammers - two "identical hammers,

2. Sample position - the hammers were capable of compacting two samples simultaneously.

3. Molds - four molds were used in the experiment A single mix design with a $9.5 \mathrm{~mm}$ maximum aggregate size and 85/ 100 penetration grade binder was used for all samples. A total of 64 samples were prepared over a 4 week period. The standard deviation for all samples was $304 \mathrm{~N}$, which was considerably less than the previously unpublished values. Kovac found significant differences in the compactive effort produced by the two "identical" hammers. Also, the first sample made each day had the highest variability. After the variability associated with experimental factors was removed from the analysis, the resulting error standard deviation for the Marshall stability was $272 \mathrm{~N}$.

The WVDOH sponsored a project at WVU to quantify the single laboratory precision for Marshall mix design tests for $102 \mathrm{~mm}$ and $152 \mathrm{~mm}$ samples (Head, 93). Four mix types were evaluated:

1. Patching and Leveling $2,12.5 \mathrm{~mm}$ max aggregate size, $102 \mathrm{~mm}$ mold,

2. Wearing 3, $4.75 \mathrm{~mm}$ maximum aggregate size, $102 \mathrm{~mm}$ mold,

3. Base $1,37.5 \mathrm{~mm}$ maximum aggregate size, $152 \mathrm{~mm}$ mold, and

4. Modified Base 1, $19 \mathrm{~mm}$ maximum aggregate size, $152 \mathrm{~mm}$ mold.

The gradation for each mix type was established by using the midpoint of the allowable range for percent passing for each sieve size. The optimum asphalt content was determined in accordance with provisions contained in the Asphalt Institute Manual MS-2, Pennsylvania D epartment of Transportation (PennD OT) Marshall criteria for compacted specimens, and WVD OH specifications. Ten samples were prepared for each mix type. A sample consisted of 
the average of three results. The Marshall parameters evaluated in the study were stability, flow, unit weight, and percent air voids.

The WVU research found the variability of the Marshall parameters was greater for the $152 \mathrm{~mm}$ samples than for the $102 \mathrm{~mm}$ samples. The mean value for stability, flow, and unit weight were greater for the $152 \mathrm{~mm}$ samples than for the $102 \mathrm{~mm}$ samples (Head, 93). The material types and sample size were confounded in the experiment, i.e., no material type was tested at both sample sizes. Hence, the difference in the means and variability may be attributed to either material type or sample size.

\subsection{INTER-LABORATORY VARIABILITY}

The precision of the Marshall procedure for $152 \mathrm{~mm}$ samples was evaluated when ASTM published a standard test method for preparing and testing this size sample (Kandhal, 96). The AASHTO Material Reference Laboratory (AMRL) distributed replicate samples to twelve laboratories. The laboratories were instructed to follow ASTM D 5581, "Test Method for Resistance to Flow of Bituminous Mixtures Using Marshall Apparatus (6 inch Diameter Specimen)". The laboratories mixed and compacted samples, at temperatures specified by the researchers, and then tested for Marshall stability and flow, air voids, and bulk specific gravity. The laboratories were provided with a sufficient amount of $25 \mathrm{~mm}$ maximum size aggregates and AC-20 to prepare 3 Marshall sampled, "butter" the mixer, and make samples for determining the maximum theoretical specific gravity.

The data received from the laboratories were analyzed using ASTM Practice for Preparing Precision and Bias Statements for Test Methods for Construction Materials (C 670), the AST M practice for Conducting an Inter-laboratory Test Program to D etermine the Precision of Test Methods for Construction Materials (C 802), and ASTM Practice for Use of the Terms Precision and Bias in ASTM Test Methods (E 177) (Kandhal, 96). The parameters of precision from this study are presented in Table B.1.

Siddiqui, Trethewey, and Anderson studied variables affecting Marshall test results (Siddiqui, 95). The primary objectives of the study were to identify the key equipment-related factors associated with inconsistencies in test results obtained by using different compaction 
equipment and to recommend calibration equipment and techniques for Marshall compaction equipment.

Inter-laboratory variability results from differences in equipment characteristics, and the skill of the technician. The variability of the Marshall procedures has been a concern since at least 1984 (Lee, 84). However, there are relatively few published studies which quantify the precision of these procedures.

Siddiqui reported on experts' and users' opinions on the sources of variability in the Marshall procedure. A questionnaire was used to capture the opinion of eleven experts concerning the variables that significantly affect Marshall compaction. Analysis of the questionnaire identified the rank order of the five most influential variables as:

1. Hammer alignment,

2. Pedestal support,

3. Height of free fall,

4. Hammer weight, and

5. Pedestal construction.

Users were then interviewed relative to the differences in brands of equipment and operator technique. These users reported significant differences in pedestal construction, shape of the hammer foot, hammer weight and dimensions of the breaking head used in the stability and flow tests. In addition, the users identified concerns that experienced technicians were not following the ASTM standard test procedure (Siddiqui, 95).

The experts' and users' opinions provide an expectation of high inter-laboratory variability. This expectation was verified with data collected by highway agencies in G eorgia, Utah, and Canada. These agencies conducted inter-laboratory studies to examine Marshall variability within their agency. These were unpublished studies prior to being reported by Siddiqui. The data from these studies are presented in Appendix B. An analysis of these data for the ASTM precision parameters is presented in Chapter 5 .

Q ualitative findings from these studies include (Siddiqui, 95): 
1. Results from the Georgia D epartment of Transportation (GD OT) showed samples prepared with mechanical hammers were consistently different from samples prepared with manual hammers with respect to density.

2. The GDOT data showed most laboratories could operate within the desired levels of precision, but some data indicated potential problems with either the equipment or technician technique.

3. The Utah D epartment of Transportation (UD OT) data demonstrated that the precision of the Marshall method was influenced by operator technique.

4. The Canadian data demonstrated the variability of mechanically compacted samples was higher than the variability associated with manually compacted samples.

\subsection{CALIBRATION OF MARSHALL HAMMER}

After research demonstrated the large variability in the Marshall procedure, especially for the mechanical compaction hammers, the Federal Highway Administration (FHWA) sponsored research on methods to calibrate these hammers (Sherton, 94). Since the WVDOH uses mechanical Marshall hammers, the FHWA research was reviewed to determine if it was applicable to the division's procedures.

Sherton developed equipment to measure the compaction force applied to Marshall samples. The equipment consisted of a power supply, data acquisition system and an elastic spring-mass device with an integral force transducer. The basic premise behind the equipment was that the compaction effort of the hammer could be measured with an elastic spring-mass device positioned inside a standard Marshall mold. As the hammer impacts the device, the spring is compressed. The rate of compression and maximum deformation is sent to the data acquisition system. The force, impulse, and energy are then calculated for each individual blow.

After the prototype device was developed, tests were performed to evaluate the potential of reducing variability by calibrating each hammer. This laboratory evaluation program evaluated conditions that produced scatter in Marshall test results. The topic of comparing different hammers and standardization was indirectly examined. The main focus was on Marshall 
equipment related variables such as variation in drop weight, friction, wear, and foundation compliance.

Five different machine setups were evaluated:

1. New Pine Instruments Marshall compaction hammer,

2. Twenty year old Reinhart Testing Equipment Marshall compaction hammer,

3. The Pine Instruments hammer with the mass increased by $277 \mathrm{~g}$,

4. The Reinhart Testing Equipment hammer with a rubber pad between the mold and base plate, and

5. Manual Marshall compaction hammer.

Three samples were compacted in each of the five device setups. The samples were compacted with fifty blows on each side of the sample. The bulk specific gravity, stability, stability, flow, air voids and height of each sample were determined. The standard deviation of each parameter was computed from three replicate specimens prepared with each machine setup.

The machines were then calibrated using the calibration device. A standard cumulative impulse value and cumulative energy value were computed. Calibration consisted of computing the number of times each machine would have to drop the hammer to achieve energy and impulse values theoretically computed for 50 blows per side. The "calibrated" number of blows are shown in Table 2.1.

Three samples were then compacted in each machine with the impulse and energy modified blow counts. The mean and standard deviation for the three samples were computed for each of the Marshall parameters. In almost all cases, the standard deviation of the samples prepared with the calibrated number of blows was less than the standard deviation for samples prepared using the standard number of blows. Samples prepared using the number of blows computed from the impulse calibration procedure had less variable than samples prepared using the number of blows computed the energy calibration procedure (Sherton, 96).

Sherton claimed that since the standard deviations were reduced, the calibration method was effective. However, this comparison was not made between hammers. The efficacy of the 
Table 2.1. Calibrated Machine Blow Count

\begin{tabular}{|l|c|c|c|c|c|}
\cline { 2 - 6 } \multicolumn{1}{c|}{} & $\begin{array}{c}\text { Standard } \\
\text { Pine }\end{array}$ & $\begin{array}{c}\text { Standard } \\
\text { Reinhart }\end{array}$ & $\begin{array}{c}\text { Modified } \\
\text { Pine }\end{array}$ & $\begin{array}{c}\text { Modified } \\
\text { Reinhart }\end{array}$ & $\begin{array}{c}\text { Manual } \\
\text { Hammer }\end{array}$ \\
\hline $\begin{array}{l}\text { Energy } \\
\text { Calibration }\end{array}$ & 38 & 66 & 41 & 103 & 53 \\
\hline $\begin{array}{l}\text { Impulse } \\
\text { Calibration }\end{array}$ & 53 & 56 & 50 & 60 & 43 \\
\hline
\end{tabular}

calibration method to produce consistent results with different compaction machines was not determined during the research. O ne test compared the bulk specific gravity, stability, flow, air voids, and height of the specimens compacted to the same impulse and energy levels.

However, these samples were compacted with a rubber pad between the pedestal and the sample, so the conclusions cannot be applied to standard practices.

The finding that the modified Pine (with extra weight) requires more blows than the standard Pine to achieve the same total energy is highly questionable. Clearly, increasing the mass of the falling hammer while maintaining a constant the drop height should increase the compaction energy and reduce the number of blows required to produce a fixed amount of compaction energy.

\subsection{SUMMARY}

Although the Marshall procedure was developed over 50 years ago, there is relatively little information in the literature to quantify the variability of the test method. Studies have demonstrated that differences in equipment and operator technique affect variability. The literature demonstrates that different manufactures' equipment produce different results and may or may not comply with ASTM standards. In addition, experienced technicians may become complacent and not follow prescribed test methods. Therefore, data on Marshall variability from the literature while interesting and only provides a benchmark for comparison to the other studies. However, the available literature is not sufficient for determining Marshall precision statements for the WVD OH. 


\section{BUCKET MIXER TESTING}

\subsection{INTRODUCTION}

In the past, the size and capacity of a laboratory asphalt concrete mixer has been of little concern due to the small quantities needed. Samples were mixed in a tabletop mechanical mixer or by hand. These two methods sufficed because the Marshall and the Hveem mix design method were the two predominant mix design methods. Both procedures use $102 \mathrm{~mm}$ diameter by $63 \mathrm{~mm}$ high samples requiring approximately $1200 \mathrm{~g}$ of aggregate.

In recent years, new testing procedures have been accepted in the asphalt industry. In 1996, AST M introduced a testing procedure for $152 \mathrm{~mm}$ diameter Marshall apparatus. The Strategic Highway Research Program (SHRP) developed a new system for asphalt concrete mix design using the Superpave Gyratory Compactor. This machine, over the next several years, will replace the Hveem and Marshall methods. The Superpave Gyratory Compactor uses a $150 \mathrm{~mm}$ diameter sample. The samples weigh more than $4500 \mathrm{~g}$. This quantity of material is difficult to mix with traditional methods. Since AASHTO and ASTM mix design test standards for Marshall and Superpave only specify that the mixture have a uniform distribution of asphalt binder, a different style mixer may be introduced.

A few laboratories across the country have started using five-gallon bucket mixers, depicted in Figure 3.1. The effectiveness of this style mixer was investigated to in this study to determine if quantities of material needed for $152 \mathrm{~mm}$ Marshall and Superpave samples can be mixed successfully. 


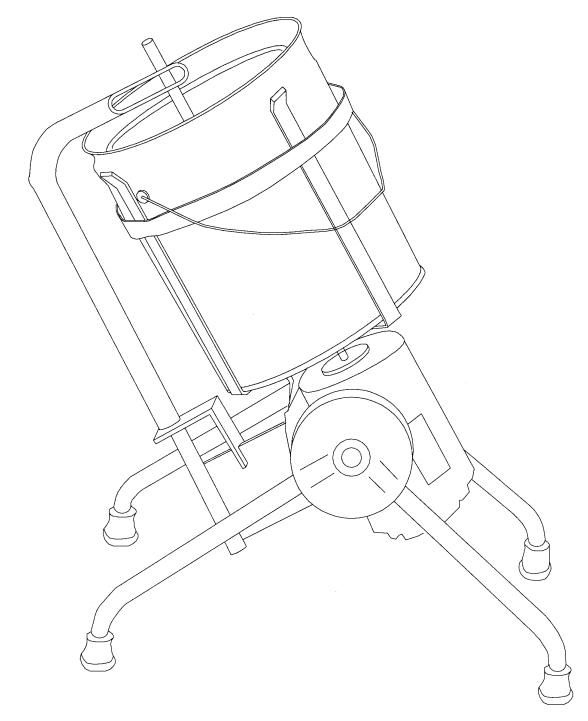

Figure 3.1. Diagram of Bucket Mixer

\subsection{MIXER DESCRIPTION}

A Kol Brand five-gallon bucket mixer was purchased from QC Resource, the asphalt equipment division of Virginia Laboratories Inc. The mixer has a 1/2horsepower motor, which rotates the bucket at a constant rate of $60 \mathrm{RPM}$. The mixer can be tilted about a plane perpendicular to the floor, and can be locked at six different positions in $15^{\circ}$ increments from upright to $15^{\circ}$ from horizontal. Virginia Laboratories Inc. developed the paddle, Figure 3.2, included with the mixer, specifically for mixing asphalt concrete.

\subsection{MIXER EVALUATION}

The first objective in evaluating the mixer was to determine the most effective setup and procedure for using the mixer. No instructions were included with the mixer. Virginia Laboratories Inc. was contacted for instructions. The contact explained that the mixer should be locked at the lowest angle possible without allowing any of the mixture to spill out. The orientation of the paddle inside the bucket was not described. 

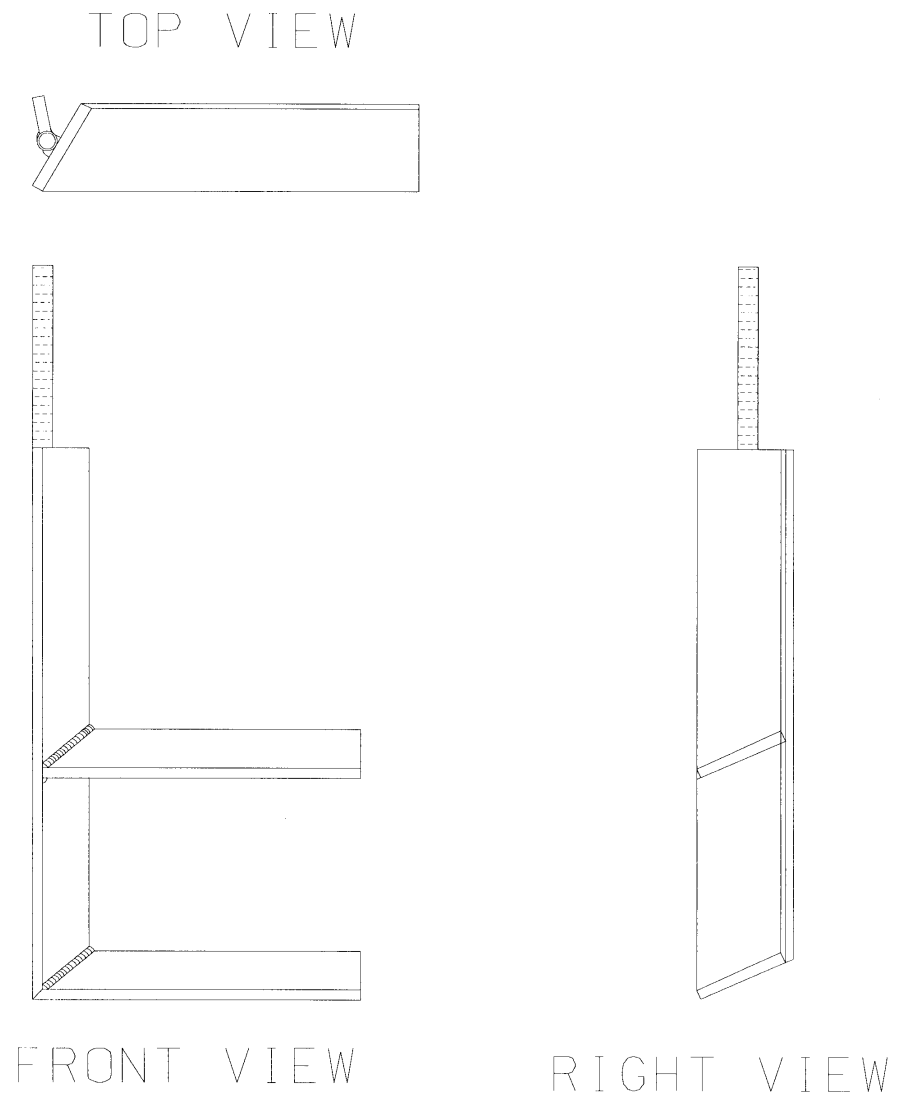

\section{Figure 3.2. Isometric Drawing of Paddle}

Several configurations were tested to determine the paddle orientation that mixed asphalt concrete most effectively. The first position was to set the along the diameter of the bucket mixer as shown in Figure 3.3. Heated aggregates for a Base 1 mixture were placed in the heated metal bucket and asphalt cement was poured into a crater formed in the center of the rocks. The bucket was placed in the mixer and the hot paddle was bolted onto the paddle arm. The mixer was turned on and tilted down to a $15^{\circ}$ angle as Virginia Laboratories Inc. had specified. Initially, the mixture turned over, but after a few seconds the mix clumped up against the paddle while the bucket was spinning freely. Eventually, the torque of the mix against the end of the paddle caused the paddle to rotate out of position. Different tilt angles were tried but the asphalt concrete would not mix. It became apparent that there was not enough friction between the paddle bolt and the paddle arm to hold it in place. 


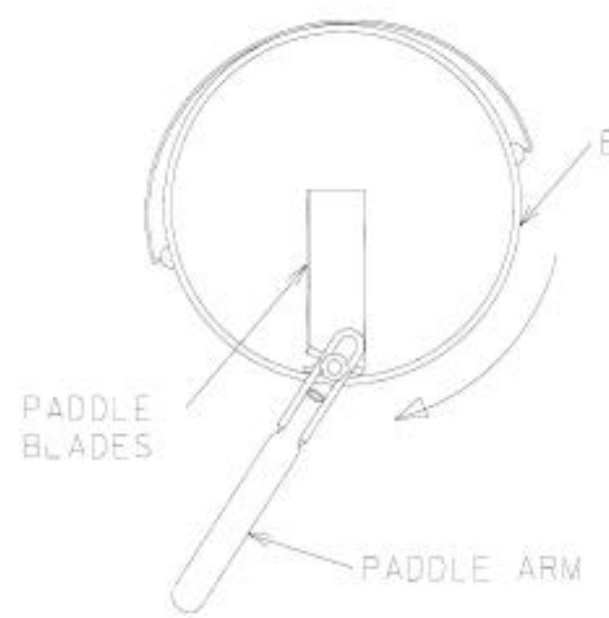

\section{Figure 3.3. First Bucket Mixer Configuration}

Virginia Laboratories Inc. was contacted about this problem. The company shipped a speed nut to the laboratory to see if it would hold the paddle in place. The speed nut was easier to use but the paddle would still rotate. In addition, securing the paddle took too much time, allowing the mixture to cool.

The decision was made to secure the paddle with the conventional nut to the paddle arm before heating. The two items could be heated together. The paddle arm could be placed onto its holding rod, slid down in place and secured. This resolved the problems with the paddle rotating while mixing and the excessive time required for setting up the mixer.

Several mixes were run with the paddle properly secured. Although the paddle did not move, the mix clumped up against the paddle rather than mixing freely. A new paddle orientation was needed. For the next configuration the paddle arm, was oriented parallel to the bucket's tilting plane as shown in Figure 3.4. When the material was placed in the mixer and run, the same problem occurred. The material would mix briefly then become lodged against the paddle. Mixes were attempted at every tilting angle with no success. Next, the bucket mixer was tilted in the opposite direction, away from the lock stops. The material circulated around the bucket until the mix encountered the paddle blades. The blades scraped the material from the side and bottom of the bucket and caused the mixture to free-fall. The mixture would fall on itself 


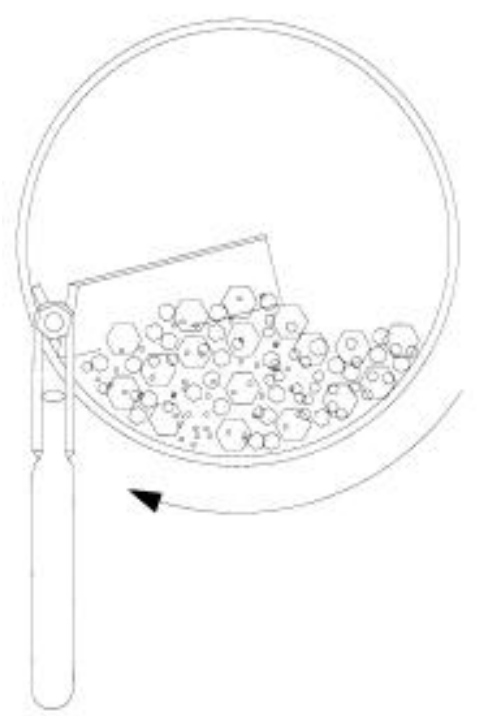

Figure 3.4. Aggregates Lodged Against Paddle in the Second Configuration

and coat the aggregates with asphalt. The aggregates would continuously spin around in an elliptical/ D -shaped cycle coating aggregates.

Although this seemed to be the most effective way to run the mixer there were other problems. It was observed that the finer aggregates circulate near the edge of the bucket while the larger aggregates migrated to the center and never contacted to the paddle blade. This caused two problems; the large aggregates were not getting completely coated with asphalt and the aggregates were segregated. Changing the angle at which the bucket was tilted alleviated most of the segregation. The closer the tilt angle was to vertical the wider the ellipse became. The closer to the angle came to horizontal the narrower the ellipse became. By rocking the bucket back and forth, the large aggregates were reintroduced into the mixture. This procedure improved coating of the large aggregates, but did not completely relieve the problem. 


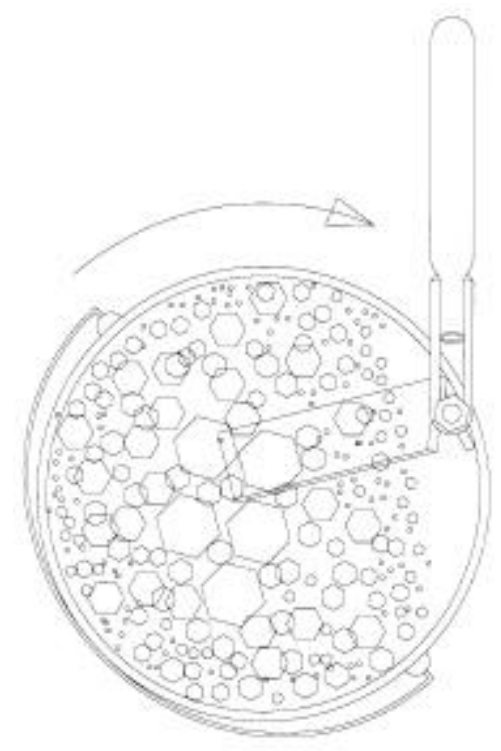

Figure 3.5. Segregation of Aggregates with Mixer Tilted Away from Lock Stops

Different attempts were made to improve coating of the large aggregates. Specifications for the gyratory compactor require heating that the mixture in a shallow pan for a period of two hours after mixing. This allowed the large aggregates to become completely coated as the heated asphalt cement flowed to the uncoated surfaces. However, heating after mixing is not part of the Marshall specifications, so a better mixing method was still needed.

It was observed that upon initial mixing, there was thorough coating of the fine aggregates but inadequate coating of the largest aggregate. Hence, it was decided to try a two step mixing process. In the first step, the coarse aggregate and asphalt were placed in the bucket and mixed for about 10 seconds. Then the fine aggregates were introduced while the mixer was running and the bucket was locked in the vertical position. The fine aggregates were poured into the center of the mix, avoiding the bucket side and paddle. It was observed that after another 20 seconds of mixing, all aggregates were thoroughly coated.

Different separations between large and small aggregates were attempted to see which separations allowed for the fastest mixing time while still completely coating all aggregates. It was discovered that for mixtures with a nominal maximum aggregate size of $9.5 \mathrm{~mm}$ or smaller, aggregates retained on $2.36 \mathrm{~mm}$ sieves should be mixed first. Aggregates passing the $2.36 \mathrm{~mm}$ sieve are then introduced and mixed until all aggregates are uniformly coated. For 
mixtures with a nominal maximum aggregate size of $12.5 \mathrm{~mm}$ or greater, aggregates retained on a $4.75 \mathrm{~mm}$ sieve are mixed first, followed by the smaller aggregates.

An additional problem with the mixer was its inability to scrape the entire bucket. In the center of the bucket, a $25 \mathrm{~mm}$ to $75 \mathrm{~mm}$ circle of asphalt cement and fines was never scraped from the bottom of the bucket. The paddle was long enough but the bottom edge of the paddle blade did not contact the bottom of the bucket at the center. As the bucket spun, the area of the bucket not reached by the blade had a thin coating of asphalt and fine material. These materials had to be scraped with a spoon and reintroduced with the rest of the material after the mechanical mixing was complete. At the seam where the side of the bucket and the bottom met there was a three millimeter wide two millimeter deep indent. While the mixer was running, the end of a metal spatula was placed in this indent to dig out the fines and allow them to be mixed.

\subsection{MIXER CAPACITY}

The next phase of the evaluation was to the bucket mixer's capacity. In the previous phase of the testing it was observed that the mixer could provide a homogeneous mixture for $4000 \mathrm{~g}$ samples. It now needed to be seen if the mixer could handle mixes significantly smaller and larger.

It was decided that the smallest size mixture that would be needed for asphalt concrete mix design would be for a single Marshall sample, $1200 \mathrm{~g}$. The mixing procedures developed for the $4000 \mathrm{~g}$ samples were used for all of the samples. Both WVD OH Base 2 and Wearing 1 mix designs were evaluated at optimum asphalt content. $1200 \mathrm{~g}$ samples the paddle was hardly touched by the material when the bucket was tilted to a steep angle. The material mixed through centripetal acceleration and gravity, providing a uniform coating of the aggregates. In mixing the smaller samples, segregation was not a problem.

Next, the ability of the bucket mixer to prepare large batch sizes was evaluated. An 18,000 g batch was selected this would enable asphalt samples to be quartered into Superpave Gyratory Compactor specimens of approximately $4500 \mathrm{~g}$. 
The first samples were run at the optimum asphalt content. The bucket was unable to be tilted over very far because the mixture was approximately $70 \mathrm{~mm}$ from the top of the bucket. The aggregates tumed over very well and the mixer had no problem handling such a large batch. Through visible inspection it was determined that all of the aggregates were evenly coated. However, severe segregation was observed. The fine aggregates migrated to the bottom of the bucket while the larger aggregates remained on top. No method could be seen to alleviate this. Careful quartering of the batch into the required sample size should mitigate this segregation problem.

Mixes were evaluated with low asphalt contents. For this particular aggregate gradation no problems occurred in mixing at one percent below optimum asphalt content. When a mixture was attempted at 1.5 percent below optimum asphalt content it was observed that not all of the aggregates were evenly coated with asphalt. The fine aggregates that were introduced into the mixture after the large aggregates were not being completely coated. The aggregates were migrating to the bottom of the bucket forcing the coarse aggregates to surface. The large aggregates that were thoroughly coated with asphalt were not coming in contact with the fine aggregates at the bottom. Agitating the mixture with a hot spoon did not improve coating.

$18000 \mathrm{~g}$ batches were run at high asphalt contents. The asphalt cement on the bucket and aggregates acted as a lubricant. There was not enough friction between the aggregate and the bucket to cause the mix to turn over. The mix would stop moving. When this occurred the bucket was rocked back-and-forth vigorously and a hot spoon was used to agitate the stopped mixture. This reactivated the mixing and good aggregate coating was achieved.

\subsection{TEMPERATURE TESTS}

Tests were run to see if different bucket setups would affect the temperature retained in a sample after mixing. Three different five-gallon bucket configurations were evaluated, the standard bucket, a 16 gauge steel bucket, and the standard bucket with a fiberglass insulated wrap. Mixtures were run at optimum asphalt content on batch of sizes $18000 \mathrm{~g}, 4000 \mathrm{~g}$ and $1200 \mathrm{~g}$. 
Table 3.1. Temperature at Completion of Mixing for Different Bucket Configurations in Celsius

\begin{tabular}{|c|c|c|c|}
\hline $\begin{array}{c}\text { Sample size } \\
(\mathrm{g})\end{array}$ & $\begin{array}{c}\text { Standard Steel } \\
\text { Bucket }\end{array}$ & $\begin{array}{c}\text { Standard Steel } \\
\text { Bucket } \\
\text { Insulated }\end{array}$ & $\begin{array}{c}16 \text { Gauge } \\
\text { Steel Bucket }\end{array}$ \\
\hline 1200 & $151.7-154.4$ & $151.7-154.4$ & $155.6-156.7$ \\
4000 & $154.4-155.6$ & $160-162.8$ & $157.2-160$ \\
18000 & $162.2-162.8$ & $167.2-168.3$ & $162.8-163.3$ \\
\hline
\end{tabular}

WVD OH Base 1 gradation was used for the $18000 \mathrm{~g}$ and $4000 \mathrm{~g}$ samples while WVD OH Base 2 gradation was used for the $1200 \mathrm{~g}$ samples. The buckets and the aggregates were heated to $170^{\circ} \mathrm{C}$. The asphalt cement was heated to $158^{\circ} \mathrm{C}$. The samples were mixed using the procedure developed previously. After the asphalt was thoroughly mixed the asphalt was formed into a cone in the bucket and a dial thermometer was placed in the center of the cone. The range of results for the three specimens under each condition is presented in Table 3.1.

It can be seen in Table 3.1 that the $1200 \mathrm{~g}$ samples in the 16 gauge steel bucket retained the heat better than the standard steel bucket, even with the insulation in place. It was hypothesized that the insulation did not improve temperature retention because the wrap only went around the sides of the bucket and not the bottom. With a small sample, little asphalt concrete touched bucket side. Heat was lost through the bottom of the bucket. The 16 gauge bucket was best for small batches. For medium and large batches there was a significant difference between the three configurations. The insulated bucket performing the best with the larger batches. There was a significant amount of contact between the sample and the side of the bucket. The insulation effectively reduced heat loss.

It should be noted that sample removal from 16 gauge steel bucket was significantly easier than the other bucket. The bottom of this bucket was welded to the sides as opposed to the standard bucket, which was crimped together. The crimped seam created a crevice that retained material. Also, because the sides and bottom of the bucket remained hot, the asphalt slid out of the bucket without sticking. With the standard bucket, even when insulated, the asphalt stuck to the bottom and sides of the bucket. This was especially true with the $1200 \mathrm{~g}$ 
samples. This is significant when preparing samples for the Marshall test method where the sample goes directly from the mixer to the compaction mold.

\subsection{CONCLUSION}

Overall, the five-gallon bucket mixer performed extremely well at mixing asphalt. An effective mixer configuration and procedure was developed for creating a well coated homogeneous mixture. Sample sizes ranging from $1200 \mathrm{~g}$ to $18,000 \mathrm{~g}$ can be effectively mixed. Large samples at low asphalt contents pose a problem in mixing and should be avoided. If heat loss is critical either fiberglass insulating blanket or a high gauge steel bucket is recommended. If individual Marshall specimens are going to be made a 16 gauge steel bucket is beneficial for consistent sample preparation. A recommended bucket mixer operating procedure is presented in Appendix C. 
CHA PTER 4

\section{DESIGN PROCEDURE AND SAMPLE PREPARATION}

\subsection{INTRODUCTION}

Three different WVD OH mixes were used in assessing the precision and repeatability of the Marshall mix design method. The three mixes selected for the testing were WVD OT Wearing 1, Base 2 and Base 1. These mixes were selected because of their frequent use by the WVDOH. The statistical evaluation is most meaningful when performed at the optimum asphalt content. This chapter describes the procedures used to determine the optimum asphalt content for each mix type.

\subsection{AGGREGATE PREPARATION}

All aggregates used for testing in this project were crushed limestone donated by G reer Limestone in Sabraton, WV. The aggregates were sieved into the following sizes: $37.5 \mathrm{~mm}$, $25 \mathrm{~mm}, 19 \mathrm{~mm}, 12.5 \mathrm{~mm}, 9.5 \mathrm{~mm}, 4.75 \mathrm{~mm}, 2.35 \mathrm{~mm}, 1.18 \mathrm{~mm}, 0.60 \mathrm{~mm}, 0.15 \mathrm{~mm}$, and $0.075 \mathrm{~mm}$. Once the aggregates were separated, the specific gravity of each sieve size was determined in accordance with ASTM C128 and ASTM 127 for fine and coarse aggregates, respectively (Table 4.1).

The Federal Highway Administration recommends using a 0.45 power gradation chart to find the best gradation for a mix. Three methods are currently recognized in practice (Roberts, 96):

Method A: D raw a straight line from the origin to the maximum aggregate size.

Method B: D raw a straight line from the origin to the nominal maximum aggregate size.

Method C: D raw a straight line from the origin to the percentage point for the largest sieve that retains material. 
Table 4.1. Specific Gravity of Individual Aggregate Sizes

\begin{tabular}{|lc|cc|}
\hline Type aggregate & $\begin{array}{c}\text { Sieve size } \\
(\mathrm{mm})\end{array}$ & $\begin{array}{c}\text { Bulk } \\
\text { Specific } \\
\text { Gravity }\end{array}$ & $\begin{array}{c}\text { Apparent } \\
\text { Specific } \\
\text { Gravity }\end{array}$ \\
\hline Coarse aggregate & 37.5 & 2.696 & 2.721 \\
& 25 & 2.695 & 2.722 \\
& 19 & 2.701 & 2.730 \\
& 12.5 & 2.691 & 2.729 \\
& 9.5 & 2.695 & 2.724 \\
& 4.75 & 2.691 & 2.718 \\
\hline Fine aggregate & 2.36 & 2.658 & 2.825 \\
& 1.18 & 2.664 & 2.882 \\
& 0.300 & 2.504 & 2.818 \\
& 0.075 & 2.327 & 2.619 \\
& Pan & & 2.568 \\
\hline
\end{tabular}

Each of the three methods is demonstrated in Figure 4.1 for the Wearing 1 gradation. Method A was chosen for each gradation. This line nearly fit the center of the WVDOH specifications.

The first attempt at finding an acceptable gradation for each mix type followed the method $\mathrm{A}$ line as closely as possible, while still staying within Superpave (Tables 4.2 to 4.4) and WVD OH (Table 4.5) specifications. The gradation deviates from the maximum density line near $1.18 \mathrm{~mm}$ to avoid the restricted zone set forth by Superpave specifications (Figures 4.2 to 4.4).

Once the gradation for each mix design was chosen the specific gravity for the aggregate blend was computed using the equation:

$$
G=\frac{P_{1}+P_{2}+\ldots+P_{n}}{\frac{P_{1}}{G_{1}}+\frac{P_{2}}{G_{2}}+\ldots+\frac{P_{n}}{G_{n}}}
$$

Where,

$\mathrm{G}=$ average specific gravity

$G_{1}, G_{2}, \ldots, G_{n}=$ specific gravity values for fraction $1,2, \ldots n$; and

$\mathrm{P}_{1}, \mathrm{P}_{2}, \ldots \mathrm{P}_{\mathrm{n}}=$ weight percentages of fraction $1,2, \ldots \mathrm{n}$ 


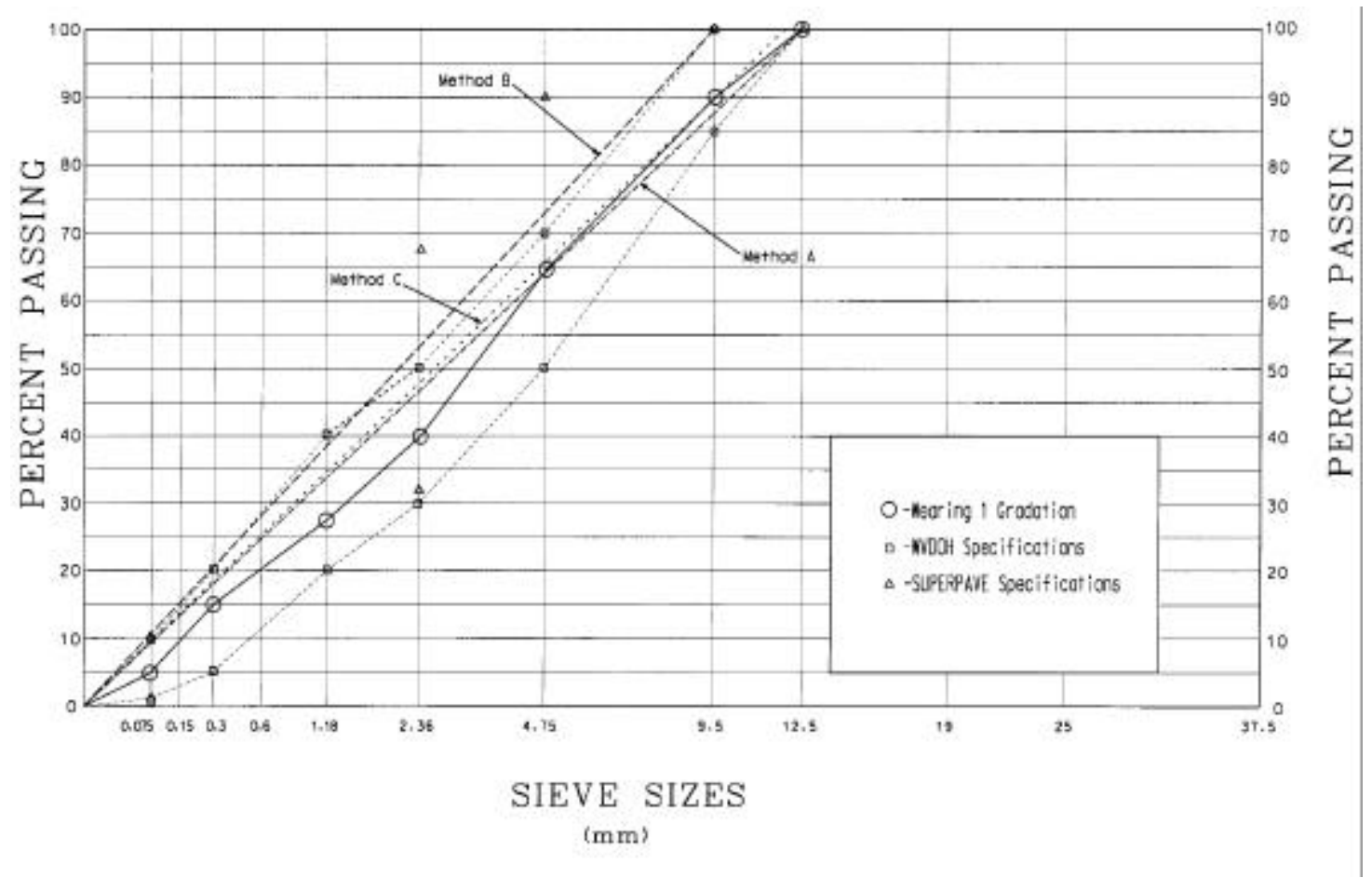

Figure 4.1. Three Methods for Determining Dense Gradation Line

Table 4.2. Superpave Specifications for $37.5 \mathrm{~mm}$ Nominal Aggregate Size Mix (Wearing 1) (Roberts, 96)

\begin{tabular}{|c|c|c|c|c|}
\hline $\begin{array}{c}\text { Sieve } \\
\text { Size } \\
(\mathrm{mm})\end{array}$ & \multicolumn{2}{|c|}{ Control Points } & \multicolumn{2}{c|}{$\begin{array}{c}\text { Restricted Zone } \\
\text { Boundary }\end{array}$} \\
\hline 12.5 & Lower & Upper & Lower & Upper \\
9.5 & 90.0 & 100.0 & - & - \\
4.75 & - & 90.0 & - & - \\
2.36 & 32.0 & 67.0 & - & - \\
1.18 & - & - & 47.2 & 47.2 \\
0.6 & - & - & 23.6 & 37.6 \\
0.3 & - & - & 18.7 & 27.5 \\
0.15 & - & - & - & - \\
0.075 & 2.0 & 10.0 & - & - \\
\hline
\end{tabular}


Table 4.3. Superpave Specifications for $19 \mathrm{~mm}$ Nominal Aggregate Size Mix (Base 2) (Roberts, 96)

\begin{tabular}{|c|c|c|c|c|}
\hline \multirow{2}{*}{$\begin{array}{c}\text { Sieve } \\
\text { Size } \\
(\mathrm{mm})\end{array}$} & \multicolumn{2}{|c|}{ Control Points } & \multicolumn{2}{|c|}{$\begin{array}{c}\text { Restricted Zone } \\
\text { Boundary }\end{array}$} \\
\hline & Lower & Upper & Lower & Upper \\
\hline 25 & 100.0 & 100.0 & - & - \\
\hline 19 & 90.0 & 100.0 & - & - \\
\hline 12.5 & - & 90.0 & - & - \\
\hline 9.5 & - & - & - & - \\
\hline 4.75 & - & - & - & - \\
\hline 2.36 & 23.0 & 49.0 & 34.6 & 34.6 \\
\hline 1.18 & - & - & 22.3 & 28.3 \\
\hline 0.6 & - & - & 16.7 & 20.7 \\
\hline 0.3 & - & - & 13.7 & 13.7 \\
\hline 0.15 & - & & - & \\
\hline 0.075 & 2.0 & 8.0 & - & - \\
\hline
\end{tabular}

Table 4.4. Superpave Specifications for $37.5 \mathrm{~mm}$ Nominal Aggregate Size Mix (Base 1) (Roberts, 96)

\begin{tabular}{|c|c|c|c|c|}
\hline \multirow{2}{*}{$\begin{array}{c}\text { Sieve } \\
\text { Size } \\
(\mathrm{mm})\end{array}$} & \multicolumn{2}{|c|}{ Control Points } & \multicolumn{2}{|c|}{$\begin{array}{c}\text { Restricted Zone } \\
\text { Boundary }\end{array}$} \\
\hline & Lower & Upper & Lower & Úpper \\
\hline 50 & 100.0 & 100.0 & - & - \\
\hline 37.5 & 90.0 & 100.0 & - & - \\
\hline 25 & - & 90.0 & - & - \\
\hline 9.5 & - & . & - & - \\
\hline 4.75 & - & - & 34.7 & 34.7 \\
\hline 2.36 & 15.0 & 41.0 & 23.3 & 27.3 \\
\hline 1.18 & - & - & 15.5 & 21.5 \\
\hline 0.6 & - & - & 11.7 & 15.7 \\
\hline 0.3 & - & - & 10.0 & 10.0 \\
\hline 0.15 & - & - & - & \\
\hline 0.075 & 0.0 & 6.0 & - & _- \\
\hline
\end{tabular}


Table 4.5. WVDOH Master Ranges for Base 1, Base 2, and Wearing 1

\begin{tabular}{|c|c|c|c|c|c|c|}
\hline $\begin{array}{c}\text { Sieve } \\
\text { Size } \\
(\mathrm{mm})\end{array}$ & \multicolumn{2}{|c|}{ Base 1 } & \multicolumn{2}{c|}{ Base 2 } & \multicolumn{2}{c|}{ Wearing 1 } \\
\hline 50 & Lower & Upper & Lower & Upper & Lower & Upper \\
\hline 37.5 & 80 & - & - & - & - & - \\
25 & - & - & - & - & - & - \\
19 & 50 & 80 & 100 & - & - & - \\
12.5 & - & - & - & 100 & - & - \\
9.5 & 35 & 65 & 60 & - & 100 & - \\
4.75 & 25 & 55 & 35 & 65 & 85 & 100 \\
2.36 & - & - & 20 & 50 & 50 & 70 \\
1.18 & 10 & 35 & - & - & 20 & 50 \\
0.6 & - & - & - & - & - & - \\
0.3 & 4.0 & 20.0 & 4 & 20 & 5 & 20 \\
0.15 & - & - & - & - & - & - \\
0.075 & 0 & 8 & 1 & 8 & 1 & 8 \\
\hline
\end{tabular}

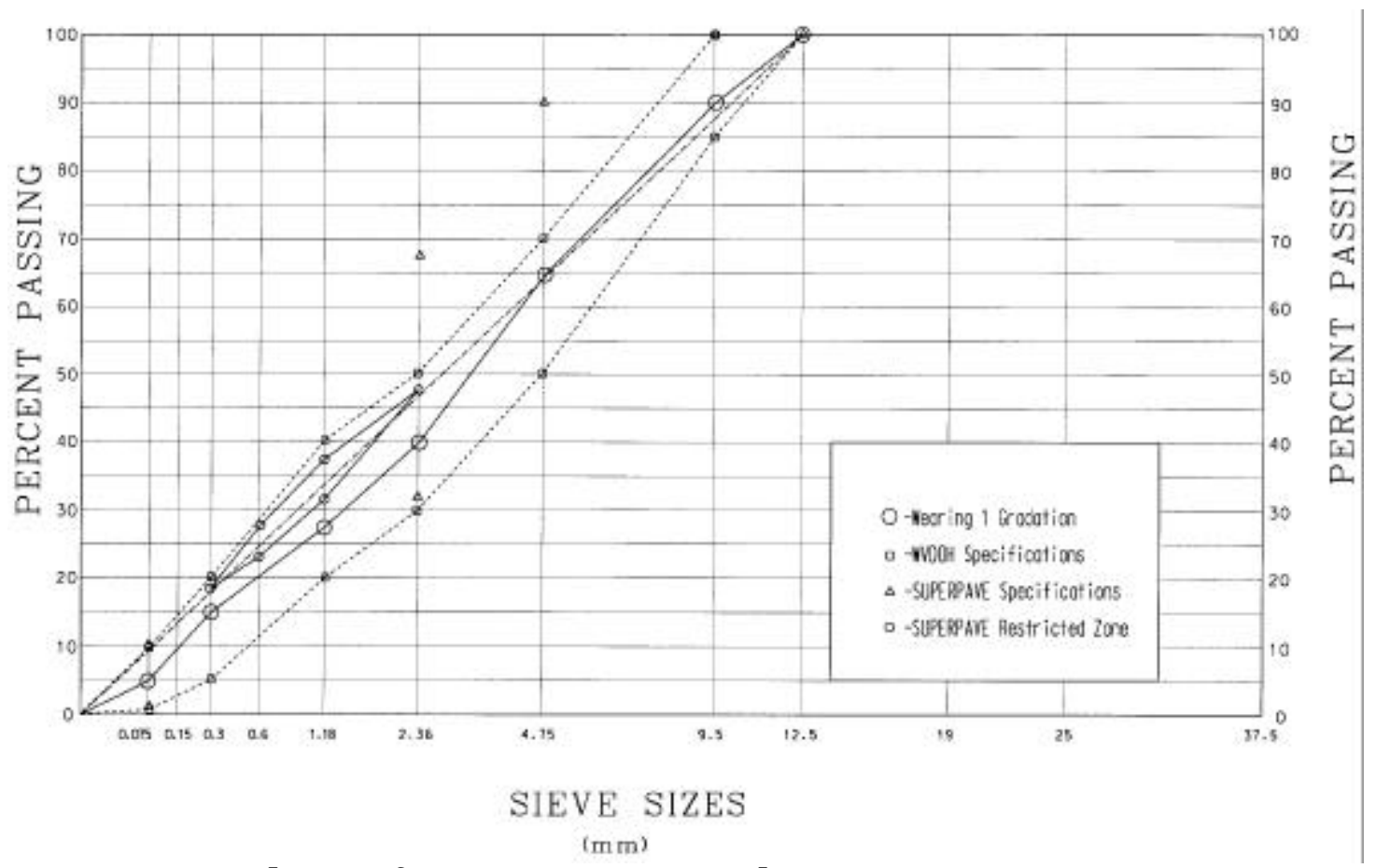

Figure 4.2. Gradation of First Wearing 1 Sample 


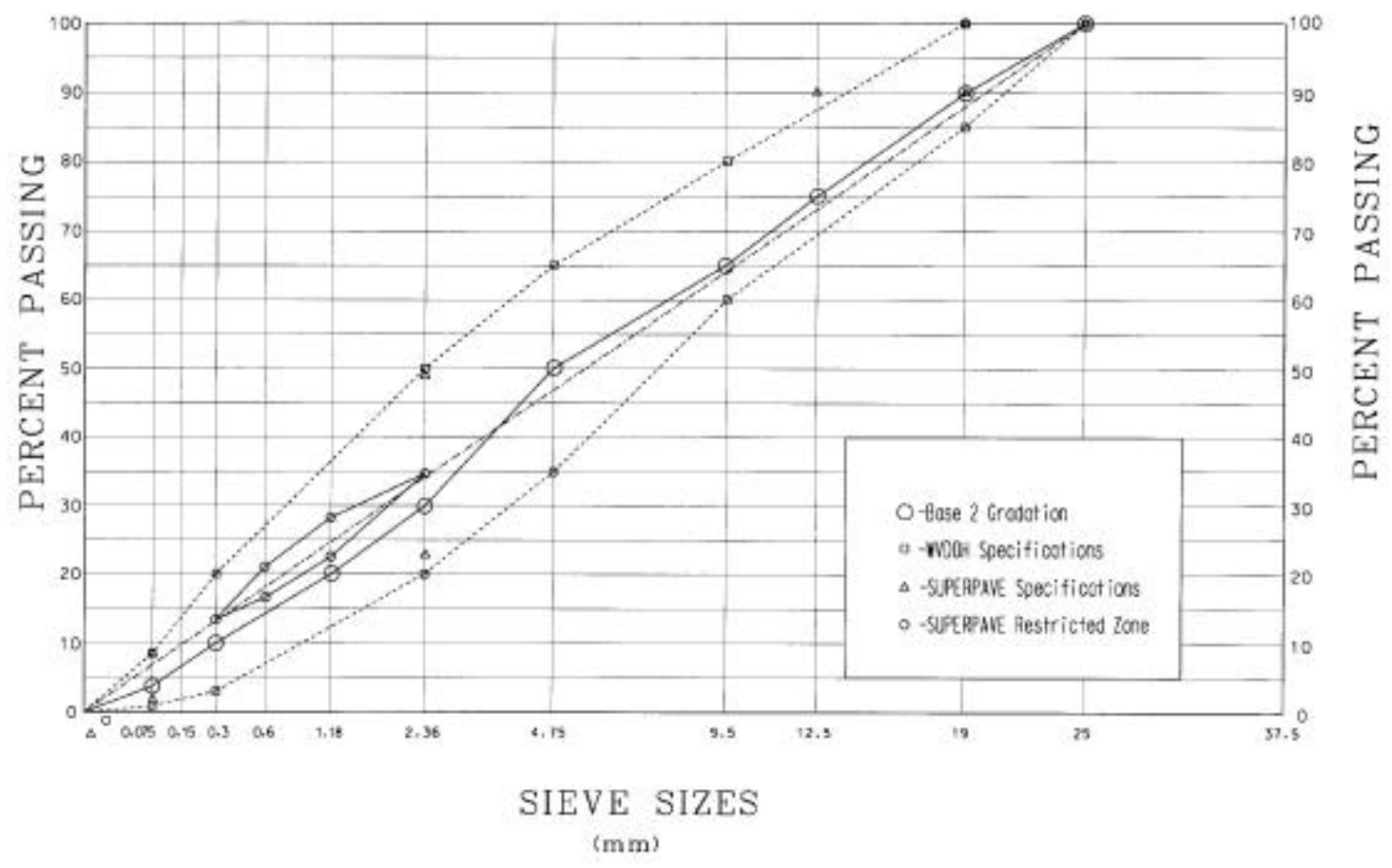

Figure 4.3. Gradation for First Base 2 Sample

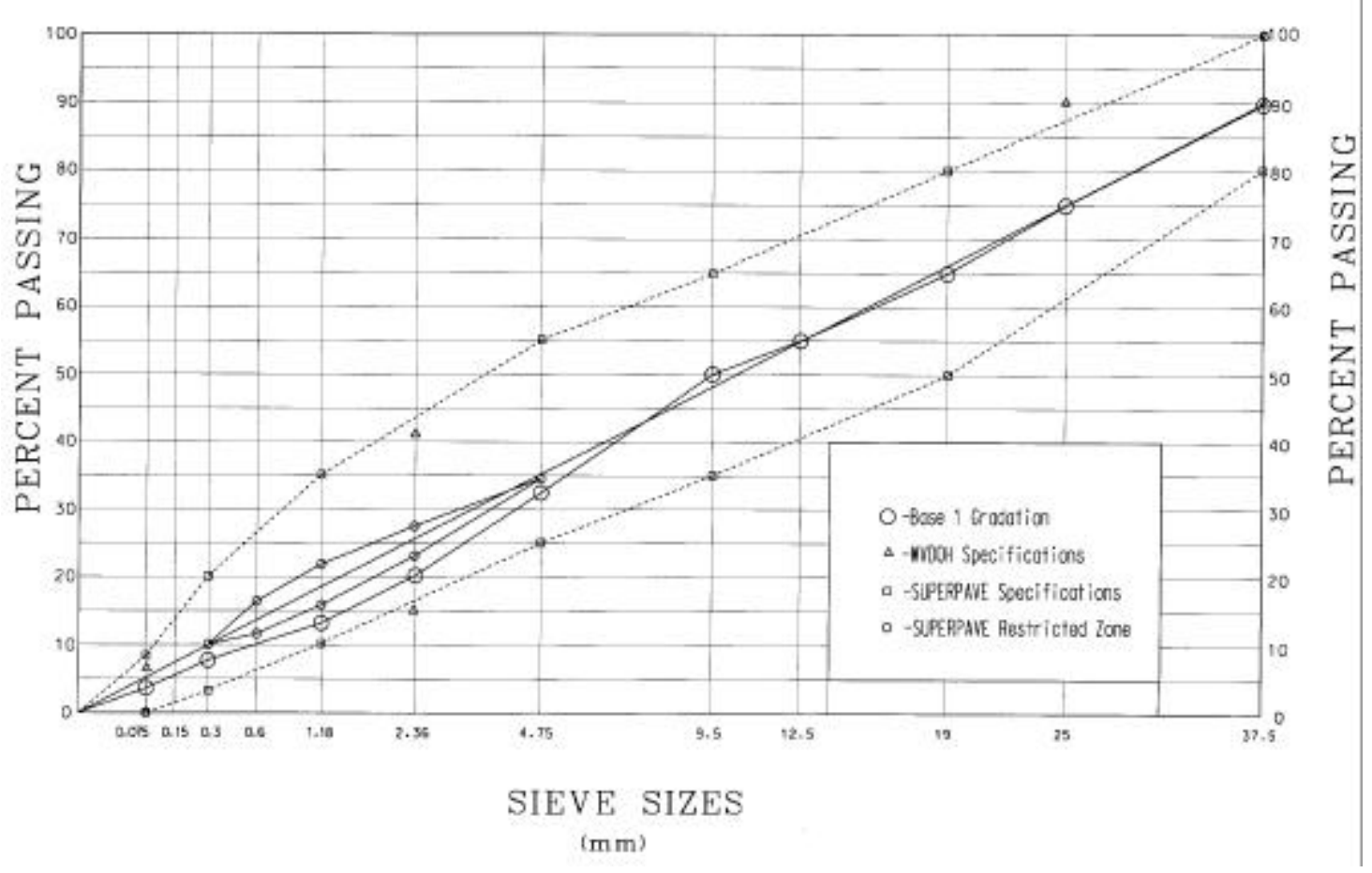

Figure 4.4. Base 1Gradation 


\subsection{SPECIMEN FABRICATION}

Once each aggregate gradation was selected, the optimum asphalt content for each mix type was determined using the Marshall method and the Asphalt Institute criteria (Roberts, 96). The Asphalt Institute criteria requires averaging the asphalt content at maximum stability, maximum density, and mid point of specified air void range (typically 4 percent) from plots of stability, flow, air voids, and VMA versus asphalt content. The properties of the mix at this asphalt content are then compared to mixture acceptance criteria.

Marshall testing for this project conformed to ASTM D 1559, for $102 \mathrm{~mm}$ samples and ASTM D 5581 for $152 \mathrm{~mm}$ samples. ASTM D 1559 was followed for the Base 2 and Wearing 1 mixes and ASTM D 5581 was followed for the Base 1 mix.

For the $102 \mathrm{~mm}$ diameter Marshall samples personnel, of WVD OH recommended that approximately $1200 \mathrm{~g}$ of hot mix asphalt be used to achieve the desired $63.5 \mathrm{~mm}$ high samples. It was determined through trial and error that $1150 \mathrm{~g}$ of aggregates produced $63.5 \mathrm{~mm}$ sample heights. Samples heights changed slightly from the varying asphalt cement content but not enough to require changing the aggregate quantity. For the $152 \mathrm{~mm}$ samples, $3950 \mathrm{~g}$ of aggregate were used in the mix to achieve the target $95.25 \mathrm{~mm}$ sample height.

The asphalt cement used in all testing was performance grade PG 64-22 produced by Ashland Petroleum Company. G reer Limestone, Sabraton, WV, donated the asphalt cement. The proper mixing temperature and compaction temperatures were determined from a temperature viscosity chart obtained from Ashland Petroleum Company. ASTM D 1559 specifies a viscosity during mixing of $170 \pm 20 \mathrm{cSt}$. and a viscosity of $280 \pm 30 \mathrm{cSt}$. for compaction. This corresponds to $153^{\circ} \mathrm{C}$ to $159^{\circ} \mathrm{C}$ and $142^{\circ} \mathrm{C}$ to $147^{\circ} \mathrm{C}$ for asphalt cement used in this project (Figure 4.5). The asphalt cement was heated to $158^{\circ} \mathrm{C}$ for mixing.

The aggregates were heated in an oven to $170^{\circ} \mathrm{C}$ as were the mixing tools, bucket, and mixing paddle. When items were heated to their proper temperatures, the asphalt cement and aggregate were mixed in accordance with the methods stated in the previous chapter. Each day the first batch in the bucket mixer was used to "butter" the bucket and paddle and was 


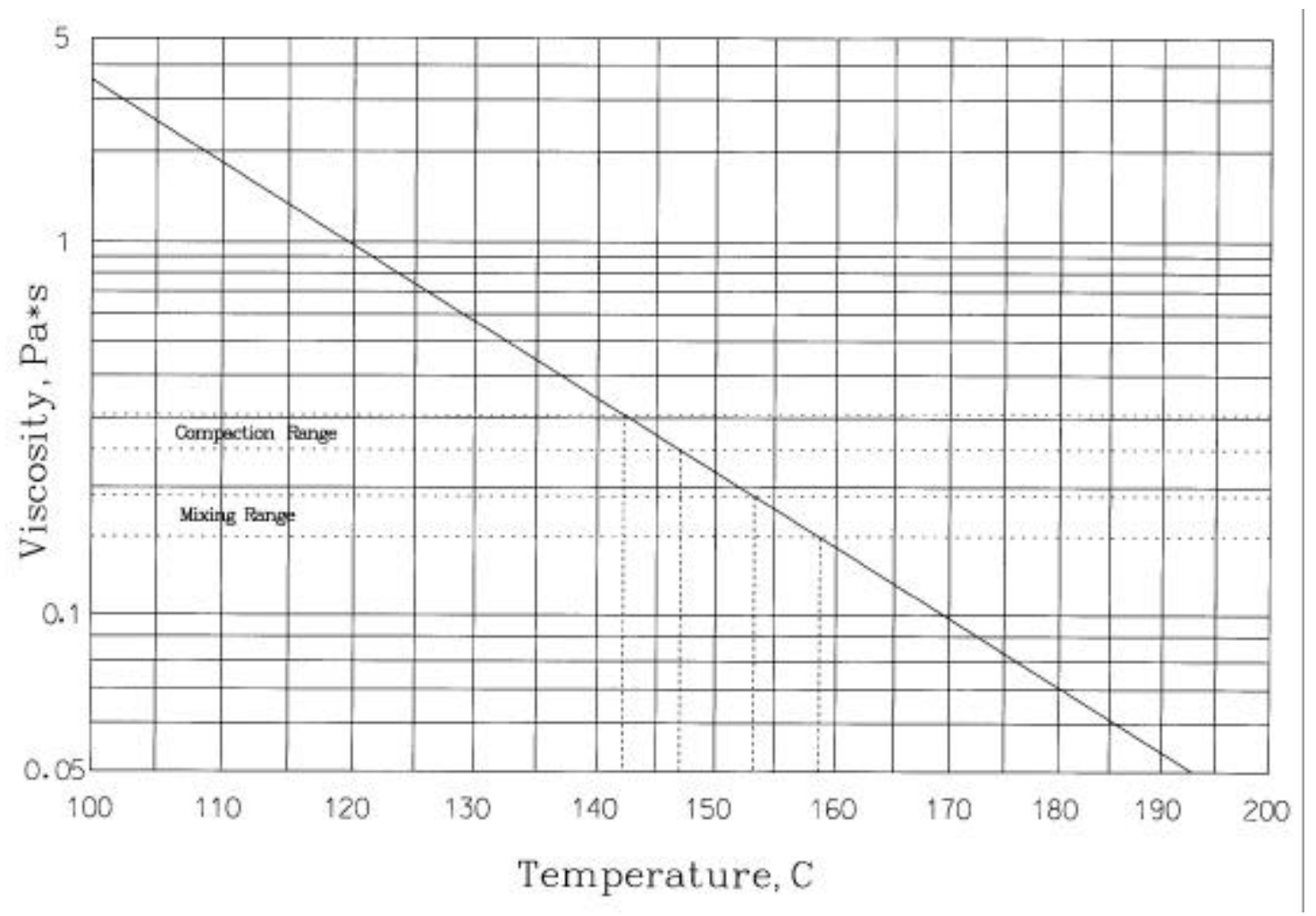

Figure 4.5. Temperature-viscosity Curve for Asphalt Cement Used in the Research

discarded. Once the aggregates were thoroughly coated, the mixture was re-heated in the oven an hour. The molds and tools were heated to $170^{\circ} \mathrm{C}$. The material was placed in the proper size mold, and spade along the inner edge of the mold 15 times and 10 times in the middle of the sample. For the $152 \mathrm{~mm}$ mold, the material was added in two lifts and the spading was applied to each lift.

The specimen was then compacted. For the $102 \mathrm{~mm}$ molds, the samples were compacted with a standard hammer. The hammer was mechanically lifted and dropped 75 times. The specimen was turned over and another 75 blows were applied. For the $152 \mathrm{~mm}$ samples, 112 blows were applied to each side with the $10.2 \mathrm{~kg}$ hammer. Once the samples were compacted they were set in front of a fan to cool. When cool to the touch, the sample was extracted from the mold and allowed to cool to room temperature.

Mixes were made at five asphalt contents for each mix type; one at the estimated optimum asphalt content, at 0.5 percent above and 0.5 percent below the estimated optimum asphalt 
content, and at 1.0 percent above and 1.0 percent below the estimated optimum asphalt content. The Greer Asphalt plant was contacted to obtain an estimate of the optimum asphalt content. For Base 1, Base 2 and Wearing 1 the recommended asphalt contents were 3.9, 4.6, and 5.5 percent, respectively. For the trial mix design the, for Base 1, Base, 2 and Wearing 1 the estimated optimum asphalt contents were $3.5,4.5$, and 5.5 percent, respectively.

\subsection{SPECIMEN TESTING}

\subsubsection{Specific Gravity}

The bulk specific gravity of the specimen was determined in accordance with ASTM D 2726. The specimen was cooled to room temperature and weighed. The specimen was hung from a scale and immersed in a water bath at $25 \pm 1^{\circ} \mathrm{C}$ for three to five minutes. The weight of the specimen in water was then recorded. The sample was removed from the water bath, surface dried with a towel and weighed again. The bulk specific gravity, $\mathrm{G}_{\mathrm{mb}}$, was determined as:

$$
G_{m b}=\frac{A}{B-C}
$$

Where:

A = D ry weight of specimen, grams

$B=$ Surface D ried weight of specimen, grams

$\mathrm{C}=$ Weight of specimen in water, grams

The unit weight of the specimen was calculated by multiplying the bulk specific gravity by the unit weight of water. The averages of the three specimens were the values recorded for unit weight and bulk specific gravity.

\subsubsection{Stability and Flow}

Once the bulk specific gravity was determined, the heights of the samples were measured. Following the height measurement the $102 \mathrm{~mm}$ specimens were immersed in a water bath at $60^{\circ} \mathrm{C}$ for $35 \pm 5$ minutes while the $152 \mathrm{~mm}$ specimens were immersed for $45 \pm 5$ minutes. A specimen was removed from the water bath and quickly placed in the Marshall loading head and then into a Pine Instrument Company brand Marshall stability apparatus. The Marshall 
apparatus deformed the specimen at a constant rate of $50.8 \mathrm{~mm}$ per minute. The apparatus automatically plotted load versus specimen deformation. Stability was identified as the maximum load sustained by the sample. Flow was the deformation at maximum load. The stability values were then adjusted with respect to sample height using the equations:

$$
\begin{aligned}
& A=\frac{B}{0.252 C-0.6016} \\
& D=\frac{E}{0.0174 * F-0.6594}
\end{aligned}
$$

Where :

A = Adjusted $102 \mathrm{~mm}$ Sample Stability

$\mathrm{B}=102 \mathrm{~mm}$ Sample Stability

$\mathrm{C}=$ Sample Height

$\mathrm{D}=$ Adjusted $152 \mathrm{~mm}$ Sample Stability

$\mathrm{E}=152 \mathrm{~mm}$ Sample Stability

$\mathrm{F}=$ Sample Height

These functions were developed by regression analysis of the correction factors given in ASTM D 1559 and ASTM D 5581.

\subsubsection{Maximum Theoretical Specific Gravity}

The maximum theoretical specific gravity of each mixture was determined in accordance with ASTM D 2041. After the sample was properly mixed, it was spread on a table and allowed to cool. The clumps of fine aggregate materials were then broken into particles $1 / 4$ inch in diameter or smaller. Following separation of the coated fine and coarse aggregate particles, the sample was weighed and then placed into a pycnometer and submerged in water at a temperature of $25 \pm 1^{\circ} \mathrm{C}$. The sample was subjected to a vacuum of $30 \mathrm{mmHg}$ for 15 minutes while the pycnometer was adgetated on a vibrating table. The pycnometer was then filled completely with water and the pycnometer and contents were weighed. The maximum theoretical specific gravity, $\mathrm{G}_{\mathrm{mm}}$, was calculated as: 


$$
G_{m m}=\frac{A}{A+B+C}
$$

Where:

A = Weight of D ry Sample, grams

$\mathrm{B}=$ Weight of pycnometer completely filled with water, grams

$\mathrm{C}=$ Weight of pycnometer filled with water and sample, grams

\subsubsection{Voids Analysis}

The percent air voids, or voids in the total mix (VTM), in the compacted mixtures was found in accordance ASTM D 2041. Percent air voids is the air voids in the compacted sample expressed as a percentage of the total volume of the sample. Percent air voids was computed as:

$V T M=\left(\frac{A-B}{A}\right) 100$

Where:

A $=$ Average bulk specific gravity of three specimens

$\mathrm{B}=$ Maximum theoretical specific gravity of the mixture

The percent voids in the mineral aggregate (VMA) is the volume of space between the aggregate particles (air voids of the compacted mixture) plus the volume of the asphalt not absorbed into the aggregates. Percent voids in the mineral aggregate was computed as:

$$
V M A=100-\left(\frac{A^{*} B}{C}\right)
$$

Where:

A = Average bulk specific gravity of compacted mixture

$\mathrm{B}=$ Percent by weight of aggregate mixture

$\mathrm{C}=$ Bulk specific gravity of combined aggregate

The percent voids filled with asphalt (VFA) is the percentage of the VMA that is made up of asphalt. The percent voids filled with asphalt was calculated using the following relationship: 
$V F A=\left(\frac{V M A-V T M}{V M A}\right) * 100$

\subsection{DESIGN RESULTS}

Once the optimum asphalt contents for the three mix designs were determined the percent air voids, bulk specific gravity, stability, flow, and VMA were compared to the values required by WVD OH. The properties of the Wearing 1 mixture were acceptable except for the VMA. For a mix with a maximum aggregate size of $9.5 \mathrm{~mm}$, the minimum VMA is 15 percent. D epending on the analytical method used, the VMA was low by 2.1 to 2.75 percent. The Base 2 mix met all criteria except for VMA. The VMA for the mix was low by 1.4 percent. The Base 1 mix met all WVD OH specifications. The VMA specification for a mixture with a maximum aggregate size of $37.5 \mathrm{~mm}$ was 11 percent and the mix had a VMA of 11.0 to 11.1 percent. In proportioning a mixture for constructed, the Base 1 mix might be redesigned however, because the scope of this study was focused on the test variability the Base 1 mix design was accepted. Since the Wearing 1 and Base 2 did not meet the VMA criteria, they were redesigned.

Alterations were first made to the Wearing 1 mixture. The gradation originally used was altered slightly (Figure 4.6). A greater amount of the large aggregates was used assuming this would increase the VMA. However, samples made with the new gradation showed only a slight change in VMA; not enough to meet the specifications. G reer Limestone was contacted to determine the gradation they used for each of the mixes. The Greer Limestone gradation was more uniformly graded than the mixes previously attempted at the WVU laboratory (Figure 4.7). The Wearing 1 gradation used by G reer Limestone had 5 percent of the aggregate retained on the $9.5 \mathrm{~mm}$ sieve. The Greer Limestone gradation was evaluated. The VMA was under specification but very close to the minimum limit. One last attempt was made to find a gradation that would provide a suitable VMA. A more exaggerated uniformly graded blend was used while staying within WVDOH and SUPERPAVE specifications (Figure 4.8). At four percent air voids the VMA was greater than the required 15 percent but the percent air voids versus percent asphalt showed that the asphalt content was close to 10 


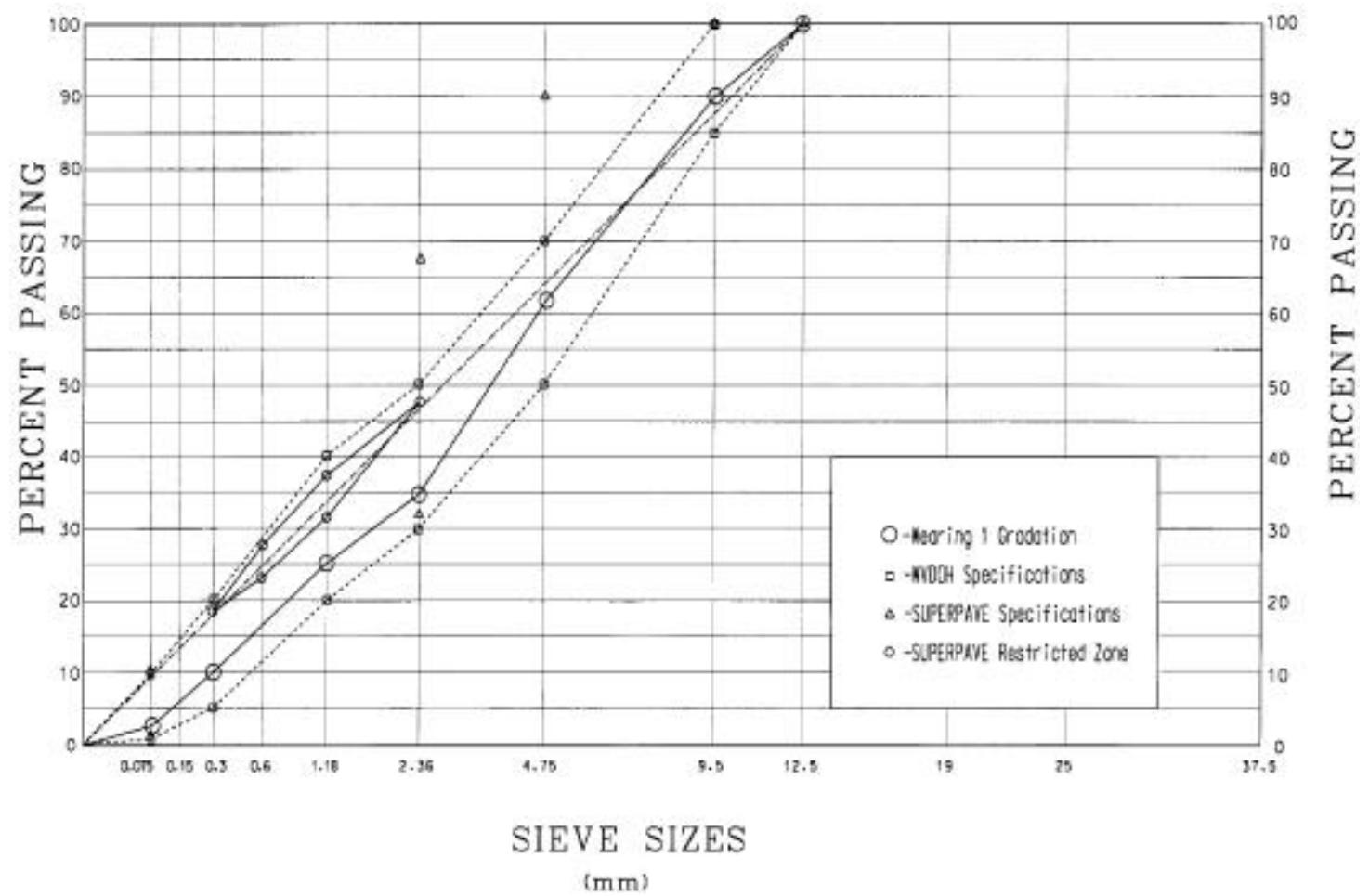

Figure 4.6. Second Gradation Attempt for Wearing 1

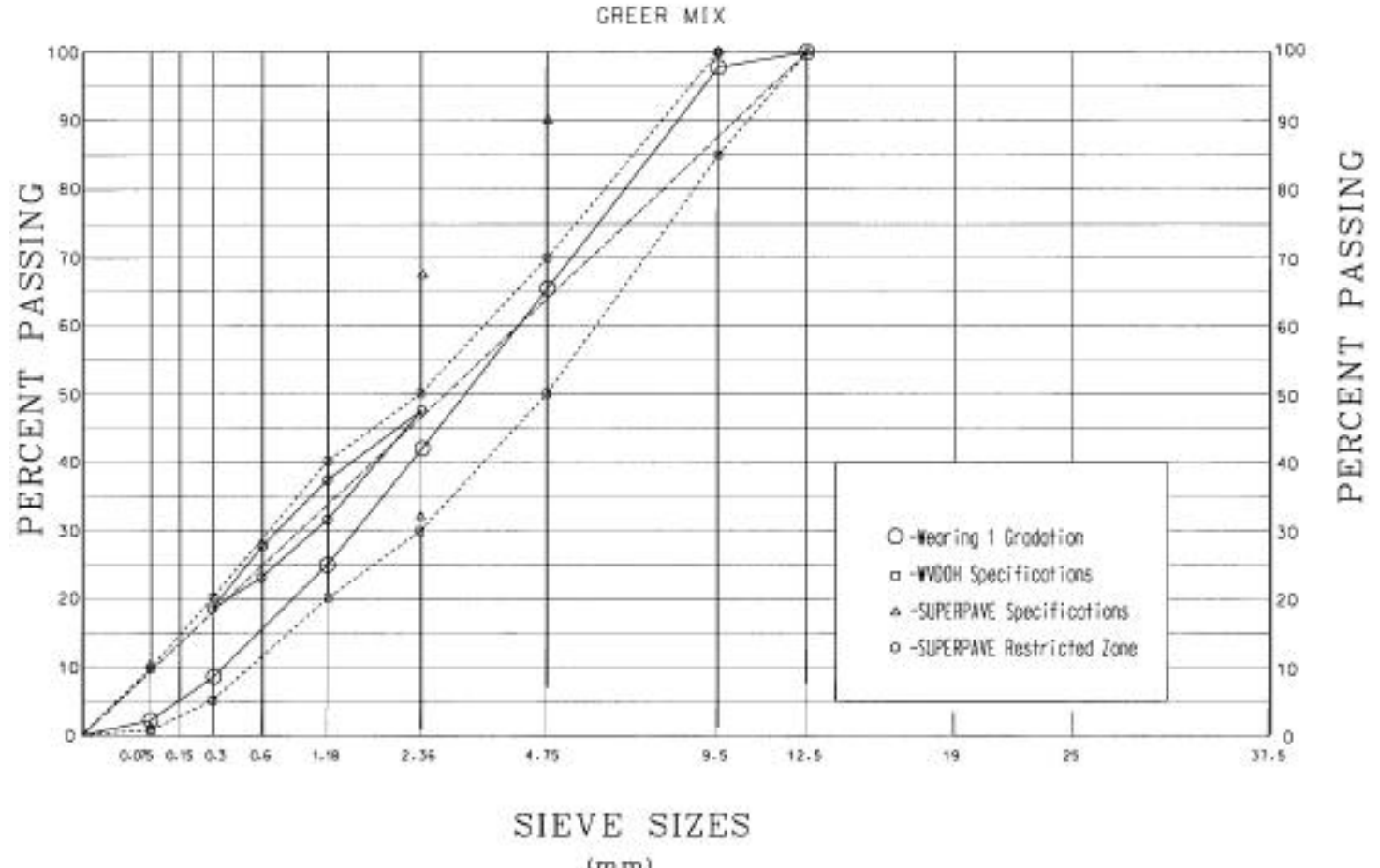

Figure 4.7. Third Gradation Attempt for Wearing 1 (Greer Gradation) 


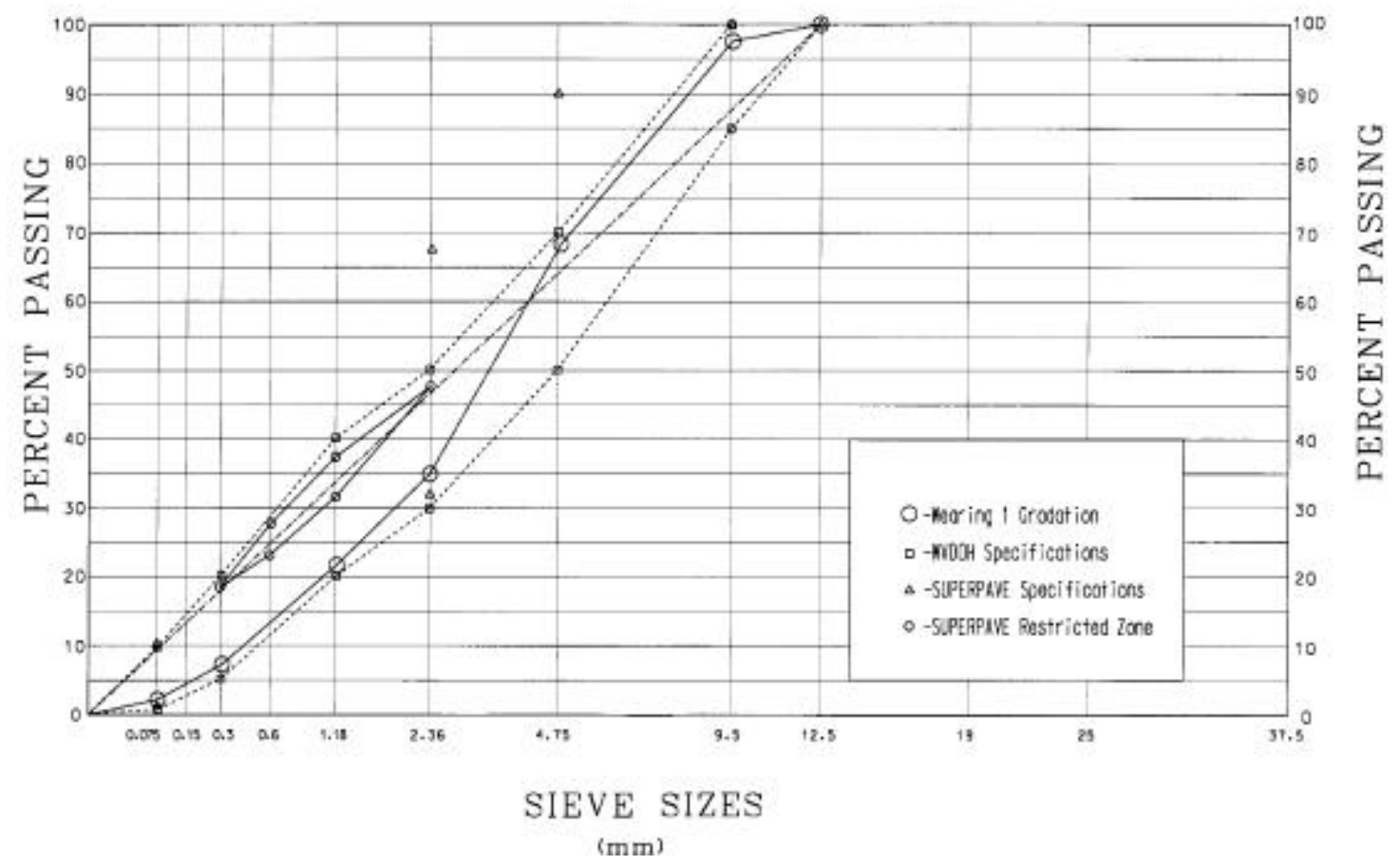

Figure 4.8. Forth Gradation Attempt for Wearing 1

percent. The WVD OH specification allows up to 10 percent asphalt content, but this would not be an economical mix and would probably fail the stability requirements.

After reviewing all four of the Wearing 1 mixes, the gradation used by Greer Limestone was selected even though it did not passed all WVD O H requirements.

The Base 2 gradation used by Greer Limestone was evaluated (Figure 4.9), even though this gradation passes through the restricted zone. However, meeting Superpave criteria was not a constraint on this project. Unfortunately, a low VMA resulted in this mixture as well. Since the $\mathrm{G}$ reer mixture was used for WVD OH projects, it was chosen over the initial mix design. The selected gradations are presented in Table 4.6.

The Marshall mix design charts for each of the mixes used in the balance of the research are presented in Appendix D. Even though the Wearing 1 and Base 2 failed the VMA criteria, they passed all of the other WVD OH criteria. Since the objective of this project is to evaluate the precision of the Marshall method, the failure of the selected mixes to satisfy the VMA criteria should not appreciably affect the research results. 


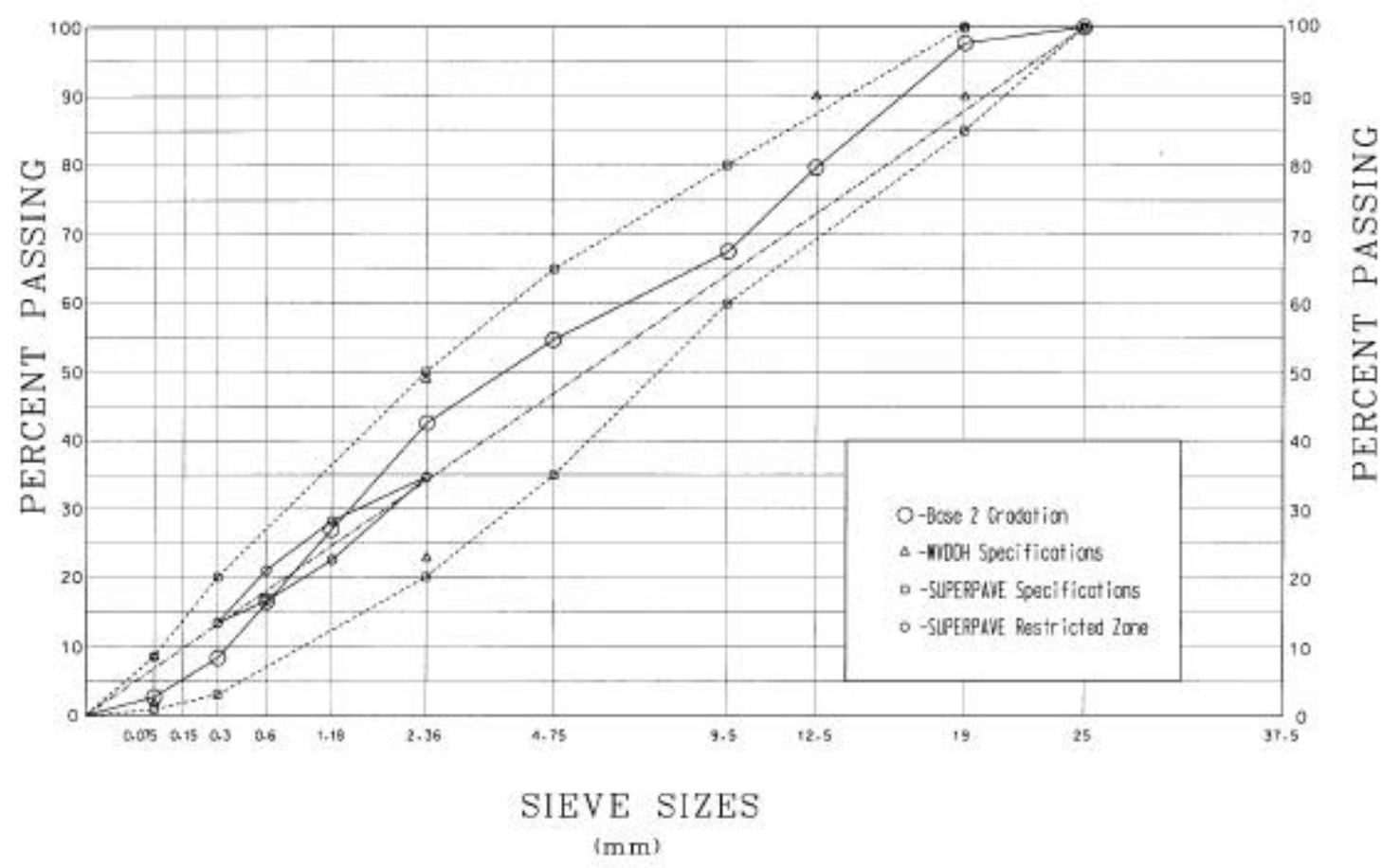

Figure 4.9. Gradation for Second Base 2 Mixture (Greer Gradation)

Table 4.6. Gradations Used in Study

\begin{tabular}{|c|c|c|c|c|c|c|c|}
\hline $\begin{array}{c}\text { Sieve } \\
\text { Size } \\
(\mathrm{mm})\end{array}$ & \multicolumn{3}{|c|}{ Percent Passing } & Sieve Size & \multicolumn{3}{c|}{ Percent Retained } \\
\hline 50 & 100 & - & - & 50 & 0 & - & - \\
37.5 & 90 & - & - & 37.5 & 10 & - & - \\
25 & 75 & 100 & - & 25 & 15 & 0 & - \\
19 & 65 & 97.8 & - & 19 & 10 & 2.2 & - \\
12.5 & 55 & 80 & 100 & 12.5 & 10 & 17.8 & - \\
9.5 & 50 & 67 & 98 & 9.5 & 5 & 13 & 2 \\
4.75 & 33 & 54.8 & 66 & 4.75 & 17 & 12.2 & 32 \\
2.36 & 20 & 40.3 & 43 & 2.36 & 13 & 14.5 & 23 \\
1.18 & 13 & 27 & 25 & 1.18 & 7 & 13.3 & 18 \\
0.6 & - & - & - & 0.6 & - & - & - \\
0.3 & 8.0 & 8.8 & 9 & 0.3 & 5 & 18.2 & 16 \\
0.15 & - & - & - & 0.15 & - & - & - \\
0.075 & 4 & 3.5 & 2.2 & 0.075 & 4 & 5.3 & 6.8 \\
- & - & - & - & Pan & 4 & 3.5 & 2.2 \\
\hline
\end{tabular}




\subsection{SAMPLE FABRICATION}

Once the mix designs for each of the mixes were completed, the samples were fabricated and distributed to laboratories. Fourteen laboratories, including the Asphalt Technology Laboratory at West Virginia University, all ten WVD OH District material laboratories, the central materials laboratory, and the Greer Limestone, and West Virginia Paving laboratories, participated in the study.

All asphalt cement and aggregates for this research were obtained from $\mathrm{G}$ reer Limestone in Clarksburg, WV. Samples were mixed in a bucket mixer at the Asphalt Technology Laboratory ant West Virginia University. Aggregates were heated to the mix temperature. The asphalt cement was kept at a constant temperature of $158^{\circ} \mathrm{C}$ in a pour pot.

Aggregates were weighed out in each sieve size to the proper amount specified for that aggregate gradation. All aggregates passing the $19 \mathrm{~mm}$ sieve were weighed to $\pm 0.1 \mathrm{~g}$. All aggregates passing the $37.5 \mathrm{~mm}$ sieve but retained on the $19 \mathrm{~mm}$ sieve or higher were weighed to $\pm 1 \mathrm{~g}$. Any aggregate retained on the $37.5 \mathrm{~mm}$ sieve was weighed to $\pm 2 \mathrm{~g}$. The scale used for weighing the asphalt cement would not allow for measurements more accurate than $\pm 0.1 \mathrm{~g}$ because of the weight of the bucket and aggregate also being weighed.

Base 1 mixes were fabricated first followed by Wearing 1 and then Base 2 mixes. The order in which the mixtures were made was deemed insignificant since comparisons of the variability between different mixture types were not the focus of this project. Only variability between the same type mixes was evaluated.

O riginally, four specimens were to be sent to each laboratory for each of mix type. Three of the samples were to be compacted and tested for voids, stability, and flow for each mixture type. The fourth sample was to be used to determine maximum theoretical specific gravity. After the Base 1 mixing was started, it was decided that two maximum theoretical specific gravity tests should be performed to provide data on the within laboratory variability. This created a problem because additional containers had to be ordered and would not arrive in time to finish all of the Base 1 mixes at one time. For this reason 60 of the Base 1 samples 
were prepared initially. The remaining Base 1 samples were prepared after the Base 2 and Wearing 1 samples were mixed. .

The samples were placed in shipment containers and labeled. The samples were randomly selected for each laboratory except for those used by the Asphalt Technology Laboratory at WVU. The samples sent to each laboratory are identified in Appendix E. The samples tested at WVU were prepared after the samples were shipped to the other laboratories. If significant differences occurred in the results then all of the results for the WVU laboratory would be disregarded since there was the potential for a bias in the sample preparation due to these samples not being randomly selected.

\subsection{SPECIMEN DISTRIBUTION}

Two days after all of the samples were mixed the samples were mailed to the laboratories. Instructions were also included with a cover letter, giving the compaction temperature range and explanation of the code on each can. The package also included a survey form with brief questions concerning the equipment and technician. A copy of the letter, survey form, and data sheets are included in Appendix F.

After all of the samples were sent to the laboratories, each laboratory was contacted to review the project requirements. The laboratories were also asked to return the results of the tests within two weeks of receiving the samples. In response to questions from the technicians at the laboratories, it was necessary to provide additional testing information requiring (1) compacting the samples for a heavy traffic design, (2) use of the dryback method for the maximum theoretical specific gravity test and (3) compaction of the samples at the middle temperature of the allowable range.. 


\section{DATA ANALYSIS AND RESULTS}

\subsection{INTRODUCTION}

The 14 laboratories returned the data within one month. The raw data were consolidated into six tables presented in Appendix E. From this raw data the stability, flow, unit weight and percent air voids were calculated and tabulated in Appendix G. These data were analyzed in accordance with ASTM Standard C 802, "Conducting an Inter-laboratory Test Program to Determine the Precision of Test Methods for Construction Materials."

Once all of the data from this experiment were analyzed, select data from the literature review were analyzed and compared to the data from this study. Finally, the data were evaluated for correlation between different characteristics of the participating laboratories and technicians. These characteristics were obtained through the survey form distributed with the samples. The survey form is included in Appendix F.

\subsection{TEST FOR OUTLIERS}

ASTM C 802 specifies that no data may be ruled as an outlier in an inter-laboratory study unless an assignable cause is identified. For this reason, in the first stage of the data analysis only two results were discarded. The two discarded values came from the District 1 maximum theoretical specific gravity tests. When analyzed, these data indicated specific gravity for two samples of asphalt concrete were 0.997 and 1.013. The laboratory technician was contacted to see if he could locate the source of the error but a cause could not be identified. Since these two values obviously resulted from a gross blunder, they were discarded. Since the calculation of percent air voids is dependent on the maximum theoretical specific gravity, the Wearing 1 percent air voids results from the District 1 laboratory were discarded as well. 


\subsection{PRELIMINARY DATA ANALYSIS}

The next stage in the research was to calculate the within-laboratory average and variance for each characteristic of the three replicates. These results are presented in Tables 5.1, 5.2, and 5.3 .

The variability of the three mix types was calculated and investigated for agreement of variances. To find out if the range of variability was too great, the ratio of the highest variance to the average variance was compared to a standard value in AST M C 802. The standard value represents a 95 percent confidence interval of how large this ratio should be for 14 laboratories and three replicate samples.

It can be seen in Table 5.4 that several samples did not meet the AST M C 802 criteria. The Wearing 1 and Base 2 samples did not fit the criteria in 4 out of the 5 characteristics. In fact, the maximum theoretical specific gravity was the only parameter where the fluctuation in the variability between laboratories was within the expected range for the Base 2 and Wearing 1 mixes.

ASTM C 802 also recommends testing to determine if the range of variability is extraordinarily low by comparing the ratio of the highest variance to the lowest variance. This ratio is compared to a standard value that represents a 95 percent confidence interval of how large this ratio should be. The low variability test determines if a laboratory has constrained the natural variability that is expected to occur. The Base 1 and Base 2 mixes failed this check for the maximum theoretical specific gravity. The Wearing 1 mix failed the criteria for the bulk specific gravity and percent air voids.

It is interesting to note that the Wearing 1 material failed both the low and high variability tests for the bulk specific gravity and the percent air voids. This is possible since the statistical tests are performed on different variability parameters. However, it does indicate that there are very unusual variability occurrences in the data set.

Multiple failures of the high variance test is a major concern. Large fluctuations in the variability indicate the test procedure is not stable. Looking at Figures 5.1 to 5.15 the nature of the variability can be more closely investigated. These charts demonstrate that of the nine 
Table 5.1 Base 1Within-laboratory Averages and Standard Deviations

\begin{tabular}{|c|c|c|c|c|c|c|c|c|c|c|c|}
\hline \multicolumn{2}{|c|}{ Laboratory } & \multicolumn{2}{|c|}{ Rice Specific Gravity } & \multicolumn{2}{|c|}{ Stability (N) } & \multicolumn{2}{|c|}{ Flow $(0.25 \mathrm{~mm})$} & \multicolumn{2}{|c|}{ Bulk Specific Gravity } & \multicolumn{2}{|c|}{ Percent Air Voids } \\
\hline & & $x$ & $s$ & $x$ & $s$ & $x$ & $s$ & $x$ & $s$ & $-x$ & $s$ \\
\hline District & 1 & * & * & 15382 & 2745 & 9.33 & 0.722 & 2.427 & 0.0053 & * & * \\
\hline District & 2 & 2.490 & 0.0001 & 13607 & 1464 & 9.60 & 0.347 & 2.408 & 0.0054 & 3.3181 & 0.210 \\
\hline District & 3 & 2.485 & 0.0021 & 7495 & 2528 & 13.27 & 1.182 & 2.278 & 0.0054 & 8.3395 & 0.209 \\
\hline District & 4 & 2.481 & 0.0004 & 14353 & 2123 & 10.83 & 0.389 & 2.407 & 0.0039 & 3.0052 & 0.153 \\
\hline District & 5 & 2.494 & 0.0254 & 11503 & 144 & 11.25 & 0.292 & 2.374 & 0.0062 & 4.7992 & 0.241 \\
\hline District & 6 & 2.484 & 0.0022 & 12961 & 3074 & 11.33 & 2.056 & 2.377 & 0.0055 & 4.2960 & 0.215 \\
\hline District & 7 & 2.472 & 0.0091 & 12424 & 1391 & 13.00 & 15.167 & 2.399 & 0.0083 & 2.9512 & 0.327 \\
\hline District & 8 & 2.486 & 0.0022 & 11249 & 511 & 10.00 & 0.500 & 2.386 & 0.0070 & 4.0209 & 0.272 \\
\hline District & 9 & 2.484 & 0.0003 & 14419 & 1922 & 9.83 & 0.222 & 2.385 & 0.0153 & 3.9862 & 0.597 \\
\hline District & 10 & 2.480 & 0.0005 & 15889 & 3915 & 9.58 & 0.347 & 2.362 & 0.0176 & 4.7421 & 0.244 \\
\hline Central & & 2.490 & 0.0021 & 12677 & 1264 & 10.33 & 0.056 & 2.403 & 0.0106 & 3.4924 & 0.224 \\
\hline Greer & & 2.481 & 0.0016 & 11883 & 1390 & 9.33 & 0.389 & 2.392 & 0.0177 & 3.6169 & 0.074 \\
\hline $\begin{array}{c}\text { WV } \\
\text { Paving }\end{array}$ & & 2.484 & 0.0010 & 10120 & 663 & 13.37 & 0.202 & 2.354 & 0.0163 & 5.2111 & 0.372 \\
\hline WVU & & 2.490 & 0.0014 & 14243 & 509 & 9.67 & 0.056 & 2.403 & 0.0078 & 3.5145 & 0.106 \\
\hline
\end{tabular}

$\mathbf{x}=$ mean

$\mathrm{s}=$ standard deviation 
Table 5.2. Base 2 Within-laboratory Averages and Standard Deviations

\begin{tabular}{|c|c|c|c|c|c|c|c|c|c|c|c|}
\hline \multirow{2}{*}{\multicolumn{2}{|c|}{ Laboratory }} & \multicolumn{2}{|c|}{ Rice Specific Gravity } & \multicolumn{2}{|c|}{ Stability $(\mathrm{N})$} & \multicolumn{2}{|c|}{ Flow $(0.25 \mathrm{~mm})$} & \multicolumn{2}{|c|}{ Bulk Specific Gravity } & \multicolumn{2}{|c|}{ Percent Air Voids } \\
\hline & & $x$ & $s$ & $-x$ & $s$ & $\mathrm{x}$ & $s$ & $\mathrm{x}$ & $s$ & $x^{-}$ & $s$ \\
\hline District & 1 & * & * & 15382 & 903 & 9.33 & 0.722 & 2.427 & 0.0061 & * & * \\
\hline District & 2 & 2.490 & 0.0001 & 13607 & 625 & 9.60 & 0.347 & 2.408 & 0.0052 & 3.3181 & 0.206 \\
\hline District & 3 & 2.485 & 0.0006 & 7495 & 2285 & 13.27 & 1.182 & 2.278 & 0.0301 & 8.3395 & 1.193 \\
\hline District & 4 & 2.481 & 0.0007 & 14353 & 378 & 10.83 & 0.389 & 2.407 & 0.0074 & 3.0052 & 0.293 \\
\hline District & 5 & 2.494 & 0.0003 & 11503 & 1340 & 11.25 & 0.292 & 2.374 & 0.0018 & 4.7992 & 0.071 \\
\hline District & 6 & 2.484 & 0.0007 & 12961 & 965 & 11.33 & 2.056 & 2.377 & 0.0045 & 4.2960 & 0.178 \\
\hline District & 7 & 2.472 & 0.0000 & 12424 & 1591 & 13.00 & 15.167 & 2.399 & 0.0078 & 2.9512 & 0.308 \\
\hline District & 8 & 2.486 & 0.0003 & 11249 & 466 & 10.00 & 0.500 & 2.386 & 0.0042 & 4.0209 & 0.165 \\
\hline District & 9 & 2.484 & 0.0020 & 14419 & 518 & 9.83 & 0.222 & 2.385 & 0.0041 & 3.9862 & 0.161 \\
\hline District & 10 & 2.480 & 0.0002 & 15889 & 1123 & 9.58 & 0.347 & 2.362 & 0.0051 & 4.7421 & 0.571 \\
\hline Central & & 2.490 & 0.0012 & 12677 & 548 & 10.33 & 0.056 & 2.403 & 0.0047 & 3.4924 & 0.343 \\
\hline Greer & & 2.481 & 0.0005 & 11883 & 590 & 9.33 & 0.389 & 2.392 & 0.0015 & 3.6169 & 0.572 \\
\hline $\begin{array}{c}\text { WV } \\
\text { Paving }\end{array}$ & & 2.484 & 0.0018 & 10120 & 1046 & 13.37 & 0.202 & 2.354 & 0.0078 & 5.2111 & 0.527 \\
\hline WVU & & 2.490 & 0.0015 & 14243 & 821 & 9.67 & 0.056 & 2.403 & 0.0022 & 3.5145 & 0.254 \\
\hline
\end{tabular}

$\overline{\mathbf{x}}=$ mean

$\mathrm{s}=$ standard deviation 
Table 5.3. Wearing 1Within-laboratory Averages and Standard Deviations

\begin{tabular}{|c|c|c|c|c|c|c|c|c|c|c|c|}
\hline \multirow[t]{2}{*}{ Laboratory } & & \multicolumn{2}{|c|}{ Rice Specific Gravity } & \multicolumn{2}{|c|}{ Stability (N) } & \multicolumn{2}{|c|}{ Flow $(0.25 \mathrm{~mm})$} & \multicolumn{2}{|c|}{ Bulk Specific Gravity } & \multicolumn{2}{|c|}{ Percent Air Voids } \\
\hline & & $\overline{\mathrm{x}}$ & $s$ & $\bar{x}$ & $s$ & $\bar{x}$ & $s$ & $\overline{\mathrm{x}}$ & $s$ & $\bar{x}$ & $s$ \\
\hline District & 1 & * & * & 15382 & 270 & 9.33 & 0.722 & 2.427 & 0.0518 & * & * \\
\hline District & 2 & 2.490 & 0.0006 & 13607 & 344 & 9.60 & 0.347 & 2.408 & 0.0083 & 3.3181 & 0.334 \\
\hline District & 3 & 2.485 & 0.0003 & 7495 & 3425 & 13.27 & 1.182 & 2.278 & 0.0699 & 8.3395 & 2.775 \\
\hline District & 4 & 2.481 & 0.0027 & 14353 & 619 & 10.83 & 0.389 & 2.407 & 0.0020 & 3.0052 & 0.081 \\
\hline District & 5 & 2.494 & 0.0001 & 11503 & 162 & 11.25 & 0.292 & 2.374 & 0.0077 & 4.7992 & 0.310 \\
\hline District & 6 & 2.484 & 0.0006 & 12961 & 352 & 11.33 & 2.056 & 2.377 & 0.0030 & 4.2960 & 0.120 \\
\hline District & 7 & 2.472 & 0.0028 & 12424 & 149 & 13.00 & 15.167 & 2.399 & 0.0044 & 2.9512 & 0.176 \\
\hline District & 8 & 2.486 & 0.0003 & 11249 & 260 & 10.00 & 0.500 & 2.386 & 0.0043 & 4.0209 & 0.174 \\
\hline District & 9 & 2.484 & 0.0006 & 14419 & 643 & 9.83 & 0.222 & 2.385 & 0.0069 & 3.9862 & 0.280 \\
\hline District & 10 & 2.480 & 0.0021 & 15889 & 797 & 9.58 & 0.347 & 2.362 & 0.0030 & 4.7421 & 0.122 \\
\hline Central & & 2.490 & 0.0026 & 12677 & 299 & 10.33 & 0.056 & 2.403 & 0.0053 & 3.4924 & 0.212 \\
\hline Greer & & 2.481 & 0.0005 & 11883 & 250 & 9.33 & 0.389 & 2.392 & 0.0066 & 3.6169 & 0.267 \\
\hline WV Paving & & 2.484 & 0.0030 & 10120 & 342 & 13.37 & 0.202 & 2.354 & 0.0093 & 5.2111 & 0.374 \\
\hline WVU & & 2.490 & 0.0019 & 14243 & 580 & 9.67 & 0.056 & 2.403 & 0.0066 & 3.5145 & 0.265 \\
\hline
\end{tabular}

$\overline{\mathbf{x}}=$ mean

$\mathrm{s}=$ standard deviation 
Table 5.4. Test for High and Low Variability

\begin{tabular}{|c|c|c|c|}
\hline Parameter & Material & $\begin{array}{c}\text { Test for High Variance } \\
\text { Upper } 5 \% \text { Level } \\
\text { (High/Sum) } \\
\text { Must be }<0.345 \\
\end{array}$ & $\begin{array}{c}\text { Test for Low Variance } \\
\text { Upper } 5 \% \text { Level } \\
\text { (High/Low) } \\
\text { Must be }<885 \\
\end{array}$ \\
\hline $\begin{array}{l}\text { Max. Theoretical } \\
\text { Specific Gravity }\end{array}$ & $\begin{array}{l}\text { Base 1 } \\
\text { Base 2 } \\
\text { Wearing 1 }\end{array}$ & $\begin{array}{l}0.298 \\
0.313 \\
0.220 \\
\end{array}$ & $\begin{array}{c}37195 \\
14915 \\
696 \\
\end{array}$ \\
\hline Stability & \begin{tabular}{|l|} 
Base 1 \\
Base 2 \\
Wearing 1
\end{tabular} & $\begin{array}{l}0.276 \\
\mathbf{0 . 7 8 3} \\
\mathbf{0 . 8 2 6}\end{array}$ & $\begin{array}{c}741 \\
37 \\
526\end{array}$ \\
\hline Flow & \begin{tabular}{|l} 
Base 1 \\
Base 2 \\
Wearing 1
\end{tabular} & $\begin{array}{l}0.266 \\
0.488 \\
\mathbf{0 . 6 9 2}\end{array}$ & $\begin{array}{c}77 \\
* \\
273\end{array}$ \\
\hline $\begin{array}{l}\text { Bulk Specific } \\
\text { Gravity }\end{array}$ & \begin{tabular}{|l} 
Base 1 \\
Base 2 \\
Wearing 1
\end{tabular} & $\begin{array}{l}0.197 \\
\mathbf{0 . 7 2 0} \\
\mathbf{0 . 6 1 0} \\
\end{array}$ & $\begin{array}{c}20 \\
378 \\
\mathbf{1 2 0 1} \\
\end{array}$ \\
\hline Percent Air Voids & $\begin{array}{l}\text { Base 1 } \\
\text { Base } 2 \\
\text { Wearing } 1\end{array}$ & $\begin{array}{l}0.336 \\
0.489 \\
0.916\end{array}$ & $\begin{array}{c}65 \\
283 \\
1167\end{array}$ \\
\hline
\end{tabular}




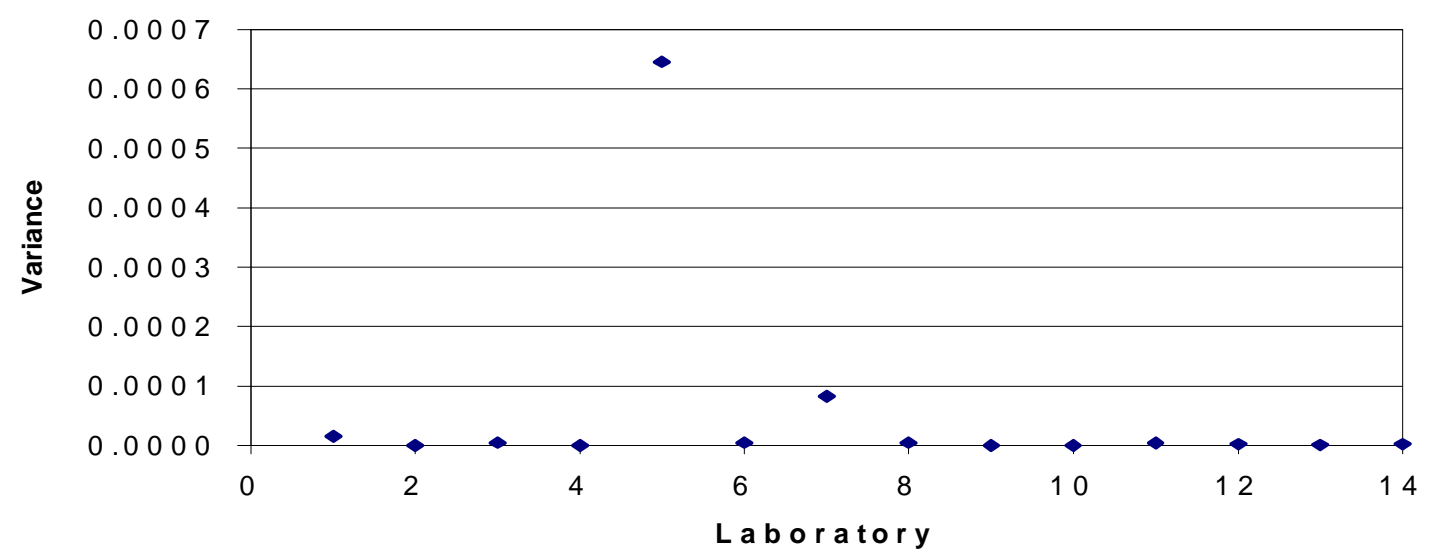

Figure 5.1. Base 1 Rice Specific Gravity Variance versus Laboratory.

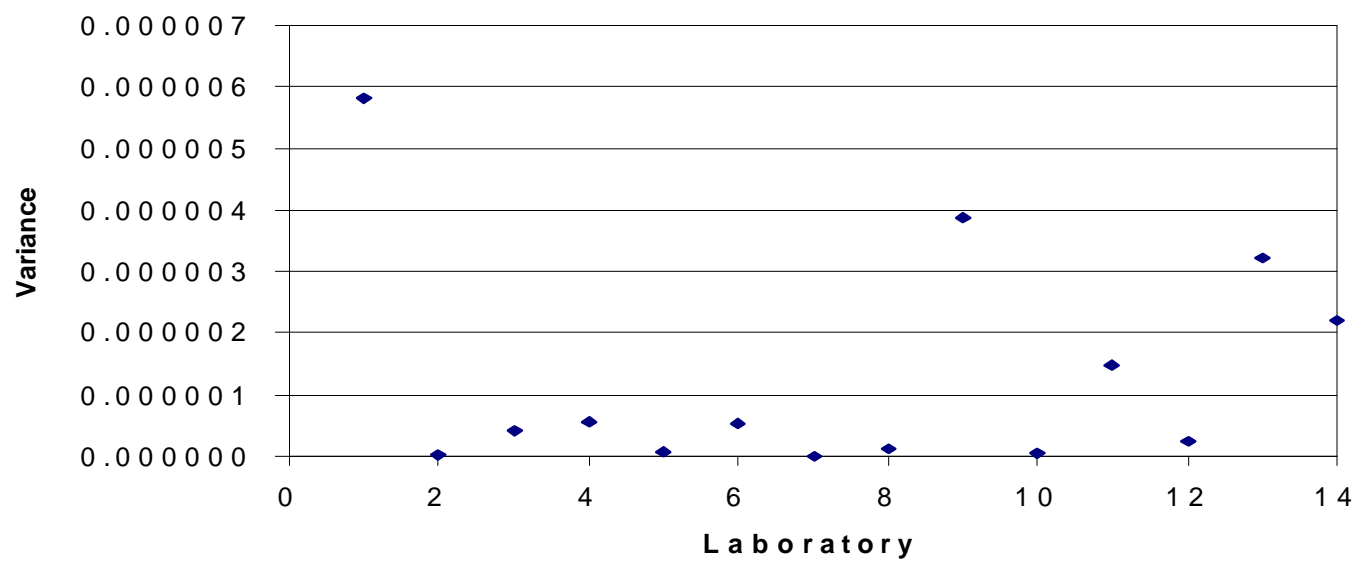

Figure 5.2. Base 2 Rice Specific Gravity Variance versus Laboratory

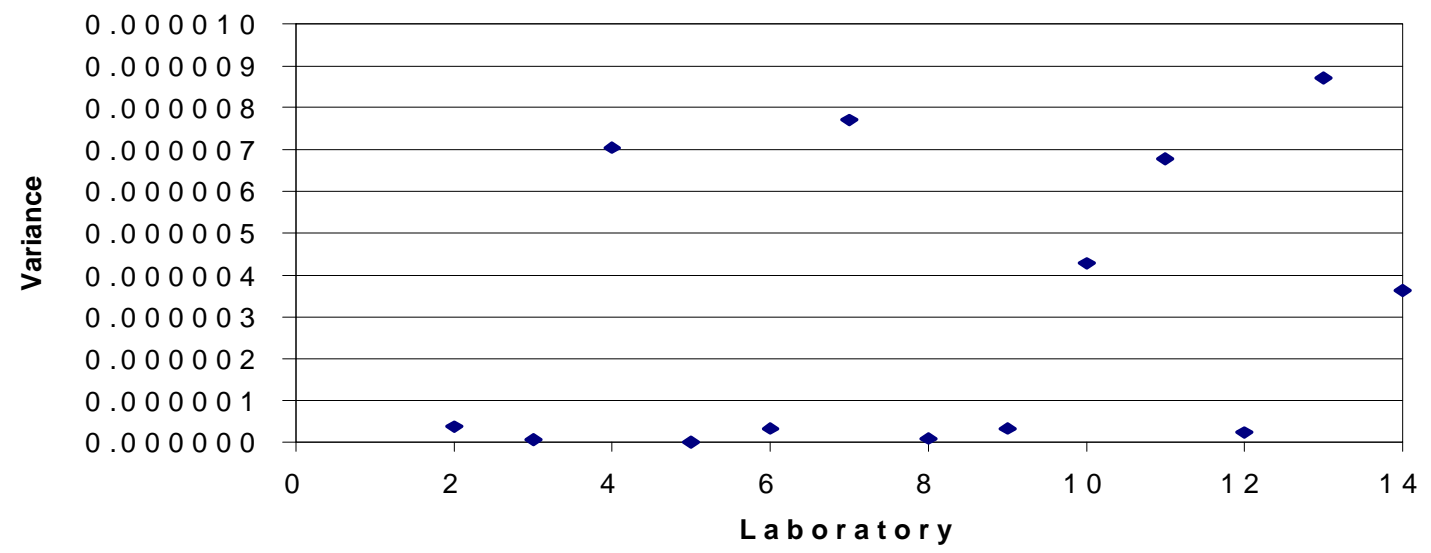

Figure 5.3. Wearing 1 Rice Specific Gravity Variance versus Laboratory 


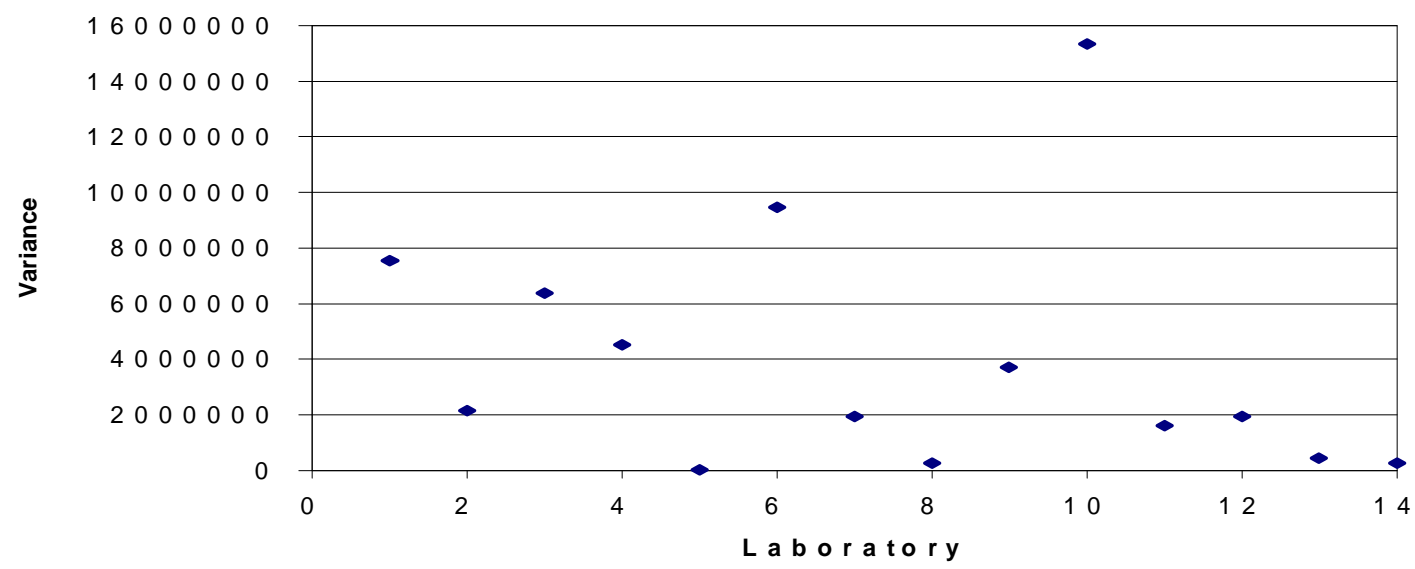

Figure 5.4. Base 1 Marshall Stability Variance versus Laboratory

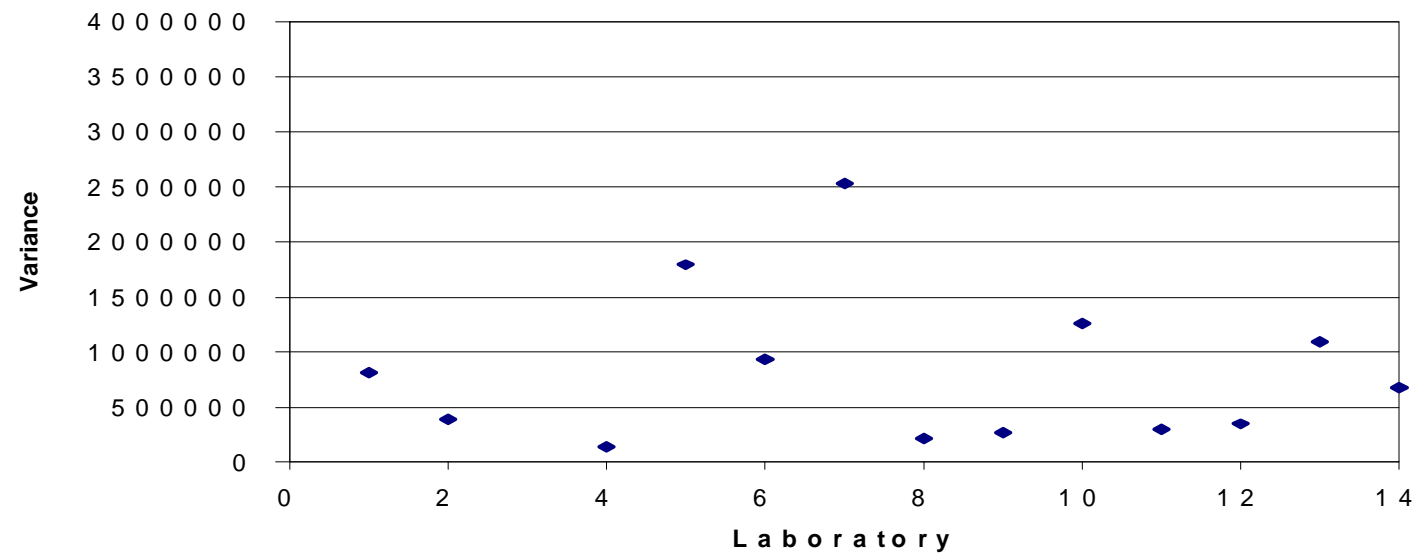

Figure 5.5. Base 2 Marshall Stability Variance versus Laboratory

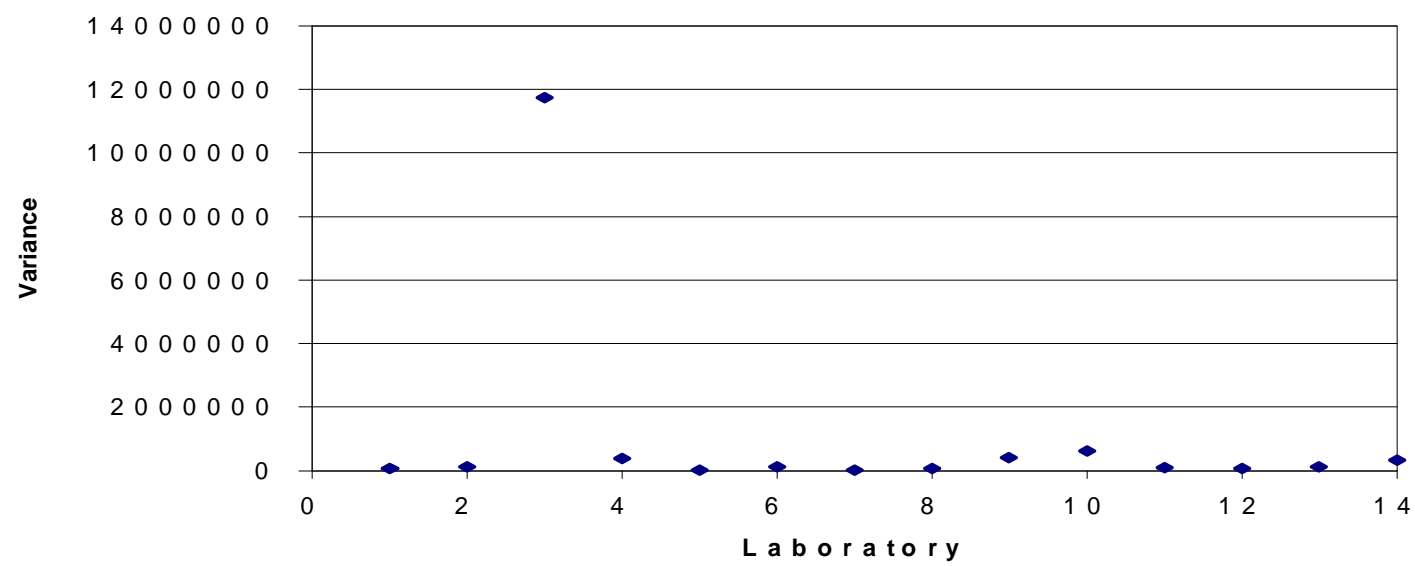

Figure 5.6. Wearing 1 Marshall Stability Variance versus Laboratory 


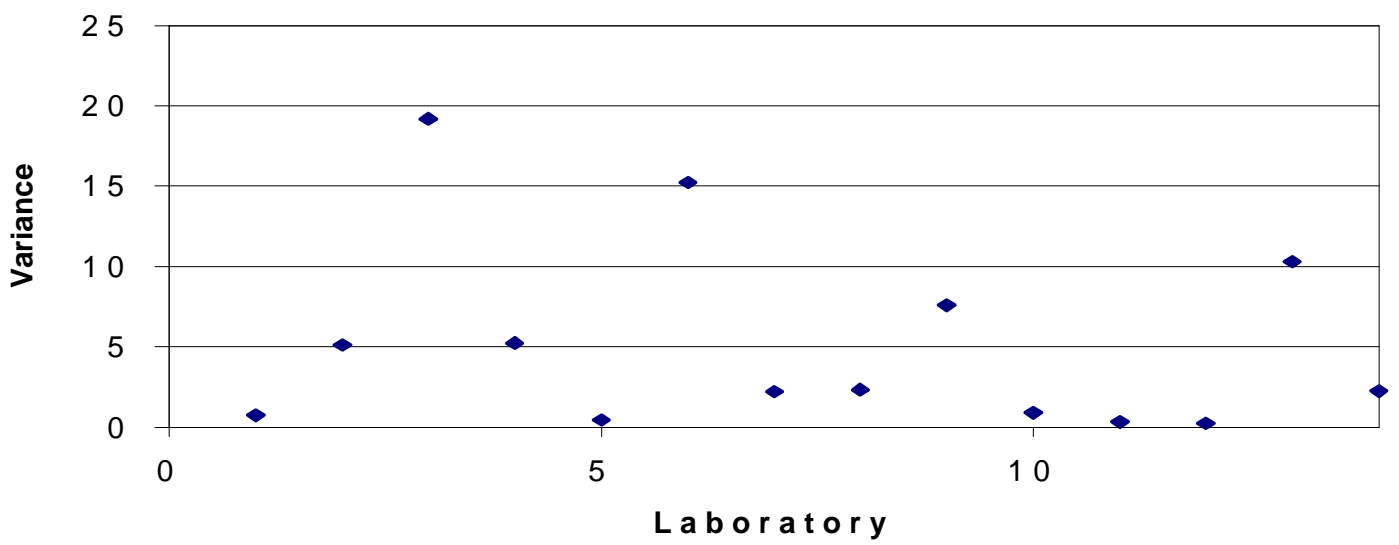

Figure 5.7. Base 1 Marshall Flow Variance versus Laboratory

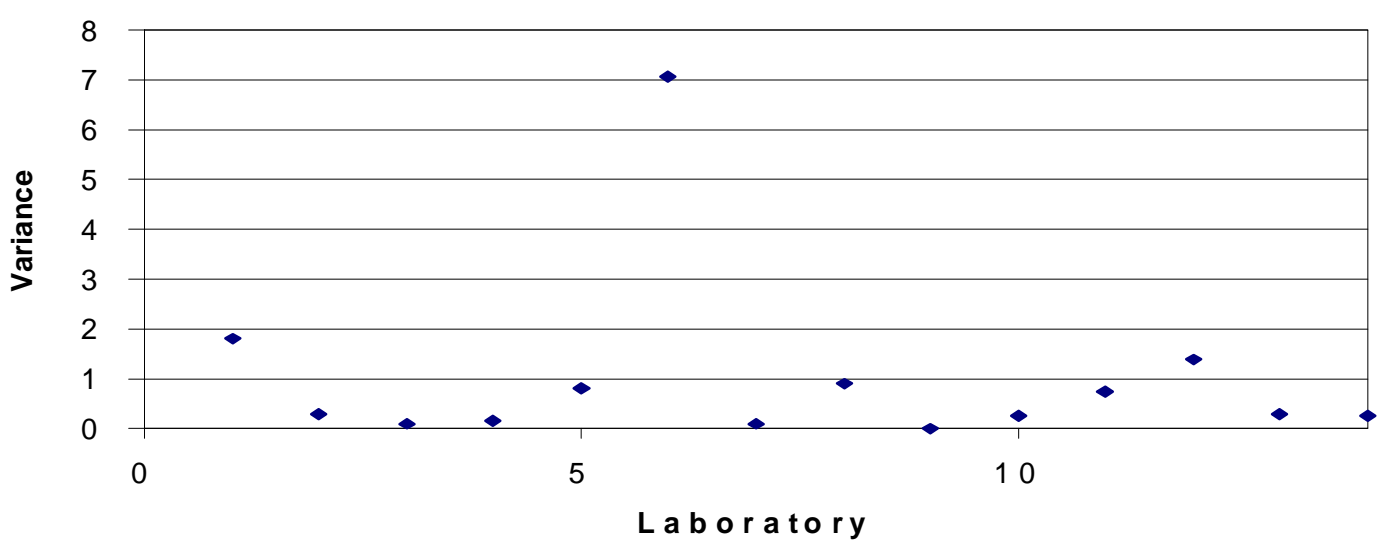

Figure 5.8. Base 2 Marshall Flow Variance versus Laboratory

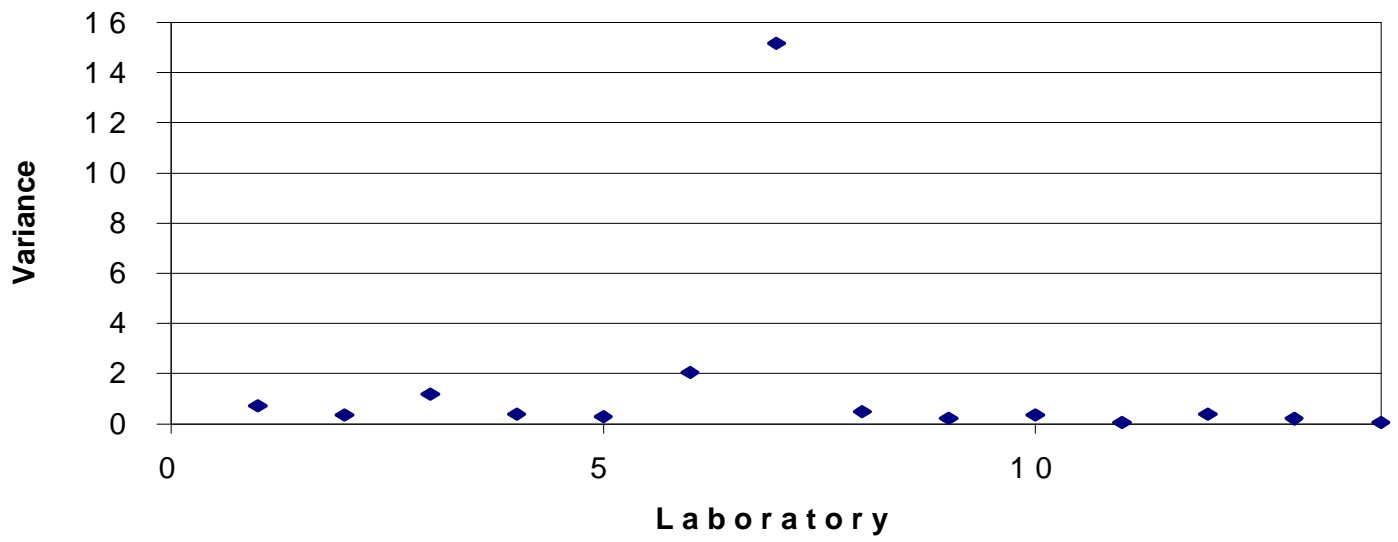

Figure 5.9. Wearing 1 Marshall Flow Variance versus Laboratory 


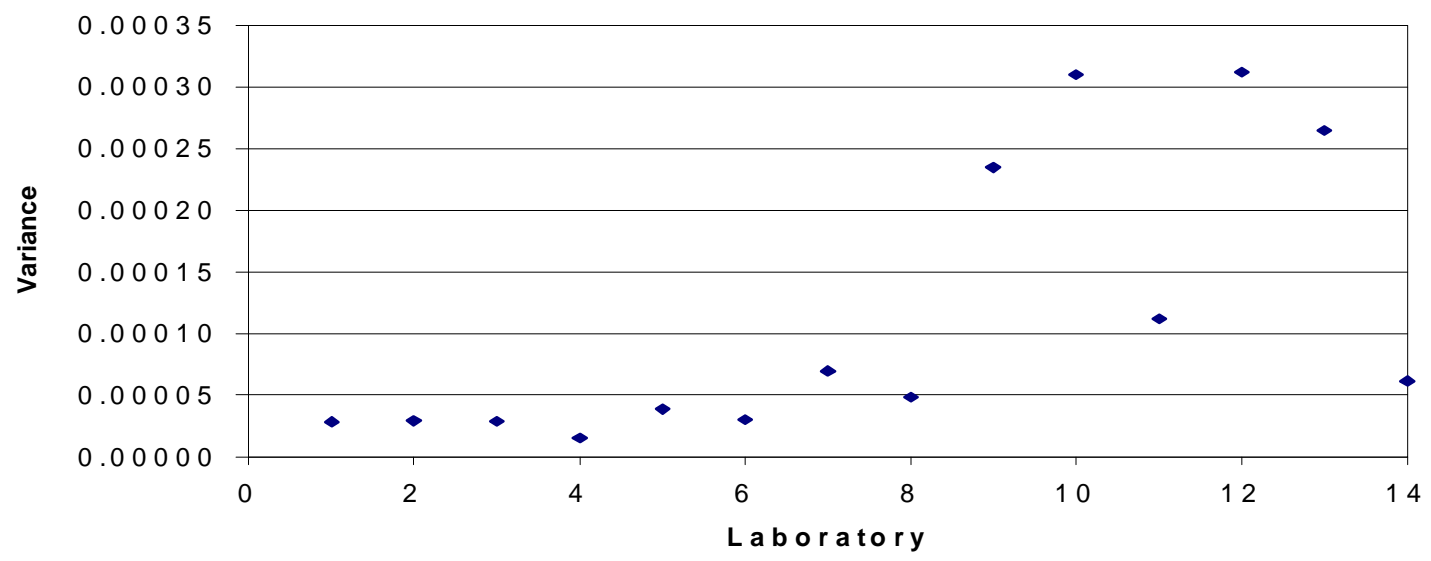

Figure 5.10. Base 1Bulk Specific Gravity Variance versus Laboratory

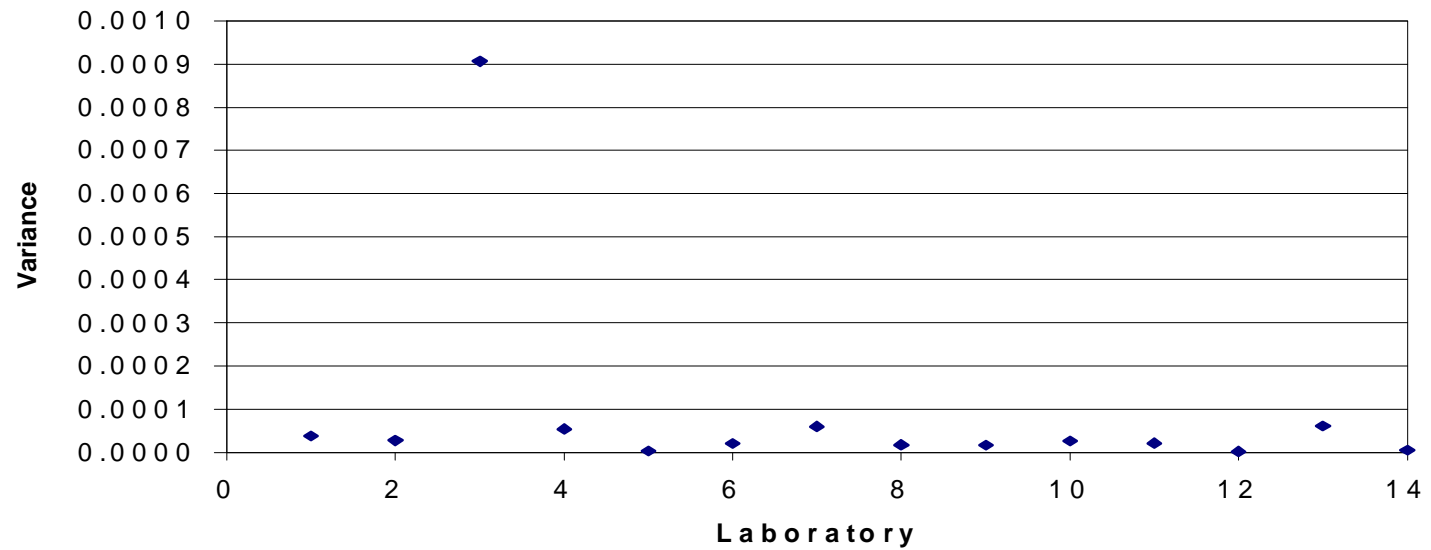

Figure 5.11. Base 2 Bulk Specific Gravity Variance versus Laboratory

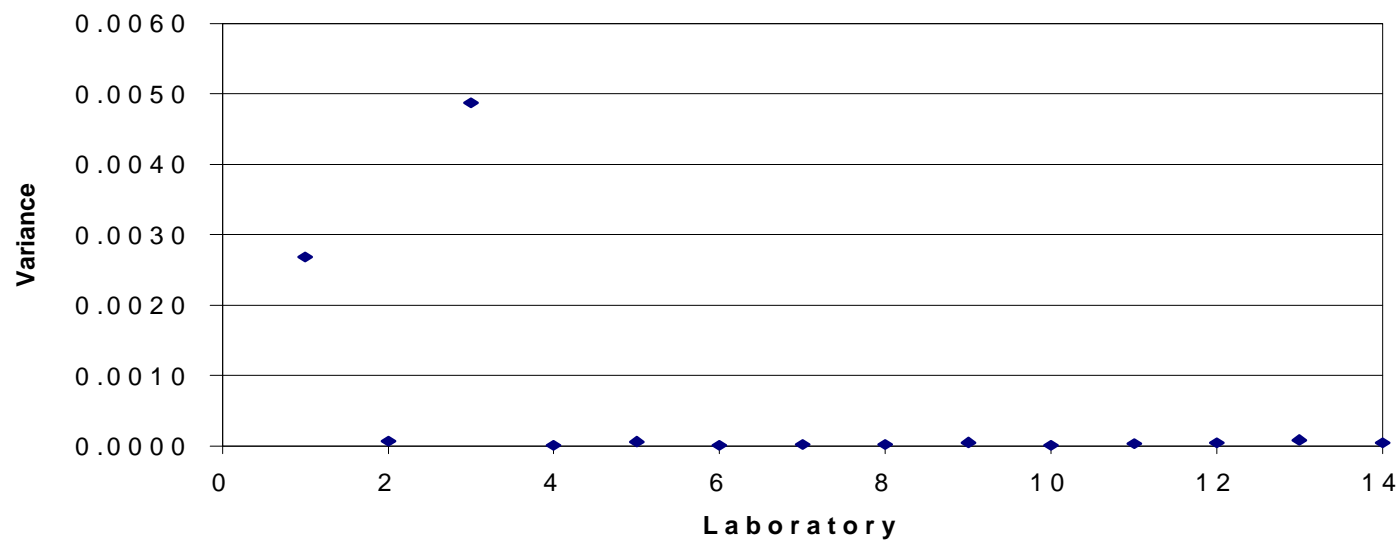

Figure 5.12. Wearing 1 Bulk Specific Gravity Variance versus Laboratory 


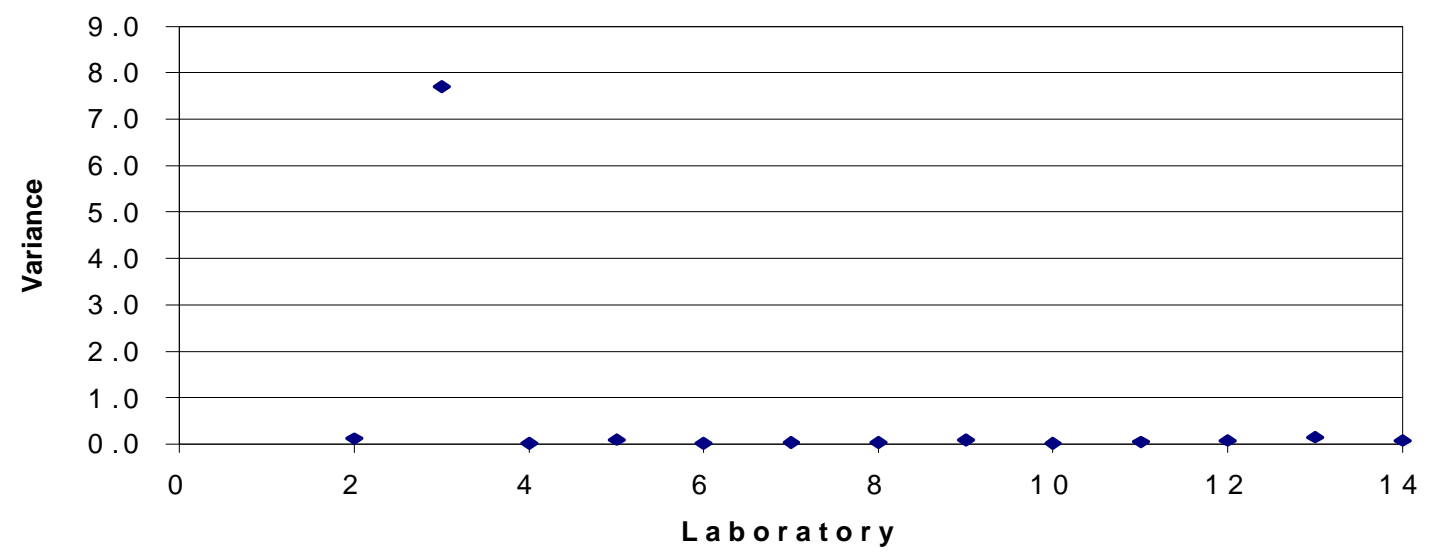

Figure 5.13. Wearing 1 Percent Air Voids Variance versus Laboratory

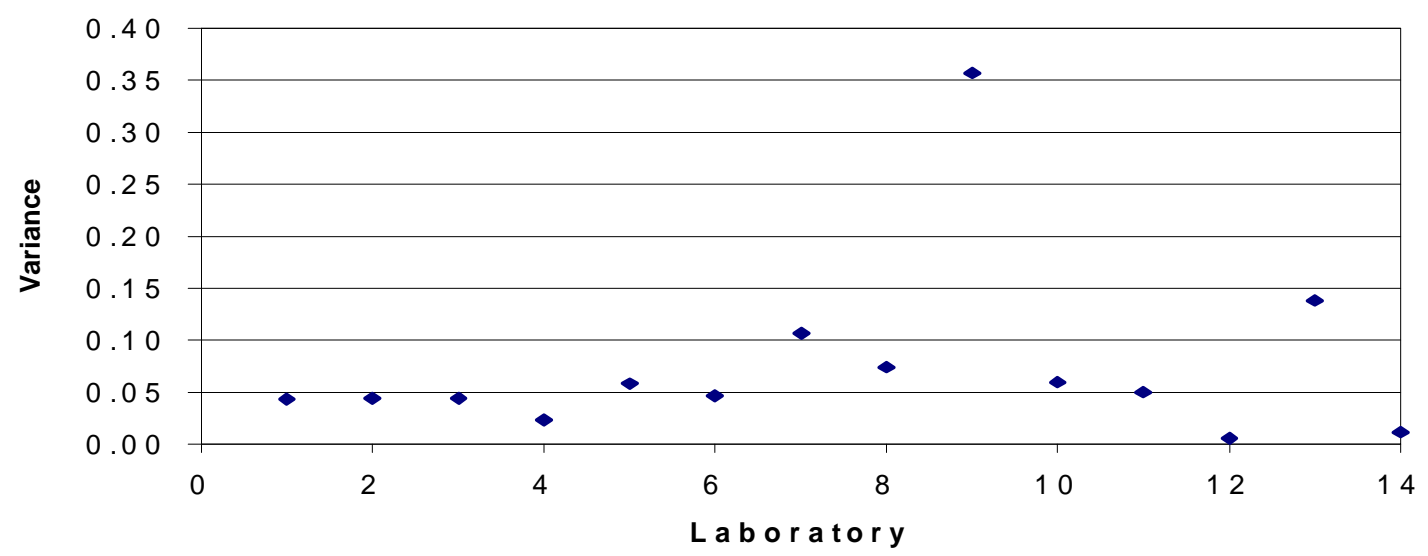

Figure 5.14. Base 1Percent Air Voids Variance versus Laboratory

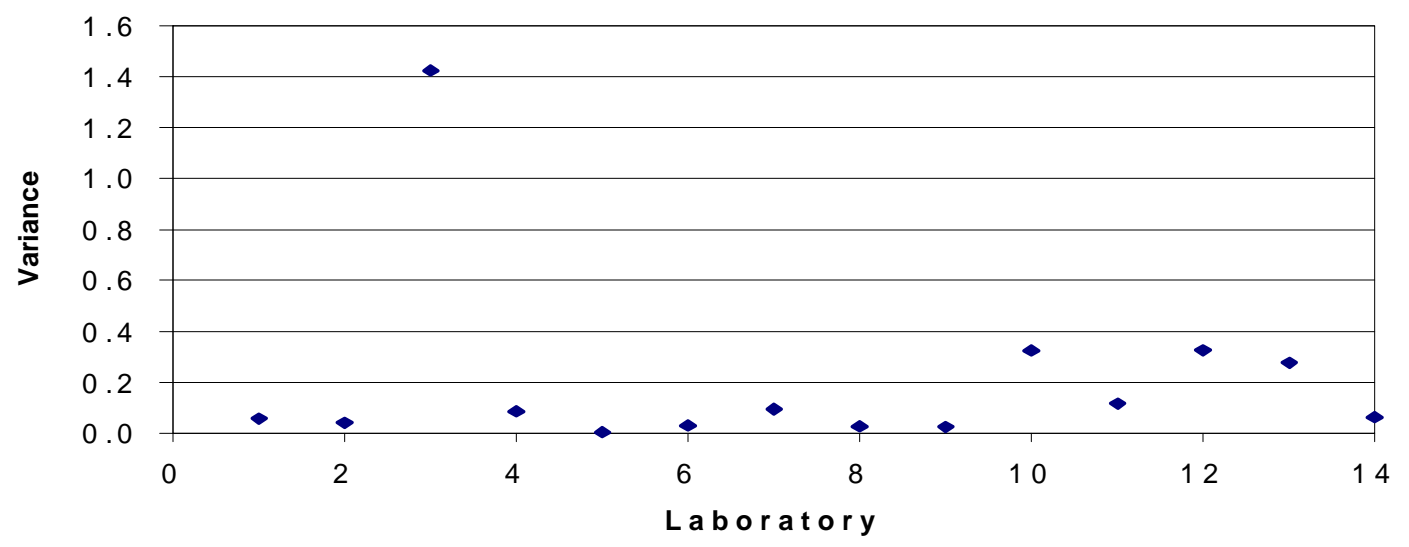

Figure 5.15. Base 2 Percent Air Voids Variance versus Laboratory 
failing tests, all variance are relatively low except for one or two laboratories: six of the failures are caused by the District 3 data.

A common problem with test results from an inter-laboratory study is the presence of interactions between the laboratories and materials. This means that the pattern of change of the results obtained on a given group of materials in one laboratory differs from the pattern obtained from other laboratories (ASTM C 802). D ifferences in the patterns between several laboratories indicate the test method should be reevaluated. To test for interactions, five charts were made. Each chart consists of a plot of the sample property against the material type. Lines are drawn between each material for each laboratory and the slope and location of the lines are compared to the other laboratories (Figures 5.16 to 5.20). The trend lines on each of these figures should have similar slopes and magnitudes. If a line for one laboratory differs from the pattern of the other laboratories the data from that laboratory may be an outliers.

Figure 5.16 shows the maximum theoretical specific gravity from District 5 is higher than the other laboratories for all three material types. For the stability data, Figure 5.17, there seem to be two laboratories that deviate from the trend set by the other laboratories. The District 3 laboratory has a high Base 1 value but low Base 2 and Wearing 1 values. D istrict 5 values seem to stay constant over the range of materials, with the Base 1 stability is lower than the other two mixes. Figure 5.18 shows no distinguishing trend across the flow values of the mixes. This is a strong indication that this test method does not evaluate the characteristic of the material very well. It has been known that flow tests have a significant amount of variation so this is not new information. WVD OH specifications of flow allow a wide range of flow values for this reason.

Figures 5.19 and 5.20 show reasonable agreement and similar trends for bulk specific gravity and percent air voids for all laboratories with the exception of District 3. The low bulk specific gravity and high air void content of the Base 2 and Wearing 1 samples from D istrict 3 indicate inadequate compaction. This could be a reason the Marshall stability of these samples was relatively low, especially for the Wearing 1 samples. 


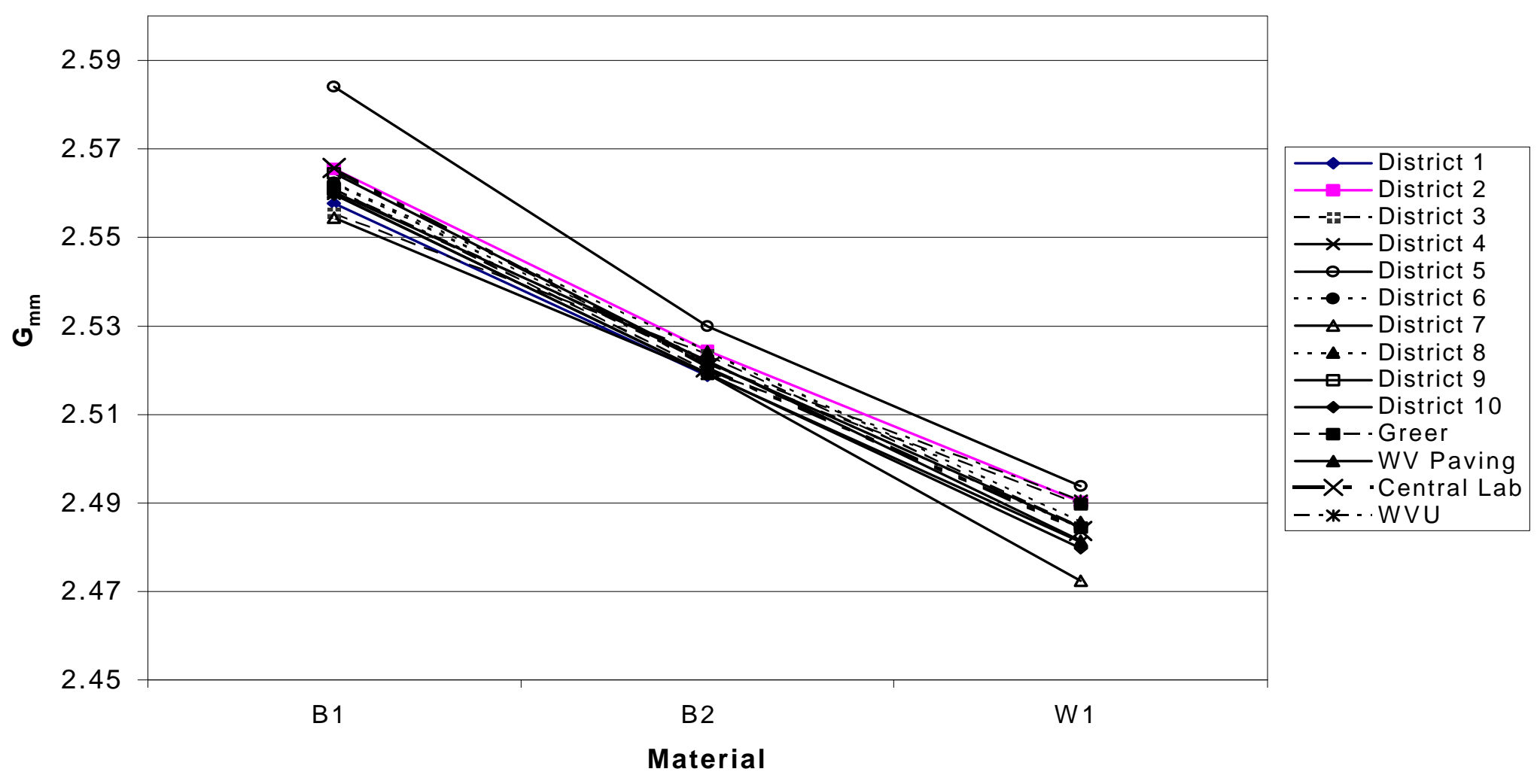

Figure 5.16. Chart of Interactions in Maximum Theoretical Specific Gravity 


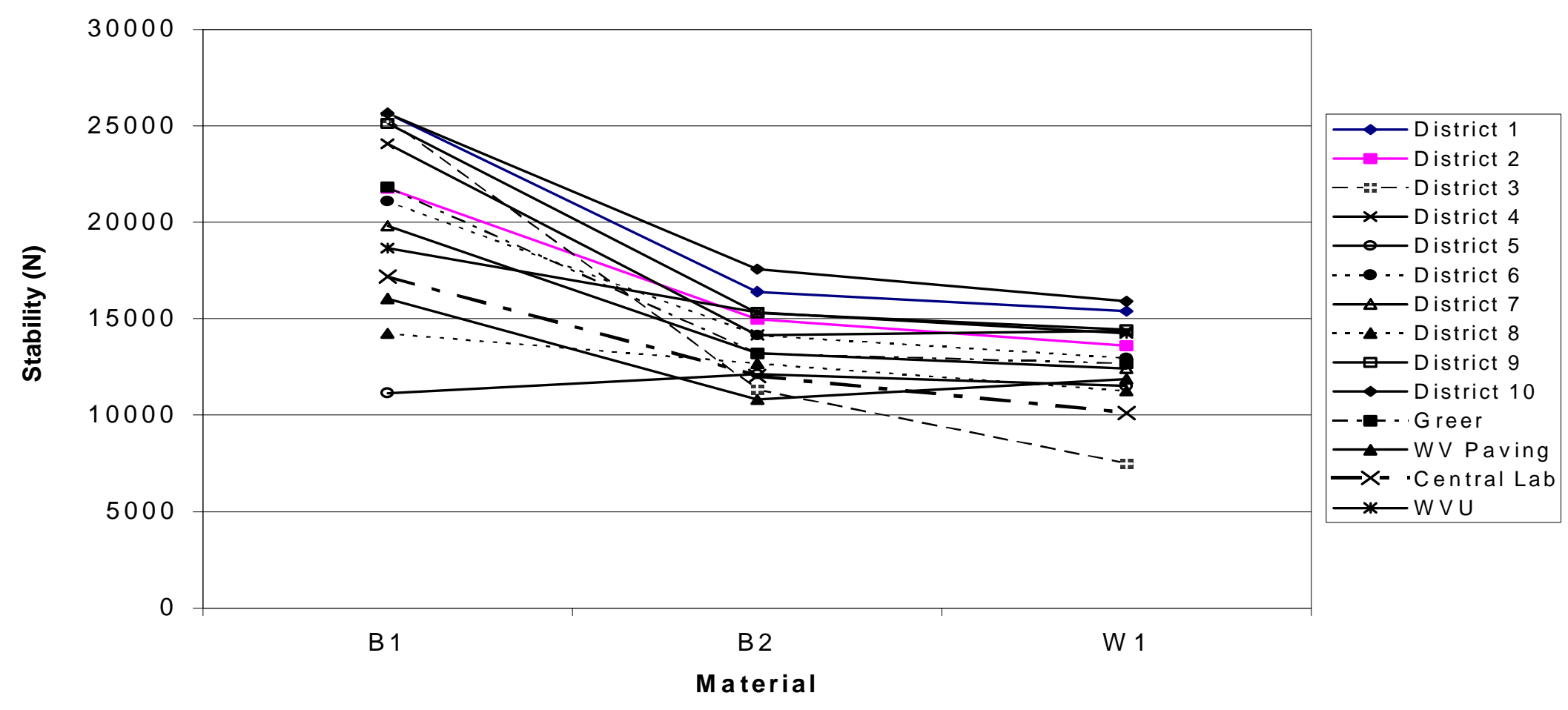

Figure 5.17. Chart of Interactions in Marshall Stability 


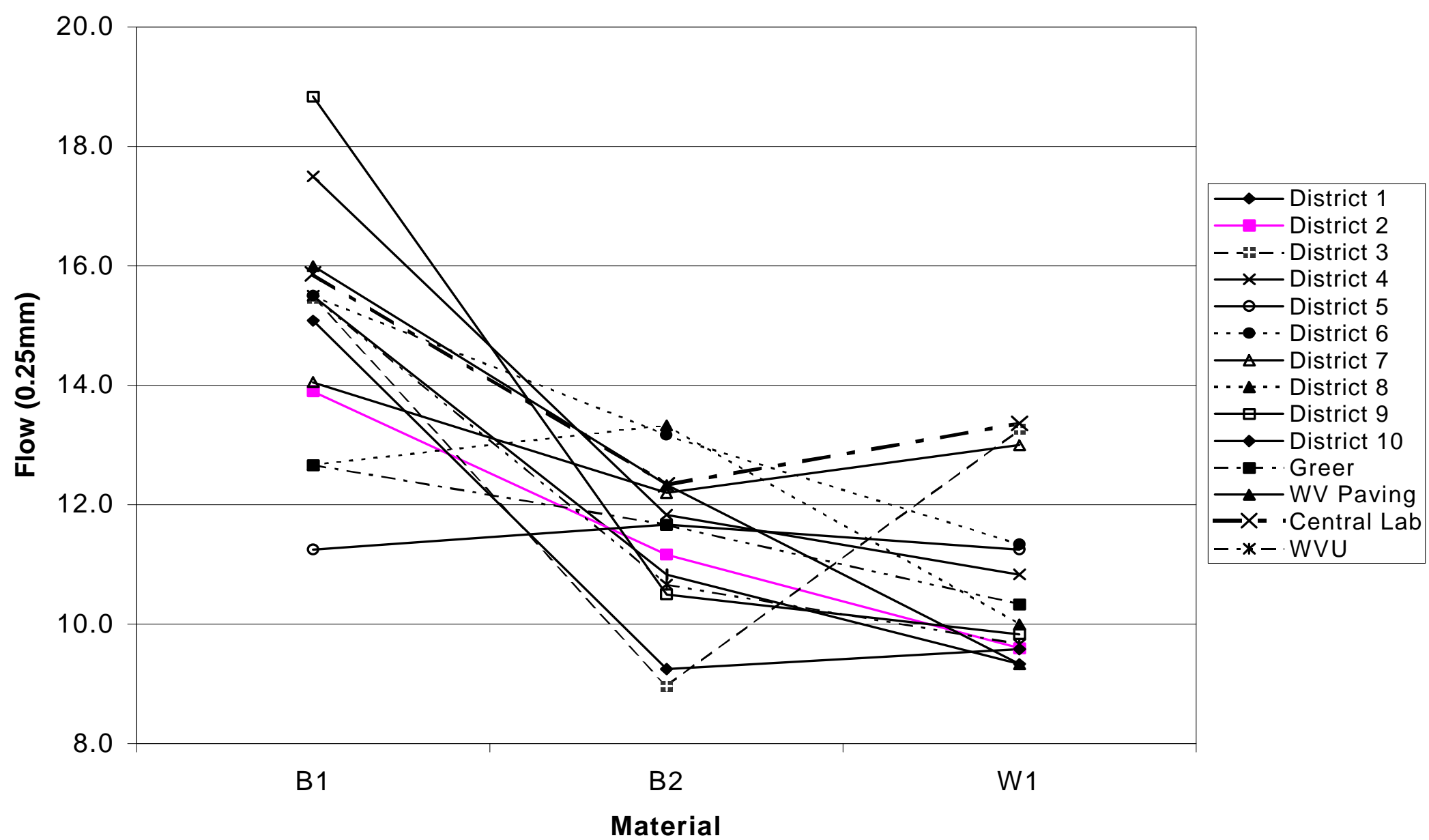

Figure 5.18. Chart of Interactions in Marshall Flow 


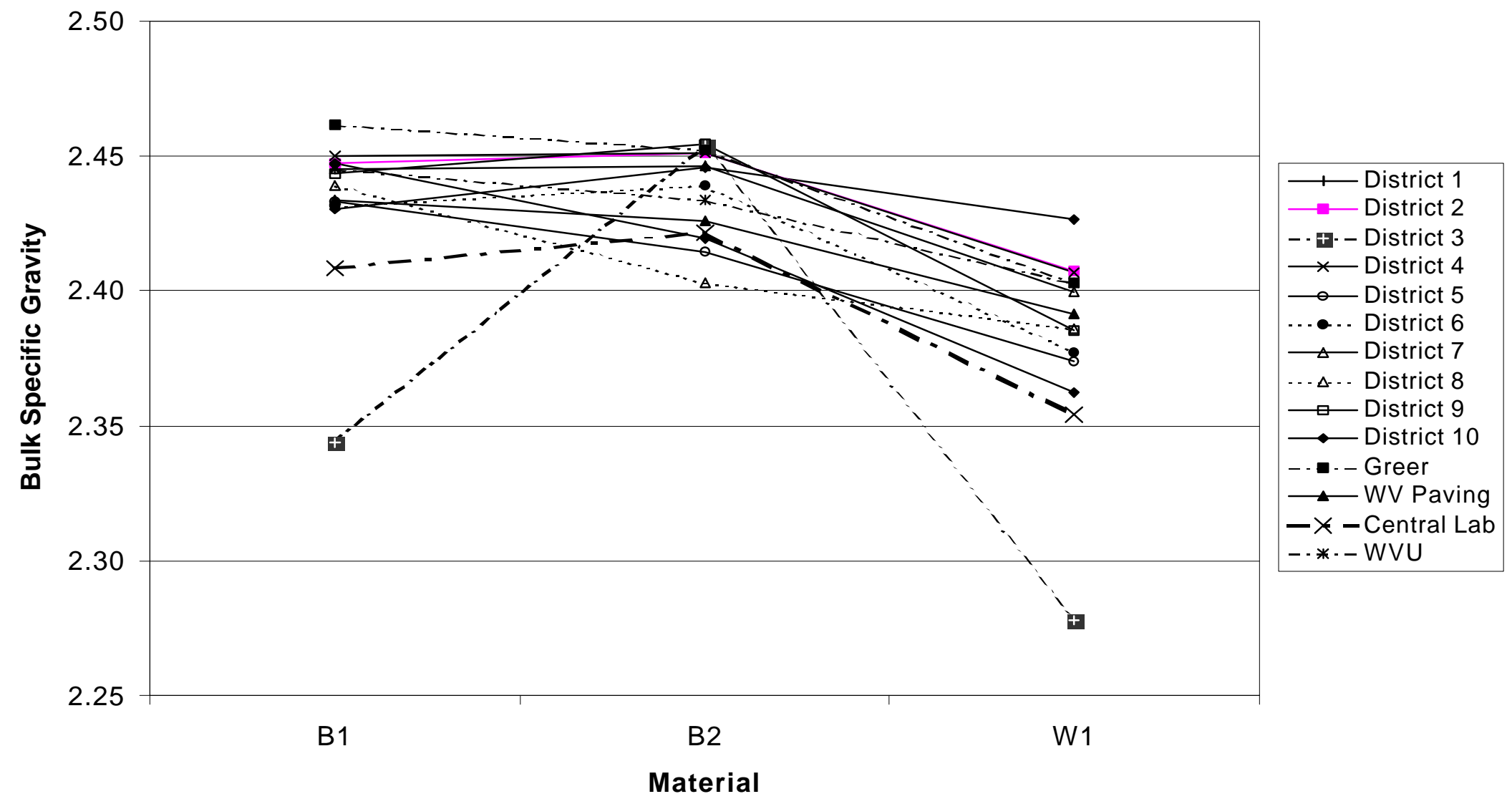

Figure 5.19. Chart of Interactions in Bulk Specific Gravity 


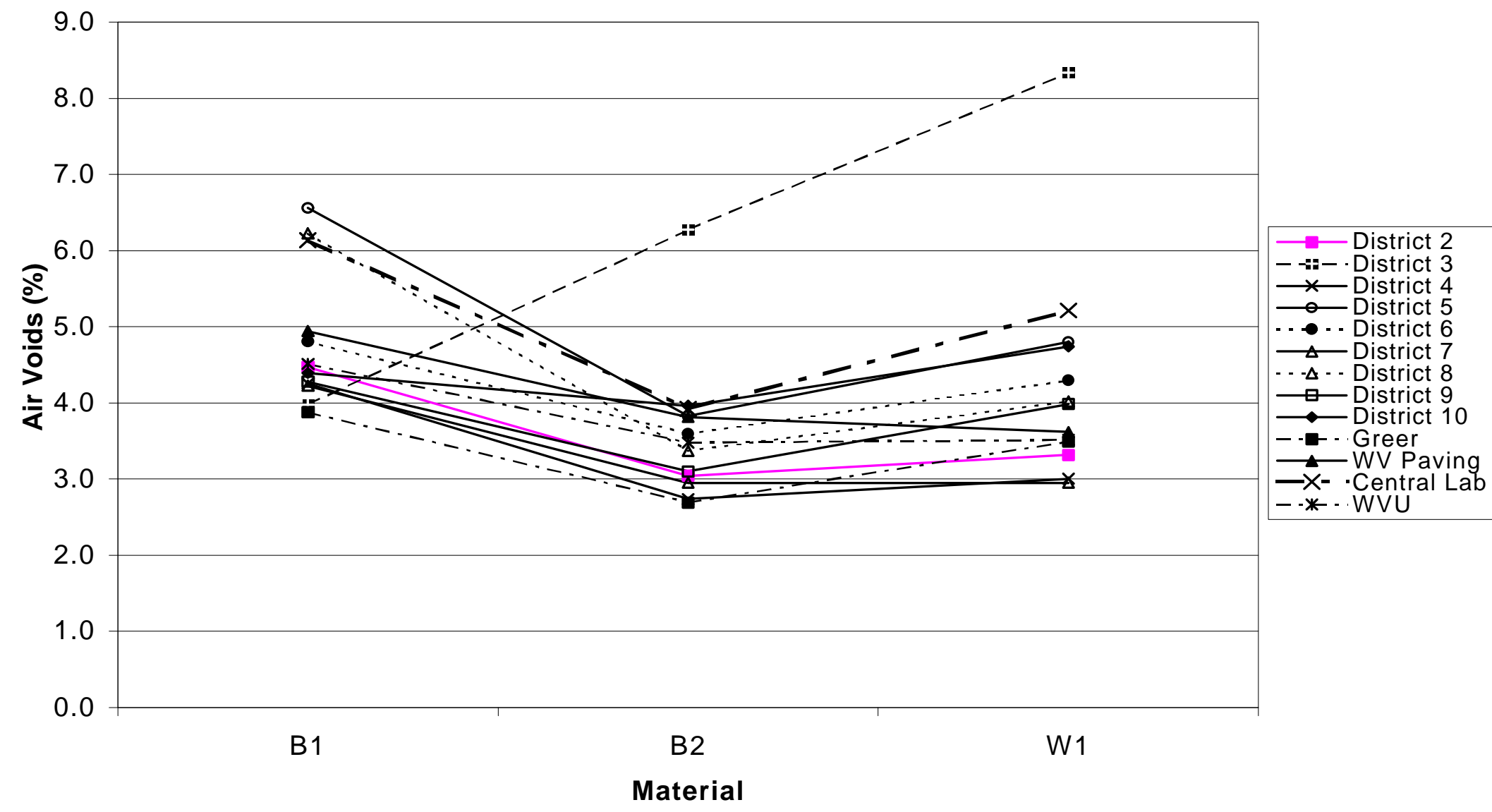

Figure 5.20. Chart of Interactions in Percent Air Voids 


\subsection{PRECISION PARAMETERS FOR ALL DATA}

The data from all 14 laboratories were used to compute the precision parameters in Tables 5.5 to 5.9. These tables present the $1 \mathrm{~s}$ and $\mathrm{d} 2 \mathrm{~s}$ values for the single operator and multi-laboratory analysis. The 1s values are the standard deviations associated with each analysis situation. The $\mathrm{d} 2 \mathrm{~s}$ values represent maximum range expected in the difference between two tests. There is a one in twenty chance of the difference between two properly conducted tests being greater than the $\mathrm{d} 2 \mathrm{~s}$ value. The precision parameters were computed for four situations:

1. Analysis of the individual material types,

2. Analysis pooling the variability of all data, and

3. Analysis pooling the variability of the $102 \mathrm{~mm}$ samples independent from the $152 \mathrm{~mm}$ samples, and

4. Analysis of the $152 \mathrm{~mm}$ samples independent from the $102 \mathrm{~mm}$ samples. The first type of analysis is used for exploring the data, not for the development of precision statements. The second type of analysis represents the ideal situation where the variability in the test method is independent of material type and sample size. However, the analysis of the data demonstrated that there are significant differences in the variability of the test results based on the sample size. Therefore, the third and fourth types of analyses are needed to identify the precision of the test methods using the $102 \mathrm{~mm}$ and $152 \mathrm{~mm}$ sample sizes.

For analysis methods 2 to 4, Tables 5.5 to 5.9 show the precision parameters for the assumptions of constant standard deviation and constant coefficient of variation. The constant standard deviation assumption applies when the magnitude of the standard deviation is independent of the magnitude of the dependent variable. The constant coefficient of variation assumption is used when the magnitude of the variation is correlated with the magnitude of the dependent variable. The analysis of the data collected during this research demonstrates the constant standard deviation assumption is acceptable for both the $102 \mathrm{~mm}$ and $152 \mathrm{~mm}$ sample sizes. 
Table 5.5 Precision of Rice Specific Gravity (all data)

\begin{tabular}{|l|c|c|c|c|}
\cline { 2 - 5 } \multicolumn{1}{c|}{} & \multicolumn{2}{c|}{ Single Operator } & \multicolumn{2}{c|}{ Multi-laboratory } \\
\cline { 2 - 5 } \multicolumn{1}{c|}{ Single Material } & $1 \mathrm{~s}$ & $\mathrm{~d} 2 \mathrm{~s}$ & $1 \mathrm{~s}$ & $\mathrm{~d} 2 \mathrm{~s}$ \\
\hline Base 1 & & & & \\
Base 2 & 0.0074 & 0.0209 & 0.0100 & 0.0284 \\
Wearing 1 & 0.0012 & 0.0033 & 0.0032 & 0.0090 \\
\hline All Materials & 0.0017 & 0.0049 & 0.0058 & 0.0164 \\
\hline Constant Standard Deviation & & & & \\
Constant Coefficient of Variation (percent) & 0.0044 & 0.0126 & 0.0069 & 0.0196 \\
\hline 102 mm Samples (Wearing 1 and Base 2) & 0.1350 & 0.3818 & 0.2504 & 0.7083 \\
\hline Constant Standard Deviation & & & & \\
Constant Coefficient of Variation (percent) & 0.0015 & 0.0042 & 0.0047 & 0.0132 \\
\hline 152 mm Sample (Base 1) & 0.0580 & 0.1639 & 0.1799 & 0.5090 \\
\hline Constant Standard Deviation & & & & \\
Constant Coefficient of Variation (percent) & 0.0074 & 0.0209 & 0.0100 & 0.0284 \\
\hline
\end{tabular}

Table 5.6 Precision of Stability (all data)

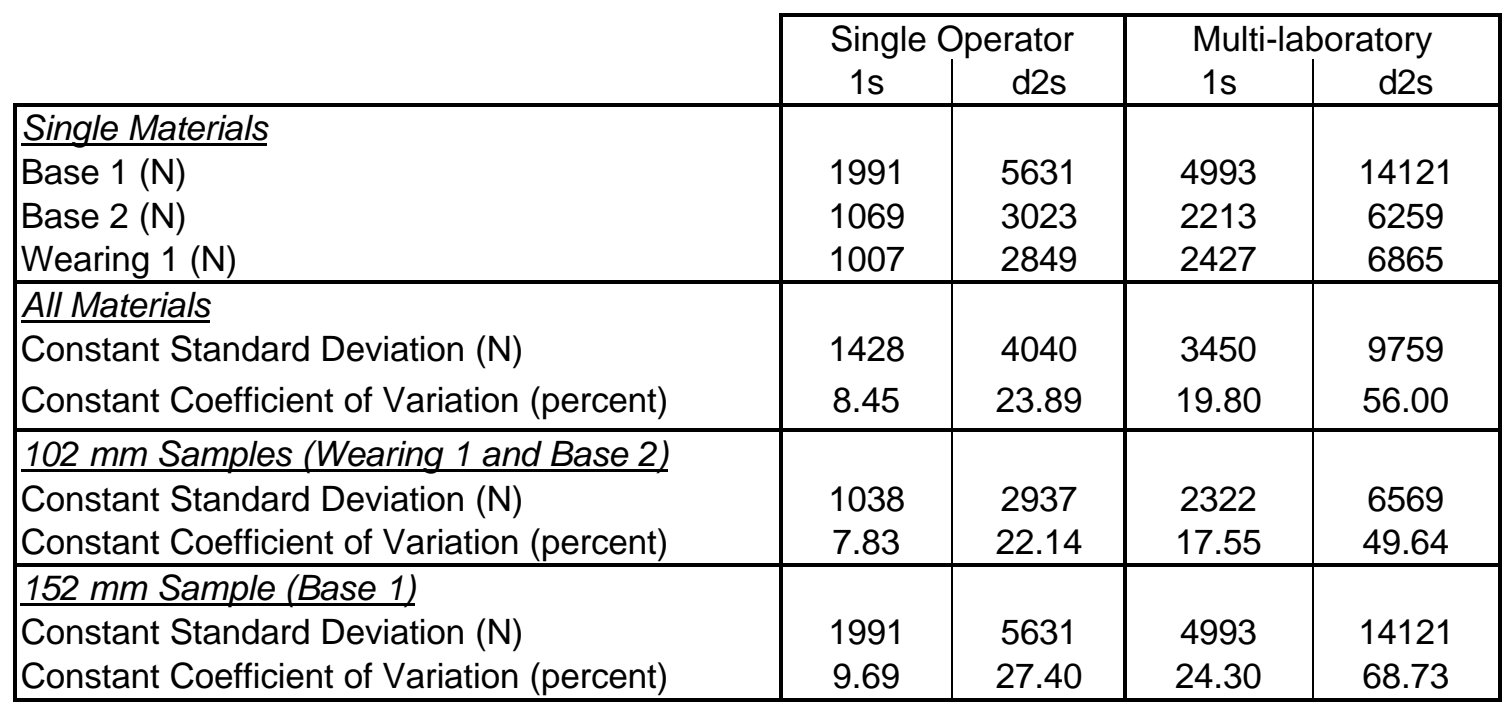


Table 5.7. Precision of Flow (all data)

\begin{tabular}{|l|c|c|c|c|}
\cline { 2 - 5 } \multicolumn{1}{c|}{} & \multicolumn{2}{c|}{ Single Operator } & \multicolumn{2}{c|}{ Multi-laboratory } \\
\cline { 2 - 5 } \multicolumn{1}{c|}{ Single Materials } & $1 \mathrm{~s}$ & d2s & $1 \mathrm{~s}$ & d2s \\
\hline Base 1 $(0.25 \mathrm{~mm})$ & 2.270 & 6.422 & 2.948 & 8.337 \\
Base 2 $(0.25 \mathrm{~mm})$ & 1.016 & 2.875 & 1.624 & 4.594 \\
Wearing 1 $(0.25 \mathrm{~mm})$ & 1.251 & 3.540 & 1.905 & 5.389 \\
\hline All Materials & & & & \\
\hline Constant Standard Deviation (0.25 mm) & 1.608 & 4.547 & 2.233 & 6.316 \\
Constant Coefficient of Variation (percent) & 11.89 & 33.63 & 17.20 & 48.64 \\
\hline 102 mm Samples (Wearing 1 and Base 2) & & & & \\
\hline Constant Standard Deviation (0.25 mm) & 1.140 & 3.224 & 1.770 & 5.007 \\
Constant Coefficient of Variation (percent) & 10.26 & 29.02 & 15.96 & 45.14 \\
\hline 152 mm Sample (Base 1) & & & & \\
\hline Constant Standard Deviation (0.25 mm) & 2.270 & 6.422 & 2.948 & 8.337 \\
Constant Coefficient of Variation (percent) & 15.15 & 42.86 & 19.67 & 55.64 \\
\hline
\end{tabular}

Table 5.8. Precision of Bulk Specific Gravity (all data)

\begin{tabular}{|c|c|c|c|c|}
\hline & \multicolumn{2}{|c|}{ Single Operator } & \multicolumn{2}{|c|}{ Multi-laboratory } \\
\hline & 1s & d2s & $1 \mathrm{~s}$ & d2s \\
\hline \multicolumn{5}{|l|}{ Single Materials } \\
\hline Base 1 & 0.0106 & 0.0301 & 0.0198 & 0.0560 \\
\hline Base 2 & 0.0095 & 0.0268 & 0.0252 & 0.0714 \\
\hline Wearing 1 & 0.0239 & 0.0676 & 0.0425 & 0.1203 \\
\hline \multicolumn{5}{|l|}{ All Materials } \\
\hline$\overline{\text { Constant Standard Deviation }}$ & 0.0161 & 0.0455 & 0.0308 & 0.0870 \\
\hline Constant Coefficient of Variation (percent) & 0.610 & 1.725 & 1.211 & 3.426 \\
\hline \multicolumn{5}{|l|}{$102 \mathrm{~mm}$ Samples (Wearing 1 and Base 2) } \\
\hline Constant Standard Deviation & 0.0182 & 0.0514 & 0.0350 & 0.0989 \\
\hline Constant Coefficient of Variation (percent) & 0.696 & 1.970 & 1.411 & 3.990 \\
\hline \multicolumn{5}{|l|}{152 mm Sample (Base 1) } \\
\hline Constant Standard Deviation & 0.0106 & 0.0301 & 0.0198 & 0.0560 \\
\hline Constant Coefficient of Variation (percent) & 0.437 & 1.235 & 0.812 & 2.298 \\
\hline
\end{tabular}


Table 5.9. Precision of Percent Air Voids (all data)

\begin{tabular}{|l|ccc|c|c|}
\cline { 2 - 5 } \multicolumn{1}{c|}{} & \multicolumn{3}{c|}{ Single Operator } & \multicolumn{2}{c|}{ Multi-laboratory } \\
\multicolumn{1}{c|}{ Single Materials } & & d2s & 1s & d2s \\
\hline Base 1 & 0.275 & 0.779 & 0.913 & 2.581 \\
Base 2 & 0.804 & 2.275 & 1.611 & 4.557 \\
Wearing 1 & 0.456 & 1.289 & 0.985 & 2.786 \\
\hline All Materials & & & & \\
\hline Constant Standard Deviation & 0.557 & 1.575 & 1.211 & 3.425 \\
Constant Coefficient of Variation (percent) & 12.45 & 35.219 & 28.124 & 79.53 \\
\hline 102 mm Samples (Wearing 1 and Base 2) & & & & \\
\hline Constant Standard Deviation & 0.654 & 1.849 & 1.335 & 3.777 \\
Constant Coefficient of Variation (percent) & 15.80 & 44.69 & 32.65 & 92.36 \\
\hline 152 mm Sample (Base 1) & & & & \\
\hline Constant Standard Deviation & 0.275 & 0.779 & 0.9127 & 2.581 \\
Constant Coefficient of Variation (percent) & 5.75 & 16.26 & 19.06 & 53.92 \\
\hline
\end{tabular}

\subsection{DATA ANALYSIS AND PRECISION PARAMETERS WITHOUT DIST RICT 3}

There was no assignable cause to remove the data from any of the laboratories. However, the D istrict 3 data have high variability in many parameters compared to the other laboratories, as demonstrated on Figures 5.16 to 5.20. An analysis of variance showed District 3 has several results that are outside the 95 percentile for the data (Appendix G, Tables G .16 to G .20). Thus, an analysis was performed without the District 3 data. Removing a suspect data set from the analysis is described in the AST M specification for developing precision statements.

The agreements of variance results, without District 3, are presented in Table 5.10. The comparative number for extreme high and low variances changed from 0.345 and 855 to 0.363 and 790, respectively. This was because of the reduction in the number of laboratories used in the analysis. It can be seen that by removing $D$ istrict 3 , five sample characteristics were identified as having a high variance as opposed to the original nine. The test for low variance showed the number of questionable data points was reduced from four to two. District 9 reported three flow values of $10.5(0.25 \mathrm{~mm})$ giving a variance of zero. This is possible, so these data were kept in the data set. 
Table 5.10. Test for High and Low Variability without District 3

\begin{tabular}{|c|c|c|c|}
\hline Parameter & Material & $\begin{array}{c}\text { Test for High Variance } \\
\text { Upper 5\% Level } \\
\text { (High/Sum) } \\
\text { Must be }<0.363\end{array}$ & $\begin{array}{c}\text { Test for Low Variance } \\
\text { Upper 5\% Level } \\
\text { (High/Low) } \\
\text { Must be }<\text { 790 }\end{array}$ \\
\hline Max. Theoretical & Base 1 & $\mathbf{0 . 8 4 5}$ & $\mathbf{3 7 1 9 5}$ \\
Specific Gravity & Base 2 & 0.319 & $\mathbf{1 4 9 1 5}$ \\
& Wearing 1 & 0.220 & 696 \\
\hline Stability & Base 1 & 0.312 & 741 \\
& Base 2 & 0.235 & 18 \\
\hline Flow & Wearing 1 & 0.257 & 28 \\
\hline Bulk 1 & Base 2 & 0.288 & 61 \\
Gravity & Wearing 1 & $\mathbf{0 . 4 9 3}$ & 273 \\
\hline Percent Air Voids & Base 1 & 0.731 & 20 \\
& Bease 2 & 0.172 & 25 \\
& Base 1 & $\mathbf{0 . 8 6 0}$ & 660 \\
\hline Zero Variability 1 & Base 2 & 0.351 & 65 \\
& Wearing 1 & 0.198 & 65 \\
\hline
\end{tabular}

The parameters of precision without D istrict 3 are reported in Tables 5.11 to 5.15. Comparing these results to those with the entire data set shows little change for most parameters.

However, the 1s and d2s single operator limits changes from 1038 and 2937 to 714 and 2018 for the $102 \mathrm{~mm}$ samples by the elimination of District 3. The multi-laboratory $1 \mathrm{~s}$ and $\mathrm{d} 2 \mathrm{~s}$ limits for this sample size changed from 2322 and 6569 to 1931 and 5460 by eliminating District 3 from the data set. The changes for the $152 \mathrm{~mm}$ samples were relatively small.

\subsection{ANALYSIS OF OTHER STUDIES}

Next, the results from this research were compared to the results from similar studies. Table B.1 in Appendix B is a summary of the precision found from a round-robin study between AMRL laboratories, conducted for ASTM (Kandhal, 96). This study used $152 \mathrm{~mm}$ samples and a $25.4 \mathrm{~mm}$ maximum aggregate sized, so the results are compared to the Base 1 data from the current study. The Kandhal results are similar to the Base 1 standard deviations for bulk specific gravity, flow, and percent air voids to the current study. The Kandhal single operator standard deviation for stability was 65 percent greater than the Base 1 results, while the multi- 
Table 5.11 Precision of Rice Specific Gravity without District 3

\begin{tabular}{|l|c|c|c|c|}
\cline { 2 - 5 } \multicolumn{1}{c|}{} & \multicolumn{2}{|c|}{ Single Operator } & \multicolumn{2}{c|}{ Multi-laboratory } \\
\hline Single Materials & & d2s & $1 \mathrm{~s}$ & d2s \\
\hline Base 1 & 0.0077 & 0.0217 & 0.0102 & 0.0288 \\
Base 2 & 0.0012 & 0.0033 & 0.0033 & 0.0092 \\
Wearing 1 & 0.0018 & 0.0051 & 0.0061 & 0.0172 \\
\hline All Materials & & & & \\
\hline Constant Standard Deviation & 0.0046 & 0.0130 & 0.0071 & 0.0201 \\
Constant Coefficient of Variation & 0.1396 & 0.3949 & 0.2572 & 0.7276 \\
\hline 102 mm Samples (Wearing 1 and Base 2) & & & & \\
\hline Constant Standard Deviation & 0.0015 & 0.0043 & 0.0049 & 0.0138 \\
Constant Coefficient of Variation & 0.0600 & 0.1696 & 0.1869 & 0.5285 \\
\hline 152 mm Sample (Base 1) & & & & \\
\hline Constant Standard Deviation & 0.0077 & 0.0217 & 0.0102 & 0.0288 \\
Constant Coefficient of Variation & 0.2990 & 0.8456 & 0.3980 & 1.1256 \\
\hline
\end{tabular}

Table 5.12 Precision of Stability without District 3

\begin{tabular}{|l|c|c|c|c|}
\cline { 2 - 5 } \multicolumn{1}{c|}{} & \multicolumn{3}{c|}{ Single Operator } & \multicolumn{2}{c|}{ Multi-laboratory } \\
\cline { 1 - 5 } \multicolumn{1}{c|}{ Single Materials } & 1943 & 5497 & 4940 & 13972 \\
\hline Base 1 (N) & 910 & 2574 & 2092 & 5916 \\
Base 2 (N) & 436 & 1233 & 1755 & 4963 \\
Wearing 1 (N) & & & & \\
\hline All Materials & 1264 & 3576 & 3259 & 9217 \\
\hline Constant Standard Deviation & 6.49 & 18.34 & 17.60 & 49.78 \\
\hline Constant Coefficient of Variation & 714 & 2018 & 1931 & 5460 \\
\hline 102 mm Samples (Wearing 1 and Base 2) & & & & \\
\hline Constant Standard Deviation & 4.91 & 13.89 & 14.15 & 40.04 \\
\hline Constant Coefficient of Variation & & & & \\
\hline 152 mm Sample (Base 1) & 1943 & 5497 & 4940 & 13972 \\
\hline Constant Standard Deviation & 9.63 & 27.25 & 24.49 & 69.26 \\
\hline Constant Coefficient of Variation & & & & \\
\hline
\end{tabular}


Table 5.13 Precision of Flow without D istrict 3

\begin{tabular}{|c|c|c|c|c|}
\hline & \multicolumn{2}{|c|}{ Single Operator } & \multicolumn{2}{|c|}{ Multi-laboratory } \\
\hline & $1 \mathrm{~s}$ & d2s & 1s & d2s \\
\hline Single Materials & & & & \\
\hline Base $1(0.25 \mathrm{~mm})$ & 2.018 & 5.709 & 2.827 & 7.995 \\
\hline Base $2(0.25 \mathrm{~mm})$ & 1.049 & 2.968 & 1.517 & 4.290 \\
\hline Wearing $1(0.25 \mathrm{~mm})$ & 1.263 & 3.573 & 1.810 & 5.121 \\
\hline All Materials & & & & \\
\hline Constant Standard Deviation & 1.502 & 4.249 & 2.127 & 6.015 \\
\hline Constant Coefficient of Variation & 11.50 & 32.51 & 16.36 & 46.29 \\
\hline $102 \mathrm{~mm}$ Samples (Wearing 1 and Base 2) & & & & \\
\hline Constant Standard Deviation & 1.161 & 3.284 & 1.670 & 4.724 \\
\hline Constant Coefficient of Variation & 10.49 & 29.67 & 15.09 & 42.68 \\
\hline 152 mm Sample (Base 1) & & & & \\
\hline Constant Standard Deviation & 2.018 & 5.709 & 2.827 & 7.995 \\
\hline Constant Coefficient of Variation & 13.50 & 38.19 & 18.91 & 53.49 \\
\hline
\end{tabular}

Table 5.14 Precision of Bulk Specific Gravity without District 3

\begin{tabular}{|c|c|c|c|c|}
\hline & \multicolumn{2}{|c|}{ Single Operator } & \multicolumn{2}{|c|}{ Multi-laboratory } \\
\hline & $1 \mathrm{~s}$ & d2s & $1 \mathrm{~s}$ & d2s \\
\hline Single Materials & & & & \\
\hline Base 1 & 0.0109 & 0.0309 & 0.0199 & 0.0562 \\
\hline Base 2 & 0.0052 & 0.0147 & 0.0139 & 0.0394 \\
\hline Wearing 1 & 0.0155 & 0.0438 & 0.0250 & 0.0708 \\
\hline All Materials & & & & \\
\hline Constant Standard Deviation & 0.0114 & 0.0321 & 0.0201 & 0.0570 \\
\hline Constant Coefficient of Variation & 0.437 & 1.236 & 0.812 & 2.296 \\
\hline $102 \mathrm{~mm}$ Samples (Wearing 1 and Base 2) & & & & \\
\hline Constant Standard Deviation & 0.0116 & 0.0327 & 0.0203 & 0.0573 \\
\hline Constant Coefficient of Variation & 0.431 & 1.218 & 0.809 & 2.289 \\
\hline 152 mm Sample (Base 1) & & & & \\
\hline Constant Standard Deviation & 0.0109 & 0.0309 & 0.0199 & 0.0562 \\
\hline Constant Coefficient of Variation & 0.449 & 1.271 & 0.816 & 2.309 \\
\hline
\end{tabular}


Table 5.15 Precision of Percent Air Voids without District 3

\begin{tabular}{|l|c|c|c|c|}
\cline { 2 - 5 } \multicolumn{1}{c|}{} & \multicolumn{3}{|c|}{ Single Operator } & \multicolumn{2}{c|}{ Multi-laboratory } \\
\cline { 1 - 5 } \multicolumn{1}{c|}{ Single Materials } & & d2s & $1 \mathrm{~s}$ & d2s \\
\hline Base 1 & 0.2798 & 0.7914 & 0.9163 & 2.5917 \\
Base 2 & 0.2431 & 0.6877 & 0.7659 & 2.1662 \\
Wearing 1 & 0.3380 & 0.9559 & 0.5497 & 1.5549 \\
\hline All Materials & & & & \\
\hline Constant Standard Deviation & 0.2896 & 0.8191 & 0.7590 & 2.1469 \\
Constant Coefficient of Variation & 7.323 & 20.713 & 18.237 & 51.581 \\
\hline 102 mm Samples (Wearing 1 and Base 2) & & & & \\
\hline Constant Standard Deviation & 0.2944 & 0.8327 & 0.6666 & 1.8855 \\
Constant Coefficient of Variation & 8.101 & 22.912 & 17.909 & 50.655 \\
\hline 152 mm Sample (Base 1) & & & & \\
\hline Constant Standard Deviation & 0.2798 & 0.7914 & 0.9163 & 2.5917 \\
Constant Coefficient of Variation & 5.769 & 16.316 & 18.892 & 53.434 \\
\hline
\end{tabular}

laboratory standard deviation was 23 percent lower. Given the magnitude of the variability in the stability testing, this amount of difference in two studies conducted at different times, with different materials and laboratories, is not unreasonable.

The G eorgia D OH study (Siddiqui, 95) provides results comparable to the Base 2 and Wearing 1 materials (Table B.2). The within laboratory and between-laboratory standard deviation of stability for the G eorgia Study were $968 \mathrm{~N}$ and $1232 \mathrm{~N}$, respectively. These compare to values of $714 \mathrm{~N}$ and $1931 \mathrm{~N}$, respectively, for the current study.

Siddiqui also provided data from Canadian and Utah studies, but only the average test values from each of the laboratories were reported. Thus, the precision statements cannot be calculated. To compare the results of these studies to the current study, the standard deviation of the average results from each laboratory were calculated (Table 5.16). The magnitude of the standard deviation between laboratories is similar to the data in the literature. The WVU Base 1 results correspond to the ASTM study. The Base 2 and Wearing 1 results correspond to the Utah, G eorgia, and Canadian studies. 


\section{Table 5.16. Comparison of Standard Deviations From Average Laboratory Results From Different Inter-laboratory Studies}

\begin{tabular}{|ll|c|c|c|c|}
\cline { 3 - 6 } \multicolumn{1}{c|}{} & $\begin{array}{c}\text { Bulk } \\
\text { Specific } \\
\text { Gravity }\end{array}$ & $\begin{array}{c}\text { Air Voids } \\
\text { (Percent) }\end{array}$ & $\begin{array}{c}\text { Stability } \\
(\mathrm{N})\end{array}$ & $\begin{array}{c}\text { Flow } \\
(0.25 \mathrm{~mm})\end{array}$ \\
\hline WVU Study & Base 1 & 0.017 & 0.88 & 4571 & 2.05 \\
& Base 2 & 0.013 & 0.44 & 1899 & 1.13 \\
& Wearing 1 & 0.020 & 0.73 & 1704 & 1.13 \\
\hline Utah Study & $5.5 \%$ Asphalt & 0.013 & 0.05 & 2304 & 3.49 \\
& $6.0 \%$ Asphalt & 0.012 & 0.35 & 1739 & 2.91 \\
& $6.5 \%$ Asphalt & 0.090 & 2.00 & 1263 & 2.95 \\
\hline Canadian Study & 0.031 & - & 2500 & 2.00 \\
\hline Georgia Study & & 0.015 & 0.58 & 3673 & 1.64 \\
\hline ASTM Study & 152 mm sample & 0.022 & 0.74 & 3034 & 3.59 \\
\hline
\end{tabular}

\subsection{EVALUATION OF QUEST IONNAIRE INFORMATION}

Regression analyses was performed to determine if a correlation existed between information on the questionnaire and the results from each laboratory. All Marshall hammers and stability and flow machines where manufactured by Pine Instruments, which eliminates the possibility of variability between brands of equipment. The technicians' experience was evaluated but there was no correlation with the averages and variances of the test results. A regression analysis was performed on the stability of Base 1 samples and the re-heating oven temperature showed a positive trend but statistical tests showed the correlation was not significant, as shown on Figure 5.21. This trend was less evident for the Base 2 and Wearing 1 materials, as shown on Figures 5.22 and 5.23 .

It is commonly know in the industry that the maximum aggregate size should not exceed onefourth the mold diameter. It was hypothesized that variability in stability is related to the ratio of the maximum aggregate size to mold diameter. With a small ratio there is little room for the aggregates to move into a dense configuration. With only a vertical force on the sample from the hammer, little lateral movement can occur. A regression analysis was performed on the ratios of the maximum aggregate size to mold diameter for Base 1, Base 2 and Wearing 1 samples. For single operator variability an inverse trend could be seen. However, the significance of this trend cannot be evaluated since only three points were available to develop the model. 


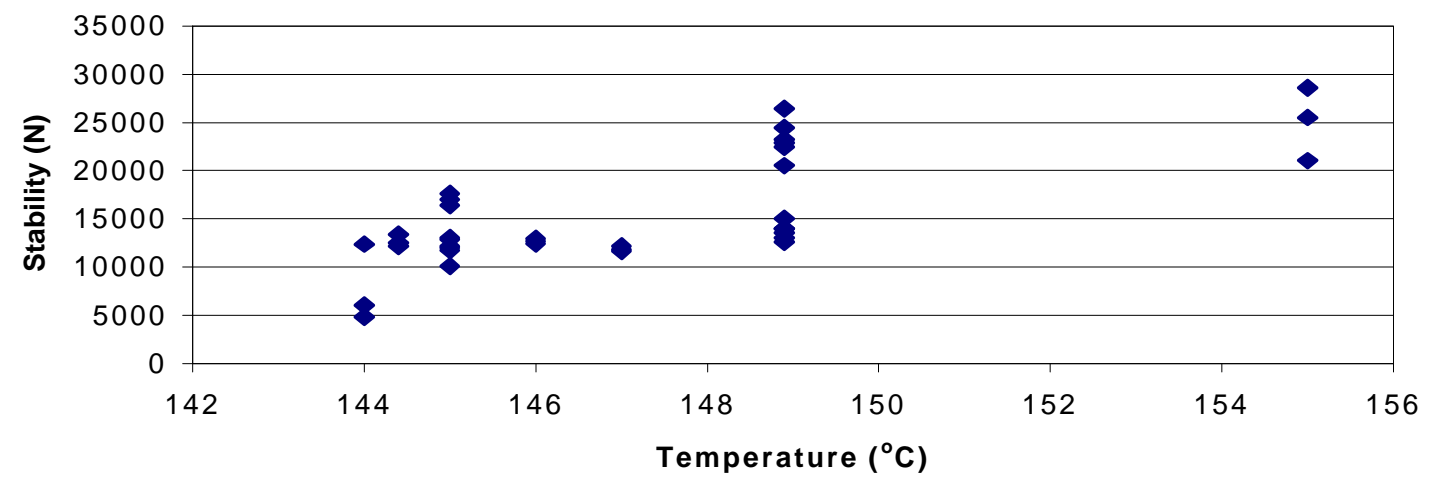

Figure 5.21. Re-heat Temperature versus Base 1Stability

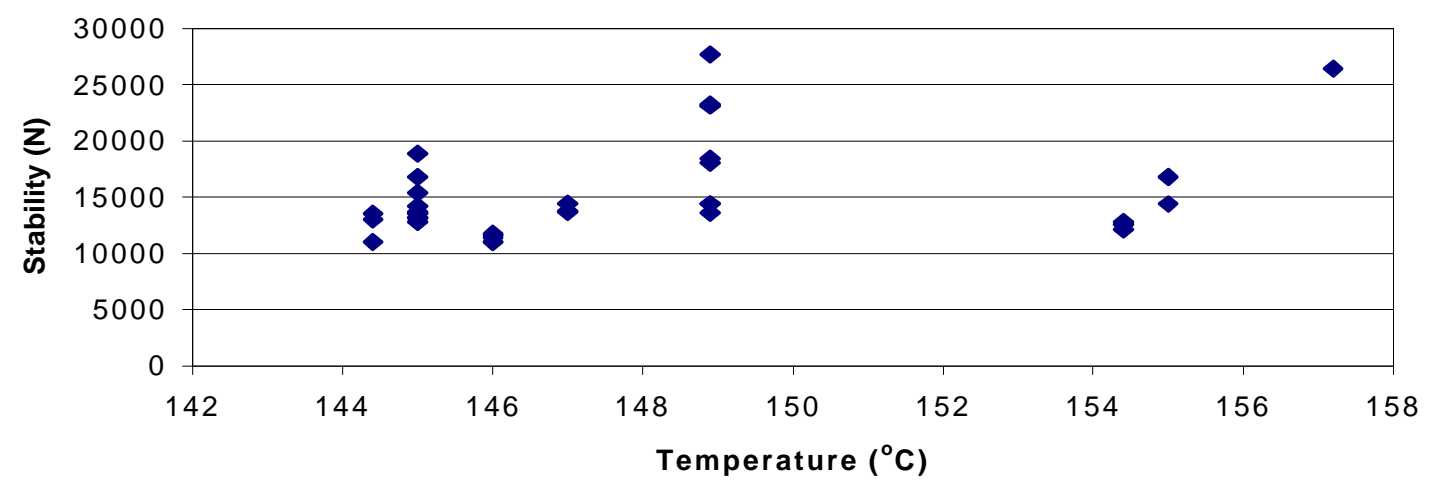

Figure 5.22. Re-heat Temperature versus Wearing 1Stability

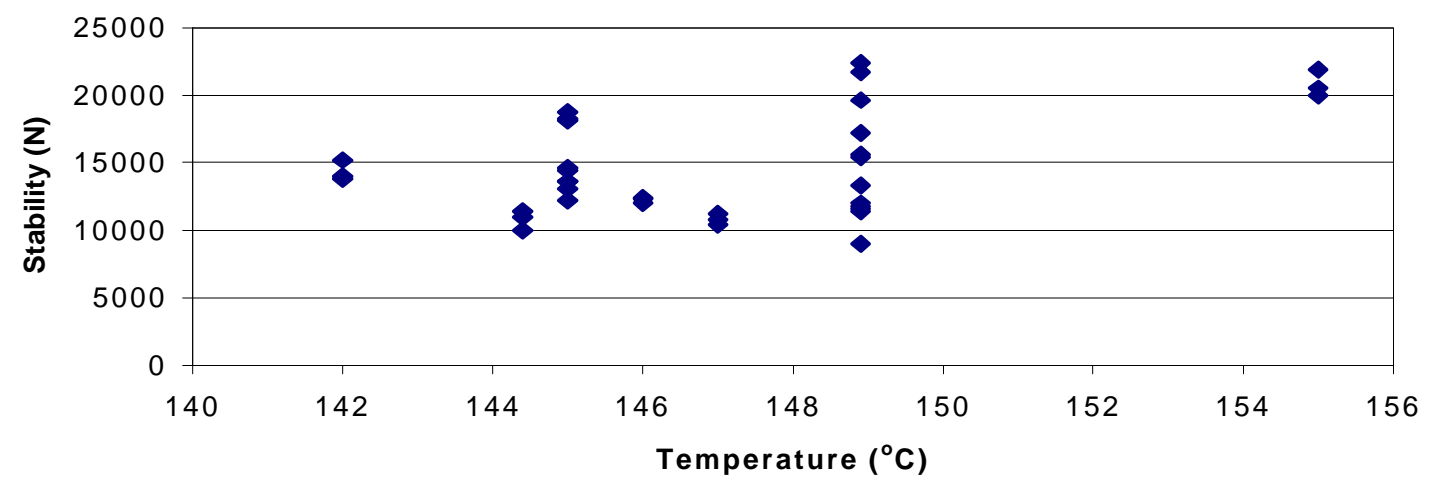

Figure 5.23. Plot of Re-heat Temperature versus Base 2 Stability 


\subsection{PRECISION STATEMENTS}

The data collected for this project compare favorably with information in the literature. Thus, precision statements based on these data are defensible. Since there are differences in the variances for the $102 \mathrm{~mm}$ and $152 \mathrm{~mm}$ samples, separate precision statements are needed. The statements for the $152 \mathrm{~mm}$ samples are from the Base 1 data and were developed with the assumption that the standard deviation is constant. The statements for the $102 \mathrm{~mm}$ samples combine the data from the Wearing 1 and Base 2 mixes and the standand deviation was assumed to be constant.

The treatment of the data from District 3 is a concern. A rigorous statistical analysis would include these data since there was not an assignable cause to support their exclusion. However, the fact that five of the nine stability values reported by D istrict 3 were more than two standard deviations from the mean for all the data indicates there is a problem with the data and the cause was undiscovered. There is a one in twenty chance for one value to be more than two standard deviations from the mean. When one laboratory has five values that exceed this limit there is a strong indication that an undetected factor was affecting the results produced at that lab. Using this reasoning, it is prudent to exclude the District 3 data when developing the precision statements. Therefore, the following precision statements are recommended based on the data in Tables 5.11 to 5.15 .

\section{Maximum Theoretical Specific Gravity (152 mm samples):}

The single-operator standard deviation is 0.0077 for calculated maximum theoretical specific gravities ranging from 2.554 to 2.584. Therefore, the results of two properly conducted tests by the same operator on the same mix should not differ by more than the difference two-sigma limit of 0.0217 .

The multi-laboratory standard deviation is 0.0102. Therefore, the results of properly conducted tests from two different laboratories on the same mix should not differ by more than 0.0288 .

Maximum Theoretical Specific Gravity (102 mm samples):

The single-operator standard deviation is 0.0015 calculated maximum theoretical specific gravities ranging from 2.472 to 2.530. Therefore, the results of two properly conducted tests by the same operator on the same mix should not differ by more than the difference two-sigma limit of 0.0043. 
The multi-laboratory standard deviation is 0.0049. Therefore, the results of properly conducted tests from two different laboratories on the same mix should not differ by more than 0.0138 .

\section{Marshall Stability (152 mm samples):}

The single-operator standard deviation is 1943 N for measured Marshall stability ranging from 11138 to $25644 \mathrm{~N}$. Therefore, the results of two properly conducted tests by the same operator on the same mix should not differ by more than the difference two-sigma limit of $5497 N$.

The multi-laboratory standard deviation is $4940 \mathrm{~N}$. Therefore, the results of properly conducted tests from two different laboratories on the same mix should not differ by more than $13972 \mathrm{~N}$.

Marshall Stability (102 mm samples):

The single-operator standard deviation is 714 N for Marshall stability ranging from 10120 to $17558 \mathrm{~N}$. Therefore, the results of two properly conducted tests by the same operator on the same mix should not differ by more than the difference two-sigma limit of 2018. The multi-laboratory standard deviation is $1931 \mathrm{~N}$. Therefore, the results of properly conducted tests from two different laboratories on the same mix should not differ by more than $5460 \mathrm{~N}$.

\section{Marshall Flow (152 mm samples):}

The single-operator standard deviation is $2.018(0.25 \mathrm{~mm})$ for measured Marshall flow ranging from 11.25 to $18.83(0.25 \mathrm{~mm})$. Therefore, the results of two properly conducted tests by the same operator on the same mix should not differ by more than the difference two-sigma limit of $5.709(0.25 \mathrm{~mm})$.

The multi-laboratory standard deviation is $2.827(0.25 \mathrm{~mm})$. Therefore, the results of properly conducted tests from two different laboratories on the same mix should not differ by more than $7.995(0.25 \mathrm{~mm})$.

\section{Marshall Flow (152 mm samples):}

The single-operator standard deviation is $1.161(0.25 \mathrm{~mm})$ for measured Marshall flow ranging from 9.25 to $13.37(0.25 \mathrm{~mm})$. Therefore, the results of two properly conducted tests by the same operator on the same mix should not differ by more than the difference two-sigma limit of $3.284(0.25 \mathrm{~mm})$.

The multi-laboratory standard deviation is $1.670(0.25 \mathrm{~mm})$. Therefore, the results of properly conducted tests from two different laboratories on the same mix should not differ by more than $4.724(0.25 \mathrm{~mm})$. 


\section{Bulk Specific Gravity (152 mm samples):}

The single-operator standard deviation is 0.0109 for calculated bulk specific gravities ranging from 2.405 to 2.455 . Therefore, the results of two properly conducted tests by the same operator on the same mix should not differ by more than the difference two-sigma limit of 0.0309 .

The multi-laboratory standard deviation is 0.0199. Therefore, the results of properly conducted tests from two different laboratories on the same mix should not differ by more than 0.0562 .

Bulk Specific Gravity (102 mm samples):

The single-operator standard deviation is 0.0116 calculated bulk specific gravities ranging from 2.362 to 2.462. Therefore, the results of two properly conducted tests by the same operator on the same mix should not differ by more than the difference two-sigma limit of 0.0327 .

The multi-laboratory standard deviation is 0.0203 . Therefore, the results of properly conducted tests from two different laboratories on the same mix should not differ by more than 0.0573 .

Percent Air Voids (152 mm samples):

The single-operator standard deviation is 0.280 for percent air voids ranging from 3.88 to 6.56. Therefore, the results of two properly conducted tests by the same operator on the same mix should not differ by more than the difference two-sigma limit of 0.791.

The multi-laboratory standard deviation is 0.916. Therefore, the results of properly conducted tests from two different laboratories on the same mix should not differ by more than 2.591.

\section{Percent Air Voids (102 mm samples):}

The single-operator standard deviation is 0.294 for percent air voids ranging 2.69 to 5.21. Therefore, the results of two properly conducted tests by the same operator on the same mix should not differ by more than the difference two-sigma limit of 0.833 .

The multi-laboratory standard deviation is 0.667 . Therefore, the results of properly conducted tests from two different laboratories on the same mix should not differ by more than 1.886 .

\subsection{SUMMARY OF ANALYSIS}

After performing analysis on the asphalt samples tested by the fourteen laboratories across the state, precision parameters were computed. Comparing the results to those of similar studies from the literature validated these results. Precision statements were developed for maximum 
theoretical specific gravity, Marshall stability, Marshall flow, bulk specific gravity and percent air voids. D ue to the nature of the data provided by the District 3 laboratory, these data were excluded from the recommended precision statements. Separate precision statements were prepared for $102 \mathrm{~mm}$ and $152 \mathrm{~mm}$ samples. In all cases, the standard deviation was assumed constant for each Marshall parameter. 


\title{
CONCLUSIONS AND RECOMMENDATIONS
}

\subsection{CONCLUSIONS}

The objective of this research, the development of precision statements for the Marshall method, was accomplished. Of the 14 laboratories participating in the study, the data from 13 laboratories were of sufficient quality to include in the analysis to develop the precision statements. Three WVD OH mixes were included in the study, Wearing 1, Base 1, and Base 2. D ue to the maximum aggregate size of these mixes, the Wearing 1 and Base 2 mixes were evaluated in the standard $102 \mathrm{~mm}$ Marshall mold. The maximum aggregate size of the Base 2 mix requires use of the $152 \mathrm{~mm}$ mold. Evaluation of the variability of the data from these two mold sizes demonstrated that separate precision statements are needed for each. Based on these data, precision statements for each sample size, were prepared for:

\author{
Marshall stability, \\ Marshall flow, \\ Bulk specific gravity, \\ Percent air voids, and \\ Maximum theoretical specific gravity.
}

The results from this study were compared to data from the literature. Similar results were found, indicating that the data used to develop the precision statements are reasonable when compared to the results of other asphalt technologists. Thus, the WVD OH can implement the results of this research with some assurance that all laboratories in the state should be capable of achieving these levels of testing precision.

In a side issue, the $152 \mathrm{~mm}$ Marshall and the Superpave molds require sample sizes that are difficult to prepare with conventional mixers. A bucket mixer was evaluated and operating 
procedures were developed. The mixer and operating procedures were found to prepare the larger sample size mixes efficiently.

\subsection{RECOMMENDATIONS}

It is recommended that precision statements based on the results found in this study be used in the WVDOH specifications for asphalt concrete. These statements identify the variability of the different parameters of the Marshall method. These precision statements will also aid in the quality assurance process for reviewing the work performed by contractors on WVDOH projects.

Further research could improve the precision statements for WVD OH. The results of this project are based on single sources for the aggregates and asphalt cement. The study should be expanded to include more aggregate and asphalt cement types. This will return more representative precision statements of the mixes used the state.

The study was limited to three of the standard WVDOH mix types. To make precision statements that better represent the variability of Marshall testing, an inter-laboratory study could be conducted using all of the WVD OH mix types. Also, only one mix design was used to develop precision statements for all $152 \mathrm{~mm}$ samples and only two samples were used to develop $102 \mathrm{~mm}$ sample precision statements. ASTM C802 recommends a minimum of three material types for developing precision statements. Since the magnitude of the variability between the $102 \mathrm{~mm}$ and $152 \mathrm{~mm}$ samples required separate precision statements, the ASTM recommendation of a minimum of three materials for each type of precision statement was not followed. D ata should be collected from at least one additional material using the $102 \mathrm{~mm}$ mold and two additional materials using the $152 \mathrm{~mm}$ mold.

As the WVD OH implements the Superpave gyratory compactor, an experiment should be performed to determine precision statements for the test parameters for this method. 


\section{RE FERE N CE S}

Head, W.J., Iskander, W.H., and Frisco, M.R., July 1993. “D evelopment of Precision Statements and Tolerance Limits For test Parameters Associated with Four and Six-Inch Diameter Marshall Method Mix D esign Specimens: A Feasibility Study," West Virginia University, Morgantown, WV.

Kandhal, P.S., Wu, Y., Parker, F., Jr., and Spellerberg, P.A., 1996, "Precision of Marshall Stability and Flow Test Using 6-in. (152.4 mm) Diameter Specimens," ASTM Journal of Testing and Evaluation, Vol. 24, No. 1, pp. 20-25.

Lee, G.J., and Arsenault, P.J., 1984. Report on the 1983 Canadian Asphalt Mix Exchange. Proc., Twenty-Ninth Annual Conference of Canadian Technical Asphalt Association, pp. 2-29.

Roberts, F. L., Kandhal, P.S., Brown, E.R., Lee, D., and Kennedy, T.W., 1996, Hd Mix Asphalt Mateials, MixtureDeign, andConsturtionLanham, MD.

Sherton, H., Cassidy, M., Spellerberg, P. and Savage, D ., January 1994. "A System for Calibration of the Marshall Compaction Hammer," FHWA Report. AASHTO Materials Reference Laboratory

Siddiqui, Z., Trethewey, M.W. and Anderson D .A., 1995. "Variables Affecting Marshall Test Results," Transportation Research Record 1171, TRB, National Research Council, Washington D.C., pp. 139-148

Kovac, R., 1962. "Repeatability of Marshall Test by Analysis of Factorial Experiment Data," Proceedings of the Association of A sphalt Paving Technologists Volume 31. pp. 533-562. New O rleans, LA.

West Virginia D epartment of Highways, Standard Specifications, Roads and Bridges, 1994, Charleston, WV. 
A ppendix A

\section{PROCEDURE FOR DEVELOPING PRECISION STATEMENTS}




\section{PROCEDURE FOR DEVELOPING PRECISION STATEMENTS}

The objective of this research is to determine precision statements for Marshall testing. A similar study was performed for $152 \mathrm{~mm}$ size Marshall stability and flow parameters (Kandhal, 96). The resulting precision statement was used as a model for this study. The precision statement was:

The single-operator standard deviation is $722 \mathrm{lbs}(3212 \mathrm{~N}$ ) for measured Marshall stabilities ranging from $4657 \mathrm{lbs}(20,715 \mathrm{~N})$ to $6852 \mathrm{lbs}(30,524 \mathrm{~N})$. Therefore, the results of two properly conducted tests by the same operator on the same mix should not differ by more than the difference of two-sigma limit of $2042 \mathrm{lbs}(9083 \mathrm{~N})$,

The multilaboratory standand deviation is $901 \mathrm{lbs}(408 \mathrm{~N})$. Therefore, the results of the properly conducted tests from two different laboratories on the same mix should not differ by more than $2548 \mathrm{lbs}(11,334 \mathrm{~N})$.

D eveloping this type of precision statement requires determining the single-operator and multilaboratory standard deviations. In ASTM terminology, these are the 1s values. The two sigma limit equals the standand deviation times $2 \sqrt{2}$. In ASTM termonology, this is the d2s values. This limit is used to represent 95 percent of the data. Thus, to develop the precision statements requires collecting and analysing stat to quantify the single operator and multilaboreatory standard deviations. The procedures for setting up the experiments and performing the analysis are defined in several ASTM standards.

ASTM standard C 802 - "Standard Practice for Conduting an Inter-laboratory Test Program to D etermine the Precision of Test Methods of Construction Materials," gives procedures for designing the experiment and analysing the data for preparing precision statements. This practice was closely followed during research. The experimental design requirement and analytical procedures are summarized below. In addition, ASTM C 670 - "Practice for 
Preparing Precison and Bias Statements for Test Methods for Construction Materials," provides detailed instrucions for preparing precision statements as needed for this research.

ASTM C 802 requires a minimum of ten laboratories participate in the study. Each laboratory needs personnel with practiced knowledge of the test method being analysed. A minimum of three materials with at least three replicates each are required for developing multi-laoreatory precision statements. A replicate is defined as a materal samples which are faricated to have "identical" characteristics and properties. Laboratories participatng in the study are instructed to follow "normal" operating procedures when testing the samples. All materials should be the "same" and no special instructions should be given on how to test them. The idea is to compare how the tests are normally run.

Once the laboratories submit the test data, ASTM C 802 gives analytical methods for evaluating the data quality prior to the calculation of the precision statement parameters. The data are analysed for outliers, agreement of variance and interactions. To evaluate outliers ASTM C 802 refers to ASTM E 178 "D ealing With Outlying Observations." ASTM E 178 recommeds the Student's t test for evaluating the sample population for outliers. InSudent's t test, the normalied difference between an observation and the mean for all observations in the sample are the selected confidence level. The normalized difference is compted as:

$t_{i}=\frac{\left(x_{i}-\bar{x}\right)}{s}$

Where:

$t_{i}=$ computed $t$ value for observation $\mathrm{i}$

$\mathrm{x}_{\mathrm{i}}=$ single observation from population

$\bar{x}=$ arithmetic average of all $\mathrm{n}$ values

$\mathrm{s}=$ estimate of population standard deviation based on the sample data

If the computed $t$ value is greater than the corresponding table value, at that confidence level, the data point is a potential outlier. The standard deviation emphasizes that values should not 
be eliminated from the analysis simply because they fall outside of the selected confidence range. Some samples will be outside this range through natural variability. For example, if a confidence level of 95 percent was selected, one observation out of twenty will fall outside of this range. However, the test is helpful in identifying obervations that can be investigated to determine if there is an assignable cause for the abnormal observation.

Variance is a measure of the spread in the data. Variances are tested for being either too high, indicating flawed testing methods, or too low, indicating a constraint on the actual material variability. The test for high variance consists of comparing the ratio of the highest variance within a laboratory to the sum of the variances from all of the laboratories. The ratio is then compared to a value based on the number or replicates for each sample, the number of laboratories, and a confidence limit (Table A.1). The test for low variance consists of comparing the ratio of the highest variance within a laboratory to the lowest variance withn a laboratory to a standard table (Table A.2). If the ratios from either test are greater than their respective table values then the variance of the material parameter must be investigated more closly by examinimg plots of the variance for each laboratory. If the plot shows one high or low variance then that laboratory may be removed from the analysis. If the data points are scattered then the test method may need to be re-evaluated.

Once the data has been evaluated for agreement of variance, the data must be checked for interactions. Interactions are when "... the pattern of change of results obtained on a given group of materials in one laboratory differs from the pattern obtained in another laboratory. In extreme cases, different laboratories may even fail to rate materials in the same order." (ASTM C 802). Agreement of variance can be checked either by performing an analysis of variance or by observing a plot of the material versus the parameter value. Looking at this plot, the relationship between the materials may be compared to that of the other laboratories. Similar slopes from one material to the next should be observed. If the relationship between materials form one laboratory differ greatly from the other observations there may have been some testing error ato that laboratory. The difference in interactions for this laboratory may be cause to omit the results from the analysis.

Once outliers, agreement of variance and interactions have been checked within-laboratory and between laboratory variances, standard deviations, and coefficient of variations should be 
Table A.1 Approximate Values (Upper 5 percent Level) for the Ratio of the Largest Variance to the Sum of the Variances

\begin{tabular}{|c|c|c|c|c|c|}
\hline No. of & \multicolumn{5}{|c|}{ No. of replicates } \\
Labs & 2 & 3 & 4 & 5 & 6 \\
\hline 5 & 0.8412 & 0.6838 & 0.5981 & 0.5441 & 0.5065 \\
6 & 0.7808 & 0.6161 & 0.5321 & 0.4803 & 0.4447 \\
7 & 0.7271 & 0.5612 & 0.48 & 0.4307 & 0.3974 \\
8 & 0.6798 & 0.5157 & 0.4377 & 0.391 & 0.3595 \\
9 & 0.9385 & 0.4775 & 0.4027 & 0.3584 & 0.3286 \\
10 & 0.602 & 0.445 & 0.3733 & 0.3311 & 0.3029 \\
11 & 0.57 & 0.414 & 0.348 & 0.307 & 0.281 \\
12 & 0.541 & 0.3924 & 0.3264 & 0.288 & 0.2624 \\
13 & 0.514 & 0.363 & 0.308 & 0.269 & 0.247 \\
14 & 0.492 & 0.345 & 0.291 & 253 & 0.232 \\
15 & 0.4709 & 0.3346 & 0.2758 & 2419 & 0.2195 \\
20 & 0.3894 & 0.2705 & 0.2205 & 1921 & 0.1735 \\
30 & 0.2929 & 0.198 & 0.1593 & 1377 & 0.1237 \\
\hline
\end{tabular}

Table A.2 Approximate Values (Upper 5 percent Level) for the Ratio of the Highest to Lowest Variance

\begin{tabular}{|c|c|c|c|c|}
\hline $\begin{array}{c}\text { No. of } \\
\text { Labs }\end{array}$ & 3 & 4 & 5 & 6 \\
\hline 5 & 202 & 51 & 25 & 16 \\
6 & 266 & 62 & 30 & 19 \\
7 & 333 & 73 & 34 & 21 \\
8 & 403 & 84 & 38 & 23 \\
9 & 475 & 94 & 41 & 25 \\
10 & 550 & 104 & 45 & 26 \\
11 & 626 & 114 & 48 & 28 \\
12 & 704 & 124 & 51 & 30 \\
13 & 790 & 135 & 54 & 31 \\
14 & 885 & 145 & 57 & 32 \\
15 & 995 & 155 & 59 & 33 \\
\hline
\end{tabular}

calculated. The within-laboratory and between-laboratory components of variation are calculated, as:

Within - Laboratory Component of Variance $=\operatorname{average}(A)$

Between - Laboratory Component of Variance $=\operatorname{variance}(B)-\frac{\operatorname{average}(A)}{n}$ 
Where:

$A=$ Variance of the replicates tested by each laboratory for each mix (within laboratory variance)

$\mathrm{B}=$ Average value of three replicates tested by each laboratory for each mix.

$\mathrm{n}=$ the number of laboratories

Table A.3 is an example of the calculation of the component of variance. In this example, there are three materials with three replicate each, and 10 laboratories. For material $\mathrm{A}$, the within-laboratory component of variance is 6.1 . The between laboratory component of variance is $1.1-(6.1 / 10)=0.49$.

\section{Table A.3. Example Calculation of Components of Variance}

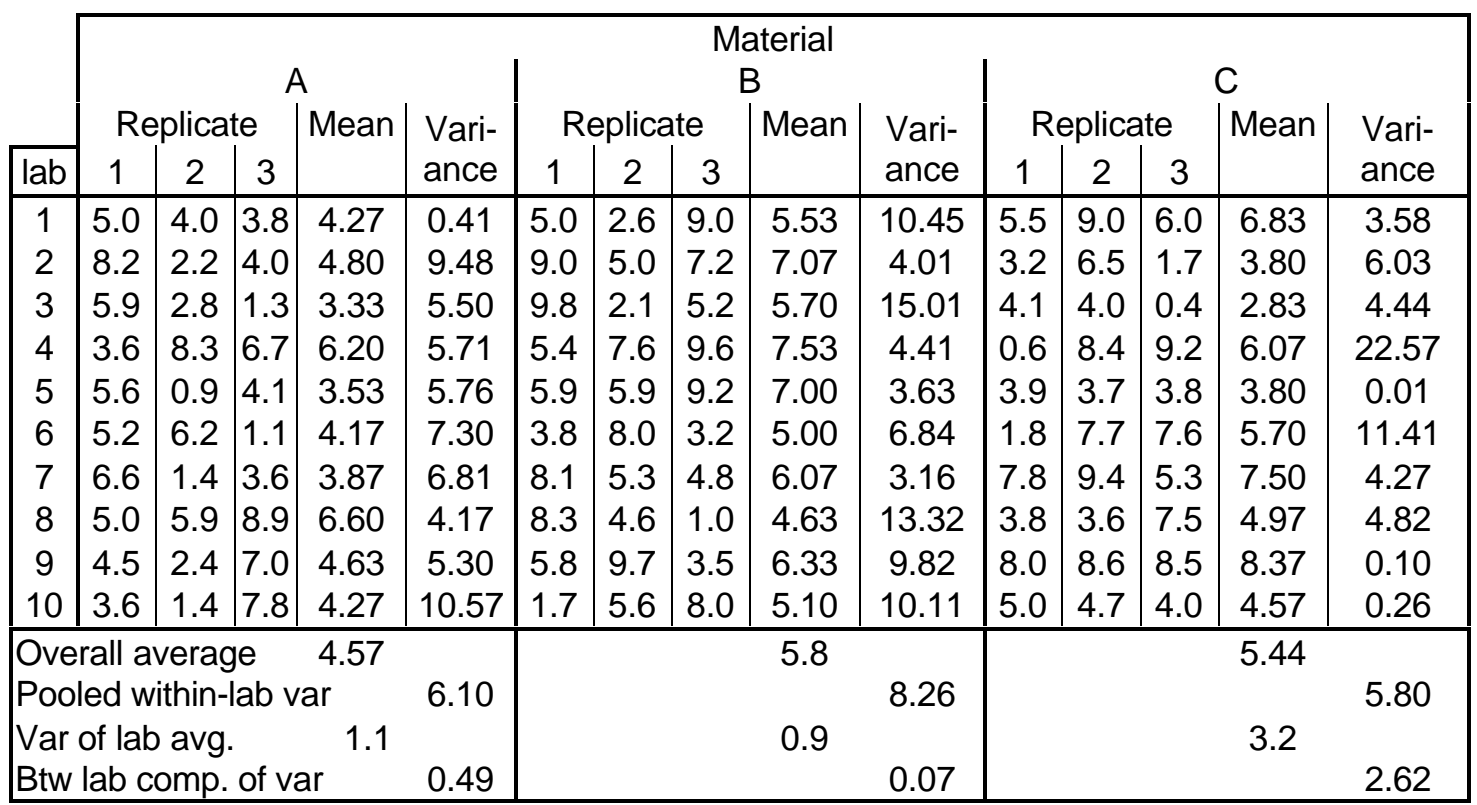

Knowing the within and between-laboratory variance, the standard deviation and coefficient of variation can be calculated. The within and between-laboratory standard deviations are the square roots of their respective variances. The coefficient of variation can be calculated using the following relationship: 
$C O V=100 \frac{s}{x}$

Where:

$\mathrm{s}=$ standard deviation

$\bar{x}=$ average of all observations

From these values the parameters of precision can be calculated. 
A ppendix B

\section{DATA FROM PREVIOUS STUDIES}


Table B.1. Precision Summary of Study by ASTM (Kanhdal, 96)

\begin{tabular}{|l|c|c|c|c|}
\cline { 2 - 5 } \multicolumn{1}{c|}{} & \multicolumn{2}{c|}{ Single Operator } & \multicolumn{2}{c|}{ Multi-laboratory } \\
\multicolumn{1}{c|}{ ASTM Study Data Analysis } & & d2s & $1 \mathrm{~s}$ & d2s \\
\hline Stability & 3206 & 4534 & 4006.1 & 11331 \\
Stability COV ( percent) & 12.26 & 17.34 & 15.32 & 43 \\
\hline Flow & 3.11 & 4.40 & 4.40 & 12.44 \\
Flow COV ( percent) & 16.79 & 23.74 & 23.71 & 67.07 \\
\hline Bulk Specific Gravity & 0.0084 & 0.012 & 0.0921 & 0.260 \\
Bulk Specific Gravity COV ( percent) & 0.32 & 0.45 & 3.46 & 9.77 \\
\hline Percent Air Voids & 0.30 & 0.43 & 0.78 & 2.22 \\
Percent Air Voids COV ( percent) & 7.80 & 11.03 & 20.14 & 56.97 \\
\hline
\end{tabular}


Table B.2. Georgia Laboratory Comparison Study (Siddiqui, 95)

\begin{tabular}{|c|c|c|c|c|c|}
\hline Laboratory Location & $\begin{array}{l}\text { Height } \\
\text { (in.) }\end{array}$ & $\begin{array}{l}\text { Density } \\
\left(\mathrm{lb} / \mathrm{ft}^{3}\right)\end{array}$ & $\begin{array}{c}\text { Voids } \\
\text { (percent) }\end{array}$ & $\begin{array}{l}\text { Stability } \\
\text { (lb) }\end{array}$ & $\begin{array}{c}\text { Flow } \\
\text { (0.01 in.) }\end{array}$ \\
\hline Tennille, Ga. & 2.55 & 154.4 & 4.3 & 2500 & 12 \\
\hline & 2.6 & 150.3 & 6.8 & 2240 & 12 \\
\hline & 2.51 & 155.6 & 3.6 & 3020 & 15 \\
\hline Tifton, Ga. & 2.5 & 154.8 & 4.1 & 2880 & 13.1 \\
\hline & 2.5 & 152.9 & 5.3 & 2350 & 13.3 \\
\hline \multirow[t]{3}{*}{ District 5} & 2.5 & 154.6 & 4.2 & 2200 & 15 \\
\hline & 2.5 & 154.3 & 4.4 & 2175 & 14.8 \\
\hline & 2.5 & 154.6 & 4.2 & 2275 & 13.6 \\
\hline \multirow[t]{3}{*}{ orest Park Ga. } & 2.562 & 153 & 5.2 & 2100 & 12 \\
\hline & 2.555 & 154.1 & 4.5 & 2460 & 13 \\
\hline & 2.54 & 154.3 & 4.4 & 2520 & 11 \\
\hline \multirow[t]{3}{*}{ Producer 1 Macon Ga. } & 2.567 & 153.1 & 5.1 & 2150 & 10 \\
\hline & 2.574 & 153.6 & 4.8 & 2190 & 9 \\
\hline & 2.562 & 153.6 & 4.8 & 2340 & 10 \\
\hline \multirow[t]{3}{*}{ Producer 2 Atlanta Ga. } & 2.56 & 152.6 & 5.4 & 2320 & 11 \\
\hline & 2.56 & 153.2 & 5.1 & 2470 & 13 \\
\hline & 2.56 & 152.8 & 5.3 & 2330 & 13 \\
\hline \multirow[t]{3}{*}{ Producer 3 Doraville, Ga. } & 2.44 & 154.4 & 4.3 & 2200 & 9 \\
\hline & 2.5 & 153.6 & 4.8 & 2050 & 10 \\
\hline & 2.5 & 152.5 & 5.5 & 1950 & 10 \\
\hline \multirow[t]{3}{*}{ Producer 4 Birmingham, Ala. } & 2.51 & 153 & 4.9 & 2400 & 13.5 \\
\hline & 2.5 & 157 & 2.9 & 2650 & 13.5 \\
\hline & 2.5 & 155 & 3.8 & 2250 & 12 \\
\hline \multirow[t]{3}{*}{ Producer 5 Chattanooga, Tenn. } & 2.615 & 152.9 & 5.3 & 2550 & 11 \\
\hline & 2.615 & 151.6 & 6 & 2550 & 10 \\
\hline & 2.615 & 150.8 & 6.5 & 2525 & 12 \\
\hline Average (of all laboratories) & & 153.6 & 4.8 & 2371 & 12 \\
\hline $\begin{array}{l}\text { Acceptable range for a given } \\
\text { Laboratory }\end{array}$ & & $\begin{array}{l}152.1 \text { to } \\
155.1\end{array}$ & & $\begin{array}{l}1971 \text { to } \\
2771\end{array}$ & 10 to 14 \\
\hline
\end{tabular}

Note: Values in bold are outside acceptable (95 percent) confidence range 
Table B.3. Utah-Marshall Study, Same Operator, Different Equipment at Various Laboratories (Siddiqui, 95)

\begin{tabular}{|c|c|c|c|c|c|c|c|c|c|c|c|c|c|c|c|}
\hline \multirow[b]{2}{*}{ Laboratory } & \multicolumn{3}{|c|}{$\begin{array}{c}\text { Bulk Specific Gravity at } \\
\text { Asphalt Content }\end{array}$} & \multicolumn{3}{|c|}{$\begin{array}{c}\text { Voids (\%) at Asphalt } \\
\text { Content }\end{array}$} & \multicolumn{3}{|c|}{$\begin{array}{l}\text { VMA Filled (\%) at } \\
\text { Asphalt Content }\end{array}$} & \multicolumn{3}{|c|}{$\begin{array}{l}\text { Stability (Ib) Asphalt } \\
\text { Content }\end{array}$} & \multicolumn{3}{|c|}{$\begin{array}{l}\text { Flow }(0.01 \text { in.) at } \\
\text { Asphalt Content }\end{array}$} \\
\hline & $5.50 \%$ & $6.00 \%$ & $6.50 \%$ & $5.50 \%$ & $6.00 \%$ & $6.50 \%$ & $5.50 \%$ & $6.00 \%$ & $6.50 \%$ & $5.50 \%$ & $6.00 \%$ & $6.50 \%$ & $5.50 \%$ & $6.00 \%$ & $6.50 \%$ \\
\hline District 1 & 2.29 & 2.29 & 2.30 & 3.3 & 2.4 & 1.5 & 78.7 & 84.7 & 90.6 & 2256 & 2064 & 1871 & 10 & 11 & 14 \\
\hline District 2 & 2.29 & 2.30 & 2.30 & 2.8 & 2.0 & 1.5 & 81.4 & 87.0 & 90.6 & 2477 & 2559 & 2216 & 9 & 9 & 12 \\
\hline District 3 & 2.29 & 2.30 & 2.30 & 3.3 & 2.0 & 1.5 & 78.7 & 87.0 & 90.8 & 2538 & 2642 & 2380 & 8 & 9 & 11 \\
\hline District 4 & 2.29 & 2.30 & 2.29 & 3.3 & 2.0 & 1.9 & 78.7 & 87.0 & 88.4 & 2663 & 2678 & 1825 & 10 & 11 & 14 \\
\hline District 5 & 2.30 & 2.31 & 2.30 & 2.8 & 2.6 & 1.5 & 81.9 & 89.4 & 90.6 & 2729 & 2620 & 2045 & 10 & 11 & 14 \\
\hline District 6 & 2.29 & 2.29 & 2.30 & 3.3 & 2.4 & 1.5 & 78.7 & 84.8 & 90.6 & 2367 & 2178 & 2023 & 8 & 11 & 12 \\
\hline Main lab & 2.29 & 2.29 & 2.29 & 3.3 & 2.4 & 1.9 & 78.7 & 84.7 & 88.4 & 2767 & 1945 & 1826 & 9 & 11 & 12 \\
\hline Average & 2.29 & 2.30 & 2.30 & 3.16 & 2.26 & 1.61 & 79.5 & 86.4 & 90.0 & 2542 & 2384 & 2027 & 9 & 10 & 13 \\
\hline Std. Dev. & 0.004 & 0.008 & 0.005 & 0.24 & 0.25 & 0.20 & 1.4 & 1.8 & 1.1 & 190 & 310 & 211 & 1 & 1 & 1 \\
\hline Range & 0.01 & 0.02 & 0.01 & 0.5 & 0.6 & 0.4 & 3.2 & 4.7 & 2.4 & 511 & 733 & 555 & 2 & 2 & 3 \\
\hline
\end{tabular}

Table B.4. Utah-Marshall Study, Different Operator and Equipment at Various Laboratories (Siddiqui, 95)

\begin{tabular}{|c|c|c|c|c|c|c|c|c|c|c|c|c|c|c|c|}
\hline \multirow[b]{2}{*}{ Laboratory } & \multicolumn{3}{|c|}{$\begin{array}{l}\text { Bulk Specific Gravity at } \\
\text { Asphalt Content }\end{array}$} & \multicolumn{3}{|c|}{$\begin{array}{c}\text { Voids (\%) at Asphalt } \\
\text { Content }\end{array}$} & \multicolumn{3}{|c|}{$\begin{array}{l}\text { VMA Filled (\%) at } \\
\text { Asphalt Content }\end{array}$} & \multicolumn{3}{|c|}{$\begin{array}{l}\text { Stability (Ib) Asphalt } \\
\text { Content }\end{array}$} & \multicolumn{3}{|c|}{$\begin{array}{l}\text { Flow (0.01 in.) at } \\
\text { Asphalt Content }\end{array}$} \\
\hline & $5.50 \%$ & $6.00 \%$ & $6.50 \%$ & $5.50 \%$ & $6.00 \%$ & $6.50 \%$ & $5.50 \%$ & $6.00 \%$ & $6.50 \%$ & $5.50 \%$ & $6.00 \%$ & $6.50 \%$ & $5.50 \%$ & $6.00 \%$ & $6.50 \%$ \\
\hline District 1 & 2.28 & 2.29 & 2.29 & 3.3 & 2.1 & 1.5 & 78.3 & 86.2 & 90.6 & 2776 & 2691 & 2237 & 10 & 10 & 14 \\
\hline District 2 & 2.31 & 2.31 & 2.31 & 2.2 & 1.5 & 0.9 & 84.9 & 90.0 & 94.2 & 3528 & 3194 & 2494 & 16 & 17 & 19 \\
\hline District 3 & 2.28 & 2.28 & 2.28 & 3.5 & 2.7 & 1.9 & 77.6 & 83.0 & 88.2 & 3012 & 3000 & 2664 & 10 & 11 & 13 \\
\hline District 4 & 2.29 & 2.30 & 2.29 & 3.3 & 2.0 & 1.9 & 78.8 & 87.0 & 88.5 & 2450 & 2762 & 2109 & 7 & 10 & 12 \\
\hline District 5 & 2.29 & 2.30 & 2.30 & 3.4 & 2.1 & 1.7 & 78.6 & 86.6 & 89.5 & 2790 & 2455 & 2065 & 10 & 10 & 13 \\
\hline District 6 & 2.29 & 2.30 & 2.29 & 3.4 & 2.1 & 1.7 & 78.4 & 86.3 & 89.4 & 3561 & 3224 & 2572 & 7 & 8 & 11 \\
\hline Main lab & 2.28 & 2.30 & 2.30 & 3.6 & 2.0 & 1.4 & 77.2 & 87.0 & 91.4 & 2166 & 2158 & 1921 & 14 & 14 & 17 \\
\hline Average & 2.29 & 2.30 & 2.29 & 3.24 & 2.07 & 1.57 & 79.1 & 86.6 & 90.3 & 2898 & 2783 & 2295 & 11 & 11 & 14 \\
\hline Std. Dev. & 0.011 & 0.010 & 0.010 & 0.472 & 0.350 & 0.350 & 2.6 & 2.0 & 2.1 & 518 & 391 & 284 & 3 & 3 & 3 \\
\hline Range & 0.03 & 0.03 & 0.03 & 1.4 & 1.2 & 1 & 7.7 & 7.0 & 6.0 & 1395 & 1066 & 743 & 9 & 9 & 8 \\
\hline
\end{tabular}




\section{Table B.5. Canadian Mix Exchange,}

Statistical Summary for All Data

\begin{tabular}{|c|c|c|c|c|c|c|c|c|c|}
\hline \multirow[b]{2}{*}{ No. of Labs -31} & \multicolumn{3}{|c|}{ Bulk Specific Gravity } & \multicolumn{3}{|c|}{ Stability (kN) } & \multicolumn{3}{|c|}{ Flow (0.25 mm.) } \\
\hline & Manual & Mechanical & Manual $^{\star}$ & Manual & Mechanical & Manual $^{\star}$ & Manual & Mechanical & Manual $^{*}$ \\
\hline Mean & 2.382 & 2.357 & 2.377 & 11.3 & 10.2 & 12.4 & 12 & 12 & 10 \\
\hline Standard & & & & & & & & & \\
\hline Deviation & 0.017 & 0.031 & 0.019 & 1.8 & 2.5 & 1.9 & 3 & 2 & 1 \\
\hline $95 \%$ confidence & $2.348-$ & $2.295-$ & 2.339- & 7.7 & $5.2-$ & 8.6- & $6-$ & 8- & 8- \\
\hline Interval & 2.416 & 2.419 & 2.415 & 14.9 & 15.2 & 16.2 & 18 & 18 & 12 \\
\hline Data & $2.322-$ & 2.273- & $2.321-$ & $5.7-$ & 4.3- & $8.2-$ & 7- & 8- & 8- \\
\hline Range & 2.412 & 2.405 & 2.322 & 14.5 & 14.6 & 15.1 & 19 & 16 & 12 \\
\hline
\end{tabular}

Statistical Summary for Selected Data (excludes data that were outside 95\% confidence interval)

\begin{tabular}{|c|c|c|c|c|c|c|c|c|c|}
\hline \multirow[b]{2}{*}{ No. of Labs -31} & \multicolumn{3}{|c|}{ Bulk Specific Gravity } & \multicolumn{3}{|c|}{ Stability (kN) } & \multicolumn{3}{|c|}{ Flow (0.25 mm.) } \\
\hline & Manual & Mechanical & Manual $^{*}$ & Manual & Mechanical & Manual $^{*}$ & Manual & Mechanical & Manual $^{*}$ \\
\hline Mean & 2.384 & 2.361 & 2.379 & 11.5 & 10.4 & 12.5 & 12 & 12 & 10 \\
\hline Standard & & & & & & & & & \\
\hline Deviation & 0.014 & 0.026 & 0.016 & 1.4 & 2.2 & 1.7 & 3 & 2 & 1 \\
\hline $95 \%$ confidence & $2.358-$ & 2.309- & $2.547-$ & $8.7-$ & $6-$ & $9.1-$ & 8- & 8- & $8-$ \\
\hline Interval & 2.41 & 2.413 & 2.411 & 14.3 & 14.8 & 13.9 & 16 & 16 & 12 \\
\hline Data & 2.359- & 2.299- & $2.346-$ & 8.6- & $6-$ & $9.2-$ & 7- & 8- & $8-$ \\
\hline Range & 2.412 & 2.405 & 2.399 & 14.5 & 14.6 & 15.1 & 18 & 16 & 12 \\
\hline
\end{tabular}

* specimens were manually compacted at participating laboratories but tested at a central laboratory 
A ppendix C

\section{BUCKET MIXER INSTRUCTIONS}




\section{BUCKET MIXER INSTRUCTIONS}

\section{SETTING UP THE MIXER.}

Install paddle arm so arm sits parallel to the plane to which the bucket can rotate

Secure paddle to paddle are so both back edges sit flush to the side of the bucket and blade touches bottom of bucket

\section{MIXING PROCEDURE}

Weigh out aggregates and separate into two containers: course and fine

Nominal maximum aggregate size $\leq 9.5 \mathrm{~mm}$

Fine aggregate $\leq 2.36 \mathrm{~mm}$

Coarse aggregate $>2.36 \mathrm{~mm}$

Nominal maximum aggregate size $>9.5 \mathrm{~mm}$

Fine aggregate $\leq 4.75 \mathrm{~mm}$

Coarse aggregate $>4.75 \mathrm{~mm}$

Heat 5-gallon bucket and paddle attached to paddle arm.

Allow enough time for bucket and paddle to achieve proper temperature

Remove bucket from oven and add coarse aggregate and asphalt to bucket

Place bucket in mixer basket and turn mixer on

Remove paddle and arm from oven and slide over rod

With aggregates moving the paddle should slide down until touching the bucket bottom.

Unlock mixer and tilt mixer away from paddle arm side.

Hold on to paddle arm and tilt bucket as far as possible without spilling contents

After 10 seconds lock bucket in upright position.

Remove fine aggregate from oven and introduce into the mix.

Pour fine aggregates into bucket with allowing aggregate to touch paddle or side of bucket

Unlock bucket and tilt

Rock bucket up-and-down to reduce segregation

After about 20 seconds when the aggregate looks thoroughly coated take a hot spatula, and as the bucket is spinning, scrape all of the material out of the seam between the bottom and side of the bucket.

Shut off mixer.

Slide paddle off of the rod and with a hot spoon scrape the asphalt off the paddle into the bucket.

Remove bucket from mixer and tilt bucket onto its side and scrape circle of asphalt and fines stuck to the center of the bucket bottom.

Scrape material out of seem again.

Dump bucket contents

Scrape entire side and bottom of bucket. 
A ppendix D

\section{DESIGN CHARTS}




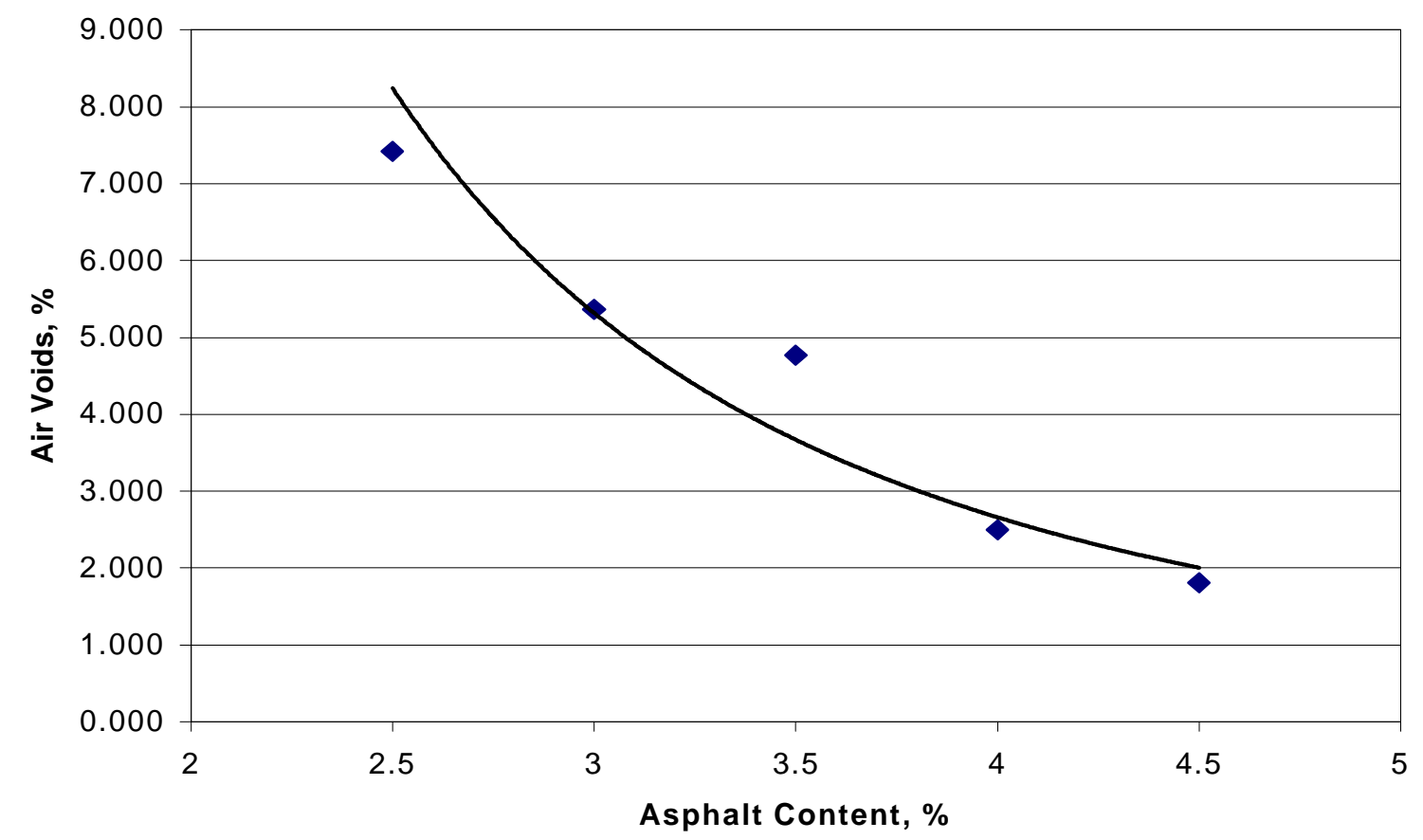

Figure D.1. Percent Air Voids Versus Asphalt Content for Base 1

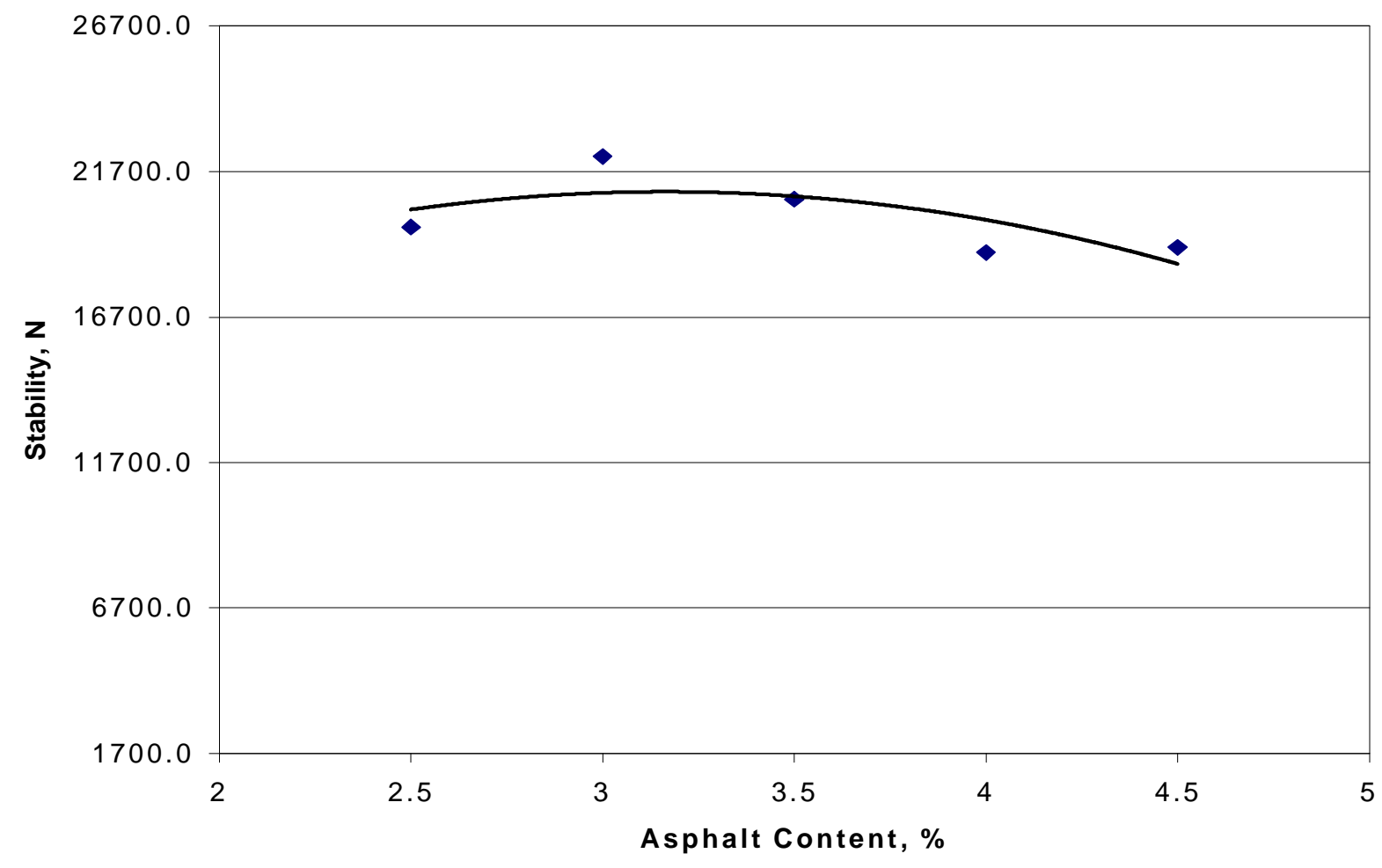

Figure D.2. Stability Versus Asphalt Content for Base 1 


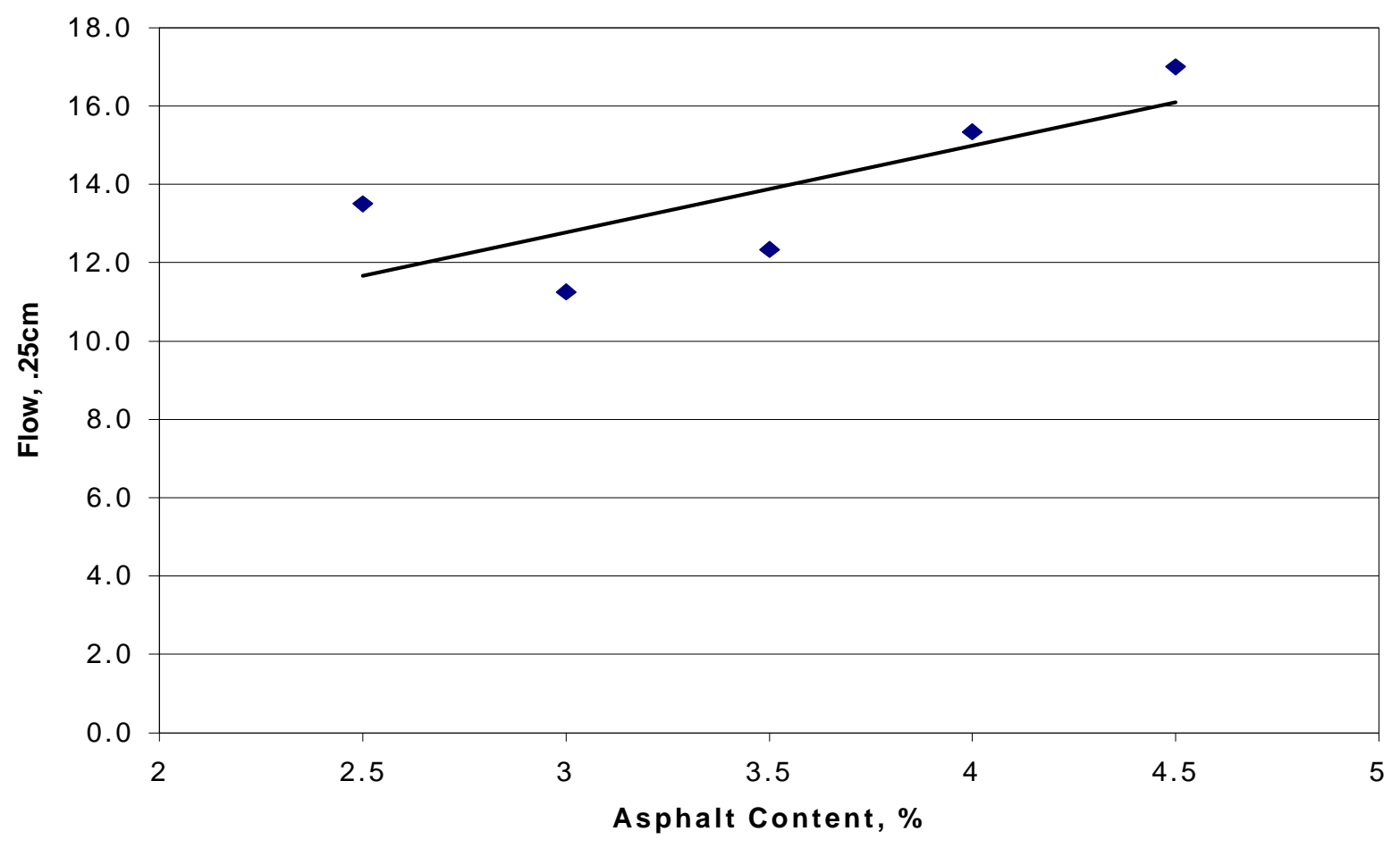

Figure D.3. Flow Versus Asphalt Content for Base 1

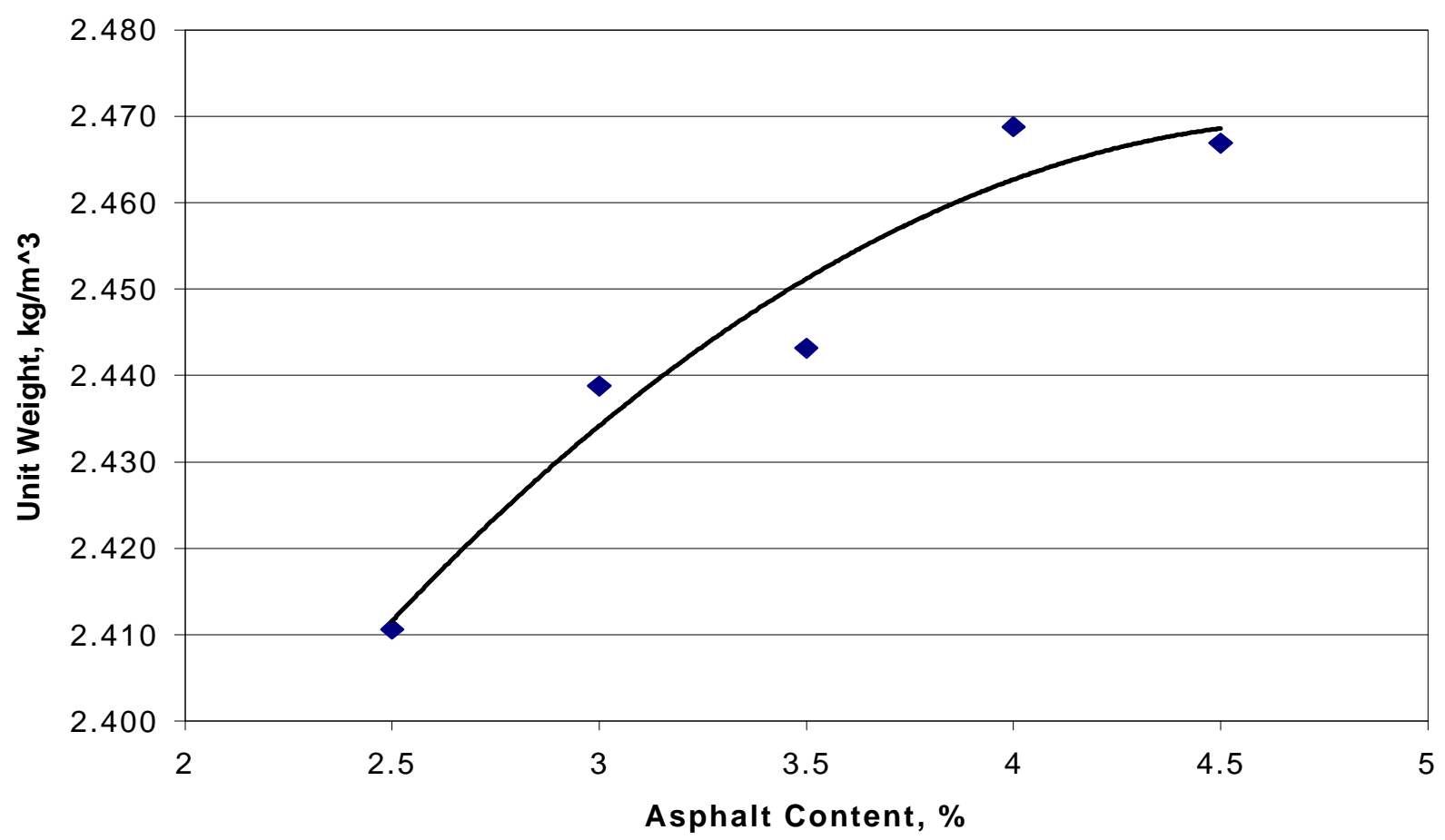

Figure D.4. Unit Weight Versus Asphalt Content for Base 1 


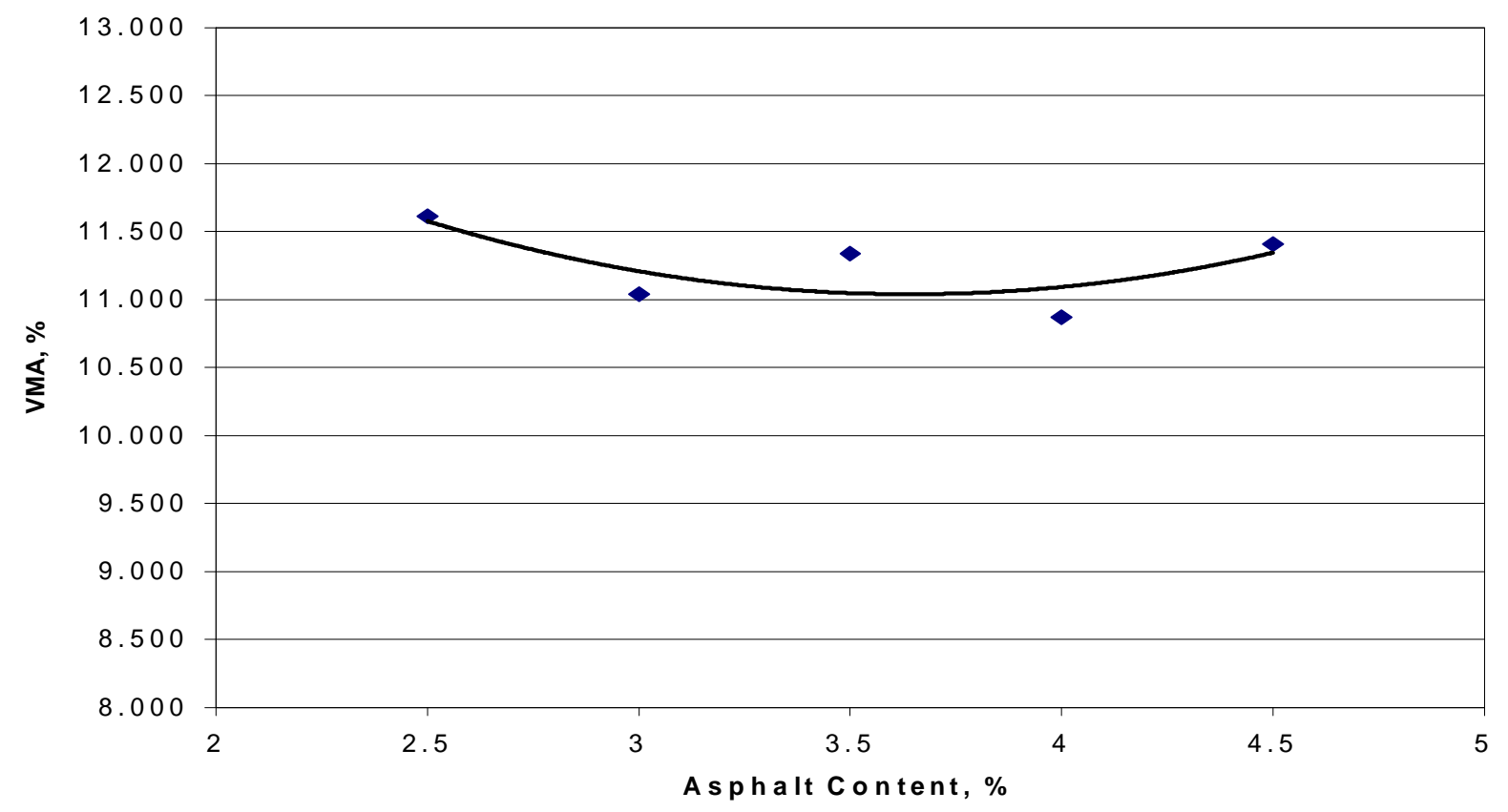

Figure D.5. Percent VMA Versus Asphalt Content for Base 1

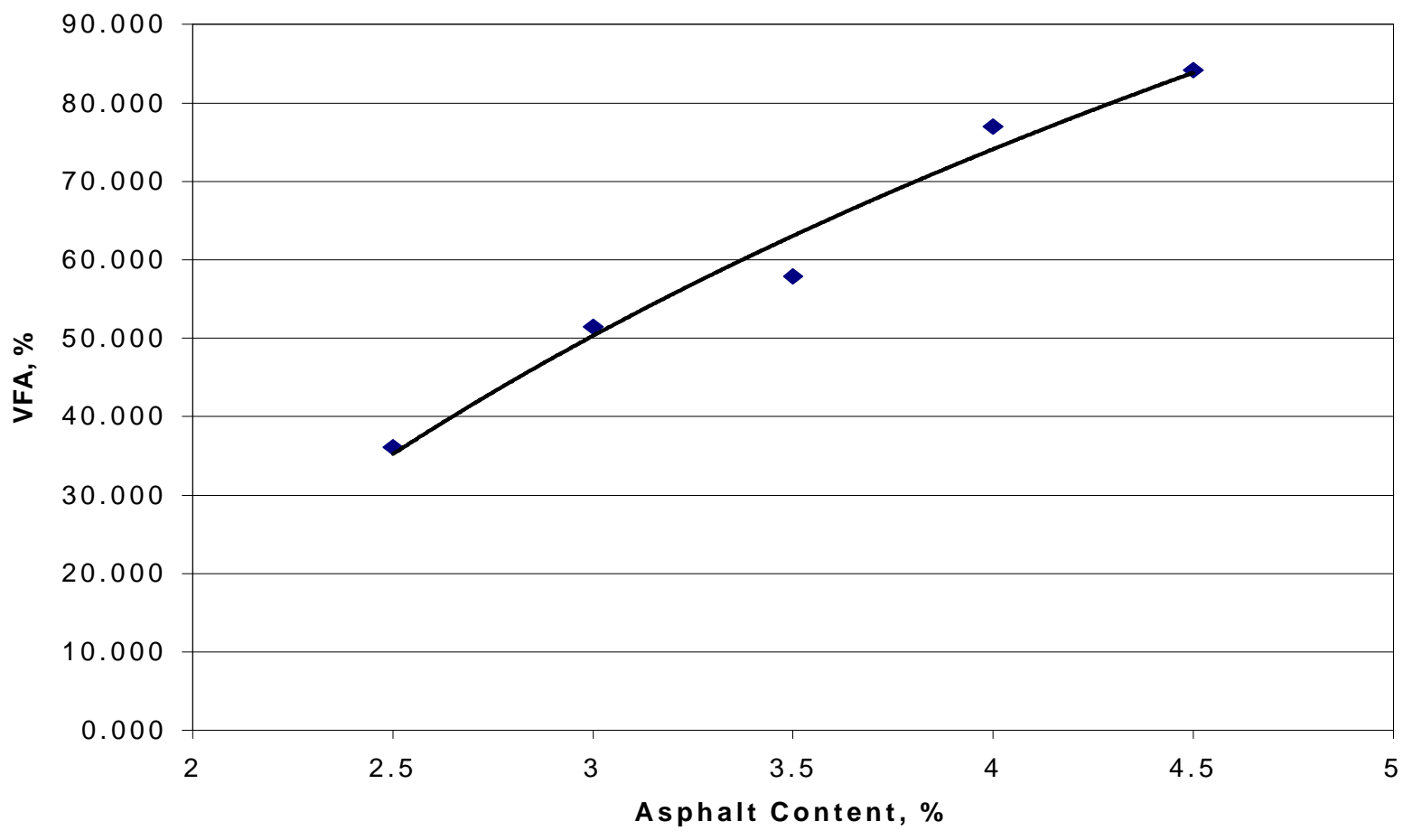

Figure D.6 Percent VMA Versus Asphalt Content for Base 1 


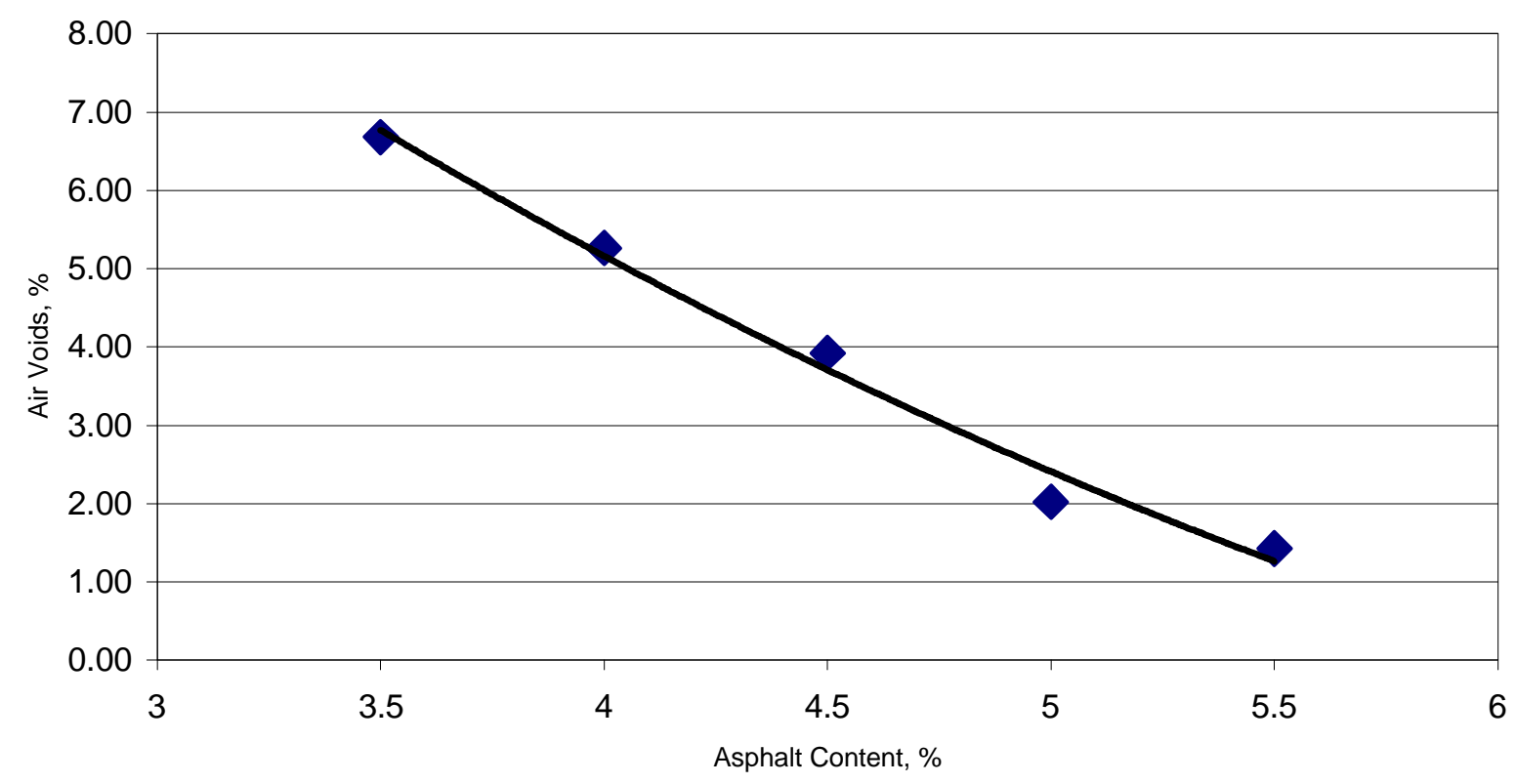

Figure D.7. Percent Air Voids Versus Asphalt Content for Base 2

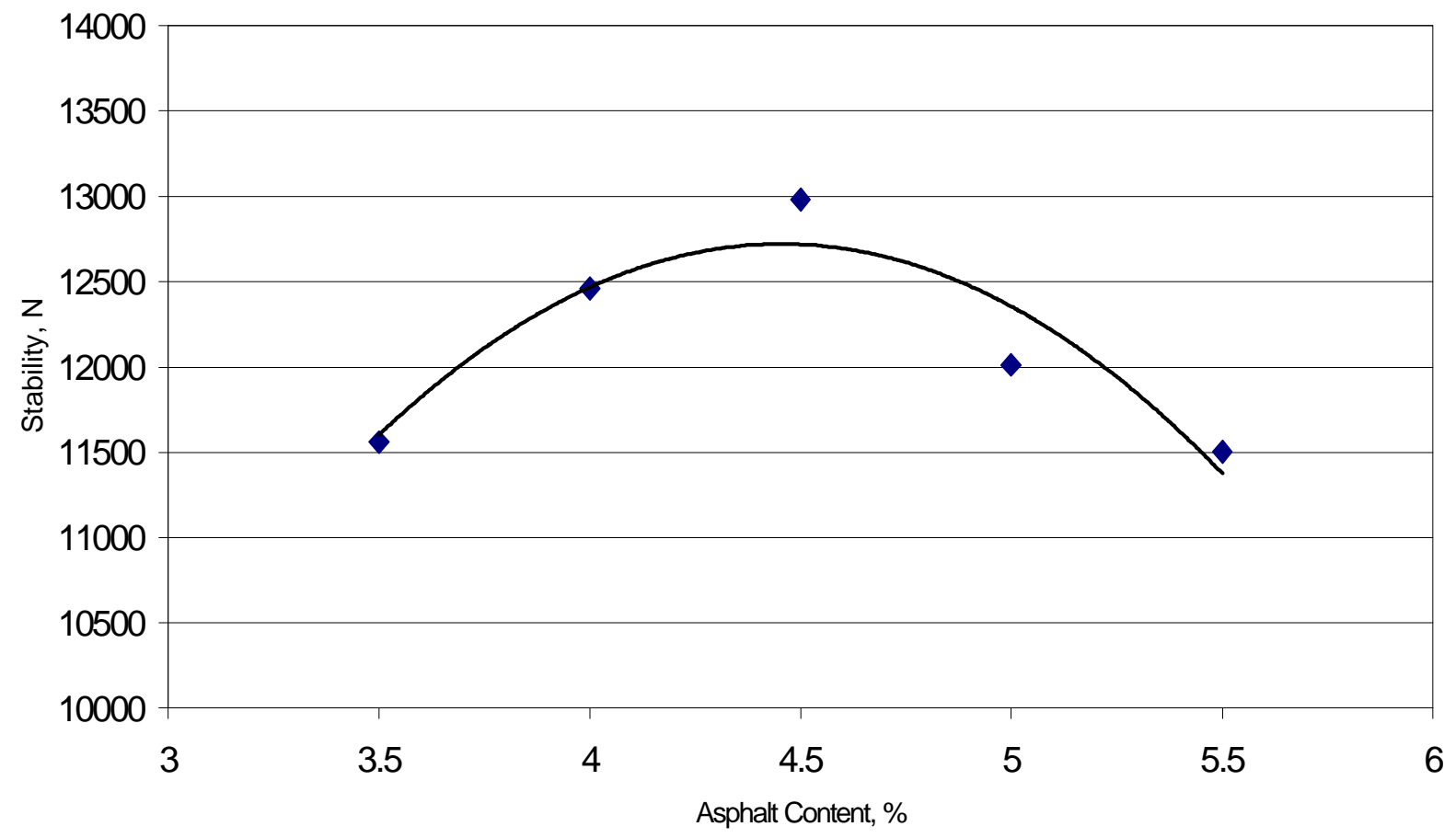

Figure D.8. Stability Versus Asphalt Content for Base 2 


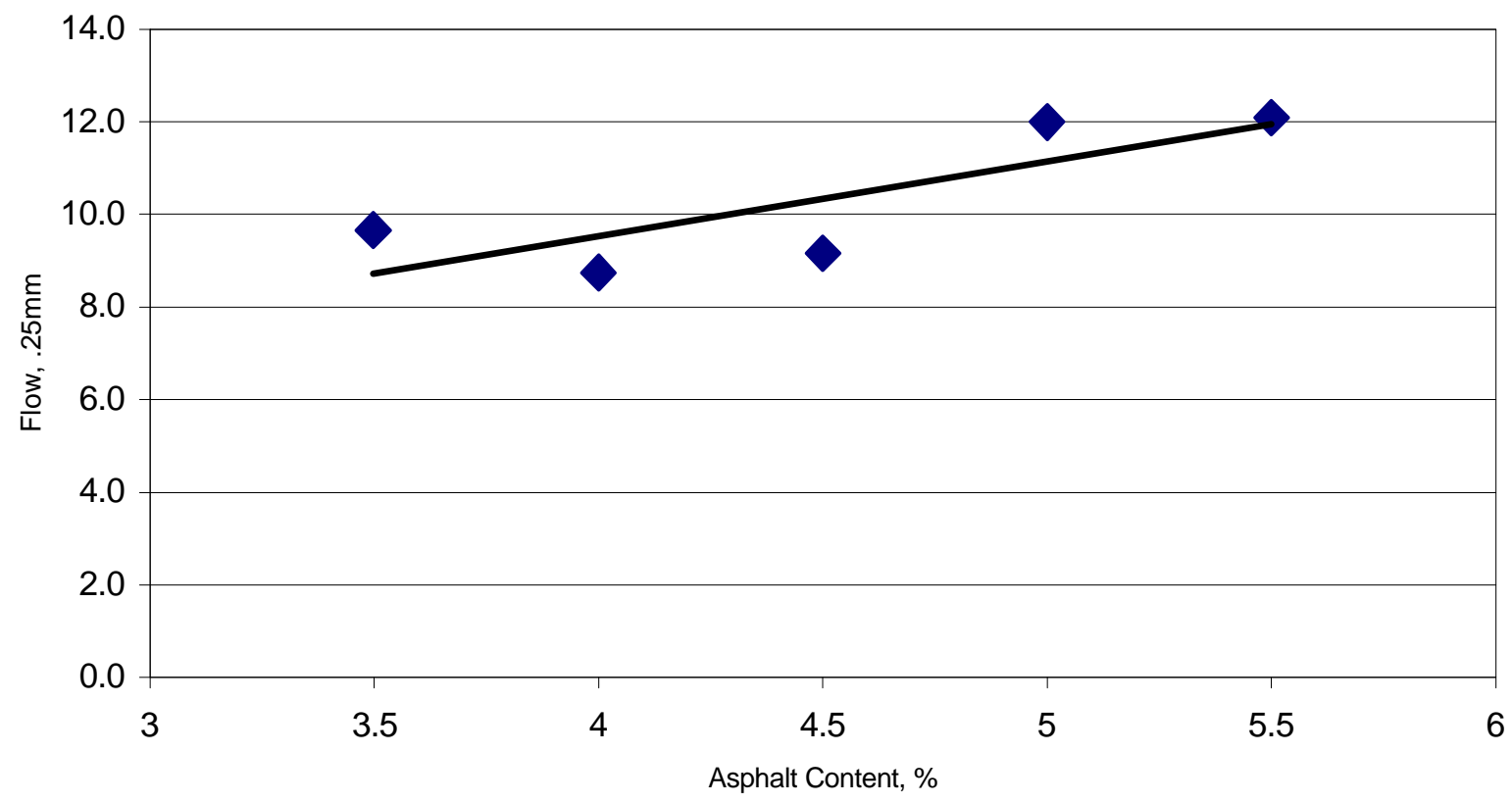

Figure D.9. Flow Versus Asphalt Content for Base 2

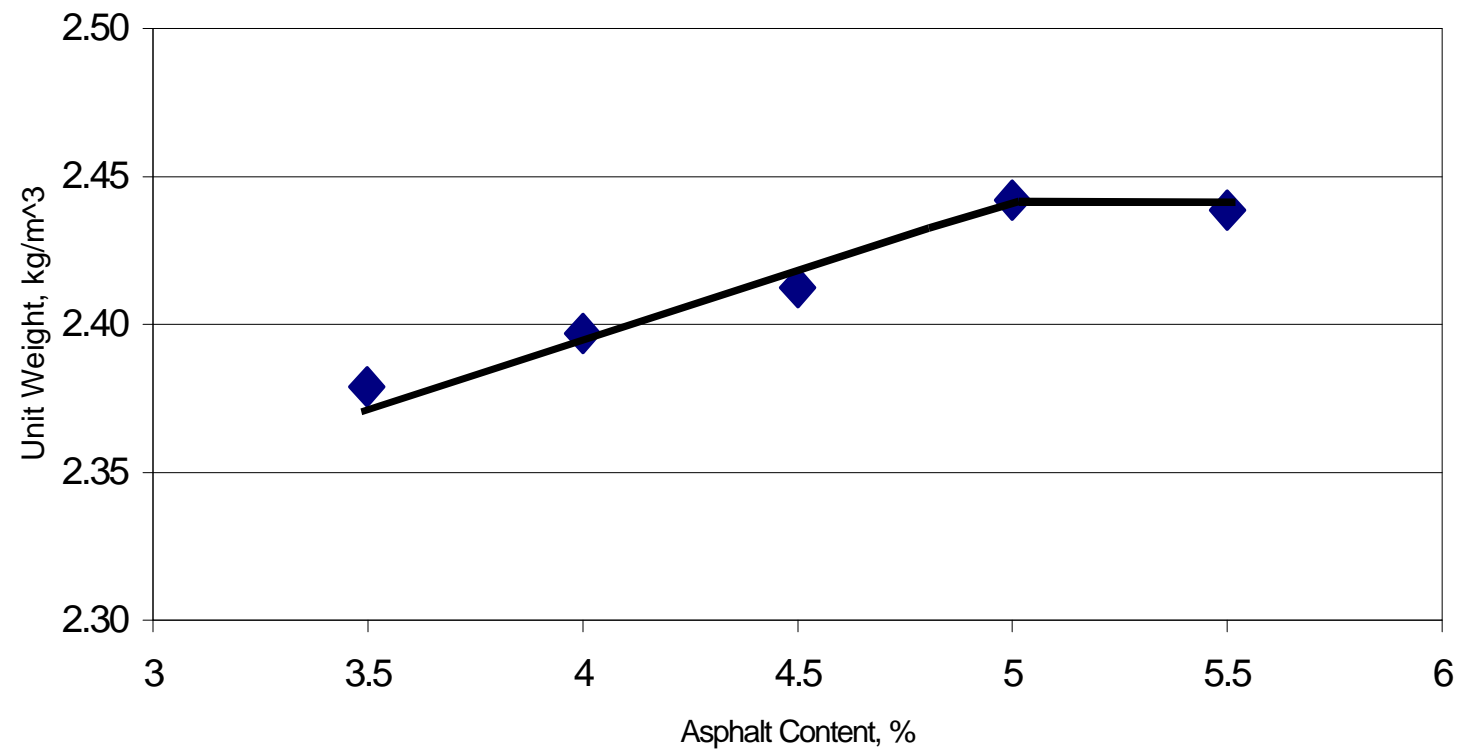

Figure D.10. Unit Weight Versus Asphalt Content for Base 2 


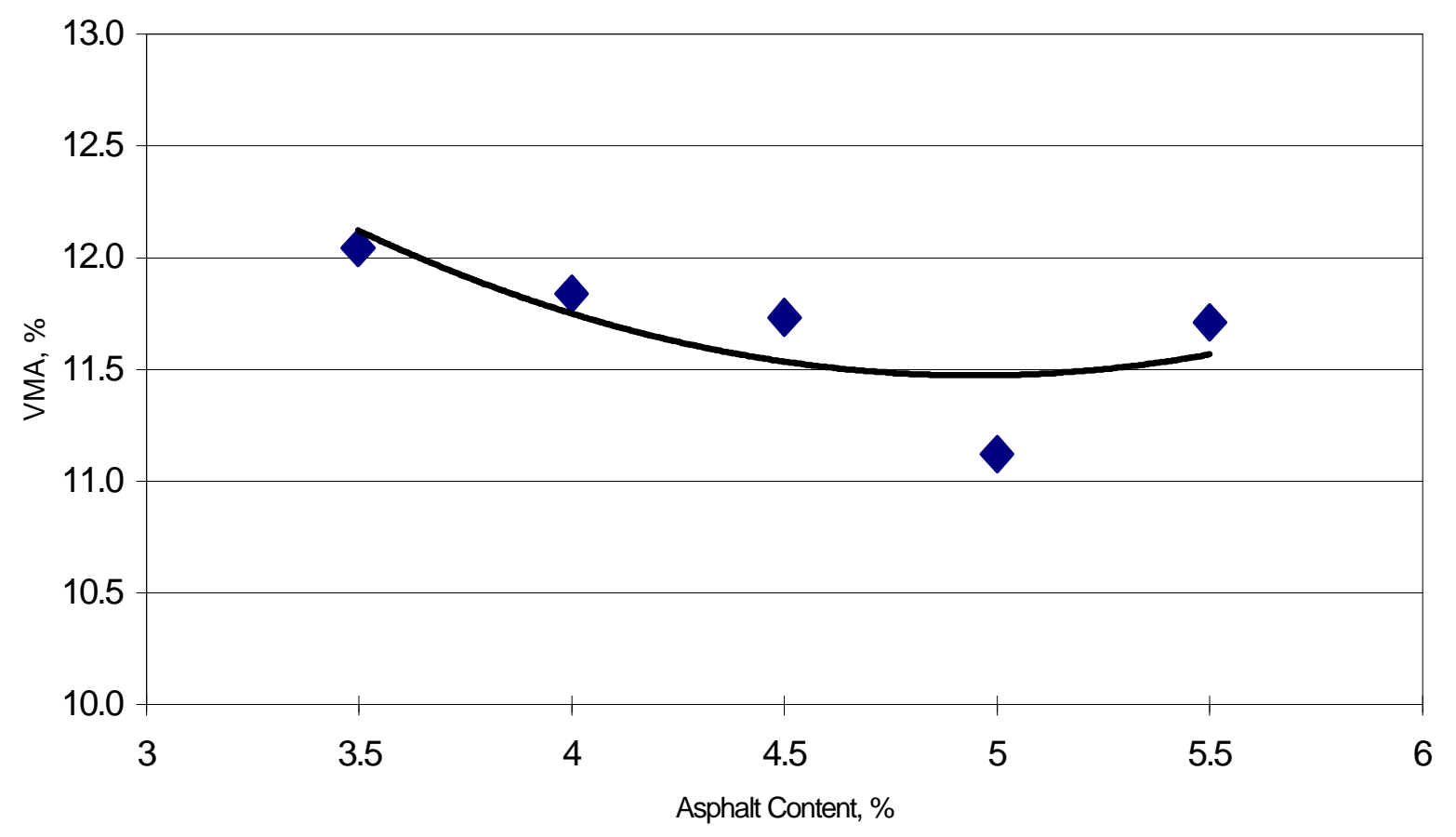

Figure D.11. Percent VMA Versus Asphalt Content for Base 2

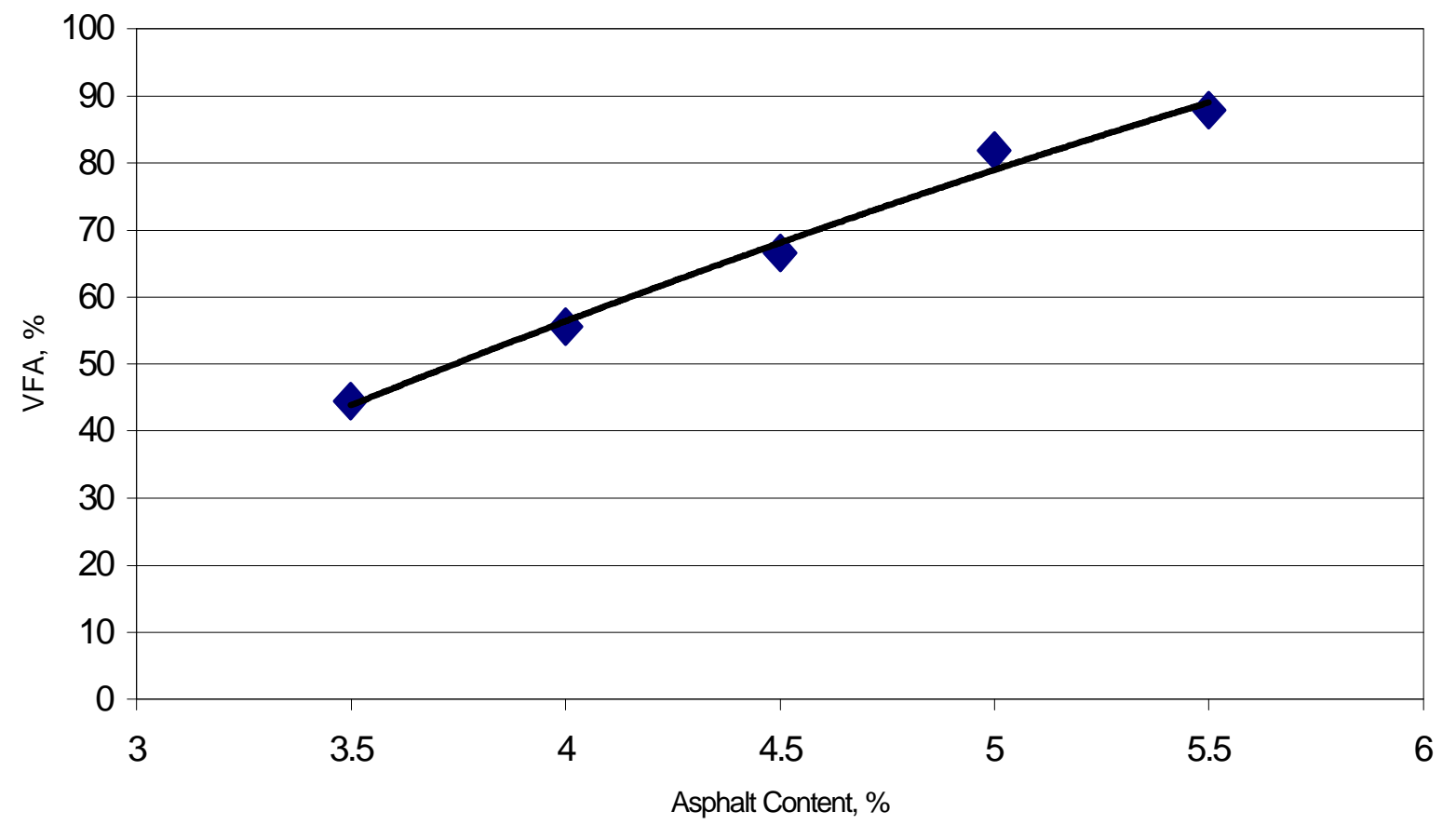

Figure D.12. Percent VFA Versus Asphalt Content for Base 2 


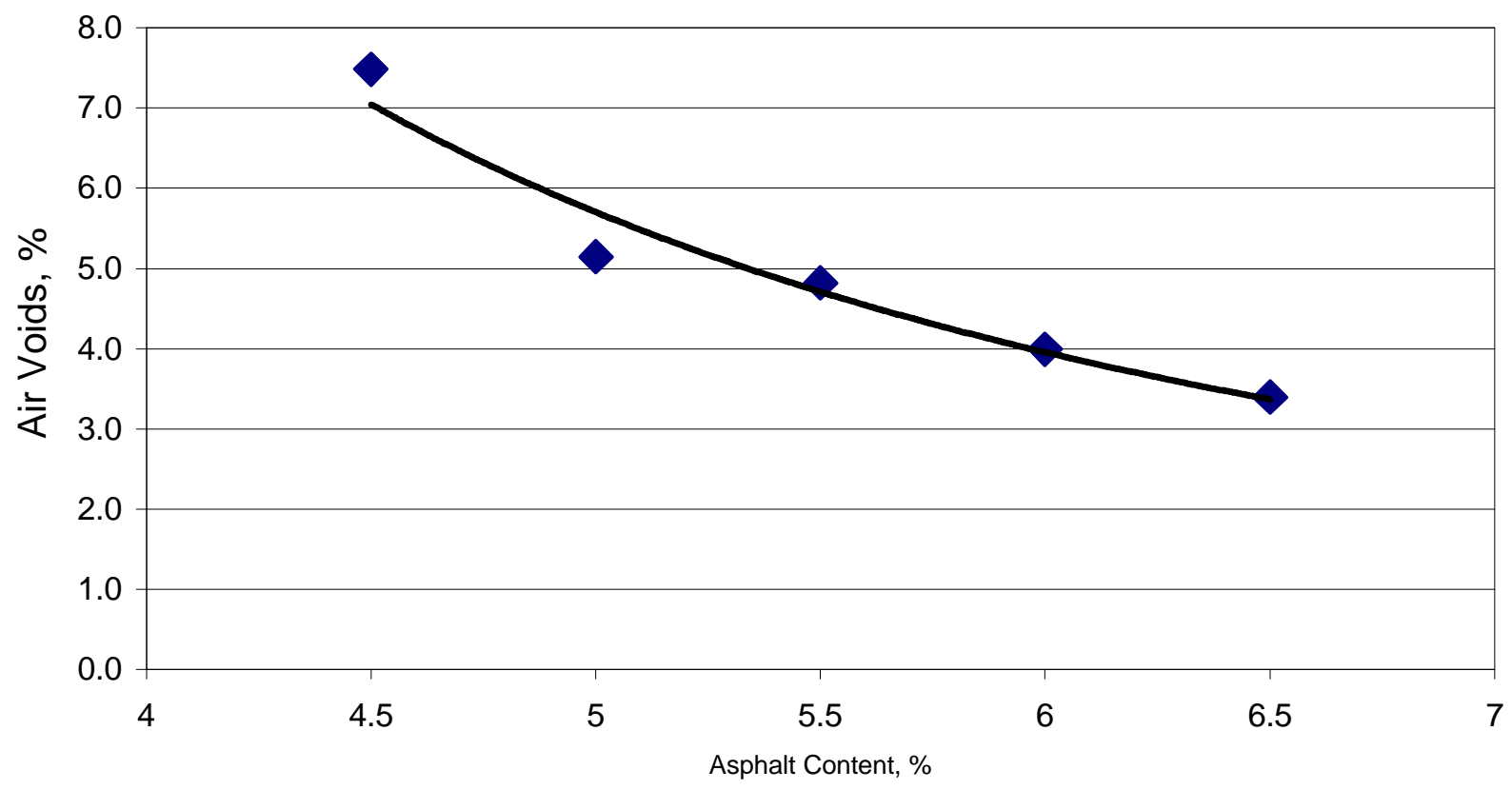

Figure D.13. Percent Air Voids Versus Asphalt Content for Wearing 1

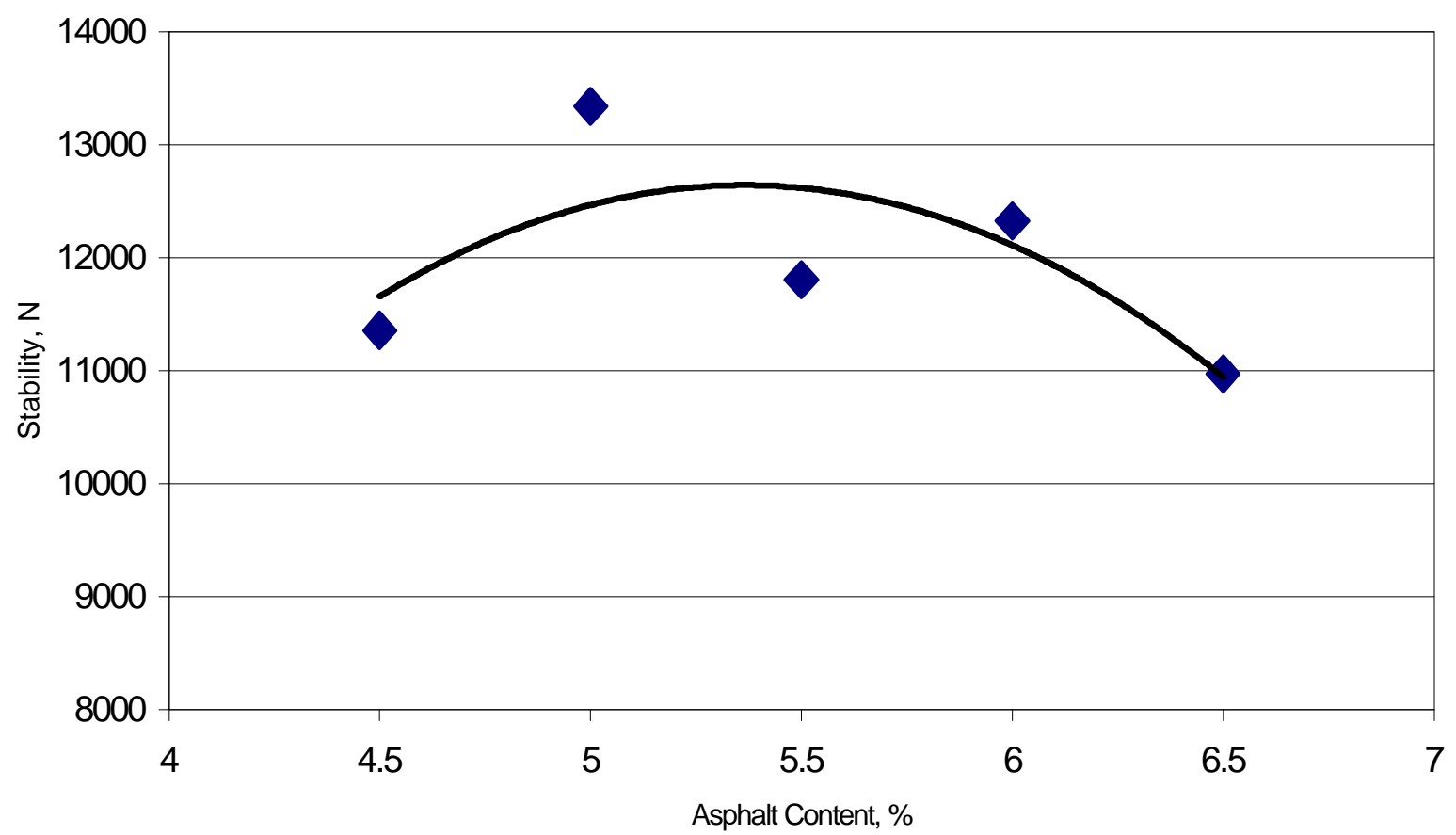

Figure D.14. Stability Versus Asphalt Content for Wearing 1 


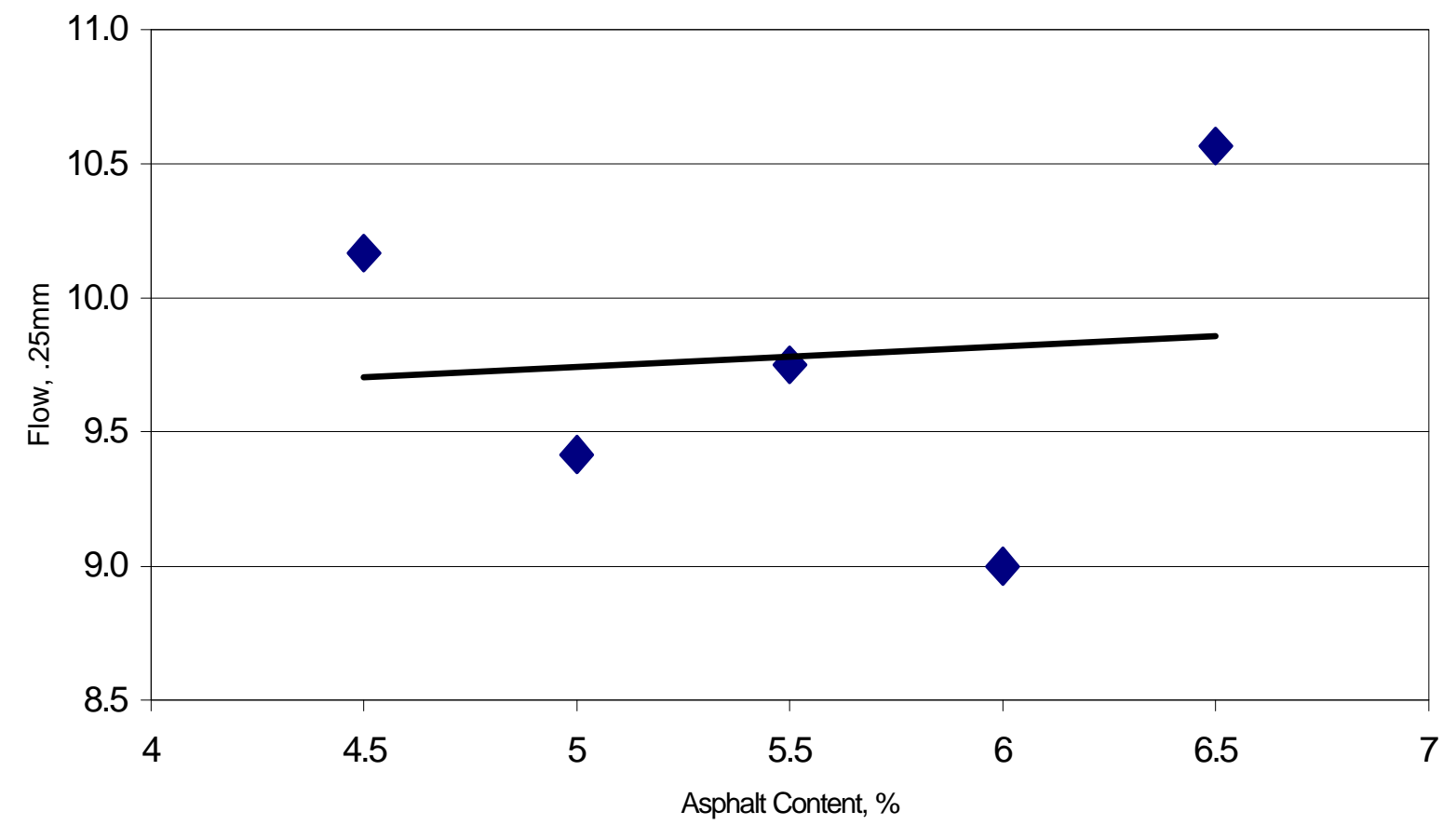

Figure D.15. Flow Versus Asphalt Content for Wearing 1

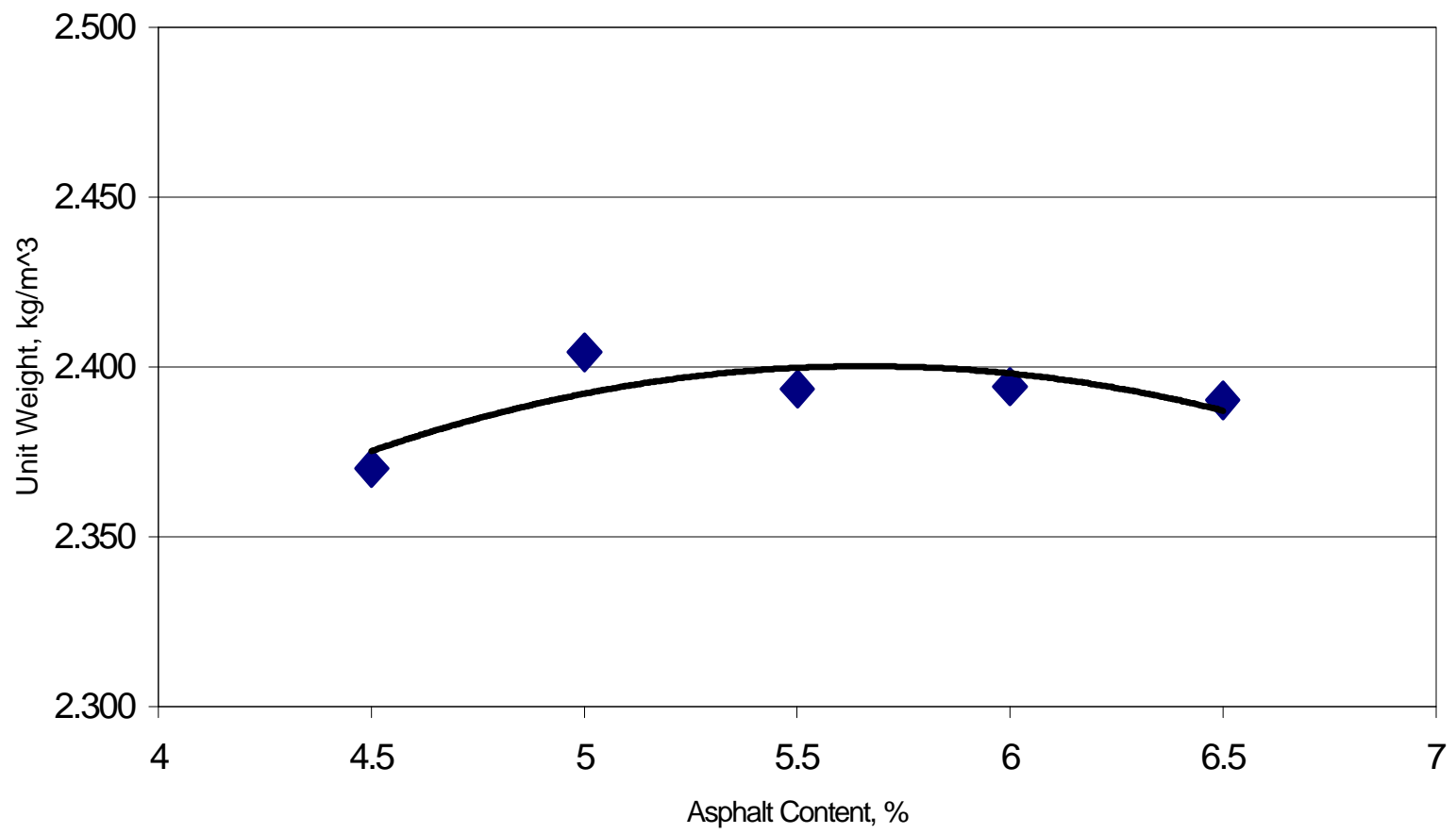

Figure D.16. Unit Weight Versus Asphalt Content for Wearing 1 


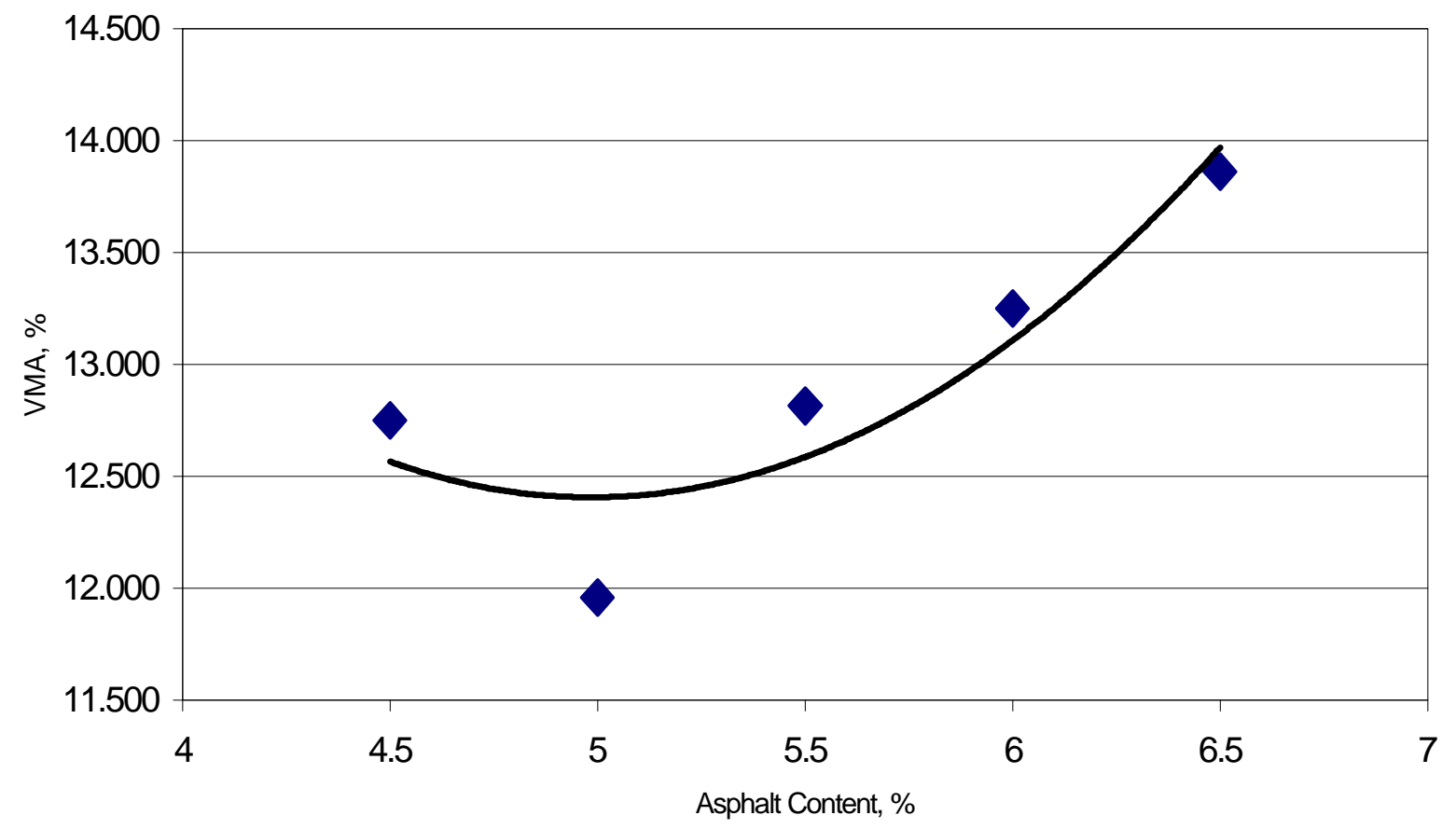

Figure D.17. Percent VMA Versus Asphalt Content for Wearing 1

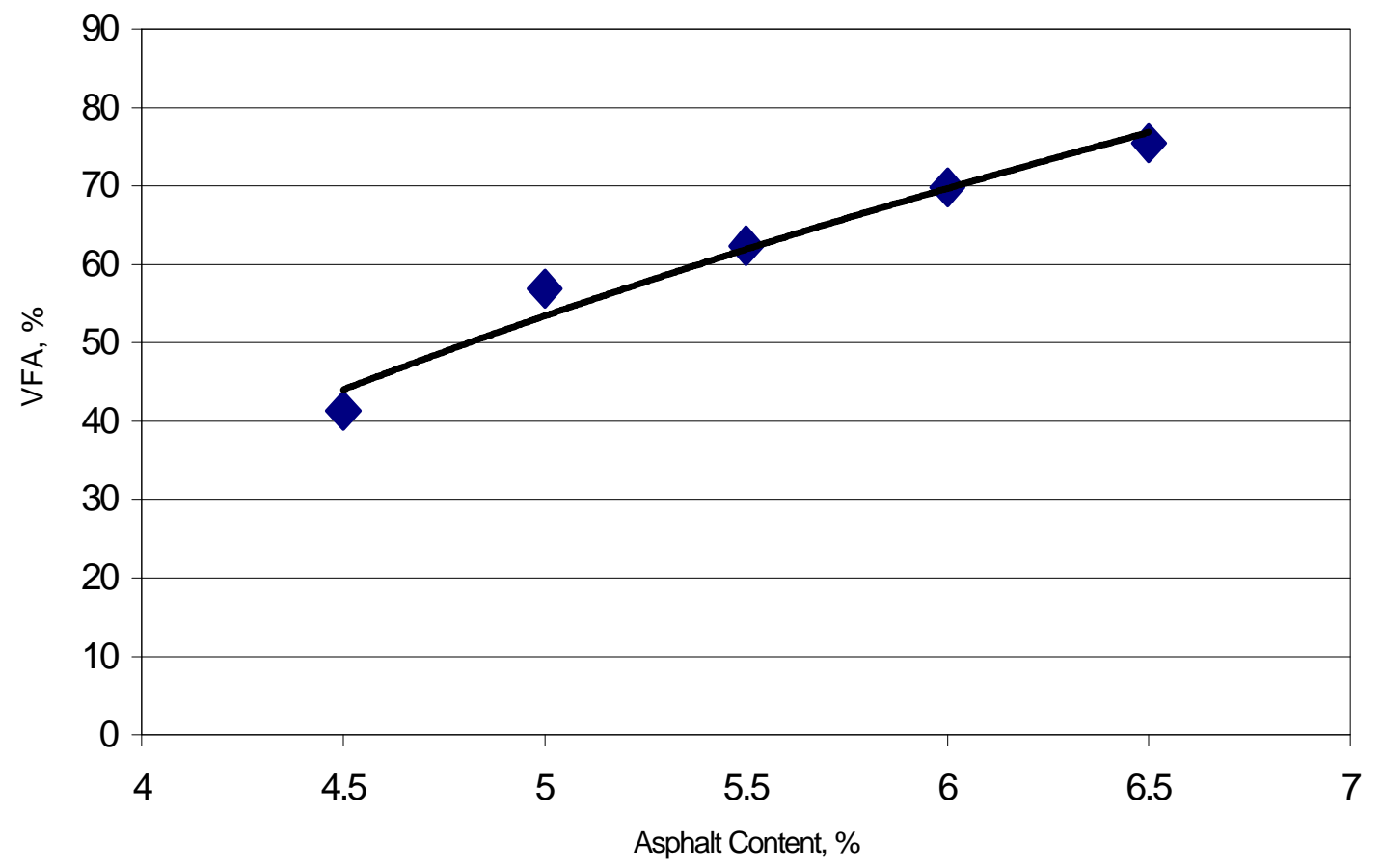

Figure D.18. Percent VFA Versus Asphalt Content for Wearing 1 
A PPENDIX E

\section{LABORATORY DATA}


Table E.1. Compacted Base 1 Samples Raw Data

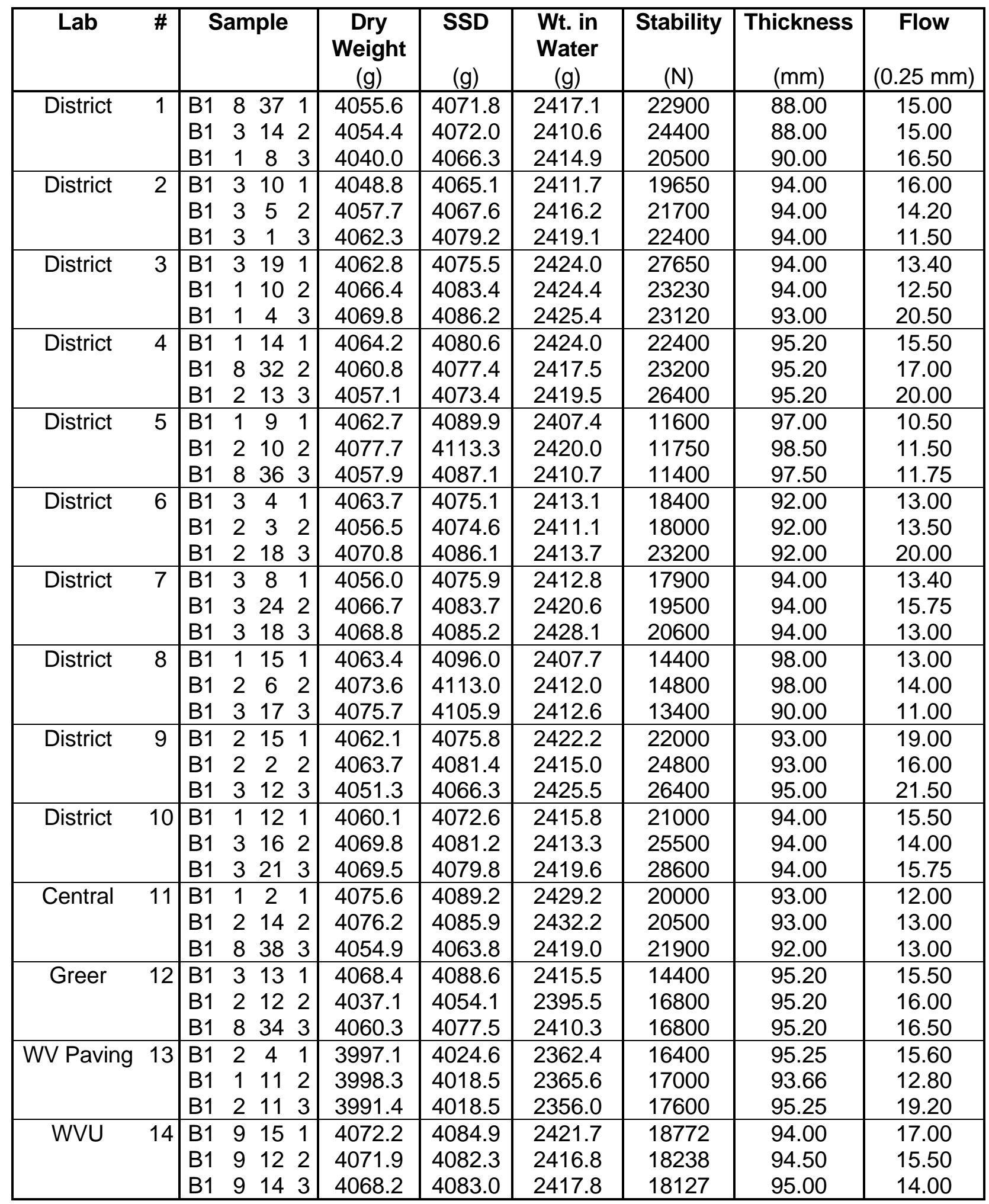


Table E.2. Compacted Base 2 Samples Raw Data

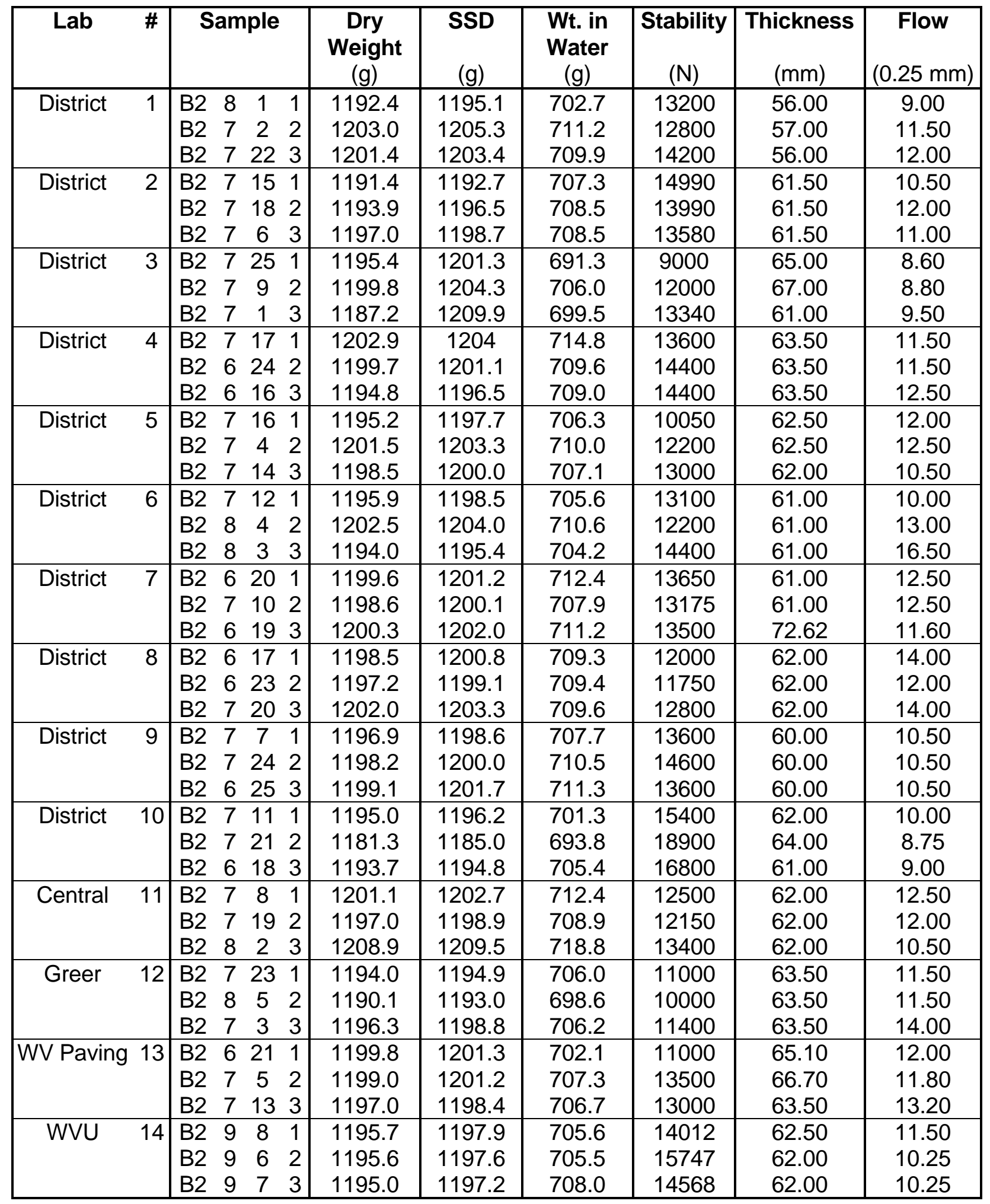


Table E.3. Compacted Wearing 1 Samples Raw Data

\begin{tabular}{|c|c|c|c|c|c|c|c|c|}
\hline Lab & $\#$ & Sample & $\begin{array}{c}\text { Dry } \\
\text { Weight } \\
(\mathrm{g})\end{array}$ & $\begin{array}{l}\text { SSD } \\
(\mathrm{g}) \\
\end{array}$ & $\begin{array}{l}\text { Wt. in } \\
\text { Water } \\
\text { (g) }\end{array}$ & $\begin{array}{c}\text { Stability } \\
(\mathrm{N})\end{array}$ & $\begin{array}{c}\text { Thickness } \\
(\mathrm{mm}) \\
\end{array}$ & $\begin{array}{c}\text { Flow } \\
(0.25 \mathrm{~mm}) \\
\end{array}$ \\
\hline District & 1 & \begin{tabular}{lccc|} 
W1 & 6 & 6 & 1 \\
W1 & 4 & 31 & 2 \\
W1 & 5 & 1 & 3
\end{tabular} & $\begin{array}{l}1191.6 \\
1202.1 \\
1203.5\end{array}$ & $\begin{array}{l}1193.3 \\
1203.4 \\
1204.8\end{array}$ & $\begin{array}{l}694.8 \\
700.4 \\
723.4\end{array}$ & $\begin{array}{l}13000 \\
12900 \\
13000\end{array}$ & $\begin{array}{l}57.00 \\
58.00 \\
57.00\end{array}$ & $\begin{array}{l}10.50 \\
8.50 \\
9.00\end{array}$ \\
\hline District & 2 & \begin{tabular}{cccc|} 
W1 & 4 & 10 & 1 \\
W1 & 5 & 9 & 2 \\
W1 & 6 & 2 & 3
\end{tabular} & $\begin{array}{l}1202.5 \\
1203.9 \\
1210.0\end{array}$ & $\begin{array}{l}1203.1 \\
1204.8 \\
1210.9\end{array}$ & $\begin{array}{l}704.1 \\
706.6 \\
706.0 \\
\end{array}$ & $\begin{array}{l}13200 \\
13400 \\
12620 \\
\end{array}$ & $\begin{array}{l}62.00 \\
62.00 \\
62.00\end{array}$ & $\begin{array}{c}9.40 \\
10.40 \\
9.00\end{array}$ \\
\hline District & 3 & $\begin{array}{llcl}\text { W1 } & 6 & 7 & 1 \\
\text { W1 } & 4 & 7 & 2 \\
\text { W1 } & 6 & 13 & 3\end{array}$ & $\begin{array}{l}1211.6 \\
1207.6 \\
1209.2\end{array}$ & $\begin{array}{l}1211.7 \\
1224.2 \\
1233.3\end{array}$ & $\begin{array}{l}701.7 \\
685.6 \\
687.7\end{array}$ & $\begin{array}{c}12380 \\
6020 \\
4770\end{array}$ & $\begin{array}{l}64.00 \\
64.00 \\
68.00\end{array}$ & $\begin{array}{l}12.40 \\
14.80 \\
12.60\end{array}$ \\
\hline District & 4 & $\begin{array}{cccc}\text { W1 } & 5 & 3 & 1 \\
\text { W1 } & 3 & 28 & 2 \\
\text { W1 } & 5 & 2 & 3\end{array}$ & $\begin{array}{l}1208.7 \\
1206.1 \\
1207.5\end{array}$ & $\begin{array}{l}1209.5 \\
1206.7 \\
1208.4\end{array}$ & $\begin{array}{l}707.7 \\
705.7 \\
706.1\end{array}$ & $\begin{array}{l}15200 \\
14000 \\
13800\end{array}$ & $\begin{array}{l}63.50 \\
63.50 \\
63.50\end{array}$ & $\begin{array}{l}10.00 \\
11.00 \\
11.50\end{array}$ \\
\hline District & 5 & \begin{tabular}{cccc|} 
W1 & 6 & 10 & 1 \\
W1 & 4 & 15 & 2 \\
W1 & 5 & 7 & 3
\end{tabular} & $\begin{array}{l}1197.0 \\
1208.9 \\
1210.4\end{array}$ & $\begin{array}{l}1198.0 \\
1209.8 \\
1211.3\end{array}$ & $\begin{array}{l}692.1 \\
700.1 \\
703.7 \\
\end{array}$ & $\begin{array}{l}11600 \\
11750 \\
11400 \\
\end{array}$ & $\begin{array}{l}63.50 \\
64.00 \\
64.00\end{array}$ & $\begin{array}{l}10.50 \\
11.50 \\
11.75 \\
\end{array}$ \\
\hline District & 6 & $\begin{array}{cccc}\text { W1 } & 4 & 6 & 1 \\
\text { W1 } & 4 & 4 & 2 \\
\text { W1 } & 4 & 12 & 3\end{array}$ & $\begin{array}{l}1210.3 \\
1206.8 \\
1205.2 \\
\end{array}$ & $\begin{array}{l}1211.4 \\
1208.0 \\
1206.1 \\
\end{array}$ & $\begin{array}{l}702.7 \\
699.5 \\
699.7 \\
\end{array}$ & $\begin{array}{l}12700 \\
12400 \\
12900 \\
\end{array}$ & $\begin{array}{l}63.00 \\
63.00 \\
62.00 \\
\end{array}$ & $\begin{array}{c}9.50 \\
11.50 \\
13.00 \\
\end{array}$ \\
\hline District & 7 & \begin{tabular}{cccc|} 
W1 & 4 & 5 & 1 \\
W1 & 4 & 19 & 2 \\
W1 & 4 & 25 & 3
\end{tabular} & $\begin{array}{l}1210.7 \\
1208.0 \\
1206.4\end{array}$ & $\begin{array}{l}1211.7 \\
1209.0 \\
1207.2\end{array}$ & $\begin{array}{l}707.2 \\
704.4 \\
705.5 \\
\end{array}$ & $\begin{array}{l}12400 \\
12300 \\
12050 \\
\end{array}$ & $\begin{array}{l}63.00 \\
63.00 \\
63.00\end{array}$ & $\begin{array}{l}18.50 \\
10.50 \\
10.00\end{array}$ \\
\hline District & 8 & \begin{tabular}{cccc|} 
W1 & 3 & 27 & 1 \\
W1 & 4 & 32 & 2 \\
W1 & 6 & 8 & 3
\end{tabular} & $\begin{array}{l}1208.9 \\
1209.6 \\
1212.7\end{array}$ & $\begin{array}{l}1210.5 \\
1210.9 \\
1214.0\end{array}$ & $\begin{array}{l}704.4 \\
702.6 \\
706.4\end{array}$ & $\begin{array}{l}11050 \\
11050 \\
11600\end{array}$ & $\begin{array}{l}63.50 \\
63.50 \\
63.50\end{array}$ & $\begin{array}{c}9.50 \\
9.50 \\
11.00\end{array}$ \\
\hline District & 9 & $\begin{array}{cccc}\text { W1 } & 4 & 28 & 1 \\
\text { W1 } & 6 & 5 & 2 \\
\text { W1 } & 4 & 33 & 3\end{array}$ & $\begin{array}{l}1207.3 \\
1208.3 \\
1209.8\end{array}$ & $\begin{array}{l}1208.1 \\
1209.2 \\
1210.5\end{array}$ & $\begin{array}{l}699.9 \\
703.7 \\
704.4\end{array}$ & $\begin{array}{l}13000 \\
12600 \\
14000\end{array}$ & $\begin{array}{l}60.20 \\
60.20 \\
60.20\end{array}$ & $\begin{array}{c}9.50 \\
9.50 \\
10.50\end{array}$ \\
\hline District & 10 & \begin{tabular}{llll|} 
W1 & 6 & 15 & 1 \\
W1 & 4 & 14 & 2 \\
W1 & 4 & 23 & 3
\end{tabular} & $\begin{array}{l}1202.1 \\
1202.6 \\
1210.4\end{array}$ & $\begin{array}{l}1203.3 \\
1203.9 \\
1211.6\end{array}$ & $\begin{array}{l}694.4 \\
695.6 \\
698.4 \\
\end{array}$ & $\begin{array}{l}15600 \\
15400 \\
17200 \\
\end{array}$ & $\begin{array}{l}64.00 \\
64.00 \\
64.00\end{array}$ & $\begin{array}{c}8.75 \\
10.00 \\
10.00\end{array}$ \\
\hline Central & 11 & \begin{tabular}{cccc|} 
W1 & 4 & 2 & 1 \\
W1 & 4 & 17 & 2 \\
W1 & 5 & 12 & 3
\end{tabular} & $\begin{array}{l}1212.5 \\
1208.1 \\
1209.4\end{array}$ & $\begin{array}{l}1213.3 \\
1208.7 \\
1209.9\end{array}$ & $\begin{array}{l}707.3 \\
705.9 \\
707.9\end{array}$ & $\begin{array}{l}12800 \\
12100 \\
12600\end{array}$ & $\begin{array}{l}63.00 \\
63.00 \\
63.00\end{array}$ & $\begin{array}{l}10.50 \\
10.00 \\
10.50\end{array}$ \\
\hline Greer & 12 & \begin{tabular}{cccc|} 
W1 & 4 & 8 & 1 \\
W1 & 4 & 13 & 2 \\
W1 & 4 & 30 & 3
\end{tabular} & $\begin{array}{l}1201.9 \\
1204.3 \\
1205.7\end{array}$ & $\begin{array}{l}1202.4 \\
1205.1 \\
1206.7\end{array}$ & $\begin{array}{l}698.3 \\
701.3 \\
704.4 \\
\end{array}$ & $\begin{array}{l}12200 \\
11800 \\
11600 \\
\end{array}$ & $\begin{array}{l}63.50 \\
63.50 \\
63.50 \\
\end{array}$ & $\begin{array}{c}10.00 \\
9.50 \\
8.50\end{array}$ \\
\hline WV Paving & 13 & $\begin{array}{cccc}\text { W1 } & 5 & 13 & 1 \\
\text { W1 } & 4 & 21 & 2 \\
\text { W1 } & 5 & 4 & 3\end{array}$ & $\begin{array}{l}1206.9 \\
1208.5 \\
1205.2\end{array}$ & $\begin{array}{l}1208.8 \\
1209.7 \\
1207.0\end{array}$ & $\begin{array}{l}695.1 \\
699.2 \\
693.3 \\
\end{array}$ & $\begin{array}{l}10400 \\
10750 \\
11200\end{array}$ & $\begin{array}{l}66.70 \\
65.10 \\
66.70\end{array}$ & $\begin{array}{l}13.90 \\
12.80 \\
13.40\end{array}$ \\
\hline WVU & 14 & $\begin{array}{llll}\text { W1 } & 9 & 3 & 1 \\
\text { W1 } & 9 & 2 & 2 \\
\text { W1 } & 9 & 5 & 3\end{array}$ & $\begin{array}{l}1200.0 \\
1203.8 \\
1208.3\end{array}$ & $\begin{array}{l}1200.4 \\
1204.9 \\
1209.0\end{array}$ & $\begin{array}{l}702.5 \\
702.1 \\
706.5\end{array}$ & $\begin{array}{l}14457 \\
13678 \\
13789\end{array}$ & $\begin{array}{l}62.00 \\
63.50 \\
63.00\end{array}$ & $\begin{array}{l}10.00 \\
9.50 \\
9.50\end{array}$ \\
\hline
\end{tabular}


Table E.4. Base 1 Rice Samples Raw Data

\begin{tabular}{|c|c|c|c|c|c|c|c|c|}
\hline Lab & \# & \multicolumn{4}{|c|}{ Sample } & $\begin{array}{c}\text { Dry Weight } \\
\text { (g) }\end{array}$ & $\begin{array}{c}\text { Asphalt+Pycnometer } \\
+ \text { Water } \\
\text { (g) }\end{array}$ & $\begin{array}{c}\text { Pycnometer+Water } \\
\text { (g) }\end{array}$ \\
\hline District & 1 & \begin{tabular}{|l} 
B1R \\
B1R
\end{tabular} & $\begin{array}{l}2 \\
3\end{array}$ & $\begin{array}{l}20 \\
25\end{array}$ & $\begin{array}{l}1 \\
2\end{array}$ & $\begin{array}{l}4090.4 \\
4067.2\end{array}$ & $\begin{array}{l}3926.7 \\
3909.1\end{array}$ & $\begin{array}{l}1433.8 \\
1433.8\end{array}$ \\
\hline District & 2 & $\begin{array}{l}\text { B1R } \\
\text { B1R }\end{array}$ & $\begin{array}{l}1 \\
2\end{array}$ & $\begin{array}{l}1 \\
5\end{array}$ & $\begin{array}{l}2 \\
1\end{array}$ & $\begin{array}{l}4064.1 \\
4068.5\end{array}$ & $\begin{array}{l}3839.7 \\
3842.5\end{array}$ & $\begin{array}{l}1359.8 \\
1359.8\end{array}$ \\
\hline District & 3 & $\begin{array}{l}\text { B1R } \\
\text { B1R }\end{array}$ & 1 & 11 & 1 & $\begin{array}{l}2013.3 \\
2067.7 \\
2209.7 \\
1870.7\end{array}$ & $\begin{array}{l}2654.9 \\
2690.4 \\
2773.1 \\
2574.1\end{array}$ & $\begin{array}{l}1429.3 \\
1429.3 \\
1429.3 \\
1429.3\end{array}$ \\
\hline District & 4 & \begin{tabular}{|l|} 
B1R \\
B1R
\end{tabular} & $\begin{array}{l}3 \\
8\end{array}$ & $\begin{array}{c}6 \\
33\end{array}$ & $\begin{array}{l}2 \\
1\end{array}$ & $\begin{array}{l}4014.4 \\
4006.6\end{array}$ & $\begin{array}{l}3842.6 \\
3838.2\end{array}$ & $\begin{array}{l}1396.6 \\
1396.6\end{array}$ \\
\hline District & 5 & $\begin{array}{l}\text { B1R } \\
\text { B1R }\end{array}$ & 1 & 35 & 1 & $\begin{array}{l}2251.6 \\
1821.2 \\
2347.5 \\
1734.2\end{array}$ & $\begin{array}{c}2760.1 \\
2497.7 \\
22821.4 \\
2494.6\end{array}$ & $\begin{array}{l}1386.1 \\
1386.1 \\
1386.1 \\
1386.1\end{array}$ \\
\hline District & 6 & $\begin{array}{l}\text { B1R } \\
\text { B1R }\end{array}$ & $\begin{array}{l}2 \\
2\end{array}$ & $\begin{array}{c}8 \\
19\end{array}$ & $\begin{array}{l}1 \\
2\end{array}$ & $\begin{array}{l}4064.1 \\
4070.9\end{array}$ & $\begin{array}{l}3864.2 \\
3870.3\end{array}$ & $\begin{array}{l}1387.2 \\
1387.2\end{array}$ \\
\hline District & 7 & \begin{tabular}{|l} 
B1R \\
B1R
\end{tabular} & $\begin{array}{l}2 \\
3\end{array}$ & $\begin{array}{l}7 \\
7\end{array}$ & $\begin{array}{l}2 \\
1\end{array}$ & $\begin{array}{l}4063.3 \\
4004.7\end{array}$ & $\begin{array}{l}3865.2 \\
3821.6\end{array}$ & $\begin{array}{l}1388.6 \\
1388.6\end{array}$ \\
\hline District & 8 & \begin{tabular}{|l} 
B1R \\
B1R
\end{tabular} & $\begin{array}{l}2 \\
3\end{array}$ & $\begin{array}{c}9 \\
22\end{array}$ & $\begin{array}{l}1 \\
2\end{array}$ & $\begin{array}{l}4089.5 \\
4094.1\end{array}$ & $\begin{array}{l}5229.5 \\
5230.4\end{array}$ & $\begin{array}{l}2735.0 \\
2735.0\end{array}$ \\
\hline District & 9 & $\begin{array}{l}\text { B1R } \\
\text { B1R }\end{array}$ & $\begin{array}{l}2 \\
3\end{array}$ & $\begin{array}{l}17 \\
15\end{array}$ & $\begin{array}{l}2 \\
1\end{array}$ & $\begin{array}{l}4061.0 \\
4075.1\end{array}$ & $\begin{array}{l}5289.7 \\
5298.6\end{array}$ & $\begin{array}{l}2812.4 \\
2812.4\end{array}$ \\
\hline District & 10 & $\begin{array}{l}\text { B1R } \\
\text { B1R } \\
\end{array}$ & $\begin{array}{l}3 \\
3\end{array}$ & $\begin{array}{l}2 \\
3 \\
\end{array}$ & $\begin{array}{l}1 \\
2 \\
\end{array}$ & $\begin{array}{l}4066.4 \\
4074.8 \\
\end{array}$ & $\begin{array}{l}3880.6 \\
3885.3 \\
\end{array}$ & $\begin{array}{l}1402.6 \\
1402.6 \\
\end{array}$ \\
\hline Central & 11 & $\begin{array}{l}\text { B1R } \\
\text { B1R } \\
\end{array}$ & $\begin{array}{l}1 \\
2 \\
\end{array}$ & $\begin{array}{l}3 \\
1 \\
\end{array}$ & $\begin{array}{l}1 \\
2 \\
\end{array}$ & $\begin{array}{l}4083.6 \\
4074.4 \\
\end{array}$ & $\begin{array}{l}3809.7 \\
3805.9 \\
\end{array}$ & $\begin{array}{l}1321.5 \\
1321.5 \\
\end{array}$ \\
\hline Greer & 12 & $\begin{array}{l}\text { B1R } \\
\text { B1R }\end{array}$ & $\begin{array}{l}1 \\
3\end{array}$ & $\begin{array}{l}5 \\
9\end{array}$ & $\begin{array}{l}1 \\
2\end{array}$ & $\begin{array}{l}4058.7 \\
4081.8\end{array}$ & $\begin{array}{l}3828.4 \\
3843.9\end{array}$ & $\begin{array}{l}1355.7 \\
1355.7\end{array}$ \\
\hline WV Paving & 13 & $\begin{array}{l}\text { B1R } \\
\text { B1R }\end{array}$ & $\begin{array}{l}1 \\
3\end{array}$ & $\begin{array}{l}13 \\
23\end{array}$ & $\begin{array}{l}2 \\
1\end{array}$ & $\begin{array}{l}4039.7 \\
4061.6\end{array}$ & $\begin{array}{l}5454.4 \\
5466.9\end{array}$ & $\begin{array}{l}2988.8 \\
2988.8\end{array}$ \\
\hline WVU & 14 & $\begin{array}{l}\text { B1R } \\
\text { B1R }\end{array}$ & $\begin{array}{l}9 \\
9\end{array}$ & $\begin{array}{l}11 \\
13\end{array}$ & $\begin{array}{l}1 \\
2\end{array}$ & $\begin{array}{l}4061.1 \\
4087.1\end{array}$ & $\begin{array}{l}9956.2 \\
9970.8\end{array}$ & $\begin{array}{l}7480.2 \\
7480.2\end{array}$ \\
\hline
\end{tabular}


Table E.5. Base 2 Rice Samples Raw Data

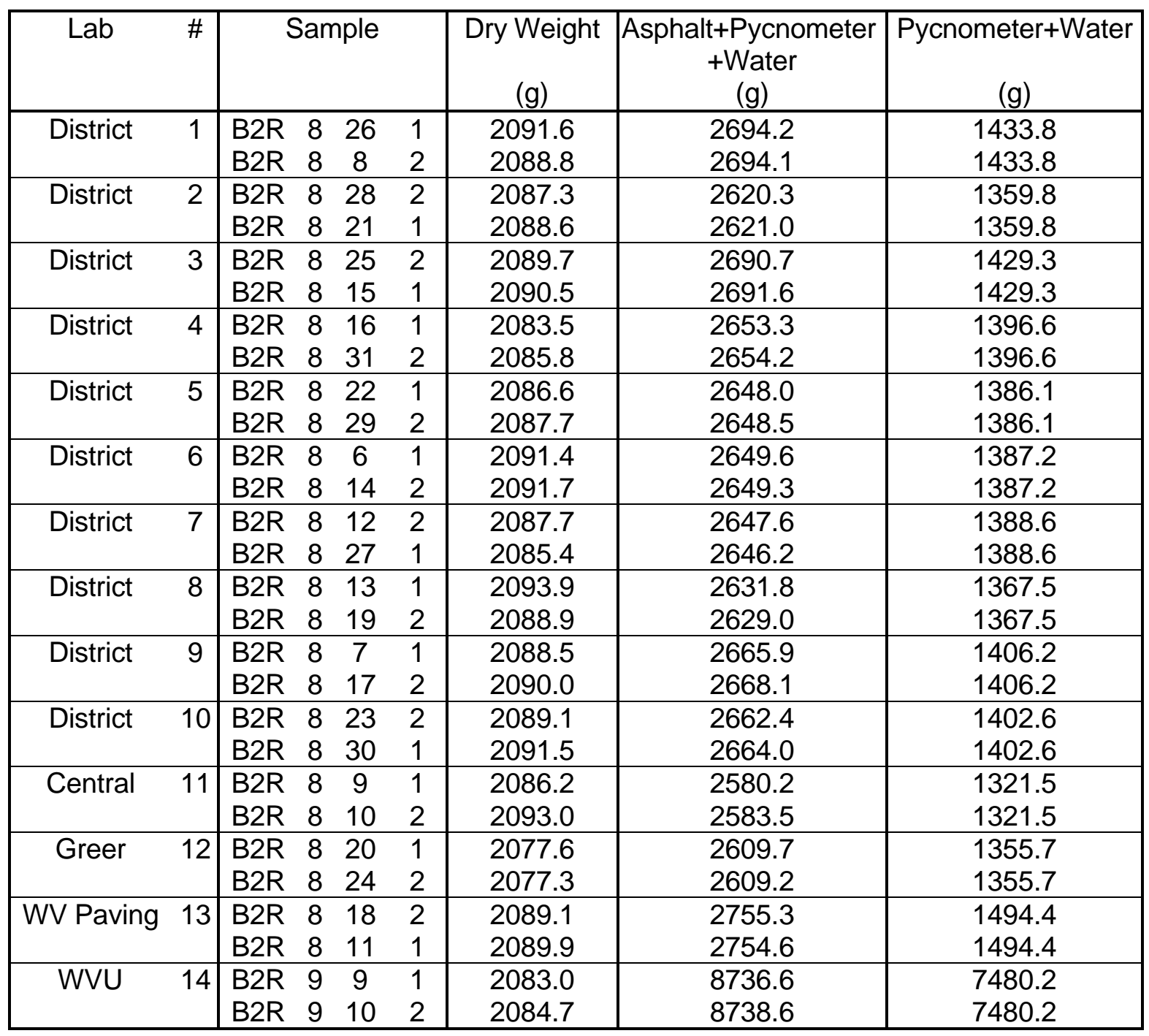


Table E.6. Compacted Wearing 1 Rice Samples Raw Data

\begin{tabular}{|c|c|c|c|c|c|c|c|c|}
\hline Lab & $\#$ & & San & & & $\begin{array}{c}\text { Dry Weight } \\
(\mathrm{g}) \\
\end{array}$ & $\begin{array}{c}\text { Asphalt+Pycnometer } \\
\text { +Water } \\
(\mathrm{g})\end{array}$ & $\begin{array}{c}\text { Pycnometer+Water } \\
(\mathrm{g}) \\
\end{array}$ \\
\hline District & 1 & W1R & 5 & 11 & 1 & 1200.5 & 1430.1 & 1433.8 \\
\hline & & W1R & 4 & 29 & 2 & 1218.0 & 1449.1 & 1433.8 \\
\hline District & 2 & W1R & 5 & 15 & 2 & 1211.3 & 2084.8 & 1359.8 \\
\hline & & W1R & 6 & 9 & 1 & 1212.2 & 2085.1 & 1359.8 \\
\hline District & 3 & W1R & 4 & 3 & 1 & 1211.6 & 2153.3 & 1429.3 \\
\hline & & W1R & 4 & 18 & 2 & 1219.8 & 2158.1 & 1429.3 \\
\hline District & 4 & W1R & 6 & 4 & 2 & 1211.4 & 2120.3 & 1396.6 \\
\hline & & W1R & 6 & 12 & 1 & 1216.0 & 2122.0 & 1396.6 \\
\hline District & 5 & W1R & 4 & 26 & 1 & 1213.3 & 2112.9 & 1386.1 \\
\hline & & W1R & 5 & 8 & 1 & 1209.7 & 2110.7 & 1386.1 \\
\hline District & 6 & W1R & 4 & 24 & 1 & 1212.0 & 2111.2 & 1387.2 \\
\hline & & W1R & 5 & 5 & 2 & 1214.8 & 2113.1 & 1387.2 \\
\hline District & 7 & W1R & 6 & 11 & 2 & 1213.1 & 2111.6 & 1388.6 \\
\hline & & W1R & 3 & 26 & 1 & 1216.8 & 2112.7 & 1388.6 \\
\hline District & 8 & W1R & 6 & 14 & 2 & 1213.2 & 2092.7 & 1367.5 \\
\hline & & W1R & 4 & 20 & 1 & 1213.9 & 2093.0 & 1367.5 \\
\hline District & 9 & W1R & 4 & 11 & 2 & 1212.4 & 2130.5 & 1406.2 \\
\hline & & W1R & 4 & 9 & 1 & 1215.7 & 2132.7 & 1406.2 \\
\hline District & 10 & W1R & 6 & 3 & 2 & 1211.4 & 2125.9 & 1402.6 \\
\hline & & W1R & 5 & 14 & 1 & 1212.6 & 2125.8 & 1402.6 \\
\hline Central & 11 & W1R & 6 & 1 & 2 & 1211.2 & 2045.7 & 1321.5 \\
\hline & & W1R & 5 & 6 & 1 & 1209.0 & 2045.4 & 1321.5 \\
\hline Greer & 12 & W1R & 4 & 22 & 1 & 1204.5 & 2074.7 & 1355.7 \\
\hline & & W1R & 4 & 1 & 2 & 1207.7 & 2076.8 & 1355.7 \\
\hline WV Paving & 13 & W1R & 4 & 16 & 1 & 1201.8 & 2212.9 & 1494.4 \\
\hline & & W1R & 5 & 10 & 2 & 1211.6 & 2217.6 & 1494.4 \\
\hline WVU & 14 & W1R & 9 & 1 & 1 & 1212.8 & 8206.4 & 7480.2 \\
\hline & & W1R & 9 & 4 & 2 & 1210.2 & 8204.1 & 7480.2 \\
\hline
\end{tabular}


Table E.7. Q uestionnaire Results

\begin{tabular}{|c|c|c|c|c|c|c|c|}
\hline & $\begin{array}{c}\text { Experienc } \\
e \\
(\mathrm{Yrs})\end{array}$ & $\begin{array}{c}\text { Oven } \\
\text { Temp. }\left({ }^{\circ} \mathrm{C}\right)\end{array}$ & $\begin{array}{l}\text { Hammer } \\
\text { Calibrated }\end{array}$ & $\begin{array}{c}\text { Calibration } \\
\text { Verified }\end{array}$ & $\begin{array}{c}\text { Marshall Hammer } \\
\text { Brand }\end{array}$ & $\begin{array}{c}\text { Marshall Stability } \\
\text { Brand }\end{array}$ & $\begin{array}{l}\text { Hammer Calibrated } \\
\text { to Manual Hammer }\end{array}$ \\
\hline District 1 & 1 & 148.9 & Jun-90 & May-98 & Pine Inst. & Pine Inst. & No \\
\hline District 2 & 0.25 & 148.9 & Apr-98 & May-98 & Pine Inst. & Pine Inst. & No \\
\hline District 3 & 20 & 157.2 & Apr-98 & Apr-98 & Pine Inst. & Pine Inst. & No \\
\hline District 4 & 8 & 155.0 & - & - & Pine Inst. & Pine Inst. & No \\
\hline District 5 & 3 & 145.0 & Jun-91 & Jun-98 & Pine Inst. & Pine Inst. & No \\
\hline District 6 & 12 & 148.9 & Jun-90 & Jun-98 & Pine Inst. & Pine Inst. & No \\
\hline District 7 & 7 & 145.0 & - & Jul-98 & Pine Inst. & Pine Inst. & No \\
\hline District 8 & 10 & 145.0 & Apr-98 & Apr-98 & Pine Inst. & Pine Inst. & No \\
\hline District 9 & 0.667 & 144.4 & Aug-90 & Nov-97 & Pine Inst. & Pine Inst. & No \\
\hline District 10 & - & - & - & - & - & - & No \\
\hline \begin{tabular}{c|c} 
Central & Base 1 \\
& Base 2 \\
Wearing \\
1
\end{tabular} & $\begin{array}{l}8 \\
8 \\
8\end{array}$ & $\begin{array}{l}144.0 \\
142.0 \\
146.0\end{array}$ & - & Mar-98 & Pine Inst. & Pine Inst. & Yes - 75 Blows \\
\hline Greer & 20 & 146.0 & Mar-98 & Mar-98 & Pine Inst. & Pine Inst. & No \\
\hline WV Paving & 5 & 154.4 & Jul-95 & Mar-98 & Pine Inst. & Pine Inst. & No \\
\hline WVU & 1 & 147 & Jun-91 & May-98 & Pine Inst. & Pine Inst. & No \\
\hline
\end{tabular}


A PPE NDIX F

LABORATORY INSTRUCTIONS, QUESTIONNAIRE AND DATA SHEETS 


\title{
JOHN P. ZANIEWSKI
}

\author{
West Virginia University \\ P.0. Box 6103 \\ Morgantown, WV. 26506 \\ (304) 293-3031 ext. 648
}

District

Even though the SUPERPAVE procedures will eventually replace the Marshall procedure for mix design and quality control the West Virginia D OH will continue to use the Marshall method in the interim. For quality control, the inter-laboratory precision and variance in the Marshall method need to be quantified for statistical based quality control methods. WVU has a DOH contract to assist with measuring variability in the Marshall method. This requires several labs to test identical samples.

All ten West Virginia D OH district laboratories will participate in the study to provide the most reliable results possible. In addition, the headquarters, the WVU laboratory, and two contractors will participate in the study. Each laboratory will test samples of Wearing 1, Base 1 and Base 2. The Wearing 1 and Base 2 will be compacted in 4-inch molds and Base 1 will be compacted in 6-inch molds. One test will be run at each laboratory consisting of three samples each for the stability, flow, and bulk specific gravity procedures. For maximum theoretical specific gravity two samples will be used.

One person with practiced knowledge of Marshall testing procedures must be designated to do all testing at each lab. All tests for each asphalt concrete type should be performed in a single day. All tests should be performed according to standard West Virginia DOH/AASHTO testing procedures. If testing procedures are properly followed but unusual results are found the test is not to be re-run. Record the actual data.

The compaction temperature for all of the samples is $142-157^{\circ} \mathrm{C}\left(287.6-296.6^{\circ} \mathrm{F}\right)$. Each sample is coded with a number. The first two digits signifies which mix type the container holds: Base $1=\mathrm{B} 1$, Base $2=\mathrm{B} 2$, and Wearing $1=\mathrm{W} 1$. The following digit signifies which day the mix was fabricated and the next two digits signify the order at which the mix was made that day. For Base 2 mixes, two of the containers have an "R" written on them. The maximum theoretical specific gravity test should be performed on these specimens and the other three should be compacted. For Wearing 1 and Base 1 the two samples chosen for the maximum theoretical specific gravity test and three samples chosen for compaction should be randomly selected.

Please fill out the questionnaire attached to this sheet and record all data on the attached form. We will do all calculations. Once all testing has been completed and data has been recorded, photocopy each worksheet, graph and questionnaire, then fax them to John Zaniewski at (304) 293-7109 and send the original to the above address. 
Your participation in this study is greatly appreciated. If there are any questions or comments about the study please feel free to call me or the inter-laboratory study coondinator, Mike Hughes at (304) 293-3031 ext. 383.

Thank you again for your participation.

\author{
Sincerely, \\ John P. Zaniewski \\ West Virginia University
}




\section{QUESTIONNAIRE}

Please supply an answer for each question.

Name of technician performing tests:

Job Title:

Years of Marshall test experience?

When was the last time the Marshall Stability and Flow apparatus was calibrated?

When was the last time the Marshall Stability and Flow apparatus calibration was verified?

What is the brand name of the Marshall Stability and Flow apparatus?

What is the brand name of the Marshall Hammer?

Has the Marshall Hammer ever been correlated to the manual compaction hammer?

If yes, when, and how many blows is the automatic hammer set at?

At what temperature was the oven set to reheat the samples?

How long were the samples heated in the oven?

Base 1 Compacted:

Base 1 Rice:

Base 2 compacted:

Base 2 Rice:

Wearing 1 Compacted:

Wearing 1 Rice: 


\section{West Virginia University \\ Marshall Variability Study}

Lab

Technician:

Date

Completed:

\section{Base 1}

\section{Maximum Theoretical Specific}

Gravity (AASHTO T-209)

\begin{tabular}{|l|l|l|l|}
\hline Sample No: & & Sample No: & \\
\hline Sample Weight & & Sample Weight & \\
\hline Pycnometer+Sample+Water & & Pycnometer+Sample+Water & \\
\hline Pycnometer+Water & & Pycnometer+Water & \\
\hline
\end{tabular}

Bulk Specific Gravity (AASHTO

T-166)

\begin{tabular}{|l|l|l|l|}
\hline Specimen No.: & & & \\
\hline Weight in Air & & & \\
\hline Saturated Surface Dry Weight & & & \\
\hline Weight in Water & & & \\
\hline
\end{tabular}

\section{Marshall Stability and Flow}

(AASHTO T-245)

\begin{tabular}{|l|l|l|l|}
\hline Specimen Thickness (mm) & & & \\
\hline Measured Stability (N) & & & \\
\hline Flow $(0.25 \mathrm{~mm})$ & & & \\
\hline
\end{tabular}




\section{West Virginia University \\ Marshall Variability Study}

Lab

Technician:

Date Completed:

\section{Base 2}

\section{Maximum Theoretical Specific}

Gravity (AASHTO T-209)

\begin{tabular}{|l|l|l|l|}
\hline Sample No: & & Sample No: & \\
\hline Sample Weight & & Sample Weight & \\
\hline Pycnometer+Sample+Water & & Pycnometer+Sample+Water & \\
\hline Pycnometer+Water & & Pycnometer+Water & \\
\hline
\end{tabular}

Bulk Specific Gravity (AASHTO

T-166)

\begin{tabular}{|l|l|l|l|}
\hline Specimen No.: & & & \\
\hline Weight in Air & & & \\
\hline Saturated Surface Dry Weight & & & \\
\hline Weight in Water & & & \\
\hline
\end{tabular}

\section{Marshall Stability and Flow}

(AASHTO T-245)

\begin{tabular}{|l|l|l|l|}
\hline Specimen Thickness (mm) & & & \\
\hline Measured Stability (N) & & & \\
\hline Flow $(0.25 \mathrm{~mm})$ & & & \\
\hline
\end{tabular}




\section{West Virginia University \\ Marshall Variability Study}

Lab

Technician:

Date Completed:

\section{Wearing 1}

\section{Maximum Theoretical Specific}

Gravity (AASHTO T-209)

\begin{tabular}{|l|l|l|l|}
\hline Sample No: & & Sample No: & \\
\hline Sample Weight & & Sample Weight & \\
\hline Pycnometer+Sample+Water & & Pycnometer+Sample+Water & \\
\hline Pycnometer+Water & & Pycnometer+Water & \\
\hline
\end{tabular}

Bulk Specific Gravity (AASHTO

T-166)

\begin{tabular}{|l|l|l|l|}
\hline Specimen No.: & & & \\
\hline Weight in Air & & & \\
\hline Saturated Surface Dry Weight & & & \\
\hline Weight in Water & & & \\
\hline
\end{tabular}

\section{Marshall Stability and Flow}

(AASHTO T-245)

\begin{tabular}{|l|l|l|l|}
\hline Specimen Thickness (mm) & & & \\
\hline Measured Stability (N) & & & \\
\hline Flow $(0.25 \mathrm{~mm})$ & & & \\
\hline
\end{tabular}


A PPENDIX G

\section{VARIABILITY ANALYSIS TABLES}


Table G.1. Base 1, Rice, Within-Laboratory Average and Variance

\begin{tabular}{|cc|c|c|c|c|}
\hline Laboratory & $\#$ & Sample 1 & Sample 2 & Average & $\begin{array}{c}\text { Within-Laboratory } \\
\text { Variance }\end{array}$ \\
\hline District & 1 & 2.561 & 2.555 & 2.558 & 0.0000155 \\
District & 2 & 2.565 & 2.566 & 2.565 & 0.0000000 \\
District & 3 & 2.557 & 2.554 & 2.556 & 0.0000045 \\
District & 4 & 2.560 & 2.560 & 2.560 & 0.0000002 \\
District & 5 & 2.566 & 2.602 & 2.584 & 0.0006452 \\
District & 6 & 2.561 & 2.564 & 2.562 & 0.0000050 \\
District & 7 & 2.561 & 2.548 & 2.554 & 0.0000825 \\
District & 8 & 2.564 & 2.561 & 2.562 & 0.0000047 \\
District & 9 & 2.564 & 2.565 & 2.564 & 0.0000001 \\
District & 10 & 2.560 & 2.559 & 2.560 & 0.0000002 \\
Central & 11 & 2.560 & 2.563 & 2.561 & 0.0000042 \\
Greer & 12 & 2.559 & 2.561 & 2.560 & 0.0000026 \\
WV Paving & 13 & 2.566 & 2.565 & 2.566 & 0.0000010 \\
WVU & 14 & 2.562 & 2.560 & 2.561 & 0.0000020 \\
\hline
\end{tabular}

Table G.2. Base 2, Rice, Within-Laboratory Average and Variance

\begin{tabular}{|c|c|c|c|c|c|}
\hline \multicolumn{2}{|l|}{ Laboratory } & Sample 1 & Sample 2 & Average & $\begin{array}{l}\text { Within-Laboratory } \\
\text { Variance }\end{array}$ \\
\hline District & $\overline{1}$ & 2.516 & 2.521 & 2.519 & 0.0000058 \\
\hline & 2 & 2.525 & 2.524 & 2.524 & 0.0000000 \\
\hline & 3 & 2.523 & 2.524 & 2.524 & 0.0000004 \\
\hline & 4 & 2.520 & 2.518 & 2.519 & 0.0000005 \\
\hline & 5 & 2.530 & 2.530 & 2.530 & 0.0000001 \\
\hline & 6 & 2.523 & 2.521 & 2.522 & 0.0000005 \\
\hline & 7 & 2.519 & 2.519 & 2.519 & 0.0000000 \\
\hline & 8 & 2.524 & 2.525 & 2.524 & 0.0000001 \\
\hline & 9 & 2.520 & 2.524 & 2.522 & 0.0000039 \\
\hline & 10 & 2.519 & 2.520 & 2.519 & 0.0000001 \\
\hline Central & 11 & 2.521 & 2.519 & 2.520 & 0.0000015 \\
\hline Greer & 12 & 2.523 & 2.522 & 2.522 & 0.0000002 \\
\hline WV Paving & 13 & 2.522 & 2.519 & 2.521 & 0.0000032 \\
\hline WVU & 14 & 2.520 & 2.523 & 2.521 & 0.0000022 \\
\hline
\end{tabular}


Table G.3. Wearing 1, Rice, Within-Laboratory Average and Variance

\begin{tabular}{|cc|c|c|c|c|}
\hline Laboratory & & Sample 1 & Sample 2 & Average & $\begin{array}{c}\text { Within-Laboratory } \\
\text { Variance }\end{array}$ \\
\hline District & 2 & 2.491 & 2.490 & 2.490 & 0.0000004 \\
District & 3 & 2.485 & 2.484 & 2.485 & 0.0000001 \\
District & 4 & 2.484 & 2.479 & 2.481 & 0.0000070 \\
District & 5 & 2.494 & 2.494 & 2.494 & 0.0000000 \\
District & 6 & 2.484 & 2.485 & 2.484 & 0.0000003 \\
District & 7 & 2.475 & 2.470 & 2.472 & 0.0000077 \\
District & 8 & 2.486 & 2.485 & 2.486 & 0.0000001 \\
District & 9 & 2.484 & 2.485 & 2.484 & 0.0000003 \\
District & 10 & 2.482 & 2.478 & 2.480 & 0.0000043 \\
Central & 11 & 2.487 & 2.492 & 2.490 & 0.0000068 \\
Greer & 12 & 2.481 & 2.482 & 2.481 & 0.0000002 \\
WV Paving & 13 & 2.487 & 2.481 & 2.484 & 0.0000087 \\
WVU & 14 & 2.492 & 2.489 & 2.490 & 0.0000036 \\
\hline
\end{tabular}

Table G.4. Base 1, Stability, Within-Laboratory Average and Variance

\begin{tabular}{|cc|c|c|c|c|c|}
\hline Laboratory & & $\begin{array}{c}\text { Sample 1 } \\
(\mathrm{N})\end{array}$ & $\begin{array}{c}\text { Sample 2 } \\
(\mathrm{N})\end{array}$ & $\begin{array}{c}\text { Sample 3 } \\
(\mathrm{N})\end{array}$ & $\begin{array}{c}\text { Average } \\
(\mathrm{N})\end{array}$ & $\begin{array}{c}\text { Within-Laboratory } \\
\text { Variance }\end{array}$ \\
\hline District & 1 & 26267 & 27988 & 22612 & 25623 & 7537655 \\
District & 2 & 20129 & 22229 & 22946 & 21768 & 2143307 \\
District & 3 & 28324 & 23796 & 24113 & 25411 & 6388444 \\
District & 4 & 22466 & 23268 & 26477 & 24070 & 4506278 \\
District & 5 & 11280 & 11143 & 10992 & 11138 & 20675 \\
District & 6 & 19545 & 19120 & 24644 & 21103 & 9448220 \\
District & 7 & 18336 & 19975 & 21102 & 19805 & 1934311 \\
District & 8 & 13769 & 14152 & 14780 & 14234 & 260649 \\
District & 9 & 22945 & 25866 & 26570 & 25127 & 3693809 \\
District & 10 & 21512 & 26122 & 29297 & 25644 & 15324079 \\
Central & 11 & 20859 & 21381 & 23263 & 21835 & 1598910 \\
Greer & 12 & 14442 & 16849 & 16849 & 16047 & 1931262 \\
WV Paving & 13 & 16434 & 17521 & 17636 & 17197 & 440122 \\
WVU & 14 & 19230 & 18518 & 18244 & 18664 & 259004 \\
\hline
\end{tabular}


Table G.5. Base 2, Stability, Within-Laboratory Average and Variance

\begin{tabular}{|cc|c|c|c|c|c|}
\hline Laboratory & & $\begin{array}{c}\text { Sample 1 } \\
(\mathrm{N})\end{array}$ & $\begin{array}{c}\text { Sample 2 } \\
(\mathrm{N})\end{array}$ & $\begin{array}{c}\text { Sample 3 } \\
(\mathrm{N})\end{array}$ & $\begin{array}{c}\text { Average } \\
(\mathrm{N})\end{array}$ & $\begin{array}{c}\text { Within-Laboratory } \\
\text { Variance }\end{array}$ \\
\hline District & 1 & 16304 & 15333 & 17540 & 16392 & 815316 \\
District & 2 & 15809 & 14754 & 14322 & 14962 & 390052 \\
District & 3 & 8684 & 11042 & 14258 & 11328 & 5219838 \\
District & 4 & 13619 & 14420 & 14420 & 14153 & 142621 \\
District & 5 & 10325 & 12533 & 13530 & 12129 & 1794386 \\
District & 6 & 14002 & 13040 & 15391 & 14144 & 931694 \\
District & 7 & 14590 & 14082 & 10989 & 13220 & 2532198 \\
District & 8 & 12490 & 12229 & 13322 & 12680 & 217254 \\
District & 9 & 14938 & 16037 & 14938 & 15305 & 268116 \\
District & 10 & 16028 & 18691 & 17956 & 17558 & 1260532 \\
Central & 11 & 13010 & 12646 & 13947 & 13201 & 300305 \\
Greer & 12 & 11015 & 10014 & 11416 & 10815 & 347639 \\
WV Paving & 13 & 10588 & 12509 & 13018 & 12038 & 1095078 \\
WVU & 14 & 14395 & 16389 & 15162 & 15316 & 674795 \\
\hline
\end{tabular}

Table G.6. Wearing 1 Stability, Within-Laboratory Average and Variance

\begin{tabular}{|cc|c|c|c|c|c|}
\hline Laboratory & & $\begin{array}{c}\text { Sample 1 } \\
(\mathrm{N})\end{array}$ & $\begin{array}{c}\text { Sample 2 } \\
(\mathrm{N})\end{array}$ & $\begin{array}{c}\text { Sample 3 } \\
(\mathrm{N})\end{array}$ & $\begin{array}{c}\text { Average } \\
(\mathrm{N})\end{array}$ & $\begin{array}{c}\text { Within-Laboratory } \\
\text { Variance }\end{array}$ \\
\hline District & 1 & 15573 & 15000 & 15573 & 15382 & 72858 \\
District & 2 & 13739 & 13947 & 13135 & 13607 & 118533 \\
District & 3 & 12243 & 5953 & 4290 & 7495 & 11731308 \\
District & 4 & 15221 & 14020 & 13819 & 14353 & 383295 \\
District & 5 & 11616 & 11620 & 11274 & 11503 & 26349 \\
District & 6 & 12880 & 12576 & 13426 & 12961 & 123733 \\
District & 7 & 12576 & 12475 & 12221 & 12424 & 22286 \\
District & 8 & 11065 & 11065 & 11616 & 11249 & 67411 \\
District & 9 & 14201 & 13764 & 15293 & 14419 & 413668 \\
District & 10 & 15427 & 15229 & 17009 & 15889 & 634594 \\
Central & 11 & 12982 & 12272 & 12779 & 12677 & 89145 \\
Greer & 12 & 12217 & 11817 & 11616 & 11883 & 62397 \\
WV Paving & 13 & 9636 & 10347 & 10378 & 10120 & 117304 \\
WVU & 14 & 15047 & 13697 & 13985 & 14243 & 336917 \\
\hline
\end{tabular}


Table G.7. Base 1, Flow, Within-Laboratory Average and Variance

\begin{tabular}{|cc|c|c|c|c|c|}
\hline Laboratory & & $\begin{array}{c}\text { Sample 1 } \\
(0.25 \mathrm{~mm})\end{array}$ & $\begin{array}{c}\text { Sample 2 } \\
(0.25 \mathrm{~mm})\end{array}$ & $\begin{array}{c}\text { Sample 3 } \\
(0.25 \mathrm{~mm})\end{array}$ & $\begin{array}{c}\text { Average } \\
(0.25 \mathrm{~mm})\end{array}$ & $\begin{array}{c}\text { Within- } \\
\text { Laboratory } \\
\text { Variance }\end{array}$ \\
\hline District & 1 & 15.00 & 15.00 & 16.50 & 15.50 & 0.750 \\
District & 2 & 16.00 & 14.20 & 11.50 & 13.90 & 5.130 \\
District & 3 & 13.40 & 12.50 & 20.50 & 15.47 & 19.203 \\
District & 4 & 15.50 & 17.00 & 20.00 & 17.50 & 5.250 \\
District & 5 & 10.50 & 11.50 & 11.75 & 11.25 & 0.438 \\
District & 6 & 13.00 & 13.50 & 20.00 & 15.50 & 15.250 \\
District & 7 & 13.40 & 15.75 & 13.00 & 14.05 & 2.207 \\
District & 8 & 13.00 & 14.00 & 11.00 & 12.67 & 2.333 \\
District & 9 & 19.00 & 16.00 & 21.50 & 18.83 & 7.583 \\
District & 10 & 15.50 & 14.00 & 15.75 & 15.08 & 0.896 \\
Central & 11 & 12.00 & 13.00 & 13.00 & 12.67 & 0.333 \\
Greer & 12 & 15.50 & 16.00 & 16.50 & 16.00 & 0.250 \\
WV Paving & 13 & 15.60 & 12.80 & 19.20 & 15.87 & 10.293 \\
WVU & 14 & 17.00 & 15.50 & 14.00 & 15.50 & 2.250 \\
\hline \multicolumn{7}{|r|}{}
\end{tabular}


Table G.8. Base 2, Flow, Within-Laboratory Average and Variance

\begin{tabular}{|cc|c|c|c|c|c|}
\hline Laboratory & $\begin{array}{c}\text { Sample 1 } \\
(0.25 \mathrm{~mm})\end{array}$ & $\begin{array}{c}\text { Sample 2 } \\
(0.25 \mathrm{~mm})\end{array}$ & $\begin{array}{c}\text { Sample 3 } \\
(0.25 \mathrm{~mm})\end{array}$ & $\begin{array}{c}\text { Average } \\
(0.25 \mathrm{~mm})\end{array}$ & $\begin{array}{c}\text { Within- } \\
\text { Laboratory } \\
\text { Variance }\end{array}$ \\
\hline District & 1 & 9.00 & 11.50 & 12.00 & 10.83 & 1.722 \\
District & 2 & 10.50 & 12.00 & 11.00 & 11.17 & 0.389 \\
District & 3 & 8.60 & 8.80 & 9.50 & 8.97 & 0.149 \\
District & 4 & 11.50 & 11.50 & 12.50 & 11.83 & 0.222 \\
District & 5 & 12.00 & 12.50 & 10.50 & 11.67 & 0.722 \\
District & 6 & 10.00 & 13.00 & 16.50 & 13.17 & 7.056 \\
District & 7 & 12.50 & 12.50 & 11.60 & 12.20 & 0.180 \\
District & 8 & 14.00 & 12.00 & 14.00 & 13.33 & 0.889 \\
District & 9 & 10.50 & 10.50 & 10.50 & 10.50 & 0.000 \\
District & 10 & 10.00 & 8.75 & 9.00 & 9.25 & 0.292 \\
Central & 11 & 12.50 & 12.00 & 10.50 & 11.67 & 0.722 \\
Greer & 12 & 11.50 & 11.50 & 14.00 & 12.33 & 1.389 \\
WV Paving & 13 & 12.00 & 11.80 & 13.20 & 12.33 & 0.382 \\
WVU & 14 & 11.50 & 10.25 & 10.25 & 10.67 & 0.347 \\
\hline
\end{tabular}

Table G.9. Wearing 1, Flow, Within-Laboratory Average and Variance

\begin{tabular}{|cc|c|c|c|c|c|}
\hline Laboratory & $\begin{array}{c}\text { Sample 1 } \\
(0.25 \mathrm{~mm})\end{array}$ & $\begin{array}{c}\text { Sample 2 } \\
(0.25 \mathrm{~mm})\end{array}$ & $\begin{array}{c}\text { Sample 3 } \\
(0.25 \mathrm{~mm})\end{array}$ & $\begin{array}{c}\text { Average } \\
(0.25 \mathrm{~mm})\end{array}$ & $\begin{array}{c}\text { Within- } \\
\text { Laboratory } \\
\text { Variance }\end{array}$ \\
\hline District & 1 & 10.50 & 8.50 & 9.00 & 9.33 & 0.722 \\
District & 2 & 9.40 & 10.40 & 9.00 & 9.60 & 0.347 \\
District & 3 & 12.40 & 14.80 & 12.60 & 13.27 & 1.182 \\
District & 4 & 10.00 & 11.00 & 11.50 & 10.83 & 0.389 \\
District & 5 & 10.50 & 11.50 & 11.75 & 11.25 & 0.292 \\
District & 6 & 9.50 & 11.50 & 13.00 & 11.33 & 2.056 \\
District & 7 & 18.50 & 10.50 & 10.00 & 13.00 & 15.167 \\
District & 8 & 9.50 & 9.50 & 11.00 & 10.00 & 0.500 \\
District & 9 & 9.50 & 9.50 & 10.50 & 9.83 & 0.222 \\
District & 10 & 8.75 & 10.00 & 10.00 & 9.58 & 0.347 \\
Central & 11 & 10.50 & 10.00 & 10.50 & 10.33 & 0.056 \\
Greer & 12 & 10.00 & 9.50 & 8.50 & 9.33 & 0.389 \\
WV Paving 13 & 13.90 & 12.80 & 13.40 & 13.37 & 0.202 \\
WVU & 14 & 10.00 & 9.50 & 9.50 & 9.67 & 0.056 \\
\hline
\end{tabular}


Table G.10. Base 1, Bulk Specific Gravity, Within-Laboratory Average and Variance

\begin{tabular}{|cc|c|c|c|c|c|}
\hline Laboratory & & Sample 1 & Sample 2 & Sample 3 & Average & $\begin{array}{c}\text { Within-Laboratory } \\
\text { Variance }\end{array}$ \\
\hline District & 1 & 2.451 & 2.440 & 2.446 & 2.446 & 0.000028 \\
District & 2 & 2.449 & 2.457 & 2.447 & 2.451 & 0.000029 \\
District & 3 & 2.460 & 2.451 & 2.451 & 2.454 & 0.000029 \\
District & 4 & 2.453 & 2.446 & 2.453 & 2.451 & 0.000015 \\
District & 5 & 2.415 & 2.408 & 2.421 & 2.414 & 0.000039 \\
District & 6 & 2.445 & 2.439 & 2.434 & 2.439 & 0.000030 \\
District & 7 & 2.439 & 2.445 & 2.455 & 2.446 & 0.000070 \\
District & 8 & 2.407 & 2.395 & 2.407 & 2.403 & 0.000048 \\
District & 9 & 2.457 & 2.439 & 2.469 & 2.455 & 0.000235 \\
District & 10 & 2.415 & 2.405 & 2.439 & 2.420 & 0.000310 \\
Central & 11 & 2.450 & 2.443 & 2.464 & 2.452 & 0.000112 \\
Greer & 12 & 2.442 & 2.407 & 2.429 & 2.426 & 0.000312 \\
WV Paving & 13 & 2.403 & 2.428 & 2.434 & 2.422 & 0.000265 \\
WVU & 14 & 2.429 & 2.430 & 2.443 & 2.434 & 0.000062 \\
\hline
\end{tabular}

Table G.11. Base 2, Bulk Specific Gravity, Within-Laboratory Average and Variance

\begin{tabular}{|cc|c|c|c|c|c|}
\hline Laboratory & & Sample 1 & Sample 2 & Sample 3 & Average & $\begin{array}{c}\text { Within-Laboratory } \\
\text { Variance }\end{array}$ \\
\hline District & 1 & 2.422 & 2.435 & 2.434 & 2.430 & 0.000037 \\
District & 2 & 2.454 & 2.447 & 2.442 & 2.448 & 0.000027 \\
District & 3 & 2.344 & 2.408 & 2.344 & 2.365 & 0.000906 \\
District & 4 & 2.459 & 2.441 & 2.451 & 2.450 & 0.000054 \\
District & 5 & 2.432 & 2.436 & 2.432 & 2.433 & 0.000003 \\
District & 6 & 2.426 & 2.437 & 2.431 & 2.431 & 0.000020 \\
District & 7 & 2.454 & 2.435 & 2.446 & 2.445 & 0.000060 \\
District & 8 & 2.438 & 2.445 & 2.435 & 2.439 & 0.000017 \\
District & 9 & 2.438 & 2.448 & 2.445 & 2.444 & 0.000016 \\
District & 10 & 2.451 & 2.440 & 2.451 & 2.447 & 0.000026 \\
Central & 11 & 2.455 & 2.465 & 2.465 & 2.462 & 0.000022 \\
Greer & 12 & 2.432 & 2.434 & 2.435 & 2.434 & 0.000002 \\
WV Paving & 13 & 2.405 & 2.419 & 2.401 & 2.408 & 0.000061 \\
WVU & 14 & 2.448 & 2.445 & 2.443 & 2.445 & 0.000005 \\
\hline
\end{tabular}


Table G.12. Wearing 1, Bulk Specific Gravity, Within-Laboratory Average and Variance

\begin{tabular}{|cc|c|c|c|c|c|}
\hline Laboratory & & Sample 1 & Sample 2 & Sample 3 & Average & $\begin{array}{c}\text { Within-Laboratory } \\
\text { Variance }\end{array}$ \\
\hline District & 1 & 2.390 & 2.390 & 2.500 & 2.427 & 0.002683 \\
District & 2 & 2.410 & 2.416 & 2.397 & 2.408 & 0.000069 \\
District & 3 & 2.376 & 2.242 & 2.216 & 2.278 & 0.004880 \\
District & 4 & 2.409 & 2.407 & 2.404 & 2.407 & 0.000004 \\
District & 5 & 2.366 & 2.372 & 2.385 & 2.374 & 0.000060 \\
District & 6 & 2.379 & 2.373 & 2.380 & 2.377 & 0.000009 \\
District & 7 & 2.400 & 2.394 & 2.405 & 2.399 & 0.000019 \\
District & 8 & 2.389 & 2.380 & 2.389 & 2.386 & 0.000019 \\
District & 9 & 2.376 & 2.390 & 2.390 & 2.385 & 0.000048 \\
District & 10 & 2.362 & 2.366 & 2.359 & 2.362 & 0.000009 \\
Central & 11 & 2.396 & 2.403 & 2.409 & 2.403 & 0.000028 \\
Greer & 12 & 2.384 & 2.390 & 2.400 & 2.392 & 0.000044 \\
WV Paving & 13 & 2.349 & 2.367 & 2.346 & 2.354 & 0.000086 \\
WVU & 14 & 2.410 & 2.394 & 2.405 & 2.403 & 0.000044 \\
\hline
\end{tabular}

Table G.13. Base 1, Percent Air Voids, Within-Laboratory Average and Variance

\begin{tabular}{|cc|c|c|c|c|c|}
\hline Laboratory & & $\begin{array}{c}\text { Sample 1 } \\
(\%)\end{array}$ & $\begin{array}{c}\text { Sample 2 } \\
(\%)\end{array}$ & $\begin{array}{c}\text { Sample 3 } \\
(\%)\end{array}$ & $\begin{array}{c}\text { Average } \\
(\%)\end{array}$ & $\begin{array}{c}\text { Within-Laboratory } \\
\text { Variance }\end{array}$ \\
\hline District & 1 & 4.17 & 4.59 & 4.35 & 4.37 & 0.043 \\
District & 2 & 4.56 & 4.23 & 4.63 & 4.47 & 0.044 \\
District & 3 & 3.73 & 4.08 & 4.11 & 3.98 & 0.044 \\
District & 4 & 4.16 & 4.43 & 4.17 & 4.25 & 0.023 \\
District & 5 & 6.55 & 6.81 & 6.32 & 6.56 & 0.058 \\
District & 6 & 4.57 & 4.83 & 5.00 & 4.80 & 0.046 \\
District & 7 & 4.53 & 4.27 & 3.88 & 4.23 & 0.107 \\
District & 8 & 6.07 & 6.54 & 6.07 & 6.23 & 0.074 \\
District & 9 & 4.21 & 4.91 & 3.72 & 4.28 & 0.357 \\
District & 10 & 4.26 & 4.67 & 4.24 & 4.39 & 0.060 \\
Central & 11 & 4.13 & 3.75 & 3.74 & 3.88 & 0.050 \\
Greer & 12 & 5.02 & 4.93 & 4.88 & 4.94 & 0.005 \\
WV Paving & 13 & 6.27 & 5.72 & 6.42 & 6.14 & 0.138 \\
WVU & 14 & 4.40 & 4.54 & 4.61 & 4.51 & 0.011 \\
\hline
\end{tabular}


Table G.14. Base 2, Percent Air Voids, Within-Laboratory Average and Variance

\begin{tabular}{|cc|c|c|c|c|c|}
\hline Laboratory & & $\begin{array}{c}\text { Sample 1 } \\
(\%)\end{array}$ & $\begin{array}{c}\text { Sample 2 } \\
(\%)\end{array}$ & $\begin{array}{c}\text { Sample 3 } \\
(\%)\end{array}$ & $\begin{array}{c}\text { Average } \\
(\%)\end{array}$ & $\begin{array}{c}\text { Within-Laboratory } \\
\text { Variance }\end{array}$ \\
\hline District & 1 & 3.86 & 3.34 & 3.35 & 3.51 & 0.059 \\
District & 2 & 2.77 & 3.09 & 3.27 & 3.04 & 0.043 \\
District & 3 & 7.12 & 4.59 & 7.12 & 6.27 & 1.423 \\
District & 4 & 2.39 & 3.11 & 2.71 & 2.74 & 0.086 \\
District & 5 & 3.86 & 3.73 & 3.89 & 3.82 & 0.005 \\
District & 6 & 3.80 & 3.37 & 3.62 & 3.59 & 0.032 \\
District & 7 & 2.58 & 3.34 & 2.92 & 2.95 & 0.095 \\
District & 8 & 3.40 & 3.15 & 3.55 & 3.37 & 0.027 \\
District & 9 & 3.32 & 2.94 & 3.04 & 3.10 & 0.026 \\
District & 10 & 4.16 & 4.54 & 3.18 & 3.96 & 0.326 \\
Central & 11 & 2.78 & 3.06 & 2.23 & 2.69 & 0.118 \\
Greer & 12 & 3.17 & 4.56 & 3.71 & 3.81 & 0.327 \\
WV Paving & 13 & 4.65 & 3.69 & 3.42 & 3.92 & 0.278 \\
WVU & 14 & 3.67 & 3.64 & 3.12 & 3.48 & 0.065 \\
\hline
\end{tabular}

Table G.15. Wearing 1, Percent Air Voids, Within-Laboratory Average and Variance

\begin{tabular}{|cc|c|c|c|c|c|}
\hline Laboratory & & $\begin{array}{c}\text { Sample 1 } \\
(\%)\end{array}$ & $\begin{array}{c}\text { Sample 2 } \\
(\%)\end{array}$ & $\begin{array}{c}\text { Sample 3 } \\
(\%)\end{array}$ & $\begin{array}{c}\text { Average } \\
(\%)\end{array}$ & $\begin{array}{c}\text { Within-Laboratory } \\
\text { Variance }\end{array}$ \\
\hline District & 2 & 3.2294 & 2.9611 & 3.7637 & 3.3181 & 0.111279 \\
District & 3 & 4.4613 & 9.7587 & 10.7984 & 8.3395 & 7.700207 \\
District & 4 & 2.9228 & 2.9770 & 3.1157 & 3.0052 & 0.006601 \\
District & 5 & 5.1224 & 4.8936 & 4.3816 & 4.7992 & 0.095920 \\
District & 6 & 4.2260 & 4.4654 & 4.1964 & 4.2960 & 0.014505 \\
District & 7 & 2.9376 & 3.1733 & 2.7426 & 2.9512 & 0.031009 \\
District & 8 & 3.9065 & 4.2670 & 3.8893 & 4.0209 & 0.030325 \\
District & 9 & 4.3815 & 3.7911 & 3.7859 & 3.9862 & 0.078139 \\
District & 10 & 4.7441 & 4.5920 & 4.8901 & 4.7421 & 0.014807 \\
Central & 11 & 3.7524 & 3.4913 & 3.2335 & 3.4924 & 0.044873 \\
Greer & 12 & 3.9164 & 3.6672 & 3.2672 & 3.6169 & 0.071505 \\
WV Paving & 13 & 5.4064 & 4.6872 & 5.5396 & 5.2111 & 0.140162 \\
WVU & 14 & 3.2270 & 3.8667 & 3.4497 & 3.5145 & 0.070286 \\
\hline
\end{tabular}


Table G.16. O utlying Percentile for Rice Specific Gravity

\begin{tabular}{|ll|c|c|c|c|c|c|c|}
\hline Laboratory & & Replicate & \multicolumn{2}{|c|}{ Rice Specific Gravity } & \multicolumn{3}{c|}{ Percentile } \\
& & & Base 1 & Base 2 & Wearing 1 & Base 1 & Base 2 & Wearing 1 \\
\hline District & 1 & 1 & 2.561 & 2.516 & - & 59 & 96 & - \\
& & 2 & 2.555 & 2.521 & - & 80 & 59 & - \\
District & 2 & 1 & 2.565 & 2.525 & 2.491 & 63 & 80 & 86 \\
& & 2 & 2.566 & 2.524 & 2.490 & 64 & 78 & 80 \\
District & 3 & 1 & 2.557 & 2.523 & 2.485 & 73 & 62 & 50 \\
& & 2 & 2.554 & 2.524 & 2.484 & 83 & 76 & 53 \\
District & 4 & 1 & 2.560 & 2.520 & 2.484 & 63 & 73 & 56 \\
& & 2 & 2.560 & 2.518 & 2.479 & 60 & 86 & 86 \\
District & 5 & 1 & 2.566 & 2.530 & 2.494 & 66 & 100 & 95 \\
& & 2 & 2.602 & 2.530 & 2.494 & 100 & 99 & 94 \\
District & 6 & 1 & 2.561 & 2.523 & 2.484 & 58 & 61 & 58 \\
& & 2 & 2.564 & 2.521 & 2.485 & 57 & 57 & 50 \\
District & 7 & 1 & 2.561 & 2.519 & 2.475 & 57 & 80 & 95 \\
& & 2 & 2.548 & 2.519 & 2.470 & 95 & 80 & 100 \\
District & 8 & 1 & 2.564 & 2.524 & 2.486 & 57 & 75 & 59 \\
& & 2 & 2.561 & 2.525 & 2.485 & 57 & 81 & 55 \\
District & 9 & 1 & 2.564 & 2.520 & 2.484 & 58 & 74 & 56 \\
District & \multirow{2}{*}{10} & 2 & 2.565 & 2.524 & 2.485 & 60 & 73 & 52 \\
& & 2 & 2.560 & 2.519 & 2.482 & 61 & 81 & 69 \\
Central & & 2 & 2.559 & 2.520 & 2.478 & 64 & 77 & 89 \\
& & 1 & 2.560 & 2.521 & 2.487 & 63 & 60 & 66 \\
Greer & & 2 & 2.563 & 2.519 & 2.492 & 50 & 85 & 90 \\
& & 1 & 2.559 & 2.523 & 2.481 & 65 & 58 & 75 \\
WV & 2 & 2.561 & 2.522 & 2.482 & 55 & 54 & 69 \\
Paving & & 1 & 2.566 & 2.522 & 2.487 & 67 & 57 & 63 \\
WVU & & 2 & 2.565 & 2.519 & 2.481 & 61 & 83 & 76 \\
& & 1 & 2.562 & 2.520 & 2.492 & 52 & 73 & 91 \\
& & 2 & 2.560 & 2.523 & 2.489 & 61 & 63 & 75 \\
\hline
\end{tabular}


Table G.17. Outlying Percentile for Marshall Stability

\begin{tabular}{|c|c|c|c|c|c|c|c|}
\hline \multirow[t]{2}{*}{ Laboratory } & \multirow[t]{2}{*}{ Replicate } & \multicolumn{3}{|c|}{ Stability } & \multicolumn{3}{|c|}{ Percentile } \\
\hline & & Base 1 & Base 2 & Wearing 1 & Base 1 & Base 2 & Wearing 1 \\
\hline \multirow[t]{3}{*}{ District } & 1 & 26267 & 16304 & 15573 & 88 & 87 & 88 \\
\hline & 2 & 27988 & 15333 & 15000 & 94 & 76 & 83 \\
\hline & 3 & 22612 & 17540 & 15573 & 67 & 96 & 88 \\
\hline \multirow[t]{3}{*}{ District } & 1 & 20129 & 15809 & 13739 & 53 & 82 & 66 \\
\hline & 2 & 22229 & 14754 & 13947 & 64 & 67 & 69 \\
\hline & 3 & 22946 & 14322 & 13135 & 69 & 59 & 57 \\
\hline \multirow[t]{3}{*}{ District } & 1 & 28324 & 8684 & 12243 & 95 & 99 & 58 \\
\hline & 2 & 23796 & 11042 & 5953 & 75 & 90 & 100 \\
\hline & 3 & 24113 & 14258 & 4290 & 77 & 58 & 100 \\
\hline \multirow[t]{3}{*}{ District } & 1 & 22466 & 13619 & 15221 & 66 & 53 & 85 \\
\hline & 2 & 23268 & 14420 & 14020 & 72 & 61 & 70 \\
\hline & 3 & 26477 & 14420 & 13819 & 89 & 61 & 68 \\
\hline \multirow[t]{3}{*}{ District } & 1 & 11280 & 10325 & 11616 & 97 & 94 & 68 \\
\hline & 2 & 11143 & 12533 & 11620 & 98 & 72 & 68 \\
\hline & 3 & 10992 & 13530 & 11274 & 98 & 55 & 73 \\
\hline \multirow[t]{3}{*}{ District } & 1 & 19545 & 14002 & 12880 & 58 & 54 & 53 \\
\hline & 2 & 19120 & 13040 & 12576 & 62 & 64 & 53 \\
\hline & 3 & 24644 & 15391 & 13426 & 80 & 77 & 61 \\
\hline \multirow[t]{3}{*}{ District } & 1 & 18336 & 14590 & 12576 & 68 & 64 & 53 \\
\hline & 2 & 19975 & 14082 & 12475 & 55 & 55 & 54 \\
\hline & 3 & 21102 & 10989 & 12221 & 55 & 90 & 58 \\
\hline \multirow[t]{3}{*}{ District } & 1 & 13769 & 12490 & 11065 & 92 & 73 & 76 \\
\hline & 2 & 14152 & 12229 & 11065 & 91 & 76 & 76 \\
\hline & 3 & 14780 & 13322 & 11616 & 89 & 59 & 68 \\
\hline \multirow[t]{3}{*}{ District } & 1 & 22945 & 14938 & 14201 & 69 & 70 & 73 \\
\hline & 2 & 25866 & 16037 & 13764 & 87 & 85 & 67 \\
\hline & 3 & 26570 & 14938 & 15293 & 90 & 70 & 86 \\
\hline \multirow[t]{3}{*}{ District } & 1 & 21512 & 16028 & 15427 & 58 & 84 & 87 \\
\hline & 2 & 26122 & 18691 & 15229 & 88 & 99 & 85 \\
\hline & 3 & 29297 & 17956 & 17009 & 97 & 97 & 96 \\
\hline \multirow[t]{3}{*}{ Central } & 1 & 20859 & 13010 & 12982 & 53 & 64 & 54 \\
\hline & 2 & 21381 & 12646 & 12272 & 57 & 70 & 58 \\
\hline & 3 & 23263 & 13947 & 12779 & 71 & 53 & 51 \\
\hline \multirow[t]{3}{*}{ Greer } & 1 & 14442 & 11015 & 12217 & 90 & 90 & 58 \\
\hline & 2 & 16849 & 10014 & 11817 & 78 & 96 & 65 \\
\hline & 3 & 16849 & 11416 & 11616 & 78 & 86 & 68 \\
\hline & 1 & 16434 & 10588 & 9636 & 80 & 93 & 90 \\
\hline \multirow{2}{*}{ Paving } & 2 & 17521 & 12509 & 10347 & 74 & 72 & 84 \\
\hline & 3 & 17636 & 13018 & 10378 & 73 & 64 & 84 \\
\hline \multirow[t]{3}{*}{ WVU } & 1 & 19230 & 14395 & 15047 & 61 & 61 & 83 \\
\hline & 2 & 18518 & 16389 & 13697 & 66 & 88 & 66 \\
\hline & 3 & 18244 & 15162 & 13985 & 68 & 73 & 70 \\
\hline
\end{tabular}


Table G.18. O utlying Pencentile for Marshall Flow

\begin{tabular}{|c|c|c|c|c|c|c|c|c|}
\hline \multirow{2}{*}{\multicolumn{2}{|c|}{ Laboratory }} & \multirow[t]{2}{*}{ Replicate } & \multicolumn{3}{|c|}{ Flow } & \multicolumn{3}{|c|}{ Percentile } \\
\hline & & & Base 1 & Base 2 & Wearing 1 & Base 1 & Base 2 & Wearing 1 \\
\hline \multirow[t]{3}{*}{ District } & 1 & 1 & 15.00 & 9.00 & 10.50 & 50 & 93 & 56 \\
\hline & & 2 & 15.00 & 11.50 & 8.50 & 50 & 52 & 88 \\
\hline & & 3 & 16.50 & 12.00 & 9.00 & 71 & 64 & 82 \\
\hline \multirow[t]{3}{*}{ District } & 2 & 1 & 16.00 & 10.50 & 9.40 & 65 & 71 & 76 \\
\hline & & 2 & 14.20 & 12.00 & 10.40 & 61 & 64 & 58 \\
\hline & & 3 & 11.50 & 11.00 & 9.00 & 90 & 60 & 82 \\
\hline \multirow[t]{3}{*}{ District } & 3 & 1 & 13.40 & 8.60 & 12.40 & 72 & 96 & 80 \\
\hline & & 2 & 12.50 & 8.80 & 14.80 & 82 & 95 & 98 \\
\hline & & 3 & 20.50 & 9.50 & 12.60 & 98 & 88 & 83 \\
\hline \multirow[t]{3}{*}{ District } & 4 & 1 & 15.50 & 11.50 & 10.00 & 58 & 52 & 66 \\
\hline & & 2 & 17.00 & 11.50 & 11.00 & 77 & 52 & 55 \\
\hline & & 3 & 20.00 & 12.50 & 11.50 & 97 & 75 & 65 \\
\hline \multirow[t]{3}{*}{ District } & 5 & 1 & 10.50 & 12.00 & 10.50 & 95 & 64 & 56 \\
\hline & & 2 & 11.50 & 12.50 & 11.50 & 90 & 75 & 65 \\
\hline & & 3 & 11.75 & 10.50 & 11.75 & 89 & 71 & 70 \\
\hline \multirow[t]{3}{*}{ District } & 6 & 1 & 13.00 & 10.00 & 9.50 & 77 & 81 & 75 \\
\hline & & 2 & 13.50 & 13.00 & 11.50 & 71 & 83 & 65 \\
\hline & & 3 & 20.00 & 16.50 & 13.00 & 97 & 100 & 88 \\
\hline \multirow[t]{3}{*}{ District } & 7 & 1 & 13.40 & 12.50 & 18.50 & 72 & 75 & 100 \\
\hline & & 2 & 15.75 & 12.50 & 10.50 & 61 & 75 & 56 \\
\hline & & 3 & 13.00 & 11.60 & 10.00 & 77 & 54 & 66 \\
\hline \multirow[t]{3}{*}{ District } & 8 & 1 & 13.00 & 14.00 & 9.50 & 77 & 94 & 75 \\
\hline & & 2 & 14.00 & 12.00 & 9.50 & 64 & 64 & 75 \\
\hline & & 3 & 11.00 & 14.00 & 11.00 & 93 & 94 & 55 \\
\hline \multirow[t]{3}{*}{ District } & 9 & 1 & 19.00 & 10.50 & 9.50 & 93 & 71 & 75 \\
\hline & & 2 & 16.00 & 10.50 & 9.50 & 65 & 71 & 75 \\
\hline & & 3 & 21.50 & 10.50 & 10.50 & 99 & 71 & 56 \\
\hline \multirow[t]{3}{*}{ District } & 10 & 1 & 15.50 & 10.00 & 8.75 & 58 & 81 & 85 \\
\hline & & 2 & 14.00 & 8.75 & 10.00 & 64 & 95 & 66 \\
\hline & & 3 & 15.75 & 9.00 & 10.00 & 61 & 93 & 66 \\
\hline \multirow[t]{3}{*}{ Central } & & 1 & 12.00 & 12.50 & 10.50 & 87 & 75 & 56 \\
\hline & & 2 & 13.00 & 12.00 & 10.00 & 77 & 64 & 66 \\
\hline & & 3 & 13.00 & 10.50 & 10.50 & 77 & 71 & 56 \\
\hline \multirow[t]{3}{*}{ Greer } & & 1 & 15.50 & 11.50 & 10.00 & 58 & 52 & 66 \\
\hline & & 2 & 16.00 & 11.50 & 9.50 & 65 & 52 & 75 \\
\hline & & 3 & 16.50 & 14.00 & 8.50 & 71 & 94 & 88 \\
\hline WV & & 1 & 15.60 & 12.00 & 13.90 & 59 & 64 & 95 \\
\hline \multirow[t]{2}{*}{ Paving } & & 2 & 12.80 & 11.80 & 12.80 & 79 & 59 & 86 \\
\hline & & 3 & 19.20 & 13.20 & 13.40 & 94 & 86 & 92 \\
\hline \multirow[t]{3}{*}{ WVU } & & 1 & 17.00 & 11.50 & 10.00 & 77 & 52 & 66 \\
\hline & & 2 & 15.50 & 10.25 & 9.50 & 58 & 76 & 75 \\
\hline & & 3 & 14.00 & 10.25 & 9.50 & 64 & 76 & 75 \\
\hline
\end{tabular}


Table G.19. O utlying Percentile for Bulk Specific Gravity

\begin{tabular}{|c|c|c|c|c|c|c|c|}
\hline \multirow[t]{2}{*}{ Laboratory } & \multirow[t]{2}{*}{ Replicate } & \multicolumn{3}{|c|}{ Bulk Specific Gravity } & \multicolumn{3}{|c|}{ Percentile } \\
\hline & & Base 1 & Base 2 & Wearing 1 & Base 1 & Base 2 & Wearing 1 \\
\hline \multirow[t]{3}{*}{ District } & 1 & 2.451 & 2.422 & 2.390 & 78 & 68 & 57 \\
\hline & 2 & 2.440 & 2.435 & 2.390 & 58 & 51 & 57 \\
\hline & 3 & 2.446 & 2.434 & 2.500 & 70 & 51 & 100 \\
\hline \multirow[t]{3}{*}{ District } & 1 & 2.449 & 2.454 & 2.410 & 74 & 78 & 74 \\
\hline & 2 & 2.457 & 2.447 & 2.416 & 86 & 68 & 79 \\
\hline & 3 & 2.447 & 2.442 & 2.397 & 71 & 62 & 63 \\
\hline \multirow[t]{3}{*}{ District } & 1 & 2.460 & 2.344 & 2.376 & 89 & 100 & 56 \\
\hline & 2 & 2.451 & 2.408 & 2.242 & 78 & 84 & 100 \\
\hline & 3 & 2.451 & 2.326 & 2.216 & 77 & 100 & 100 \\
\hline \multirow[t]{3}{*}{ District } & 1 & 2.453 & 2.459 & 2.409 & 81 & 83 & 73 \\
\hline & 2 & 2.446 & 2.441 & 2.407 & 70 & 60 & 72 \\
\hline & 3 & 2.453 & 2.451 & 2.404 & 81 & 74 & 69 \\
\hline \multirow[t]{3}{*}{ District } & 1 & 2.415 & 2.432 & 2.366 & 88 & 53 & 65 \\
\hline & 2 & 2.408 & 2.436 & 2.372 & 94 & 52 & 60 \\
\hline & 3 & 2.421 & 2.432 & 2.385 & 80 & 54 & 52 \\
\hline \multirow[t]{3}{*}{ District } & 1 & 2.445 & 2.426 & 2.379 & 67 & 62 & 53 \\
\hline & 2 & 2.439 & 2.437 & 2.373 & 54 & 55 & 59 \\
\hline & 3 & 2.434 & 2.431 & 2.380 & 55 & 55 & 52 \\
\hline \multirow[t]{3}{*}{ District } & 1 & 2.439 & \begin{tabular}{|l|}
2.454 \\
\end{tabular} & 2.400 & 55 & 78 & 66 \\
\hline & 2 & 2.445 & 2.435 & 2.394 & 68 & 52 & 61 \\
\hline & 3 & 2.455 & 2.446 & 2.405 & 84 & 67 & 70 \\
\hline \multirow[t]{3}{*}{ District } & 1 & 2.407 & 2.438 & 2.389 & 94 & 57 & 56 \\
\hline & 2 & 2.395 & 2.445 & 2.380 & 99 & 66 & 53 \\
\hline & 3 & 2.407 & 2.435 & 2.389 & 94 & 51 & 56 \\
\hline \multirow[t]{3}{*}{ District } & 1 & 2.457 & 2.438 & 2.376 & 86 & 56 & 56 \\
\hline & 2 & 2.439 & 2.448 & 2.390 & 54 & 70 & 57 \\
\hline & 3 & 2.469 & 2.445 & 2.390 & 96 & 66 & 57 \\
\hline \multirow[t]{3}{*}{ District } & 1 & 2.415 & 2.451 & 2.362 & 88 & 73 & 68 \\
\hline & 2 & 2.405 & 2.440 & 2.366 & 95 & 59 & 65 \\
\hline & 3 & 2.439 & 2.451 & 2.359 & 55 & 74 & 71 \\
\hline \multirow[t]{3}{*}{ Central } & 1 & 2.450 & 2.455 & 2.396 & 76 & 79 & 63 \\
\hline & 2 & 2.443 & 2.465 & 2.403 & 63 & 88 & 68 \\
\hline & 3 & 2.464 & 2.465 & 2.409 & 93 & 88 & 73 \\
\hline \multirow[t]{3}{*}{ Greer } & 1 & 2.442 & 2.432 & 2.384 & 62 & 54 & 52 \\
\hline & 2 & 2.407 & 2.434 & 2.390 & 94 & 50 & 57 \\
\hline & 3 & 2.429 & 2.435 & 2.400 & 67 & 52 & 66 \\
\hline WV & 1 & 2.403 & 2.405 & 2.349 & 96 & 87 & 78 \\
\hline \multirow[t]{2}{*}{ Paving } & 2 & 2.428 & 2.419 & 2.367 & 68 & 71 & 64 \\
\hline & 3 & 2.434 & 2.401 & 2.346 & 55 & 89 & 80 \\
\hline \multirow[t]{3}{*}{ WVU } & 1 & 2.429 & \begin{tabular}{|l|}
2.448 \\
\end{tabular} & 2.410 & 66 & 71 & 74 \\
\hline & 2 & 2.430 & 2.445 & 2.394 & 65 & 66 & 61 \\
\hline & 3 & 2.443 & 2.443 & 2.405 & 63 & 63 & 70 \\
\hline
\end{tabular}


Table G.20. Outlying Percentile for Percent Air Voids

\begin{tabular}{|c|c|c|c|c|c|c|c|}
\hline \multirow[t]{2}{*}{ Laboratory } & \multirow[t]{2}{*}{ Replicate } & \multicolumn{3}{|c|}{ Percent Air Voids } & \multicolumn{3}{|c|}{ Percentile } \\
\hline & & Base 1 & Base 2 & Wearing 1 & Base 1 & Base 2 & Wearing 1 \\
\hline \multirow[t]{3}{*}{ District } & 1 & 4.174 & 3.858 & - & 76 & 59 & 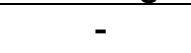 \\
\hline & 2 & 4.589 & 3.337 & 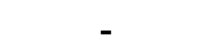 & 59 & 60 & - \\
\hline & 3 & 4.352 & 3.348 & - & 69 & 60 & - \\
\hline \multirow[t]{3}{*}{ District } & 1 & 4.557 & 2.771 & 3.229 & 60 & 79 & 74 \\
\hline & 2 & 4.232 & 3.086 & 2.961 & 74 & 69 & 79 \\
\hline & 3 & 4.626 & 3.271 & 3.764 & 57 & 63 & 62 \\
\hline \multirow[t]{3}{*}{ District } & 1 & 3.734 & 7.117 & 4.461 & 88 & 100 & 55 \\
\hline & 2 & 4.085 & 4.586 & 9.759 & 79 & 83 & 100 \\
\hline & 3 & 4.109 & 7.826 & 10.798 & 78 & 100 & 100 \\
\hline \multirow[t]{3}{*}{ District } & 1 & 4.160 & 2.394 & 2.923 & 76 & 88 & 80 \\
\hline & 2 & 4.431 & 3.109 & 2.977 & 66 & 68 & 79 \\
\hline & 3 & 4.172 & 2.713 & 3.116 & 76 & 80 & 76 \\
\hline \multirow[t]{3}{*}{ District } & 1 & 6.552 & 3.860 & 5.122 & 98 & 60 & 71 \\
\hline & 2 & 6.805 & 3.725 & 4.894 & 99 & 55 & 66 \\
\hline & 3 & 6.323 & 3.888 & 4.382 & 96 & 61 & 53 \\
\hline \multirow[t]{3}{*}{ District } & 1 & 4.575 & \begin{tabular}{|l|}
3.799 \\
\end{tabular} & 4.226 & 60 & 57 & 51 \\
\hline & 2 & 4.830 & 3.366 & 4.465 & 52 & 59 & 55 \\
\hline & 3 & 5.003 & 3.619 & 4.196 & 60 & 50 & 51 \\
\hline \multirow[t]{3}{*}{ District } & 1 & 4.526 & 2.582 & 2.938 & 62 & 84 & 79 \\
\hline & 2 & 4.274 & 3.336 & 3.173 & 72 & 60 & 75 \\
\hline & 3 & 3.878 & 2.923 & 2.743 & 85 & 74 & 83 \\
\hline \multirow[t]{3}{*}{ District } & 1 & 6.073 & 3.402 & 3.906 & 93 & 58 & 59 \\
\hline & 2 & 6.540 & 3.152 & 4.267 & 98 & 67 & 50 \\
\hline & 3 & 6.067 & 3.551 & 3.889 & 93 & 52 & 59 \\
\hline \multirow[t]{3}{*}{ District } & 1 & 4.210 & \begin{tabular}{|l|}
3.319 \\
\end{tabular} & 4.381 & 74 & 61 & 53 \\
\hline & 2 & 4.909 & 2.937 & 3.791 & 55 & 74 & 61 \\
\hline & 3 & 3.720 & 3.043 & 3.786 & 89 & 71 & 62 \\
\hline \multirow[t]{3}{*}{ District } & 1 & 4.264 & 4.156 & 4.744 & 72 & 70 & 62 \\
\hline & 2 & 4.674 & 4.542 & 4.592 & 55 & 81 & 58 \\
\hline & 3 & 4.239 & 3.185 & 4.890 & 73 & 66 & 65 \\
\hline \multirow[t]{3}{*}{ Central } & 1 & 4.134 & 2.784 & 3.752 & 77 & 79 & 62 \\
\hline & 2 & 3.755 & 3.056 & 3.491 & 88 & 70 & 68 \\
\hline & 3 & 3.740 & 2.232 & 3.233 & 88 & 91 & 74 \\
\hline \multirow[t]{3}{*}{ Greer } & 1 & 5.022 & \begin{tabular}{|l|}
3.167 \\
\end{tabular} & 3.916 & 60 & 66 & 58 \\
\hline & 2 & 4.929 & 4.557 & 3.667 & 56 & 82 & 64 \\
\hline & 3 & 4.876 & 3.709 & 3.267 & 54 & 54 & 73 \\
\hline WV & 1 & 6.273 & 4.650 & 5.406 & 95 & 84 & 76 \\
\hline \multirow[t]{2}{*}{ Paving } & 2 & 5.718 & 3.691 & 4.687 & 85 & 53 & 61 \\
\hline & 3 & 6.424 & 3.422 & 5.540 & 97 & 57 & 79 \\
\hline \multirow[t]{3}{*}{$\overline{\text { WVU }}$} & 1 & 4.398 & 3.674 & 3.227 & 67 & 53 & 74 \\
\hline & 2 & 4.537 & 3.643 & 3.867 & 61 & 51 & 60 \\
\hline & 3 & 4.606 & 3.121 & 3.450 & 58 & 68 & 69 \\
\hline
\end{tabular}




\section{I T A}

Michael S. Hughes was born in Bristol, Pennsylvania on June 10, 1975. He later graduated from Council Rock High School in Newtown, Pennsylvania in June, 1993. In May, 1997, Michael received his Bachelor's degree in civil engineering from West Virginia University in Morgantown, where he currently resides. He has since completed graduate level course work in the areas of paving materials, geotechnical engineering, and transportation engineering. Michael is currently a candidate for the Masters of Science degree in Civil Engineering at West Virginia University, and plans to graduate in D ecember, 1998. 